TRANSMEDIA

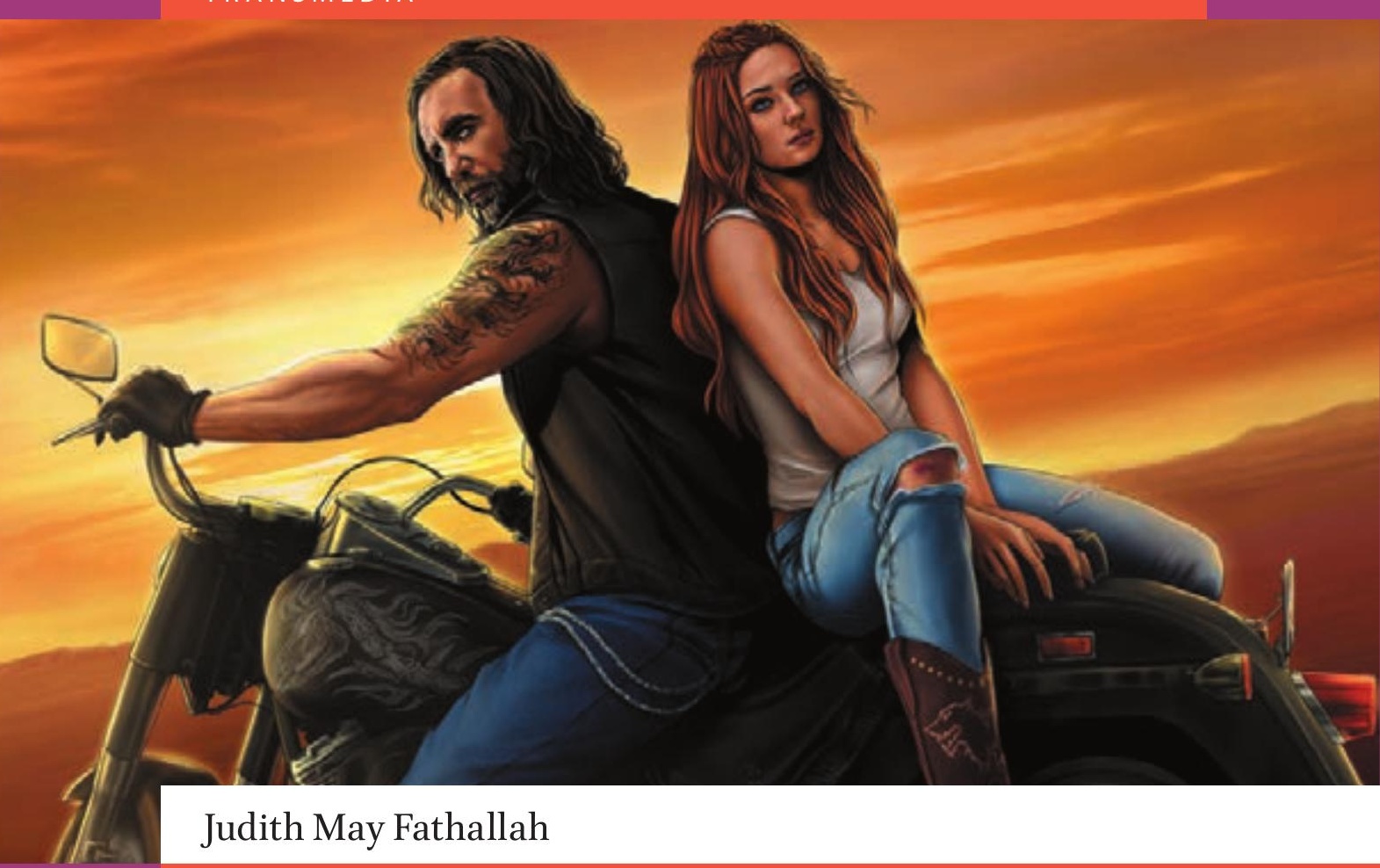

\title{
Fanfiction and the Author
}

\author{
How Fanfic Changes \\ Popular Cultural Texts
}


Fanfiction and the Author 


\section{Transmedia: Participatory Culture and Media Convergence}

The book series Transmedia: Participatory Culture and Media Convergence provides a platform for cutting-edge research in the field of media studies, with a strong focus on the impact of digitization, globalization, and fan culture. The series is dedicated to publishing the highest-quality monographs (and exceptional edited collections) on the developing social, cultural, and economic practices surrounding media convergence and audience participation. The term 'media convergence' relates to the complex ways in which the production, distribution, and consumption of contemporary media are affected by digitization, while 'participatory culture' refers to the changing relationship between media producers and their audiences.

Interdisciplinary by its very definition, the series will provide a publishing platform for international scholars doing new and critical research in relevant fields. While the main focus will be on contemporary media culture, the series is also open to research that focuses on the historical forebears of digital convergence culture, including histories of fandom, cross- and transmedia franchises, reception studies and audience ethnographies, and critical approaches to the culture industry and commodity culture.

\section{Series editors}

Dan Hassler-Forest, Utrecht University, the Netherlands

Matt Hills, University of Aberystwyth, United Kingdom

\section{Editorial Board}

Mark Bould, University of West of England, United Kingdom

Timothy Corrigan, University of Pennsylvania, United States

Henry Jenkins, University of Southern California, United States

Julia Knight, University of Sunderland, United Kingdom

Simone Murray, Monash University, Australia

Roberta Pearson, University of Nottingham, United Kingdom

John Storey, University of Sunderland, United Kingdom

William Uricchio, Massachusetts Institute of Technology, United States

Sherryl Vint, University of California, Riverside, United States

Eckart Voigts, Braunschweig Institute of Technology, Germany 


\section{Fanfiction and the Author}

How Fanfic Changes Popular Cultural Texts

Judith May Fathallah 
Cover illustration: 'Just Ride' by dwaroxxx, reproduced with the artist's permission.

Cover design: Coördesign, Leiden

Layout: Crius Group, Hulshout

Amsterdam University Press English-language titles are distributed in the US and Canada by the University of Chicago Press.
ISBN $\quad 9789089649959$
e-ISBN $\quad 9789048529087$
DOI $\quad 10.5117 / 9789089649959$
NUR $\quad 670$

(c) J.M. Fathallah / Amsterdam University Press B.V., Amsterdam 2017

All rights reserved. Without limiting the rights under copyright reserved above, no part of this book may be reproduced, stored in or introduced into a retrieval system, or transmitted, in any form or by any means (electronic, mechanical, photocopying, recording or otherwise) without the written permission of both the copyright owners and the authors of the book.

Every effort has been made to obtain permission to use all copyrighted illustrations reproduced in this book. Nonetheless, whosoever believes to have rights to this material is advised to contact the publisher. 


\section{Acknowledgements}

I would like to thank my former $\mathrm{PhD}$ supervisor and current peer reviewer,

Professor Matt Hills, for his thoughtful, thorough and stimulating guidance throughout this project. I am also indebted to the staff and post-graduate community at Cardiff School of Journalism, Media and Cultural Studies, for creating and sustaining such an exciting and productive research environment, especially Dr Paul Bowman, Head of PhD Studies, and Mr Andrew Blackmore, Subject Librarian. Equally, I would like to thank the team and editorial board at Amsterdam University Press, and my other peer reviewer Kathy Larsen for her insightful feedback on a draft.

Finally, many thanks are owed to the fan communities and fanfiction writers whose work is at the core of this project. Without your talent, generosity and friendship, this project would never have been possible. 



\section{Contents}

Acknowledgements $\quad 5$

Introduction $\quad 9$

1. From Foucault to Fanfic 17

$\begin{array}{ll}\text { Foucault and Language } & 17\end{array}$

$\begin{array}{ll}\text { Fanfiction in the Academy } & 21\end{array}$

2. Methodology 33

Discourse Analysis $\quad 33$

Internet Studies $\quad 35$

$\begin{array}{ll}\text { Sampling and Process } & 38\end{array}$

3. The White Man at the Centre of the World: Masculinity in Sherlock 47 Introduction $\quad 47$

Masculinity in Sherlock $\quad 53$

Fandom's Reconstruction of Masculinity in Sherlock 65

4. 'I AM YOUR KING': Authority in Game of Thrones 101 Introduction 101

Authority in Game of Thrones 104

Fandom's Reconstruction of Authority in Game of Thrones 119

5. 'I'm a God': The Author and the Writing Fan in Supernatural 157 $\begin{array}{ll} & 157 \\ \text { Introduction } & 157\end{array}$

The Construction of Authorship and Fandom in Supernatural $\quad{ }_{160}$

Fandom's Reconstruction of Authorship and Fandom $\quad 170$

6. Conclusion 199

Bibliography 205

Written Texts 205

Film, Television and Other Media $\quad 228$

$\begin{array}{ll}\text { Index } & 231\end{array}$ 



\section{Introduction}

Fanfiction, the unauthorised adaptation and re-writing of media texts, is the fastest growing form of writing in the world (Mirmohamadi 2014, p. 5). Fanfic is typically freely shared, makes no money and, though it has an analogue history, now exists primarily on the internet. Early academic interest in the subject tended to be quite utopian, seeing fandoms as a democratic and socially progressive response to increasingly homogenized and corporate media industries. Gray et al. called this the 'Fandom is Beautiful' phase of academia $(2007$, p. 1). It is generally now accepted that fanfic is neither automatically transformative of media texts, nor a peacefully democratic and supportive community. It is a complex and contested arena of textual production with its own hierarchies, norms and structuring practices (Scodari 2003; Thomas 2005; Hills 2013, p. 149). Moreover, despite and because of the laissez-faire attitudes to fanwork by TV auteurs like Buffy's Joss Whedon and Supernatural's Eric Kripke, fanfic still negotiates a subordinated relationship to its canons (Scott 2011).

This book adapts discourse theory, developed from the work of the Michel Foucault, to address the question of how fanfic generates new statements that alter or uphold discursive formations from three of the most popular and influential franchises on TV today. Through the tools of discourse theory and network analysis, I hope to provide one answer to Artieri's timely call for investigation 'whether and in what ways' fannish textual production can take 'forms that allow us to experience media contents differently as well as generate different interpretative categories of our society' (2012, p. 463). The shows chosen for study are the BBC's Sherlock, HBO's Game of Thrones, and the CW's Supernatural. This is partly due to their impact on popular culture, but, equally, some of the most prominent discursive formations in these shows relate directly to the cultural constructions of authorship and authority that lie at the heart of this argument.

The work of Suzanne Scott (2011) sets an important precedent here, identifying a gendered divide between legitimated and culturally approved work by fans, (primarily coded masculine, e.g. vid creation from licenced material) and fanwork that is scorned and devalued (primarily coded feminine, e.g. fanfic). Building on her recognition of the 'fanboy-auteur', who performs acceptance and legitimation of fannish production para-textually whilst retaining a position of economic and industrial power, this book is going to argue that fanwork is pervaded by and functions through what I call the legitimation paradox. Here, the legitimation and revaluation of the 
Other - be it racial, sexual, or gendered — is enabled and enacted through the cultural capital of the White male. The formations selected for analysis build upon each other to demonstrate this construction: First, (White) masculinity in Sherlock; second, authority in Game of Thrones; and finally, authorship in Supernatural. In this clearest example, the fan's writing is legitimated by the TV-auteur, simultaneously empowered and contained as showrunners grant metatextual acknowledgement of and paratextual permission for fanfic. Derivative writing that changes popular culture is legitimated and empowered-because and so far as the author says so. By the final chapter, however, we will begin to see the deconstruction of the legitimation paradox at work, as the legitimacy of authorship itself begins to be questioned. From a similar standpoint, Paul Booth recently argued that 'media fandom is best understood as continual, shifting negotiation and dialogue within already-extant industrial relations' (2015, p. 1), wherein industry professionals and increasingly-visible fandoms are presently repositioning themselves with regard to each other. I locate this work, then, as responsive to Louisa Stein's call for a 'third wave of fan studies' that 'recognize(s) the deepening relationship between fandom and mainstream culture' with attention to the political-economic and cultural factors that influence that relationship (2015, p. 11).

Firstly, I will situate this work in the context of Foucauldian approaches to text and authorship. I argue that a discourse analysis based on Foucault's theories of power as an 'open and capillary network' (Callewaert 2006, p. 87) is appropriate to the online context of fanfic today. Moreover, Foucault's (1991) theory of the author-function and the ability of discourse theory to account for statements from fictional genres, traditions and contexts provides appropriate tools for treating fanfic as fiction: something that previous commentators on fanfic have either elided (e.g. Jenkins 1992; Black 2008), or bracketed to the exclusion of social context (e.g. Pugh 2005; Kaplan 2006). Therefore, as I go on to summarize previous work on fandom and fanfic, I locate the contribution of this research as a discourse analysis that accommodates the networked context and fictional orientation of fic.

Chapter 2, the methodology, explains in detail the processes by which I found, coded and analysed relevant fanfic. As Evans and Stasi have argued (2014), fan studies has not always been sufficiently rigorous and transparent in presenting its methodologies. Some of this resistance comes from a reluctance to engage with problematic notions of objectivity and truthfulness (pp. 8-9), particularly when quantitative methods are concerned, but this project combines an autoethnographic lens with a mixed methods approach, which I hope can balance rigour with accountability on behalf 
of the researcher. I will be paying specific attention to the means by which fandom hierarchizes, silences and disciplines its own texts via feedback, including praise and recommendation, insults and mockery; for, as Foucault has argued, discourses are constrained and ordered not only by external forces, but by powerful internal mechanisms of regulation (1981, p. 56). This is the first extended project to analyse the receptive, interactive, networked context of fanfic in web 2.0. Network analysis seeks to chart and analyse connections between nodes not simply in their functional capacity, but the capital and de/legitimation they confer (see Beaulieu 2005; Rebaza 2010), and the affiliations they indicate. A node, in this sense, simply means a definable point on a network, 'such as people, organizations, web pages, or nation states' (Hogan 2008, p. 143). Unsurprisingly, it has been frequently applied to studies of blogs, websites and social media. Yet, it has not been applied to fanfic before now. I address this gap; for, as Bronwen Thomas wrote in a stimulating article whose implications deserve more followup, these 'new modes of user involvement for online narratives [...] mean that we cannot [properly] analyse what is produced without analysing how it is produced and made available to others' and 'fanfiction cannot be understood in isolation from the network culture' (2011, pp. 206-207) facilitated by the structures of Web 2.o. I take specific note of link and recommendation networks as an indicator of the impact works of fanfiction make in their context.

Chapters $3-5$ present the results of the research, treating the discursive formations in turn. The case studies of Sherlock, Game of Thrones and Supernatural have been chosen for several interlocking reasons. Firstly, each is presently an influential cult text with a productive, active online fandom. Moreover, the creators and owners of these texts have taken explicit notice of fandom, making strong contrasting paratextual statements on their attitudes and policies towards it. At one extreme, George R. R. Martin initially sought to prohibit fanfic utilising his characters, though his stance has necessarily softened with the adaptation of his work to HBO and the introduction of new author figures in showrunners David Benioff and D. B. Weiss. At the other, Eric Kripke and the writers of Supernatural have gone to unprecedented lengths in the acknowledgement and address of their fandom, up to the inclusion of fanfiction and fan culture in the canon text. The Sherlock franchise operates somewhere in the middle, neither seeking to prohibit fan activity nor precisely embracing it, and its showrunners contradictory statements of attitude towards it. A discursive analysis that addresses these authorial paratexts before going on to discuss fanfic's transformation of the canon benefits from these contrasting cases, casting 
light on how authorial positioning may or may not inflect the discourse (re) construction. Finally, three prominent discursive constructions in these texts and the consequent (re)constructive work of their fandoms connect intrinsically to the traditional figure of the White Male Author which still holds sway in popular imagination. (White) masculinity is addressed in Sherlock; the formation and fragmentations of authority in Game of Thrones; then the study culminates with an explicit address of authorship in Supernatural. First, the discursive construction in and around the texts are analysed, taking account of statements by showrunners and other author figures; then, consolidations and transformations by fandom are presented. The formations build upon each other: first, the BBC's construction of White masculinity in Sherlock is shown to be essentially conservative and rooted in the Victorian heritage of the character. It is predicated on the hierarchical division of mind and body and the superiority of White masculinity over other races and genders. Fanfic is shown to transform this discourse construction dramatically, yet in illustration of the legitimation paradox, these transformations are legitimated by and through the authorizing figure of the White man. Fandom's transformative reconstruction, then, paradoxically depends what is already culturally author-ized: the White male hero, and frequently the White male author figure behind him. This is the first illustration of the legitimation paradox, and accords with Booth's argument that whilst specific fan practices may well be resistant and transformative of mainstream ideologies, and underlying connection to and identity with the canonical source means that fanworks are 'in an always liminal state between resistant and complicit (2015, p. 3). Occasionally, we find the paradox working inversely, so that criticism of for example violence is not well received when it entails criticism of the author-ized White man. Fan writing can be made legitimate through the White male figure, and there is some resistance to attribute him with qualities that would make his authority less legitimate. Then, in Chapter 4, the fragmented and tenuous construction of authority in Game of Thrones is shown to be at odds with the traditional author figure of George R. R. Martin, and informed by broader cultural discourse on the conflict and connections between authority and power. Writing any kind of fanfic for Game of Thrones is a challenge to the construction of author as sole font of knowledge and the guardian of 'correct' meaning, as Martin has stated explicitly his dislike of the form and attempted to prohibit it for his book series. Perhaps in an ironic kind of deference to these wishes, fandom's transformations of the authority construct are quite subtle, constrained to a degree by the author-function as the limitation on 'proliferation of meaning' (Foucault 1991, p. 118). The 
structures of authority in the text are not dramatically transformed, and where they are, this tends to operate again through channels that are already constructed as culturally legitimate within the diegesis of the canon. The most distinct transformation fanfic makes is the attribution of authority to women. Yet again, a certain deference to the concept of a 'real' text and the wishes of the 'real' author(-function) complicate the transformative impulse at work, and fan texts are sometimes praised in terms of their authenticity or faithfulness to the author figure's canonical statements. We observe the legitimation paradox at work both diegetically and extra-diegetically at the same time: as characters in fanfic enact transformation of the system by and through traditional forms of authority, fanfic transforms the discourse through self-conscious appropriation of Martin's text.

The final research chapter demonstrates the paradox most explicitly. Here, fanfic as a practice is legitimated yet contained by its presence in the show. By inclusion of fanfic about the show's own characters (Supernatural 5 x01; 10x05), this writing has been sanctioned by the fanboy-auteur. Notably, as Newman and Levine have argued, the industrial construction of a televisual author-figure is itself a legitimation strategy, comparing television with traditionally legitimate art forms like the novel and later film (2012, p. 198). Fan discourse, then, takes the next step, frequently legitimating its own production in terms of the auteur's word. Paratextually, showrunner Eric Kripke professes to 'love' and 'welcome' fan production (Zubernis and Larsen 2012, p. 214). However, the manner in which fanfic is initially presented, as the work of the silly, obsessed, nymphomaniac fangirl, is a powerful discursive gesture of containment. Moreover, as a contrast, the author appears as a character in the text (Supernatural 5x01, 5xo9, $5 \times 22$ ), either a prophet or, it is audaciously implied, God Himself. Whilst the second episode to feature fanfic mitigated this construction, fandom was reconstructing the author/fan relationship long before it aired, and this perhaps produces the most radical change to a discursive formation. Often, the primacy of the author and his text is affirmed. However, some fic, combining statements from the discourses of academia, literature and fandom to produce new knowledge, here begin to deconstruct the terms of the paradox in which the fic is only legitimated through the author. Assertions of a primary or original discrete text, a text that exists apart from the reader and/or fanfic writer, begin to be deconstructed. This, I suggest, is the means by which fanfic can compromise the legitimation paradox. Fanfic can thus be understood in postmodern terms, not only as a response or tactical counter to its predecessors, but as deconstructive of the concept of original, essentialist texts authored by God and White men, 
and Supernatural's re-(re)integration of that argument back into canon demonstrates the effect of these statements on media. Other postmodern art forms, especially the postcolonial, are already understood as deconstructive of this concept (see e.g. Kraus 1985; Hutcheon 1988; Bhabha 1994; Anyinefa 2000; Bannet 2011), even as they may problematically reaffirm it through citation, reference or the stance of tactically opposing a great predecessor (Jacziminski 2009; Singh 2012). Moreover, these meta-textual statements take highly self-conscious forms, demonstrating alertness within fandom to the problematics of the legitimation paradox, and wariness with regards validating one's work through what is already culturally legitimate (cf. Booth 2015, p. 11).

Supernatural's construction of its fandom has been double-edged. The first writing fangirl introduced onscreen was Becky Rosen (5xo1), a hyperfeminine, slash-obsessed young woman who was permitted her onscreen pleasures at the cost of a degree of mockery. Johnson names this practices 'fan-tagonism': a form of discipline by discursive containment, in which the text displays the fan to herself in controlling forms (2007). Fan-tagonism supposedly de-legitimates certain kinds of fandom — notably the excessive and feminine - by exposing, exaggerating and shaming (pp. 295-299). Yet, if discursive containment was the aim here, it has the opposite effect: a large body of fic (re)appropriates and transforms both Becky and the character of the author. I prefer the term textual provocation to describe the construction of fandom by canon and author figures. The double meaning in the term is intentional: such statements can be provocative in the sense of baiting, but they also provoke the production of more text, which potentially alters the formation. We will note instances of textual provocation in the paratexts around Sherlock and Game of Thrones, but the theory comes to full fruition in the final research chapter. Indeed, when Supernatural next introduced fangirl characters in 10x05, Fan Fiction, their construction was dramatically modified. These creative girls were fans, certainly, and ultimately still deferent to the diegetic the author figure, but they were, nonetheless, capable and creative writers in their own right, producing their own version of the text according to their desires. Here, we may see a concrete example of how fanfic has changed canonical popular text.

Chapter 6 concludes with a summary, a discussion of the limitations of this study and implications for further research. I suggest that the legitimation paradox could be utilised to study how other kinds of text negotiate their reference to an author-ized predecessor, and the points where, through deconstruction of that concept, they might compromise the paradox. For the construction of the author is powerful; but it is still a discourse formation. 
As the alteration of discursive formations by powerful new statements from fanfic will demonstrate, discourse formations are always malleable and subject to change. Moreover, as the Foucauldian method illuminates, discourse analysis is concerned with what is thinkable and sayable, in particular cultural contexts. As fandom's visibility and impact on popular culture increases, transformative work becomes a practice that may, as Artieri put it, 'generate different interpretative categories' (2012, p. 463) that reach beyond fandom and canon into broader society. If, as Booth (2015) and Chin (2013, p. 88) argue, big media producers are engaging with fan audiences in increasingly innovative and visible ways, the discursive transformations and consolidations constructed through fanfic hold increasingly higher stakes. 



\section{From Foucault to Fanfic}

\section{Foucault and Language}

A great deal of previous work on fandom takes Pierre Bourdieu's work on socio-cultural capital as its theoretical grounding. For Bourdieu, participation in culture is a matter of distinction and habitus: in demonstrating appreciation of those works to which our upbringing and social position inclines and equips us to interpret, we gain position in relation to other social agents, contrary to artistic ideologies of disinterest and self-sacrifice ([1979] 1986, [1992] 1996, 1993). For Bourdieu, even supposedly 'pure pleasure' is a matter of 'playing the cultural game well, of playing on one's skill at playing, at cultivating a pleasure which "cultivates"' (Bourdieu 1986, p. 498). In his formulation, 'taste classifies, and it classifies the classifier' (p. 6). The double application of this insight, which allows a deconstruction of dominant culture's derogation of fandom in terms of devalued emotionalism (Jenson 1992), and an understanding of inter-fan struggle and bids for distinction over the capital of particular subcultures (Thornton 1995), has influenced a wide range of scholars: see Bacon-Smith (1992); Jenkins (1992); Thornton (1995); Baym (2000); Hills (2002; 2005); Williams (2010); and Milner (2011). Bourdieu's work is useful for many studies and certainly not antithetical to this one, but Michel Foucault's work on language and power is more suited to a study dealing with primarily with text and its workings.

For Foucault, what language means is less important than what it does. Language is active, and not a reflection or sign but 'some sort of practical intervention' (Callewaert 2006, p. 91). We will not go 'from discourse towards its interior' in search of some posited hidden meaning or 'true' signification, but study 'discourse itself, its appearance and its regularity' and 'go towards external conditions of possibility' (Foucault 1981, p. 67). I am demonstrating something fanfic does and how it does it: that is, change popular cultural texts and thus cultural conditions of possibility. Foucault calls language in action 'discourse', and as the term has been so widely taken up, it will be useful to recap what he meant by that. Discourse, after all, is language without a fundamental Truth from which to interpret its meaning, language devoid of an underlying Text to provide the ultimate meaning of signs:

One no longer attempts to uncover the great enigmatic statement that lies hidden beneath its signs; one asks how it functions, what representations it designates, what elements it cuts out and removes, how it analyses and 
composes, what play of substitutions enables it to accomplish its role of representation ([1966] 2002, p. 88).

Discourses, in the plural, are the contingent codes according to which a society operates and understands itself: they are not True in any essential sense, but produce the necessary 'truths' of particular cultures. Discourses are active and productive, as well as exclusive and repressive, making this method of analysis an apt for the regulated and transformative productions of fandom.

The unity of a discourse, which Foucault calls a 'formation', is not some pre-defined topic or concept, but the rules that determine how topics or concepts are formulated, what possibilities are thereby brought into creation (Young 2001, pp. 400-401; Andersen 2003, p. 8). Discursive formations are systems of production and organization. Discursive formations pass thresholds in their development. After a certain point, they begin to produce statements about their own norms (pp.186-87). Ample evidence of this can be found in fans' commentary and analysis on fandom, much of which is archived at Fanlore.org (2015).

Discourses are comprised of 'statements'. Foucault's definition of the statement is largely negative (demonstrating that it is not a speech act, not a grammatical unit, etc.) and ultimately unhelpful-Young perhaps makes best use of it in stressing the statement as material event, an 'incision into a discursive field' (Young, p. 402; cf. Foucault 1989, p. 28). Statements may be visual/imagistic as well as linguistic. The statement's primary effect is change and discontinuity; yet, it must also have a relation to sameness and regularity in order to function within the discourse it affects (Young, p. 402). This accords with Foucault's purpose

to show that to speak is to do something-something other than to express what one thinks; to translate what one knows, and something other than to play with the structures of a language (langue); to show that to add a statement to a pre-existing series of statements is to perform a complicated and costly gesture, which involves conditions [...], and rules [...]; to show that a change in the order of discourse does not presuppose 'new ideas', a little invention and creativity, a different mentality, but transformations in a practice, perhaps also in neighbouring practices, and in their common articulation ([1969] 1989, p. 209, my emphasis).

I would add that, in their relation to sameness, statements can also solidify and reinforce structures, the primary function Edward Said attributed to them (2003). We will see this quite often in fanfic, as visual statements 
from the television texts are repeated and consolidated in stories. At the root of a discourse are governing statements, and other statements branch off according to the 'conditions of possibility' of this discourse (Foucault 1981, p. 67). So in Young's example, one would not interpret instances of colonial discourses in order to reveal their hidden meaning, an 'imperial unconscious', but attempt to formulate their rules of possibility and see how these enabled specific statements (p. 408). The governing statements are the fundamental core of a discourse, and various options will be developed at the peripheries, some of which may contradict each other (2001, p. 405). Foucault compared governing statements to the roots of a tree, opening up and demarcating the most general domain of possibilities for other statements, analogous to branches (1989, pp. 147-148). For instance, if I were to read one hundred examples of fiction about reproduction available at mainstream bookshops, I might find a governing statement like 'reproduction is achieved by penetrative intercourse between a male and a female at the time of the female's fertility' as a condition of the discursive formation 'reproduction', but many varied statements constructing 'reproduction' at the peripheries. The source texts are one obvious of governing statements, for the fic I study would not exist without it, but these consistent regularities can also have their sources in broader culture. Carabine writes that 'discourses "hook" into normative ideas' from broader society as shortcuts to complex meaning (2001, p. 269), and I find this an apt term to utilize. It would be more precise to say that statements in particular discourses 'hook' into elements of broader, normative discourses circulating in larger social contexts, and this is how I will be using the term.

Finally, for Foucault, the concept of the 'archive' is derived from all the various systems of statements operative in a culture at a particular time. It seems to be something like an arch-discourse, 'the general system of the formation and transformation of statements' (1989, p. 130). It is a hypothetical construction rather than a theoretical-methodological tool, for he states it would be impossible to describe the archive 'in its totality' (Ibid.). Our hypothetical archive might be 'media', and I would suggest that transformations in a discourse begun at the level of statement may come to have broader effects on the archive and so on culture. As Fairclough and Fairclough put it, discourse is 'on the one hand an effect of social life, and on the other, ha[s] effects on social life, both helping to keep existing forms in existence and helping to change them' (2012, p. 79). As we will come to see, the broadcast of Supernatural 10x05 at the end of 2014 demonstrates this process in action, proving the concrete effects of transformative work on the public sphere. 
Foucault's understanding of the function of authorship is also crucial to this study. Following Barthes' seminal essay 'Death of the Author', a call to arms for the liberation of the reader from pre-inscribed meaning, Foucault argued that whilst texts are certainly not complete and unified at their point of origin, it was not enough to simply claim that the author had simply disappeared, liberating the reader to make of a text what s/he will. Foucault contended that the author has not vanished, but serves as a principle by which the meaning of a text is constrained, and the text valued. Foucault uses the phrase 'author-function' to describe those cultural/ institutional operations by which an 'author' is symbolically constructed as the principle of textual interpretation (1991). In addition to writers themselves, critics, networks, studios and fans themselves all contribute to this work of attribution. We utilize the figure of the author to limit the meanings of text: 'the Author is a certain functional principle by which, in our culture, one limits, excludes and chooses' (p. 119). Author figures like George R. R. Martin or Eric Kripke are often held up as the key to the real meaning or true text behind a franchise involving the labour of thousands (Jenkins 1995, pp. 188-191) and, as we will see, Martin makes much use of this discursive construction in public comments on his work. Fanfiction sometimes consolidates the construction of the author figure in this way, especially regarding Game of Thrones. At the same time, fanfiction itself, in which the author's pseudonym stands purposely and demonstratively for a body of text, whilst the body of text forms the only clue by which one can decipher the supposed master-key of the author, seems a fruitful site to substitute the questions of discourse Foucault finds outdated-'who really spoke? And with what authenticity?' - with the more pertinent 'what are the modes of existence of this discourse?' (p. 120). These questions grant us perspective on how fanfiction changes popular texts, and equally how far it consolidates their discursive formations.

Henry Jenkins began the application of the author-function to fan studies, with an analysis of Gene Roddenberry's function in the original Star Trek series. He concluded that the figure of 'Gene' helped fans 'classify the relationships between texts, explain textual events (or neutralize discrepancies), and to demarcate a text's value through his authorship or approval' (1995, pp. 188-191). Since then, Hills (2002; 2010a); Wexelblat (2002); Gray (2010); and Kompare (2011) have discussed the function in Doctor Who, Babylon 5, Lord of the Rings and Lost. Newman and Levine have discussed the strategic positioning of author figures to increase the cultural capital of television texts, a strategy of cultural legitimation invested in the Romantic ideal of a sole genius author (2012, pp. 963-1393). Scott is concerned with the 
gendered institutional power and strategic self-presentation of cult TV figures who wield an author-function, whom she calls 'fanboy-auteurs'. These men - and they are, still, largely White men — perform self-abnegation and liberality to their fans through text and paratexts. At the same time, they retain an economic and institutional position of control over the text:

Borrowing a term from Jonathan Gray, we could frame the fanboy auteur as an 'undead author,' or an author who understands that metaphorically 'killing himself' is an ideal way to engender fannish solidarity, and [to] 'fashion himself as "just one of the fans", when he is decidedly privileged in the relationship' (Scott 2011, p. 168, quoting Gray 2010, pp. 112-113).

As we will see, writers and showrunners make varied usage of the author function in paratexts, including claims to fannish identity and solidarity. These claims set up a construction of authorship that fanfic both consolidates and transforms.

\section{Fanfiction in the Academy}

Fandom scholarship begins as development and response. Its seminal texts are a development of recuperative work on popular media by cultural critics in the second half of the twentieth century, notably Hall's encoding/decoding model of texts (1980) and Fiske's work on selective and resistant uses of popular media (1990a, b). It developed these theories into a response to the popular and academic pathologizing of fans (Jenson 1992; cf. Scott 2011, p. 19). This pathologization - of fans as outcasts, obsessive, dangerous - has not disappeared, but is complicated both by democratizing movements within education and a certain popular understanding that, in a mediated society, 'everyone's got to be a fan of something' (Hills 2005, p. 35). In this section, I trace a trajectory from celebration of fanfiction as a political resistance to corporate media (Jenkins 1992), and/or the expression and binding material of an alternative female society (Bacon-Smith 1992), through to more sceptical and reserved readings of fanfic by contemporary critics. Then, I consider perspectives treating fanfiction as literature. As work on slash (same-sex erotica) still comprises a substantial amount of the extant work and follows its own more specific narrative, I treat that separately below.

The academic history of fanfiction in general begins with Henry Jenkins' Textual Poachers, casting the resistant fan as a resistant reader who steals fleeting pleasure from the territory of the producer (1992, pp. 24-27). 
Unlike the nomad, the writer creates an artefact; thus, a community can evolve around a new corpus (pp. 44-49). Jenkins, Camille Bacon-Smith and Constance Penley dominate the early phase of fan studies, which we might call the 'valorizing of resistance': resistance to capitalism, gender conformity and the shallow, materialistic way of living Jenkins called 'mundania' (Jenkins 1992, pp. 262-264). Though broadly political in impetus, this phase overlaps with responses to pathologization, challenging the stereotype that fans have 'no life'. Penley invokes De Certeau, to theorize fans' utilization of hegemonic material to their own ends, in a process of cultural bricolage or recombination of given elements. Recombination is important, as fans typically appropriate from a wide variety of media sources, creating new meanings by recontextualizing as well as reshaping texts. As we have seen, the New Media context of convergence has dated the poaching metaphor.

Jenkins argued that fanfiction communities work according to a moral economy (2006b). This term was first utilized by E. P. Thompson to explain the morality of those historical actors behind De Certeau's metaphor. Thompson thought that the eighteenth- and nineteenth-century peasant leaders legitimized their revolts through an appeal to 'traditional rights and customs' and the 'wider consensus of the community', claiming that their actions protected pre-existing property rights 'against those who sought them abuse for their own gain'. They found 'consensus [...] so strong that it overrode motives of fear or deference' (Thompson 1971, pp.78-79). Jenkins draws a parallel with fanfiction writers who see themselves as protecting the characters they love according to a communal idea of moral right, against those who would exploit or abuse them for profit (Jenkins, 2006b, pp. 54-57). Jenkins probably exaggerates in invoking Thompsons's reference to 'fear' of traditional owners, though 'deference' might apply in some places. Contemporary fanfiction practices both exhibit and contradict a feeling of communal ownership: on the one hand, it is popular to refer to the appropriated characters as 'ours': see, for instance, the deliberately provocative subheading/assertion, 'We love our boys bloody', of a community dedicated solely to the hurt/comfort trope in Supernatural fanfiction (http://spn-hurtcomfort.livejournal.com/). On the other, the practice of disclaiming ownership of the characters used in the heading for individual fictions serves as a pre-emptive defence against alleged wrongdoing: the claim that one is taking some limited liberty with the property of another, but ultimately recognizes their rights of ownership (cf. Bailey 2005, p. 191).

Bacon-Smith (1992) inaugurated the ethnographic tradition of fanfiction studies. She argued that dominant culture silences women's pain and experiences, and makes male/female relationships difficult. The processes 
of creating fanfiction enable an alternative female community; whilst fanfiction, especially hurt-comfort, gives voice to the pain and vulnerabilities that people, especially women, are denied the expression of in life (Bacon-Smith 1992, pp. 270-279). Actually, there is a significant subsection of hurt-comfort invested in the rather less properly-feminist exploration of sadomasochism, as the community header above seems to perform. Bacon-Smith is aware of this (p. 270), yet goes out of her way to deny the possibility of erotic appeal in her archetypal story (p. 259) and suggest that sadomasochistic fantasy is 'limited to a small group' of non-American fans 'specifically interested' in using the source material for this purpose (p. 280, 14n). She considers that fanfiction and the fan community have reformist potential, but, like Geertz's deep play (1973), could also retard social change by providing means for the expression of tension whilst maintaining the status quo (Bacon-Smith, p. 287). Under a guise of play, fanfiction creates an alternative culture and alternative narratives to express their experience (pp. 292-294); but Bacon-Smith is not prepared to claim this can alter hegemony. Bacon-Smith does not account for the ability of discourse to affect transformations in neighbouring discourses, or the media 'archive'.

Jenkins's later work casts fanfiction as a point of potential convergence between corporate and grassroots media. He stresses the educational potential of fanfiction for teenagers, who are creatively utilizing 'affinity spaces' useful to the types of work and learning they will need as adults in the present economy (2006a, pp. 169-177). This potential of fanfiction as training in new literacy is increasingly noted by education researchers, teachers and librarians. The most prolific writer on this topic is Rebecca Black, whose Adolescents and Online Fanfiction (2008) comes endorsed by Jenkins.

Others have followed Jenkins and Bacon-Smith in the study of fanfiction by adults. Here, perspectives diverge. Jenkins notes that one reservation he has about Textual Poachers is that it encouraged academics 'to read fanfiction in primarily political terms' (2006b, p. 37). I agree, but observe another tendency, rooted in the literary tradition, to embrace the opposite extreme, bracketing politics to construct a discourse of fanfiction as art, specifically a postmodern art, worthy of studying like any other literature but exempt from theorization of what fiction is and does. This is the impression one gets from Pugh (2005). Pugh's work studies intertextuality; the communal writing process; genres and tropes; authorial voice; and the different experiences of professional and fanfiction writing. However, it lacks theory, and leaves one wondering what the argument is. Despite Pugh's appreciation of 
intertextuality, the book actually falls into the Modernist trap of the literary work as self-sufficient, existing without social context.

Other literature-orientated theories of fandom include Stein's models of boundaries and opportunities: fanfiction, she theorizes, thrives within communal and practical limitations such as the use of canon, use of fantext (fan-originated ideas regarding character, theme and plot that have come to be commonly accepted within discrete communities), genre expectations and technology. These boundaries place restrictions on fic, but simultaneously create its possibilities and impetuses (Stein and Busse, 2009; Stein 2006, 2008). These concepts integrate neatly with Foucauldian discourse analysis, with canon, fantext, genre and technology being observable factors in the development of discursive formations. In collaboration with Busse, Stein suggests that fanfiction might be viewed as part of a tradition that celebrates reproduction, mechanical or digital, and therefore poses a challenge to concepts of originality as creativity and the ownership of art (Stein and Busse, 2009, p. 193). The creation of fanfiction in practice challenges notions of originality as being the condition of creativity; however, Stein and Busse also observe that the rhetoric of fandom tends to stress the innovative qualities of fic writing rather than appropriative remix. Jenkins thought that 'a poached culture requires a conception of aesthetics emphasizing borrowing and recombination as much or more as original creation and artistic innovation' (1992, p. 224), but, in fact, fandom's rhetoric of originality suggests lingering adherence to older models of cultural authority (Stein and Busse 2009, p. 205). This residual tendency supports the legitimation paradox in that it affirms the legitimacy of a fanfic, a practice of pastiche, via a lexis of authorial genius and completeness. For example, performances of speechlessness or incoherence in the face of brilliance are expressed as random lines of keyboard characters, or claims to have 'died' from the experience of reading. Another dialogue-closing gesture is the expression 'You win the internets', which performs resignation of the discourse into the hands of the most accomplished, most creative writers. All three of these tropes can be observed in the hundreds of comments on an acknowledged fandom masterpiece, Fleshflutter's hilarious yet profoundly moving epic farce, The Incestuous Courtship of the Anti-Christ's Bride (2009). I suggest we understand these as statements in a construction called the author, which informs the fifth chapter of this thesis.

Still privileging a traditionally literary perspective, Derecho (2006) suggests that fanfiction be viewed as a form of archontic literature: this concept, again adapted from Derrida, views fanfic as an always-open archive of text of the sort historically used for cultural critique by marginalized groups. 
The main problem with this, aside from the dialogue-closing gestures noted above, is Derecho's too-easy comparisons between fanfic and early forms of literary appropriation. She claims that

Historically, writing archontic literature has been a risky undertaking for women, and this is as true of contemporary fanfic authors today as it was for the first published women authors. Today, women who write fanfiction write under threat of legal prosecution (p. 72).

Derecho writes that 'many' fanfiction participants have 'received warnings or cease-and-desist letters' (p. 72), a rather disingenuous generalization considering the millions of fanworks in existence versus the proportion that have drawn corporate attention. To the individual, the chances of being noticed by the corporate owners of her fanfiction characters, and that said corporate owners would consider it worth pursuing the particular infringement, are insignificant. Lindgren Leavenworth and Isaksson have taken up Derecho's theory to analyse specific works of fanfic from a literary perspective, contending that 'canon works occasion fanfic in the first place and fanfic, in turn, deposits interpretations and associations into the archive which may influence any new reading of the canons' (2013, p. 12). This may be so, but their lack of attention to inter-fan or fan-producer tensions and hierarchies fails to account for the fact that different statements in fanfic make different levels of impact on fandom and canon, and some make no impact at all.

When critics write about fanfiction as 'works of literature' (Kaplan 2006, p. 135), they typically address those texts that exhibit literary cultural capital in a scholastic context. That is, texts that are polished, stylish, complete, conform to Standard English spelling and grammar, and exhibit the sort of literary tropes, jokes and references that suggest a degree of higher education in the arts. Kaplan goes some way towards acknowledging this omission when she notes the question of 'whether only literature of a certain quality rewards literary analysis' (2006, p. 151, 1n). I am not content with her continuation that 'regardless, there exists plenty of fanfiction which meets the criteria of quality usually desired by literary critics' such as that she analyses. Fic that meets these standards is still more likely to make an impact on the discursive formation in question, but we should also pay attention to how and where lack of these capitals minimize impact or how fic can wield impact despite lack of them.

Bury's Cyberspaces of Their Own (2005), Williamson's The Lure of the Vampire (2005) and Wright's (2009) thesis, 'The Discourse of Fanfiction' 
address class and language use. Wright's 'discourse' is different to my use of the term: she means, following Bakhtin, 'the centripetal and centrifugal struggles of the fanfiction (discourse) community' (p. 13). She is not concerned with fiction so much as the textual power struggles between older, established fans and less literate newcomers. She primarily chooses fic according to the fan-profile of the author (p. 66). The actual texts she cites are reviews and interviews. Still, her work provides useful insight into some discursive practices constructing proper/legitimate fanfiction and silencing, segregating or normalizing that fanfic constructed as inferior, notably due to literacy and the inferred aged of its authors. Here, Bourdieu's theories of capital can be utilized to observe how degrees of cultural and educational capital influence the impact of statements on discursive formations. Wright documents strong peer pressure for Standard English (pp. 79; 99-100; 115; 139; 141; 159; 160). Bury, too, analyses a fanfiction community's language use, revealing commitments that are unsurprising after Bourdieu: to a traditional model of education and the valuation of distanced aesthetic criticism over emotional or voyeuristic engagement, though the tongue-in-cheek performance of such was permitted (pp. 108-130). Bury asks participants what sort of fanfiction they avoid at all costs: their replies include work with poor spelling, grammar, lack of style, lack of the canon knowledge, and headers implying that the author has written the fic due to an experience she had, which she would like to see the characters negotiate. This last stricture, which not all participants agreed with, demands as Bury notes a critically proper degree of distance between author and artefact (pp. 98-103). The more personal, emotive involvement is viewed by some as amateurish and naïve. Overall, 'there is a strong bent towards quality literature' and 'a concern for quality is highly normative in terms of class' (p. 103), and quality can be defined as exhibiting a high degree of cultural and literary capital.

More critics are coming to recognize, then, that fanfiction should not be hastily generalized as radical (cf. Bury, p. 205), but has both 'transformational' and 'affirmational' properties (fan obsession_inc, quoted in Booth 2015, p. 12), often simultaneously and within the same text. Several essays in Internet Fictions (2009) take this perspective (Grandi; Pimenova; Lepännen). For Lepännen, fanfic is

simultaneously about change, innovation and creativity, as well as about insuring that what gets communicated is comprehensible and appropriate, i.e. about regulating and constraining what can be said and written, in what ways (Leppänen 2009, p. 64). 
She likewise observes that fic is regulated by normative measures and controls and is therefore inseparable from politics and language ideologies (p. 63). Further, the transgressive nature of the driving question behind fic, which she calls 'what if', is somewhat neutralized by the conventionalization and categorizations of the fanfiction archive. I, too, understand the archive as a code-based normative organizational principle, but it should be remembered that the degree to which fic communities are moderated is variable. (For further perspectives on fanfiction with a literary/linguistic slant that neglects socio-political context, see Grandi; Collin-Smith 2009).

Now, we must outline the academic history of a particular kind of fanfic. Same-sex erotica and/or relationship-focused stories have a strong presence in fandom, and the history of slash in academia, despite its narrower focus, pre-dates academic attention to fanfiction in general. Nonetheless, we can discern a similar movement in terms of a valorization of resistance giving way to more situated, sceptical perspectives.

In 1985, Joanna Russ published two versions of the same essay. Intended for a scholarly audience, 'Pornography for women, by women, with love', appeared in an academic book (1985a), whilst 'Another addict raves about $\mathrm{K} / \mathrm{S}$ ' appeared in the Star Trek fanzine Nome (1985b). The central argument was the same: that Kirk/Spock slash fanfiction is not about homosexuality, but a coded exploration of ideal love as desired by women: the perfect union between egalitarian partners, free of gender roles and dominance. Russ theorized that this was impossible to envisage in a heterosexual union. In a similar vein, Lamb and Veith (1986) described Kirk/Spock as an 'androgynous' union uniting and emphasizing the culturally-masculine and culturally-feminine qualities of both characters (pp. 242-244). They found that egalitarianism in a heterosexual relationship was extremely difficult to write (1986, pp. 239-240), This idea of slash as gender-transcendence and the elision or bracketing of the gendered body reaches its height in Lamb and Veith's assertion that K/S is 'not about sex' (p. 254). The idea used to be quite influential: Russ drew heavily on it from the pre-publication and conference papers of Lamb and Veith (1985a, pp. 83-84). Bacon-Smith appears to endorse it when she repeats the question Lamb and Veith attributed to the slash writer: 'Not, why can't men be more like women, but why can't we all just be human?'(1992, p. 249).

Likewise, Falzone (2005) insists that slash is more a matter of spiritual unity than a genre of the body, repeating the myth of the reunification of two halves of a complete being, which Plato attributed to Aristophanes (pp. 254-255). Yet, this article also attempts to import the lenses of queer theory and post-Marxism: K/S, Falzone claims, 'has defeated the system 
of market reappropriation, and in its aberrancy, remained somehow pure' (p. 250). Moreover: 'In the same sense that mechanically reproducible art was useless for purposes of fascism, slashed narratives are useless for purposes of patriarchy, heterosexism, and commodification' (p. 251). Even if Falzone is unaware of the feminist and queer problematization of slash (see below), I would question how, given the sheer proliferation and ever-surprising variation of slash online by 2005 , academics could still be attempting to valorize it as something 'pure'. Further, Kripke's introduction of slash to Supernatural demonstrates that 'slashed narratives' certainly can be re-appropriated and utilized by industry (see episodes 5 X01; 5 X18). This gesture does not necessarily deflate all subversive potential: some fans thought the official 'approval' of incest slash a delightfully progressive introduction of outsider-statements to mainstream TV discourse. Arguably, it inscribes in popular myth a relationship with genuinely radical potential. But it is certainly not 'pure' fannish resistance to the market.

Bacon-Smith also broaches some different theories of slash. She briefly admits the possibility that women just like writing about attractive men having sex with each other, moving swiftly on to the consideration that, at the time of writing, there were not many female characters in the media and fewer still interesting enough to write about (pp. 239-242). She also suggests that women identify 'within' the television screen, finding sensuality in the relationships between characters, as opposed to projecting an objectifying gaze across it. Therefore, literature dealing with connections between three-dimensional characters, which at the time of her writing usually meant male ones, was more likely to bring pleasure to women (pp. 193-197).

In Textual Poachers, Jenkins sees slash as a female-orientated critique of 'masculinity'. He suggests that slash breaks down the artificial barriers and restrictions patriarchy imposes on male/male relationships, denying the continuum between friendship and love (1992, pp. 202-219). The central issue with this is a problem underlying the treatment of 'masculinity' in many slash theories (Bacon-Smith 1992; Kustritz 2003; Lamb and Veith 1986; Russ 1985a; Penley 1997; Woledge 2006): it is pervasively Western-centric. On the pleasures and problems of slash for a woman raised partly or wholly according to Eastern social norms - the present writer included - wherein strong and demonstrative same-sex bonds are a very condition of masculinity and sociality in general, academia is silent.

Jenkins expands on the 'critique of masculinity' model in the brilliantly titled 'Normal Female Interest in Men Bonking' (Green, Jenkins and Jenkins 1998). There is deliberately no unifying theory here: the article is written in discussion with the slash writers, some of whom espouse earlier theories, 
including the reconstruction of masculinity and the lack of interesting female characters in media, but others of whom take the unapologetic sex-radical position implied by the title. 'To be honest,' says one informant, 'I don't even identify with any of the characters. I'm just fascinated by them. Plus, I'm prurient and salacious and simply adore to watch' (p. 17). The article also notes some problems recognized in and around slash: the potential misogyny of erasing women from the narrative (pp. 20-22); the separation of gay sex from queer political experience; the homophobic overtones of the trope noted by Penley, wherein characters are portrayed as 'normally' straight, yet irresistibly in love with each other (pp. 22-30); and the tension between 'acceptably feminine' narratives (p. 32) and stories depicting, for instance, rape, sadomasochism and alienation. Cynthia Jenkins observes a tendency to divide 'good porn', which is 'relationship orientated as hell, oh so caring and tender', from 'bad porn', which is neither (pp. 32-33). Relatedly, Lepännen suggests that it is 'because [slash] does not involve women' that it can be a 'neutral' way for girls and young women to explore sexuality (Leppänen 2008, p. 170). The absence of female bodies probably makes for a safe read given that 'no female characters are taken advantage of or abused' (p. 170), but I would question the descriptor of 'neutral'-slash often involves distinct power inequalities, variably related to Western constructions of masculine and feminine sexuality.

Cicioni (1998) considers slash more radical than romance fiction, because it voices women's desires outside the dominant notions of acceptable heterosexual relationships. In her work, we see the beginnings of a newer influence on slash critics: queer theory, which tends towards a broadly Foucauldian conception of resistance as multiple and polymorphous pleasures, a 'creative practice of producing new ways of relating to others and ourselves' (Hayes and Ball 2010, p. 224). Slash, writes Cicioni, is queer in the sense of a non-heterosexual response to mass culture-a response from people who do not share the orientations supplied in the texts they respond to (p. 175). This conception of queerness is from Doty (1993, xviii), a strong influence on slash theory since the mid-20oos.

If a queer perspective and methodology is the first hallmark of recent slash theory, the second is scepticism towards anything 'inherently' resistant-feminist or subversive in slash (see especially Scodari 2003; Flegel and Roth 2010; Booth 2015, pp. 131-135). Contemporary critics are alert to the alternative potential in slash: to re-inscribe both sexism and heteronormativity through its treatment or elision of women, and its attitudes to power roles in relationships. Thirdly, it should be recalled that contemporary theorists are working in the context of fandom post home-internet, which 
amongst other changes, has prompted an unprecedented increase in the volume and visibility of slash, wider demographic variation in its author/ readership, and erased the complex initiation and barriers to entrance Bacon-Smith detailed in print-zine culture.

The phrase 'queer female space' as a way of thinking about slash was coined by Busse (2005, p. 105). She points out that slashers have a great variety of sexual identities, and argues that the subversive nature of slash is the erotic space in which readers and writers can experience, explore and connect through sexualities outside the heteronormative binary. She takes up queer theory's focus on the performative, non-essential nature of gender, especially flexible in cyberspace. Busse's paradigm has been taken up by Lackner, Lucas et al. (2006) and Lothian (2007; Busse and Lothian 2009). Lackner, Lucas et al. note that the complaint that women are absent from slash only makes sense in terms of a Modernist conception of the text as eliding the reader and writer (pp. 195-196). Busse and Lothian (2009) extend the focus on multiplicity and inessentiality by discussing the queer potential of genderswap slash, wherein the trope of two straight men who happen to love each other often gives way to depictions less definable in terms of sexual orientation', and 'rather than the attainment of a pre-destined love despite bodies, this relationship happens because of the ways that bodies trouble identities and desires' in the realization of a queer commonality (pp. 116, 119). Elsewhere, however, Busse notes that a playful performance of queerness in a safe online space can be problematic when disconnected from queer identity and activism in real life, and may be seen as 'exploitative and offensive' to those who live with the oppression and risk of being queer in daily life. The negative potential is for a 'fetishization of gay sex and the lack of a clear sociocultural and historicopolitical context' discrimination (2006, p. 211).

This concept of queer female space has the advantage of being more flexible than the old binary of resistance or misogyny, is better informed by postmodern gender theory and is sensitive to the new online context of fandom. Russo stresses the interactive, not-for-profit nature of the online slash community as a microcosmic manifestation of the new sorts of queer possibility slash narratives make manifest (2002, pp. 24-28). However, I question the blanket employment of 'female'. Male slash writers are numerically few, but I can attest from thirteen years of experience in slash communities that they a) exist; b) identify as men; and c) identify their work as slash. According to Dennis (2010), at least one third of the slash writers on Fanfiction.net are male. His source is their profiles (p. 749), a questionable gauge of accuracy, but as queer relations gain in acceptability, especially 
amongst young people, it is not unreasonable to assume that at least some of them are telling the truth.

Two further questions have been raised regarding the resistant or subversive nature of slash: firstly, do slash writers subversively create a queer subtext in the source, by way of a resistant reading, or are they making latent what is already there? The latter is Jones's (2002) opinion: slash centres on 'cult' texts, she argues, precisely because these fantastic, open-ended narratives resist the stability and closure of domestic heterosexuality. Woledge also focuses on latent elements, though pace Jones, she considers these to be the intimacy of the Kirk/Spock relationship rather than Star Trek's cult qualities (Woledge 2005a, p. 238). She therefore reads the pairing using an encoding/decoding model, considering slash a decoding of the encoded relationship. Tosenberger, too, takes this perspective, on Supernatural slash, noting that 'too strong a focus upon slash as a subversion of canon can mask consideration of the ways in which the canon itself may make queer readings available' $(2008,1.3)$. She cites Doty's observation that

to base queer readings only upon notions of audience and reception leaves you open to the kind of dismissive attitude that sees queer understandings of popular culture as being the result of 'wishful thinking' about a text or 'appropriation' of a text by a cultural and/or critical special interest group (Doty 2000, p. 4).

From a Foucauldian perspective on language, slash need not be either extracted/made latent, or radically invented, because new statements in a discourse alter discourse: there is no clear separation between source text and fandom, but the creative language use of fandom creates possibilities in the text and vice versa. Fanfic inflects and alters statements from the source text through reiteration with variation, using hints, lines and references to create alternative explanations and expansions, which are then read back onto the source text and, in some cases, taken up by the producers for explicit reference. Regarding Sherlock and Supernatural, this is highly and demonstratively relevant due to canonical reference to slash, and the fact that its most-slashed protagonists will never actually become a couple on screen according to the showrunners' denials. I would note, however, that cult texts are increasingly open to textual exchange with their fandoms, and only Western-centric, 'heterosexist logic' (Jenkins 1992, p. 204) assumes that everybody is straight until proven otherwise.

No recent attempts have been made to present a universal theory of slash, and this is probably due to a tacit acknowledgement of its endless 
variation. Slash can be progressive or regressive, transgressive or traditional, pornographic, romantic or both (Driscoll 2006). The term covers relentlessly brutal tales of alienation and violence, and sweetly domestic vignettes. It can be homophobic or gay-positive, parodic or serious, and depict anything from hand-holding to gang rape. It is more productive, I think, to take a focused perspective on slash in a particular fandom. This project, then, offers a perspective on fanfic that affords precise attention to its social, cultural and technological situation, without losing focus on the specificity of what fiction is. The theoretical tools best suited to this are drawn from Foucauldian discourse theory, with attention to the influence of cultural and literary capitals recognized by Bourdieu. It does not attempt to account for 'slash' as a specific phenomenon, but as one of those discursive practices where, in the recombination of statements of varied provenance, assumptions may be revealed and alternative possibilities suggested. The next chapter lays out the exact process. 


\section{Methodology}

Two research traditions inform the methodology of this study: discourse analysis inspired by Foucault, and internet studies. This section outlines the contribution of each. I explain how I apply those Foucauldian principles of discourse as active, constructive, formative language and practices to the context of online fanfiction, informed by earlier Foucauldian studies of text and network analyses online. I note particularly a lack of methodical attention to the reception of statements in discourse, crucial to the hierarchization and regulation of fanfic, which this project addresses. Finally, I explain the ethical protocols of the project.

\section{Discourse Analysis}

Foucault considered his texts as tool boxes, from which useful parts could be taken or discarded as required (1975 interview, cited in Patton 1979, p. 115). Previous researchers have taken up these tools in ways that set some precedent for this project. Foucault's influence can be generalized or specific: on the general side, Critical Discourse Analysis takes him as one of its founding philosophers (see e.g., Fairclough 1993, 2003; Wetherell, Taylor and Yates 2001; Van Dijk 2001). A problem here is that 'discourse' can be interpreted in terms so broad as to be unhelpful. Fairclough, whose precedent is a useful one to me, links close textual analysis to relevant social structures, arguing that discourses can be 'invested' with ideologies even though they are not ideological in themselves (1993, pp. 59-6o, 67, 91). He seeks the sources of discourses in socially available genres, so that each discourse combines pieces of many others (1993, pp. 65, 80, 105, 115-119). A newspaper article on a promising new drug might combine lexes from the discourses of religion (miracle, hope), science (jargon) and commerce (brand names, costs and benefits). This intertextuality and interdiscursivity creates ambivalence and potentially changes the discourse, as meanings associated with the source texts carry more or less powerfully into the new one (pp.104-105). As we will see, statements from canon mix in fanfic with statements from other discourses, inflecting the new formations with their histories.

Others employ Foucault's tools more specifically. The most famous 'Foucauldian' work is probably Said's Orientalism, which argued that the powerful, cumulative, tight-knit discourse of the title produced an entire 
field of study for imperial Europe (Said [1978] 2003). The construction of the 'Oriental Other' will be further explored with regards to Sherlock (p. 59, pp. 93-98), but, regarding language generally, Said shared Foucault's perception of the constructive and organizational capacities of discourse. He understood the 'enormously systematic discipline' by which the West has invaded, administrated and exploited the East as a discourse (p. 3). However, Said's use of 'discourse' is primarily concerned with the formation of objects (Young 2001, p. 403): in this case, the object of 'The Orient'. He neglects the other constructive aspects of discourse, such as the means by which statements authorize individuals, make concepts emerge and make choices available (this is Young's helpful gloss on Foucault's 'formation of strategies': see Young, Ibid.). The aim here is not to validate or invalidate truth-claims, but 'to establish the rules according to which [...] discursive events emerge' (Young 2001, p. 389). Said remains a strong influence in postcolonial work, but has been modified by Bhabha especially to account for the ambivalence and heterogeneity, which Foucault himself understood to inhere in power. Bhabha draws attention to Foucault's 'repeatable materiality' of statements, the 'process by which statements from one institution can be transcribed in the discourse of another', where the change in context renders the statement different (1994, p. 22). In a project dealing with fiction that appropriates a canon, identifying statements which accumulate this materiality across various contexts is important (cf. Hodges 2011). Each repetition thus involves both citation/consolidation of a statement, and variation or transformation of it (cf. Kristeva 1980). Clearly, citation and variation of statements is a large part of how fanfic consolidates and changes popular texts.

Closer to my subject matter, Miles (2002) conducts a Foucauldian 'genealogy' of Gothic fiction from $175^{\circ}$ to 1820 . Genealogy, in this sense, is the technique of tracing discourses backwards to their unstable and fragmentary origins, thus unsettling assumptions certain cultures take for granted. Miles historicizes the Gothic genre in terms of eighteenth-century discourses such as 'national origin' and 'the sublime' (2002, pp. 1-6) then conducts close intertextual readings in which those discourses are evident, focusing on particular codes and devices. But Miles lacks a systematic analysis of the reception, validation or rejection of the texts he studies. Therefore, his perception of discourse suffers theoretically: recall that a discourse is defined by its regularities and conditions of existence, and statements become significant through their support or alteration of those conditions. Sparing attention to the reception of texts makes it hard to see the regularities and boundaries of discourse formations in Miles's study; though, in fairness, evidence of such phenomena is much easier to find for a project 
like my own. Where Miles does discuss critical reactions (pp. 176-191), these are not clearly linked to how the text's statements challenge or uphold a discursive formation.

Lack of attention to the reception of statements also weakens Said's argument (Young 2001, pp. 389-390). Indeed, this is a significant gap in Foucault-inspired studies dealing with texts, which the present research addresses (note the lack in, for instance, Halperin 2002; Walker 2002; Fuentes Peres 2003; Archimedes 2005; Harwood 2006; Berglund 2008, Fejes 2008; Fogde 2008; Skålén et al. 2008; Solomon 2008; Kirchengast 2010; Mazher 2012; Moncrieff and Timimi 2013). The problem is not that these previous studies never acknowledge intertextuality or responses to statements, but that they lack a methodical and transparent way of addressing them and tend to treat them thinly: why is a particular critic quoted? Where did the author find that particular response? How popular is 'popular' or 'influential'? Compared to what? These questions must be addressed in order to see how a discursive formation takes the shape it does, and how it changes. In this project, I conduct systematic analysis of response and reception to statements in the form of further statements, enabling me to support arguments about boundaries and changes in discourse without sliding into objectivist fallacies that claim knowledge of essential meaning or authorial psyches.

In summary, then, I follow the Foucauldian tradition back to Said in seeking the regularities and boundaries of discursive formations, taking note of Fairclough's precedent in intertextual effects. Originally, however, I attend in a methodical way to the reception, affirmation and rejection of statements in discursive formations. As I coded fic, I kept qualitative and quantitative records of the amount and type of feedback each work received in different online contexts, including recommendations and insults. This data forms an integral part of the analysis. For, if, as Andersen writes, the aim of Foucauldian discourse analysis is to 'detect the rules that govern the way different statements come into being in discursive formations' (Andersen 2003, p. 18), it is necessary to ask how those rules come to be put in place, how and where their implicit power operates.

\section{Internet Studies}

Much research on internet text and communication takes the label 'cyberethnographic'. The reference to culture in the 'ethno' morpheme exhibits its early impetus: to rebut fears that the internet would damage social 
ties through the medium's inability to convey emotion or sustain 'real' relationships (Walther 1992; Hine 2008, p. 259). Important works in this vein include Rheingold 1993; Watson 1997; Mackinnon 1997; Hine 2000; and on fan community specifically Baym (1995, 1998, 2000) and Bury (2005). Most of the procedures are recognizable adaptations from traditional ethnography: participant observation, interviewing and surveying online and in person, focus groups, close linguistic analysis and coding procedures taken from quantitative discourse analysis (Baym 2000, pp. 24-30; 219-230; Bury pp. 18-30; 217-223). Baym notes that ethnographic work on fan audiences relies on shorter research duration and smaller subject pools than ethnography typically demands (2000, p. 19). Though I am a full participant in fandom, and in agreement with Hine that 'being a participant in [discourse] creation allows for deeper understanding' (2000, p. 23), my methodological deficiencies from the perspective of traditional ethnography are not problematic, as I make no claims to overarching description of a culture. I do agree with Samutina that long-term participant observation, which presupposes extensive reading and communication within fan fiction communities [is] important condition for the study of specifics of this type of literature' (2016, p. 3), as it is this that affords the researcher perception of community tropes, conditions and patters; however, not have sociological data on the backgrounds, aims and perspectives of the writers quoted, nor have I attempted to describe or explain what fandom is, who counts as a 'fan', or where. This sort of data is unneeded for a discursive study that declines to read authorial intention into text or posit text as symbolizing or representing extra-discursive cultural phenomena.

Aycock and Buchignani (1995) took a Foucauldian approach in their study of events on a Usenet newsgroup, tracing both the continuity and discontinuity of related postings. Rather than topics or objects, they found 'broadly constrained chronological incoherence [in posts that] disperse themselves along tangentially related threads of discussion' (pp. 200-201). Strategies of coherence-like citing past posts - could be undermined by the way Usenet technology mixed up posts and by cross-posting (p. 205). Threads nominally on the same topic could be 'genealogically coiled differently' and 'unwind at different rates' (p. 205). This genealogy showed the discourse in the process of object formation, but also revealed the fragility of the ideology on which the group was based (science as an objective practice). Their brief but dense article is a useful demonstration of how the Foucauldian concept of fragmentary origins resulting in apparent coherence can be visibly demonstrated online, structured partly by code and its flaws. For my work, the technological and social codes that govern fanfiction archives 
and community spaces must be considered as shaping factors of discourse (see also Rebaza 2008; Schäfer 2011).

Though neither a discursive, nor linguistic study, Schultz's (2011) work provides some precedent in considering how the technological structures of Livejournal and Fanfiction.net structure participation differently. She posits these sites as 'sponsors of literacy' after Brandt (1998, 2001), which 'recruit, enable, regulate, and suppress' literacy as they position participants (Schultz, p. ix): an argument very compatible with Foucauldian theory. Shultz is concerned with what university instructors of composition can learn from college students' extracurricular practices, and pays little attention to the actual fic in favour of analysing the positioning of writers and readers. Nonetheless, she makes several useful observations, including how Fanfiction.net's posting rules 'position FFN as a site that shares some of the same standards as the dominant culture' regarding good writing, such as correctness in spelling and grammar (Shultz, p. 84). She also explores the ways profile and homepage templates shape, to some extent, the presentation of authors and beta-readers, in conjunction with the users' own input (pp. 90-116;121-136); and observes that LiveJournal encourages more interactivity and more in-depth criticism of fic (p. 86), as the Fanfiction.net review page does not allow the two-way conversations LiveJournal's comment feature does (pp. 155-158). These are good examples of how techno/ social codes work to structure discourse, though Shultz underestimates how the shared codes of specific fandoms and fandom in general operate across different sites to form a websphere, though a varied one. Further, at several points Shultz displays a lack of familiarity with fan practice that undermines her perceptions of regulation. For instance, she posits without context that slash is 'controversial' (pp. 54, 68-69, 100), which is hardly the case every where, and that writing OOC (out-of character) is a 'cardinal sin' (pp. 2, 123), whereas crack and parody can depend on it. ${ }^{1}$

This method is best characterized as an archaeology. Archaeological analysis is concerned with the conditions of a discursive formation at a particular moment, though this may include 'displacement over time' (Andersen, p. 30), which is necessary in tracing reception. Genealogical criticism, the other tradition claiming inheritance from Foucault, is less applicable. Foucault stated that

1 'Crack', appearing in all fandoms, is outrageous and/or surreal humour, often featuring bizarre adventures, semi-coherent plots, transformations, talking objects and/or animals, and a variety of in-jokes. The name is derived from the double implication that it is addictive, and that it makes sense when one is high (cf. Supernatural Wiki 2011a, 'Crack'). 
'archaeology' would be the appropriate methodology of the analysis of local discursivities, and 'genealogy' would be the tactics whereby, on the basis of the descriptions of these local discursivities, the subjected knowledges which were thus released would be brought into play ([1976] 1980, p. 85).

Kendall and Wickham suggest that archaeology be seen as the explicit method, genealogy more of a strategy, a way of putting archaeology to work (p. 31). Despite much overlap between the concepts (Neal 2006, p. 41), it is archaeology that 'describes regularities of statements in a non-interpretative manner [...]; analyses the relation between one statement and other statements [and] [...] formulates rules for the repeatability of statements' (Kendall and Wickham 1999, p. 33). Archaeology also 'analyses the positions which are established between subjects in regard to statements' (p. 33), rather than seeking the interpretative principle of an author. There is some consensus that genealogy is broader, more historical and more concerned with subjectivity than archaeology. My work is better characterized as archaeology, because it is a close study of specific local discursive formations that have existed for a relatively short period of time. I do, however, trace the descent of certain statements in a small-scale way, notably from canon to fanon, thus showing in genealogical moves the contingency of certain solidified regularities. I also draw attention to the possibilities and eruptions of subjected knowledges. I take precedent from internet studies in developing the concrete, pragmatic steps to do so.

\section{Sampling and Process}

I locate this work as Foucauldian archaeology in an online context. I am attempting first to identify statements in the discursive formations of masculinity, authority and authorship in Sherlock, Game of Thrones and Supernatural fanfiction, respectively; then, working outwards, the governing statements and conditions of possibility of the formation to which the statement belongs (cf. Foucault 1981, p. 67). The research on fanfic was conducted between 2012 and 2015, and I kept a research diary dating all searches and findings: formations change, after all, and archaeology can only hope to describe them at a certain point in time. Fanfiction exists all over the internet, but I began seeking material in the points of highest centralization, i.e. the fanfiction.net category for the fandoms and LiveJournal communities dedicated to them. However, as Hine notes, technologies themselves are not research sites (2005, p. 111; cf. Kennedy and Hills 2009, 
p. 171): over the course of this project, the fan-run Archive of Our Own (hereafter A03) became an increasingly important repository for texts and another major research sites. There is much cross-posting between the sites: fanfiction is best conceived of as a 'websphere': a set of 'dynamically defined digital resources spanning multiple sites' requiring a process of 'dynamic bounding' to analyse (Schneider and Foot 2005, pp. 158, 161-163). In other words, the 'site' is not defined at the outset but 'explored through the course' of the work (Hine 2000, p. 64).

From points of centralization, I followed links to any relevant fics on other sites and pages, including Dreamwidth and Deviantart. These fics contributed statements at the edges of the discursive formation, partly due to their niche context. Each site has searching tools, which made finding fic related to my discourse formations easier (cf. Lindgren Leavenworth and Isaksson 2013, pp. 44-45). LiveJournal and Ao3 rely largely on tags, whilst Fanfiction.net has genre and character filters as well as a keyword search. LiveJournal also has a function called 'memories', allowing users to affix keywords to entries. The introduction of each chapter specifies the relevant keywords used to locate fic, informed by the discursive formations under study and my insider knowledge of fandom.

Fig. 1: A variously tagged entry on A03. Clicking on one of the tags will produce a chronological list of fics with the same tag. Clicking on the title takes one to the story.

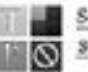

See No Evil by Susangel

stom

Author Chose Not To Use Archive Warniegs. Jessa Moore/Sam Winchester, Castiel/Dean Wixchetiter. Whan Winchesaer/Mary Wischeuer, Castiel/t uciter (Superaturaf). Castiel, Dean Wischeurer, limmy Novalk, Gabrie!

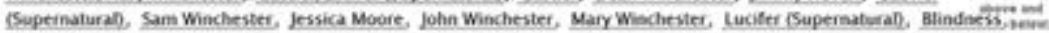

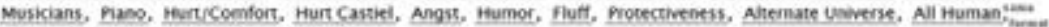
Abusive Relationship, Past Relationship(s)

Human AU, Dear's life is about as normal as can be, he has his jeh and hes beother and is perfectly happy. Then Cas, a blind pianst, enters his life and everything gets terned upside đown. Co-writen with zeppx.

Words: 15,972 Chapters: 2713 Comments \& Kudos: 12 bookmarks: \& Vits: 259

Each time I found a relevant fic, I coded it for discursive regularities by close reading. I noted whenever a statement contributed to an emerging regularity, or transformed or subverted one. No computer program has the necessary understanding of context and semantics to automate the process (cf. Deacon 2007; Blank 2008, p. 547). Having viewed instructional videos for the latest versions of NVivo, Atlas:ti and MAXQDA at their respective websites, it seems the only advantages they would afford me are organizational and 
tagging functions, which I can do sufficiently in MS Office programs. Fiction is sufficiently allusive and unpredictable that I would still have to close-read large bodies of text, because I would not know what kind of statement would change or consolidate a discursive formation until I found it.

Though keywords can be a useful means of locating material for analysis if supplemented with other search methods, I would not depend on keywordsearching as a means of analysis itself. As Willig notes,

Both explicit and implicit references need to be included. The fact that a text does not contain a direct reference to the discursive object can tell us a lot about the way in which the object is constructed (2001, p. 109).

As I read, I considered how significant statements enacted and affected the regularities that comprised the discursive formations. Where applicable, I theorized the most consistent regularities as governing statements, for, as Young observes, there is a hierarchy of importance within the regularities of a discourse.

Next, in order to claim that any particular statement is 'transformative', I will need evidence of its impact on a discourse. As noted above, this is where many discourse analyses lapse. The context of my work allows a sustained and comparative study of reception and discursive impact, based on the number and content of reviews a work receives, number of recommendations and other responses. I established versions of what network analysts call 'ego networks' (Beaulieu 2005, p. 186) for each fic, by searching for the title and/or author in quotation marks, always remembering that the context of a connection bears on its importance in a network (Park and Thelwall 2003). This part of the process has an unavoidable margin of error: occasionally, where both the title and username were very common words, I had to enclose '[title] by [author]' in quotation marks, and thus may have missed some references. A title-and-author reference, whether a recommendation or a negative comment, almost always takes the form of a hyperlink. I began these searches with Google, as it is the world's most-used search engine, then repeated them on Yahoo and Bing, the world's secondand third-most used search engines at the time this research commenced. After these, the market share in search engines drops dramatically, so it is unlikely that further engines would yield more relevant data. ${ }^{2}$ Figure 2 presents the process as a flowchart.

2 Search engine data correct as of 29/12/11 (Experian Hitwise 2011). The shares are 61.71\% (Google), $16.26 \%$ (Yahoo) and $15.06 \%$ (Bing). After this usage shares drop to $3.93 \%$ (Ask). These 
Fig. 2: Methodology as a flowchart.

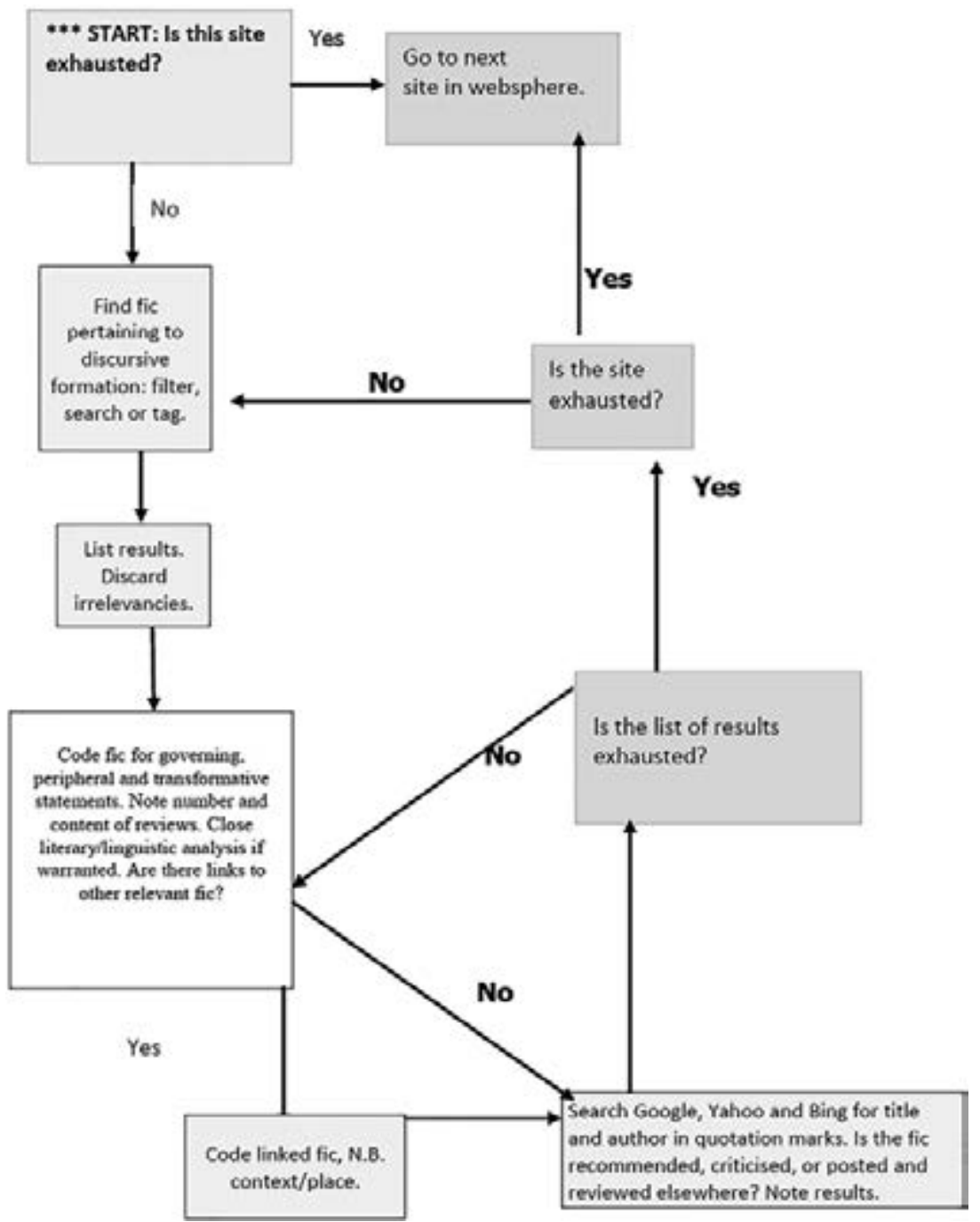

This brings me to the issue of comprehensiveness. To engage a reflexive lens that Foucauldian research can be criticized for lacking, if technology and contexts shape the discourse studied, so do they shape this research. Firstly, I am only able to read fics written in English. The majority are: for example,

figures are based on volume of searches. Measured by visits, Bing and Yahoo exchange places, but the top three sites are the same. 
of the 58,669 available on Fanfiction.net as of 24/02/12, 46,656 were English language (79.5\%). Secondly, just as Hine notes that her virtual ethnography is 'shaped by the available technology and [her] understandings of it' (2000, p. 81), so is my archaeology. According to the search methods above, I attempted to catalogue every relevant fic, at least for statistical purposes, in the more centralized archives during the periods of the study, though this approach had to be modified slightly in the case of the vast Sherlock fandom (see p. 66). However, whilst I am computer literate, I am certainly not an expert in IT, and where on some LiveJournal communities I have had to resort to insite searches, I am less certain of its comprehensiveness. It is possible that a researcher capable of designing his or her own search programmes would present a different project.

Even given those constraints, I am dealing with a vast amount of material. Some fics will warrant close analysis, others mere inclusion in statistics. I take note of highly influential fics - those with the most reviews, most references and links - for their impact on discourse. Some are chosen for analysis for that reason. But I also consider texts that are otherwise illustrative of the discursive formation. Either they are paradigmatic, exhibiting discursive regularities clearly, or they are critical cases: texts that most visibly alter or challenge those regularities (the criteria are adapted from Flyvbjerg 2006). As Jäger and Maier (2009) advise, I pay particular attention to discursive limits, or peripheries as Young might say, seeking techniques for extending those limits and narrowing them down. Where fic contributes statements that alter boundaries, there may be special techniques necessary to render the statement acceptable or intelligible, to produce a relation to sameness and regularity as well as difference and change.

Thus, I combine Foucauldian principles with techniques of network analysis and participant observation to access and analyse my material. My means of observation have been adequately discussed, and I must now locate my positon as researcher with regard to the material before proceeding to the analysis.

\section{Position and ethics}

Given that I have been writing and reading fanfic since I was 14, I locate this project as 'insider research' (Hodkinson 2005). 'Insider', however, does need some qualification. Supernatural has been one of my main fandoms, though I have also read and written a fair amount of GoT fic; the BBC's Sherlock fandom is newer territory to me. Larsen and Zubernis rightly note a 'danger for the researcher [...] in believing that whatever slice of fandom he 
or she knows best is therefore representative of the whole' (2012, p. 36). This would be an irresponsible over-representation, given that the researcher addresses an academic audience as well as a fannish one. I am not claiming to be 'inside' some holistic entity called 'fandom' (cf. Campbell 2011), but rather to use the term signalling my 'location' in 'a set of [particular, fannish] networks and connections', which properties the label 'aca-fan' signals to Lothian (2011). The way I write to and for other fans is a learned practice common to these particular networks, and, internalized long before I started this project.

Moreover, deciding to approach one's fandom academically has consequences. I write from an institutional context as well as a fannish one, a 'culture of research production' (May and Perry 2011, p. 176) with its own narratives, priorities and expectations. Conversely, bringing fanfic to academic and/or outsider attention, removing it from its context of publication and reprinting it as part of an academic text for a new audience, is an exercise of the power that my institutional position gives me.

Therefore, my ethical policy is openness with regard to my project. I sought permission for every fic and review quoted, and offered to share a draft with the author. In this way, I hope to mitigate the power imbalance of the 'politics of knowledge production' (Sultana 2007, p. 376) between the 'knower and the known' (Adkins 2002, p. 340). This is particularly important given my privileged education and networked institutional context, which afford me with protections and advantages that the fans whose work has gone into the making of this thesis may not have.

Further, as Hine notes, becoming a researcher as well as a participant increases one's awareness of one's writing $(2005$, p. 21). I devoted time to the kind of fanwork that takes greater effort than simply reading fic-writing fanfiction, recording podfic, writing about this project in general terms in my Livejournal, maintaining fan contacts, discussing the show and revealing certain aspects of my personal life. I would have been participating regardless, but perhaps less conscientiously and, like Hine, I found myself acutely aware of my self-presentation in fandom in a way I might not be had I no professional stake in it. I leave reviews and recommendations, as I consider these contributions an important form of reciprocity to the community (Fetterman 1998, p. 143) as well as deepening my understanding of discourse practices. In that spirit, I submitted novel-length fics to the 2012 and 2013 Supernatural Big Bangs (a fandom event wherein authors write and artists illustrate long works of 20,000 words or more, publicly revealed on a calendar schedule over the summer). I have promptly found the validity of Hine's contention that 'a reflexive understanding of the 
medium, if critically examined, can provide for insights not accessible from the analysis of archives' (2000, p. 23). For instance, when a podfic I had laboured over recording apparently failed to post on an audiofic community, I witnessed how the vagaries of technology can influence visibility or its lack. When the popular hosting site Megaupload was taken down in 2012 due to allegations of copyright infringement, hundreds of podfics, including mine, disappeared (not permanently in my case-I back up). The visibility and availability of fic thus simultaneously structures and is structured by legal discourse.

As a textual analysis, this project poses no immediate harm to participants. As I am only using text that is already, technically speaking, in the public domain due to actions taken by the author, it could be argued that I have no legal obligations of protection even where said text contains sensitive information about a recognizable individual (see the Data Protection Act 1998, Schedule 3, clause 5). Logically, it seems quite defensible to freely quote any fanfiction I find unlocked. However, as fanfic is intended for limited circulation within established communities, there are ethical considerations in quoting it, its responses and reviews. Ethics must account for experience and judgement as well as law (Ess et al. 2002, p. 4), and having participated in fanfiction communities for over thirteen years, I am confident that most fans would prefer to be asked before being quoted (and cf. Freund and Fielding 2013; Busse and Farley 2013). Secondarily, to take more steps than are legally necessary for the protection of participants quoted will benefit me as researcher, because my current good reputation in fandom depends upon my maintaining trust and openness with all concerned as much as my active participation. Were I to quote without seeking permission, and that breach of trust later become known in fandom, I would jeopardize not only this research project, but any other work I might later do in the same field. I received mainly positive responses to my requests for permission to quote, with many fans thanking me for my consideration in asking, and the rare refusals were cordial. However, as Kozinets observes, the fact that some participants do refuse weighs in evidence for the duty to ask (1997, p. 471), and I myself have received a few polite refusals with expressions of appreciation for my ethics of transparency. I asked how fans would like to be named and abided by their wishes. Most opted for screen-name, but some requested that their real name be used or that they remain anonymous. There were times, however, when it is impossible to obtain consent or denial from an author, either because I could get no response or because personal message features were disabled or unavailable. This occurred most often with fic hosted only on Ao3, though some 
authors can be reached via Tumblr links from their profiles. In this case, balancing commitment to the project with ethics, I reference by the same screen-name/identifier given where the work exists online, duplicating only what has been made publicly available. Taking precedent from Hine (2000, p. 73), my practice was to send informal messages asking for permission to quote, using my fan-identity, which links to my own LiveJournal and Ao3 accounts, full of my own fan activity. In the messages I gave my real name, institution, a link to my university webpage and brief description of my project, offering more information upon request. I took the same approach to comments/reviews, as the respondent can be considered as an author in the capacity of critic. I did not seek permission for inclusion in numerical data as this does not reflect on individual personas.

This project, then, takes instruction from some of the most fruitful uses of Foucault to analyse text, and transposes it to the context of online research via network analysis techniques. It contributes to uses of Foucault through a methodical analysis of the reception of statements, revealing thereby the processes by which discursive formations are constructed. The next chapter begins the research proper, with my study of the discursive formation of masculinity in Sherlock. 



\section{The White Man at the Centre of the World: Masculinity in Sherlock}

\section{Introduction}

The BBC's modern adaptation of selected Sherlock Holmes stories has largely met with enthusiastic critical reception and great popularity. The series has sold to over 180 territories, including Canada, Australia, Sweden, India, Japan, Germany and the commercially crucial USA via the PBS syndicate network. The show received the respected Peabody award in 2011, in addition to a selection of Emmys, Baftas and other markers of cultural capital for writing, acting, direction, sound and cinematography. The fandom, meanwhile, is one of the most active and productive on Tumblr, Livejournal, Ao3 and Fanfiction.net. It is fair to say, then, that we can hardly underestimate the impact of the show in contemporary cultural discourse regarding the construction of masculinity.

The figure of Sherlock Holmes has played a key role in a particularly British discourse of masculinity since his first appearance in The Strand magazine in 1887. In fact, as Joseph Kestner demonstrates, the initial publication of the Sherlock Holmes stories functioned to 'model male gender behaviour' (1997, p. 7) appropriate to a 'stabilizing bourgeois, hegemonic masculinity' (p.13) in response to a catalogue of social concerns that sound remarkably familiar today: conflicts abroad, loss of British power, the decline of religion, the changing status of women in society and the decline of jobs involving physical labour. As I have argued elsewhere,

the character of Sherlock Holmes has historically depended upon the triumph of rationalism as an order of knowledge and a logocentric regime of enunciation that renders everything readable, knowable and masterable to the master detective (Fathallah 2014, p. 492).

The detective reassures the reader that the changing world is still readable and understandable. Kestner argues that Holmes and Watson must face and contain a range of threats to proper Victorian masculinity, be it the hysterical and disorderly clients or the symbolic swamps, adders and hounds they meet, address and contain. Holmes himself, with his eccentricity, drug use and disdain for family, exemplifies a rational masculinity haunted by its dark Other, and it is, above all, Watson, the unexceptional 
and normative Englishman, who controls and guarantees this suppression. (cf. Toadvine 2012). Watson represents intellect, balanced by athleticism and capable physicality as a counter to Victorian fears of effeminate men. The model of masculinity the Holmes stories construct is rational, logical, courageous and patriotic - though not to emotional excess. It is scientific and dispassionate, privileging mind over body. It is, above all, incisive: able to see, to dissect by seeing, and to master situations and problems though an ordering, controlling gaze. The year of Holmes' first appearance also saw the publication of criminologist Alphonse Bertillon's 'anthropometric system of bodily measurements that he had devised to classify and identify criminals' (Lavën 2013, p. 32). Holmes is the visual diagnostician of social ills that Bertillon's schema requires.

As I will argue, this Victorian construction of masculinity is still privileged in the $\mathrm{BBC}$ series, bringing with it a host of problems and erasures that fandom goes some way towards transforming through its intervention in the discourse. This is not to suggest that the construction of Sherlock Holmes in professional media never changes. On the contrary, the flexibility of the much-adapted figure is part of what makes it so crucial to discursive constructions of British masculinity. Neil McCaw demonstrates how, in the UK, TV adaptations by Granada (1984-1994), Victorian nostalgia meshed with a Thatcherite ideology of law and order, patriotism, and respect for authority (2013, pp. 38-42), whereas earlier films like The Private Life of Sherlock Holmes (1970) and The Seven Per Cent Solution (1976) critiqued and responded to rapid social and industrial changes of the 196os and 7os, constructing a more ideologically critical and more vulnerable detective (O'Brien 2012, pp. 68-73). In these films, Holmes' drug abuse is more prominent, and the value and efficacy of his work is called into question: in The Seven Percent Solution, he can solve the mystery of Jack the Ripper case, but is ultimately powerless against the Royal/masonic conspiracy behind it. O' Brien sees Holmes in the cinema of the 1980 s as regressive, by contrast: largely escapist and cynically marketed towards a profitable child audience: this was the decade that produced a teenage Holmes at boarding school (Young Sherlock Holmes, 1985) and a Holmes-esque detective as an animated mouse (The Great Mouse Detective, 1986).

As the most-adapted character in British fiction, it is difficult to make arguments that Holmes is 'always x' or 'never y' (he has, for instance, been adapted/parodied as a talking cucumber in an episode of children's animation VeggieTales, 2006). There is not nearly space here to discuss the breadth of professional adaptations: Vanacker and Wynne's Sherlock Holmes and Conan Doyle: Multimedia Afterlives (2012) is a good place for 
the interested reader to start. Nonetheless, it is fair to say that prominent constructions of his adventures exhibit certain hallmarks: Englishness, extreme rational and logical intelligence, vision, control and the superiority of mind over body. With the exception of Englishness, these hallmarks align quite neatly with Richard Dyer's arguments on the construction of White masculinity (1997).

Dyer unpacks Whiteness both as marker and the state of unmarkedness, whose primary power is its invisibility, which problematically allows it to stands for 'human'. The construction of Whiteness privileges mind, reason and civility over the embodiedness and potential wildness of the 'dark'. Key statements in this discourse can be made in visual language: Dyer argues that the proper White male body, hard and taut, should not 'look like it runs the risk of being merged into other bodies. A sense of separation and boundedness is important to the white male ego' (p. 152). The present BBC incarnation of Sherlock Holmes has not departed very far from this construction of White man, or from the ultra-rationalist conservative fantasy of the society he observes and diagnoses. In fact, despite the technological trappings, I would agree with Balaka Basu that the BBC's Sherlock is, in many ways, more Victorian than its Victorian source: that is to say, it constructs a masculinity whose governing statements are drawn from our post-Victorian fantasies of an earlier, more 'reasonable' era. The construction of an England-specifically a visibly White London-at the centre of global politics mutually reinforces that construction.

Key visual statements in the BBC text ground the discursive constructions of this Sherlock in its Victorian sources. The sign '221B' is framed in close-up on the door leading to the flat in the first episode ('A Study in Pink', hereafter ASP). The cars chosen for street views have rounded silhouettes. Victorian costume is invoked through cut and colour (cf. Basu 2012, pp. 199-200). I have observed elsewhere that the deerstalker, which Sherlock adopts in Season 2, consolidates a sense of inevitability to the sequence of citation: it is almost necessary that any modern portrayal return to some mythic essential fundament grounded in Victoriana:

if the modelling of masculinity is crucial to the initial conception and reception of Sherlock Holmes, the modern text's evocation of its own history gestures to some mythic construction of an essentially British man: a masculine hero for our time that sustains the illusion of an essential rational masculinity for all time (Fathallah 2014, p. 493; cf. Butler 1993 on citation). 
The 2016 special episode, 'The Abominable Bride' (hereafter TAB), consolidated this construct by juxtaposing contemporary Sherlock with his Victorian counterpart through a series of dream sequences. In the final scene, his Victorian embodiment declares himself 'a man out of [his] time,' as the camera pans out from the Victorian living room to the modern streets of London. Moreover, maleness is the default construct of humanity. As John Watson (Martin Freeman) stands over Sherlock's fake grave after Sherlock fakes his death in episode 2xo3, 'The Reichenbach Fall' (hereafter TRF), he laments:

You... you told me once that you weren't a hero. Umm, there were times I didn't even think you were human, but let me tell you this: you were the best man, an' the most human... human being that I've ever known.

There is an intertextual citation here of Kirk's eulogy to Spock, the ultrarational alien of Star Trek to whom Sherlock is explicitly compared in 2xo2, 'The Hounds of Baskerville' (hereafter THB). In the film Star Trek II: The Wrath of Khan, Kirk describes Spock's soul as the 'most human' he has ever known. Even as his humanity is called into question it is affirmed, indeed idealized as the most human, the pinnacle of what 'to be human' means. Nonetheless, in the series' overall construction, John's influence on Sherlock and the primacy of his narrative viewpoint balances the construction of masculinity across both characters. In some adaptations, Watson serves more as a comic foil to Sherlock's brilliance. This is acknowledged metatextually in TAB, when Watson's Victorian counterpart informs Sherlock he 'play[s] the fool' in his public presentation of their adventures only to humour Sherlock's ego.

Before we embark on a close reading of precisely how the BBC series constructs this ideal of (default, male) humanity, we must take a moment to address the Foucauldian author figures attributed to it, in order to observe how fanfic contests and solidifies the authority of the text. The showrunner position in Sherlock is shared by Steven Moffat and Mark Gatiss. Both are prime examples of Scott's fanboy-auteur, and fandom has discursively condensed them into a single author figure with the portmanteau-term 'Mofftiss'. This statement demonstrates the consciously constructed quality of the author figure: Moffat and Gatiss as people matter little. What matters are their positions and authorial statements, through which they present a united front and attitude to the show. Moffat, whose credentials include fan-favourite Doctor Who, describes himself and Gatiss as 'the biggest Sherlock Holmes geeks in the world' (BBC Media Centre 2012). He frequently employed similar discursive tactics to secure his position as a 
worthy showrunner for the Doctor Who franchise, stressing his childhood adoration for the show (Harrison 2013). Yet, his relationship with fandom is notoriously difficult. The Tumblr blog 'Stfu [Shut the fuck up]-moffat', for instance, criticizes him for fan-shaming, inability to take criticism, and the repetitive construction of one-dimensional female characters. In 2012, Moffat rather spectacularly deleted his Twitter account after several conflagrations with irate fans and has not returned to that sphere of public discussion. He is often criticized for, on the one hand, stressing his own fannishness as a credential and, on the other, dismissing fannish desire as trivial and over-invested. He is keen to retain both his position as a fanboy and the authority over his texts, merging them in statements like, 'Our own fanboyness about Sherlock Holmes means that there are absolute limits to what we do. Ours is an authentic version of Sherlock Holmes' (Jeffries 2012).

'An authentic version' is almost an oxymoron, and a neat illustration of the paradox at the heart of the fanboy-auteur posture, combined with the possessive 'our'. Moffat and Gatiss refer to Conan Doyle as their author figure, their ultimate source of authority, Gatiss naming him their 'absolute God' (Jones 2014); on the other hand, they stress their points of adaptation and alteration (cf. Hills 2012a). The strongest relevant statements are a meta-textual discussion in TAB, wherein Sherlock quotes his own earlier incarnation from Conan Doyle's 'A Scandal in Bohemia' (1891). Recall that Conan Doyle wrote in first person, assuming the voice of Watson as Holmes's biographer. Now compare:

Holmes: All emotion is abhorrent to me. It is the grit in a sensitive instrument ...

$[\ldots]$

Holmes and Watson (almost simultaneously):... the crack in the lens. Watson: Yes.

Holmes: Well, there you are, you see? I've said it all before.

Watson: No, I wrote all that. You're quoting yourself from The Strand Magazine.

Holmes: Well, exactly.

Watson: No, those are my words, not yours! That is the version of you that I present to the public: the brain without a heart; the calculating machine. I write all of that, Holmes, and the readers lap it up, but I do not believe it (TAB, transcribed by Ariane DeVere 2016).

In the same episode, the BBC's garrulous Mrs Hudson objects to her lack of lines in Watson's literary endeavours. Doyle's text, then, is constructed as 
a fiction, whilst Moffat and Gatiss's holds at least equal authority. Doyle, after all, is a weak author figure who was never much invested in Sherlock Holmes except financially and offered his usage in fiction freely to all comers. 'You may marry him or murder him or do what you like with him,' he telegraphed to dramatist William Gillette around 1900 (Redmond 2009, p. 43), considering the Holmes stories primarily as a source of income granting him time to work on more serious projects.

Further, we should here recall Foucault's contention that 'the Author is a certain functional principle by which, in our culture, one limits, excludes and chooses' (1991, p. 119): Moffat makes frequent and explicit use of this construction. He safeguards interpretation from fan-interpretations with statements like 'I think our female fan base all believe that they'll be the one to melt that glacier [that is Sherlock]. They're all wrong-nothing will melt that glacier' (quoted in Ng 2014). Gatiss, another Doctor Who alumni, is generally less inflammatory in his dealings with fandom, yet he, too, is keen to stress his fannishness on the one hand and his authority over the text on the other. He agrees wholeheartedly with Moffat's professions of fanboy enthusiasm on Sherlock DVD commentary tracks. Indeed, the two position their own work as 'fanfiction', apparently endorsing fan production wholeheartedly:

Moffat: We did this as possibly the biggest sustained act of fanfiction, and as a result there's fanfiction about our fanfiction.

Moffat: And I do think that's where story telling comes from.

Gatiss: It's that lovely thing of generating new content around it. It's the sort of thing that got us into writing (Season 3 DVD extra: 'Fans, Villains and Speculation - The Legacy of Sherlock Holmes', transcribed by Ariane Devere, 2014).

Yet, in the same commentary, he discursively contains fandom in its proper place, which is definitely not the place of the proper, author-ized text:

Gatiss: But it's also not a thing where you can respond to the fact that it has a massive international audience, 'cause shows go off the rails ... Moffat (nodding): Yes.

Gatiss: ... if you start trying to direct it towards what you think people will like, or what you think they might fear. We just have to make it for ourselves. It's a hundred-year-old spoiler, but Doctor Watson does marry Mary Morstan; and you get that sort of slightly-miffed, "You're not allowed to do this. You'll spoil it." But it's our show (Ibid.). 
Consider also the conjunction of 'fans' and 'villains' in the commentary title, constructing an easy slippage between the two categories separated only by a comma. These statements may be understood as a form of what I call textual provocation: text that provokes fans in the sense of annoyance or baiting, and text that provokes the production of further text. Specifically, the even observation of 'fanfiction about fanfiction' may be taken as an invitation to write, whilst the reservation of the true text to the fanboyauteur(s) maintains hierarchical separation.

Given that the author figure is traditionally White and male, this chapter will demonstrate how masculinity in Sherlock is reconstructed in fanfic, yet is paradoxically dependent what is already culturally author-ized: the White male hero with his established history of a model of British masculinity, and the White male author figure behind him. How, then, is masculinity constructed in the author-ized show? The next section performs a close reading.

\section{Masculinity in Sherlock}

My analysis of the BBC series suggests that the idealized masculinity of Sherlock and Watson is constructed through four discursive branches. In an adaptation of Foucault's recommendations to begin at the level of 'event' before working outwards to conditions of possibility (Foucault 1981, p. 67), I began at the level of individual statements, be they visual or aural, then worked outwards to considered the branches to which they belonged, and the solidity and boundaries of those branches (Foucault 1981, p. 67). I call them mind, body, position, and place. By 'place' I mean geographic location, be it country, city, or building; by position, I mean social position in relation to other people. Clearly, all these branches are interrelated: their distinction is for organizational purposes as we study the discourse of masculinity they combine to construct. I have found, however, that the relation of these branches to each other is much more explicit in fanfic than canon. Indeed, canon's obfuscation of their connection may be read as rather problematic, as will be explored. Bearing that in mind, then, let us address the branches one by one.

\section{Mind}

As discussed, extreme rational and logical intelligence are key in Sherlock's construction: I would argue they are governing statements (Foucault 1989, 
pp. 147-148). The writers and cinematographers of Sherlock use a range of techniques to demonstrate this onscreen. The whole show's palette is dark, but at least part of Sherlock's (Benedict Cumberbatch) face tends to be lit, particularly in moments of thought/investigation. This is an intertextual citation of Sidney Paget's illustrations, which frequently featured Holmes holding up a light or lantern to 'illuminate his surroundings' (Scott-Zechlin 2012). Holmes's rationality is a literal light in the dark. The speed of his thought processes are suggested by close-ups of his face punctuated by swooshing sounds and rapidly-moving images as he makes connections, audibly linking his mind to a computer. As Bran Nichol (2012) argues, computation is also suggested visually through bird's-eye views of London showing cars moving in neat ordered circuits: this, the cuts suggest, is London as Holmes sees and visually masters it. The imposition of text on the screen, which Sherlock is able to manipulate, depicts him in the act of sorting and ordering the masses of information he has filed away. His stores, however, are not infinite: when he is unsure of the meaning of observed clues, he produces a smartphone and seamlessly links to the broader network of the internet.

The mind-as-computer construction is complicated, however, by the linkage of sex and thought. As Nichol notes, the closest thing to sex in the BBC's Sherlock is the range of 'oh!'s and 'ah!'s vocalized by Cumberbatch as he portrays Sherlock thinking: a kind of eroticism is produced in the process of puzzle-solving, of winning the mental game. For Sherlock's mind is absolutely triumphant over his body—having been shot in 'His Last Vow' (hereafter HLV), he is able to save his own life by thinking through the correct way to fall, minimizing blood loss. Slow-motion capture of the process constructs Sherlock's mind as literally able to slow time, bending it to his will. Later, trapped in a coma, survival is constructed as a willed struggle up a staircase: using the power of his mind, he can force his body to live. He describes his mind as a 'palace', a location in which he has mapped his material for access. This is a reference to the method of loci, an Ancient Greek mnemonic device based on storing items of information in the visualized spaces of a building. Though emphasizing the grandness of his intellect, this might also construct his attendant egocentricity as slightly pretentious or risible: as John puts it in THB, 'He would [call it a palace], wouldn't he?'

Critical to the construction of mind, Sherlock's ability to diagnose based on visible information remains unchanged in the BBC series. This is a governing statement, one that 'prescribes the form(s) of description' and 'perceptual codes' that can be utilized (Foucault 1989, p. 147). According to Jaffe, this 'fantasy of social control' through readability is a hallmark of 
the detective genre (Jaffe 2000, p. 49). Not only can Sherlock read almost everything about a person immediately upon meeting them, what he primarily diagnoses is personal and social deviance. Offences range from an extra-marital affair between colleagues to implication in a major crime:

Sherlock: Mr. Ewert of Janus Cars had a twenty thousand Columbian peso note in his wallet ...

(Flashback to Sherlock seeing the note in the wallet.)

Sherlock: ... Quite a bit of change, too. He told us he hadn't been abroad recently, but when I asked him about the cars, I could see his tan line clearly.

(Flashback to Sherlock pointing out the window and Ewert turning his head to look while Sherlock sees that his tan finishes at his neck.)

Sherlock: No-one wears a shirt on a sunbed. That, plus his arm.

Lestrade: His arm?

Sherlock: Kept scratching it. Obviously irritating him, and bleeding.

(Flashback to a close-up of Ewert scratching his upper arm, and a drop of blood on his shirt sleeve.)

Sherlock: Why? Because he'd recently had a booster jab. Hep-B, probably. Difficult to tell at that distance. Conclusion: he'd just come back from settling Ian Monkford into his new life in Columbia ('The Great Game, hereafter TGG, transcribed by Ariane Devere 2012).

Sherlock's mind can deduce anything that is visible. This excludes emotional comprehension, such as the motive for using a stillborn infant's name as a password (ASP). He protests that the child's death was 'ages ago', and that he sees no reason that the mother should 'still be upset' about it. Though John reprimands him lightly for this, the moment is ultimately subsumed in Sherlock's triumph in solving the mystery.

John Watson is constructed as more capable of empathy, though not particularly emotionally literate, and develops a psychosomatic limp as a result of being unable to process his experiences at war. His mind is resilient yet damaged: the opening of ASP shows him dealing alone with his flashbacks and nightmares from service in Afghanistan. He supresses a great deal of rage, accidentally shouting at Mrs Hudson and immediately apologising in the same episode. Once finally goaded to punch Sherlock in 'A Scandal in Belgravia' (hereafter ASB), he is briefly unable to stop hitting him. Despite nightmares from the war, Mycroft accuses him of missing the war more than he is haunted by it. The camera's responding close-up on Freeman's face as he performs a giveaway twitch of facial muscles solidifies 
this statement. The construction of controlled White masculinity, as Dyer demonstrated, is internally and eternally troubled by what it supresses (1997, especially pp. 34-36, p. 82). What John supresses seems to be masculinecoded reservoirs of rage and violence. In the original stories, Watson faints upon seeing Holmes return from apparent death. In the BBC adaptation, he punches him in the face, a pointed variation of the statement cited. The rational suppression of violence is consolidated by John's dual professions: he is both a doctor (healer/scientist) and a former soldier (fighter/ man-of-action).

\section{Body}

Sherlock and John are White men. This might seem an absurdly obvious point, but it is precisely this apparent obviousness, or taken-for-grantedness, that demands we interrogate it critically. Media backlash to the casting of Lucy Liu as a female, Asian Watson in PBS's Elementary makes it clear that the fact that these characters are White men means something, which is far too often elided (see Stagg 2012). As Dyer (1997) has demonstrated, the cultural power of Whiteness is its invisibility: Non-White people are racially marked, but Whites are just people, whose interests are 'human' interests as opposed to racial ones. White is a flexible descriptor, but Cumberbatch and Freeman are well within its boundaries. Indeed, I would argue that the casting of Benedict Cumberbatch as Sherlock draws attention to a form of elevated Whiteness, as Cumberbatch has the kind of lean height and sharp features that used to be called 'Anglo-Teutonic' and directly contrasted to Othered 'races' (see Dyer, pp. $5^{2-53}$ ). He is a fair physical match for the Victorian descriptions and illustrations of Holmes, with his height, leanness, 'sharp and piercing' eyes and the strong chin that 'mark[s] the man of determination' (Conan Doyle 1887). This intertextual description hooks into contemporary scientific discourse: at the time, anthropological theories of race and character were generally accepted, and intelligence, morality or lack thereof were routinely read off features. Cumberbatch's embodiment necessarily carries the echo of such statements (cf. Fairclough 1993). He is, moreover, extraordinarily white in the sense of pigment, a feminizing visual construction and one we will see elaborated in fandom. When Sherlock dismisses his body as 'transport', stressing the dominance and control of his mind over it (ASP), the apparent meaninglessness of the White body is made explicit even as the show's visual language invests it with meaning. John, meanwhile, embodies a contrasting masculinity marked by robustness, strength rather than height, and scars rather than 
smoothness: he is damaged, as his intermittent limp and stress-lined skin make visible, but still strong, and damaged by the appropriately masculine pursuit of war.

Fig. 3: Sherlock Holmes (Benedict Cumberbatch, left) and John Watson (Martin Freeman). Source and copyright: BBC.

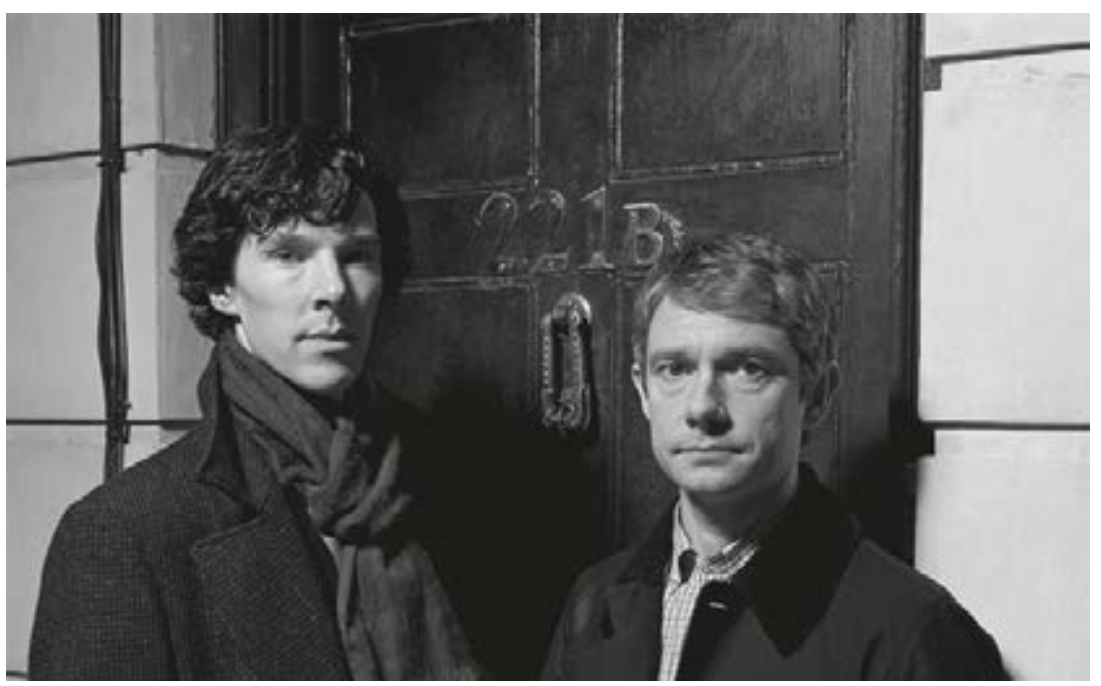

As Basu has observed, wardrobe choices consolidate the construction of a sober, contained and proper masculinity, allowing for a note of eccentricity associated with 'Englishness', which has its governing statements in Victoriana:

Sherlock's ever present scarf works as a cross between an ascot and a cravat, and his coat, with its 'pronounced collars and raised lapels' is, as noted by The Independent's fashion commentators Paul Bignell and Rachel Shields, clearly a 'modern reworking of ... Victorian designs' (Basu 2012, p. 199).

Now this hegemonic construction of the masculine body is never total: if it were, it would be unbelievable. Hegemonic gender constructions in a post-feminist context must be strong and flexible enough to absorb and incorporate irony (Talbot 1997; Benwell 2002). Sherlock draws attention to construction of gender as a performance, as a 'series of socially sanctioned citations' (Butler 1993, especially pp. 12-16) rather than an 
embodied essence. John mocks Sherlock for acting 'all mysterious with [his] cheekbones' and 'turning [his] coat collar up' (THB), pointing out the conscious creation of a masculine image by visual statements. Moreover, Sherlock's bodily performance incorporates statements associated with femininity and lightness: he often appears in white shirts and, in one notable scene from ASB, in only a sheet at Buckingham Palace. Sweeping out melodramatically, in disdain for the 'boring' case Mycroft (Mark Gatiss) wishes him to take on, this image of Sherlock's body nevertheless connotes male authority and superiority via evocation of the toga and Cumberbatch's hard, thin, defined White body (cf. Dyer above). The construction of White masculinity via the hard body is strong enough to withstand humour, indeed to assimilate it.

This tendency is likewise demonstrated in a key scene in 'The Empty Hearse' (hereafter TEH), wherein Sherlock apparently leans in to share a kiss with his arch-enemy Moriarty. As I have argued elsewhere, Moriarty embodies a disruption to the show's construction of masculinity (Fathallah 2014), through his highly improper performance. He is flamboyant, theatrical, queer, excessive, prone to rages and rants and hysteria. His is the only body that initially evades Sherlock's reading ability:

[Moriarty] poses first as the boyfriend of lab worker Molly Hooper, and Sherlock (mis)diagnoses him as 'gay' through (mis)reading signs of campness in 'The Great Game' (2010). These are his level of personal grooming' and designer 'underwear [... ] visible above the waistline,' in addition to the fact he leaves his number under Sherlock's microscope. But Sherlock's ability to read the world, indeed the readability of that world and the stability of an epistemological regime based on such reading, is disrupted by the lack of a gay essence. Moriarty was only 'playing gay,' as he later admits, asking 'did you like the little touch with the underwear?' (Fathallah 2014, p. 496).

Later, in TRF, Moriarty breaks into the case of crown jewels at the tower of London, dresses in them and enthrones himself, which, taken in the context of his earlier statements, consolidates his construction as a 'queen'. Sherlock's almost-kiss with Moriarty almost imperils the bounded construction of his body via the bodily fluids of his opposite-but not quite. At the last second, the kiss is revealed as the fantasy of an over-invested female fan: an instance of fan-shaming in which the fanboy-auteur positions the fan as wrong. She is tolerated, to an extent, even allowed to fantasize, but barred from the production of the true, author-ized explanation. The 
boundedness of the male body, then, proves to be a governing statement of this construction, a 'definition of observable structures' that 'prescribes the form of description' of masculinity (Foucault 1981, p. 447).

\section{Position}

The position of White masculinity in Sherlock, particularly in relation to women and other ethnicities, is primarily one of command and mastery. This is intricately connected to Sherlock's ability to see and read, to decode other (primitive) cultures from the position that Said famously theorized as Orientalism (1979). The Orientalist is the master of the exotic domain he surveys and understands, whilst the racially-marked other occupies the position of an object-to-be-known rather than a subject capable of understanding. The Orientalist gaze in Conan Doyle's stories is well documented (see Thompson 1993; Foss 2011), but the surprising fact is that it persists in this supposedly contemporary adaptation. 'The Blind Banker' (hereafter TBB) showcases Sherlock's understanding of, and ability to dissect a Chinese smuggling operation, read initially through supposedly mysterious ciphers left around London. Sherlock cracks the code and rescues John and his girlfriend from stereotypical Chinese assassins who have been posing as circus acrobats. As Kustritz and Kohnen write:

The smuggling of Chinese antiquities, Soo Lin's job in a museum, and the Chinese circus all mark Chinese culture as something different and separate from 21st century digital London. Moreover, the representation of Chinese culture as fundamentally alien to modern Britain places the viewer in a spectatorial position complicit with Orientalism (2012, p. 99).

Then, in ASB, Sherlock assumes a position akin to Lawrence of Arabia in order to rescue a white woman from execution by an absolutely anonymous group of turbaned terrorists. These faceless 'Orientals' are a literal prop in his performance of heroic White masculinity.

Sherlock's position with regard to women is also problematic. Said rescued woman is the character of Irene Adler, a self-professed lesbian who apparently turns straight due to the irresistible sex appeal of Sherlock. Sherlock is desired by most women in the series, whom he treats, in turn, with callous disregard or paternal protectivism. 'Don't snivel,' he reprimands Mrs Hudson in ASB, having just saved her from some violent gangsters; and he frequently insults the love-struck Molly Hooper through a mixture of insensitivity and unconcern. Granted, he demonstrates some character development 
by Season 2, and appears genuinely sorry to have upset Molly at Christmas (ASB), but by and large he is positioned as superior to and distant from women. In $\mathrm{TAB}$, he gives a problematic speech explaining feminism to the audience and Watson, whilst a hooded army of suffragettes stand by silently and apparently absorb his oration without protest. Yet, in more recent episodes, this position is changing: John, who has had several brief affairs with women, marries Mary Morstan, and after a subplot revealing Mary's former career as a spy, the domestic trope of pregnancy is introduced, apparently foreshadowing a more settled existence. In an odd change of tone, Sherlock seems to be happy for them, and appreciative and respectful of Mary (despite the fact that she had previously shot him in an attempt to conceal her identity from John). It is thus difficult to argue for a governing statement of position in canon, other than the position of reader-observer linked to the penetrating mind. This domestic repositioning has been criticized as excessive fan-service (Lawson 2014; Baker-Whitelaw 2014), i.e. catering to a fanfic-loving minority at the expense of whatever the 'real' text should be. Fanfic does frequently utilize a discourse of domesticity, transplanting characters from action or crime orientated texts into more soap-like settings; but, as we will see, this fandom is more likely to reposition John and Sherlock vis-à-vis each other than alter their relationship to women.

The relationship between Sherlock and John can be described as queerbaiting (Fathallah 2014). The characters look, touch and speak in ways coded as romantic and/or sexual, yet vehemently deny any homosexual possibility between them. Other characters perceive Sherlock and John as a couple, and this is played for humour at John's embarrassment. In ASB, John capably puts the drugged Holmes into bed, telling him, 'I'll be next door if you need me.' Sherlock asks: 'Why would I need you?', to which John replies 'No reason whatsoever' before closing the door. The visual statement solidifies the closure of queer possibilities that the dialogue has just opened. Fanfic, as we will see, pries open these possibilities again, reconstructing a British masculinity where homoeroticism is possible.

Finally, with regard to position, we must note that both Sherlock and John are constructed as firmly middle class. John's profession as a doctor and rank of Captain position him here, whilst Sherlock's class position is constructed through received pronunciation and a fondness for tailored suits. Were it not for his ordinary lodgings and the parents introduced in the third series, he could easily be read as upper class. John and Sherlock are positioned distinctly against Sherlock's 'homeless network', which he utilizes for information but 'disinfects' himself after touching (TGG). The de-humanizing noun 'network' removes humanity from homeless people. 
On entering a drug-den, Watson comments that he is 'used to a better class of criminal,' describing its inhabitants as the 'scum of the earth' (HLV). Having been apprehended by police holding the spray can of a graffiti artist they have just pumped for information, John snaps: 'They're giving me an ASBO!' (TBB). ASBO is an acronym for Anti-Social Behaviour Order, a minor British legal penalty associated with vandalism and disruption. The humour of this scene comes from the apparent incongruity between a man 'like John', and the sort of undesirable, lower class person who 'ought' to receive such an order.

There is a tension, however, between Sherlock's position as a lone hero outsider, the man who declares 'alone is what I have, alone protects me' (TRF); who stands alone on the rooftop of St. Bartholomew's hospital with the flare of his coat angled to recall Batman looking out over Gotham; who self-diagnoses as a 'high functioning sociopath' (ASP); and his implication in a number of social relations (Hills 2012b, p. 31). John is his best friend, and he is willing to undertake a complex and risky scheme to keep John, Mrs Hudson and Lestrade safe (TRF). He trusts Mycroft enough to mastermind his fake-death and disappearance (TRF; TEH) and may have some sort of affection for Molly. Implication in social networks is generally constructed in Western cultures as a feminine position, isolation and exceptionality as masculine. Fanfic takes up this tension and explores it more explicitly, as we will see below.

\section{Place}

English nationality has always been a governing statement of Sherlock's character, and the BBC iteration is intensely London-focused. Despite the complicating paratextual information that the show is filmed largely in Cardiff, episodes open with a drumroll and a sweeping musical score as the bird's-eye camera pans over famous London landmarks. Sepia-toned shots of Big Ben, the Thames and the London Eye are cut against time-lapse shots of traffic through the city centre (Porter 2012, p. 164), constructing a London that is timeless yet ultra-modern. But Sherlock's London is selective. As Busse and Stein observe, the camera shies from poorer or highly industrialized areas, preferring chrome and glass or well-preserved Victorian grandeur (2012, p. 225). This London is contemporary yet traditional, mappable, organized and clean. It is available for Sherlock's reading, and the frequent use of a bird's-eye camera position allows the spectator to partake in the position of knowing observer. 
This London is also the centre of the world. Mycroft, who is described by the other characters as 'The British Government', is constantly distracted by the crucial part he apparently plays in foreign affairs like the 'Korean elections' (TGG). Other places, notably Afghanistan and vague locations in Eastern Europe, are constructed as threats. John's flashbacks and nightmares construct Afghanistan as a land of dust, violence and chaos (ASP), whilst Sherlock, on ambiguous secret work in Serbia, is shown to be tortured by shadowed foreign criminals (TEH). At the conclusion of HLV, Mycroft means to send Sherlock on some vaguely threatening mission in 'Eastern Europe', a synecdoche that stands in discursively for threatening foreign lands, before recalling him at the last minute because 'England' needs him. 'Other places' are constructed briefly and often ambiguously, mere snapshots, as opposed to the centrality and clarity of London. The Christmas mini-episode 'Many Happy Returns' consolidates this construction with a series of clips of a disguised figure implied to be Sherlock solving difficult crimes around the world, from Hamburg to New Delhi to Tibet. The Orientalist can blend in anywhere, reading every place from his central subject position.

The preciousness of England is never questioned. When Charles Augustus Magnussen, the Danish character adapted from Conan Doyle's Milverton, is being established as a villain in 'His Last Vow', his violation of the Baker Street hearth and so symbolically of England is the discursive key:

Magnussen: Best thing about the English [...]

Magnussen:... you're so domesticated. All standing around, apologizing ... (He nods to Sherlock and then walks in between him and John towards the fireplace.)

Magnussen: ... keeping your little heads down.

(He stands in front of the fireplace, facing it. The sound of him unzipping his trousers can be heard.)

Magnussen: You can do what you like here. No-one's ever going to stop you.

(He looks down and the sound of him urinating into the fireplace can be heard. John blinks as if appalled and half-turns his head towards him. Sherlock keeps his head facing forward, his eyes fixed on the opposite wall.)

Magnussen (continuing to urinate): A nation of herbivores [...] I've interests all over the world but, er, everything starts in England.

(He looks down again as the last of his urine splashes on the grate in front of the fire.) 
Magnussen: If it works here ...

(He jiggles up and down as he 'shakes off' and then zips up his trousers.) Magnussen:... I'll try it in a real country [...] The United Kingdom, huh? (He starts to wipe his fingers.) Petri dish to the Western world (transcribed by Ariane DeVere 2014).

This sequence positions Magnussen as the defiler of home, hearth and England that John and Sherlock must defeat. They may have stood stoically by, the model of Englishness, at this outrageous display, but the logic of the genre and the fact that viewers know Sherlock will ultimately defeat his enemies guarantees Magnussen's destruction in advance here.

Related to the capacity of Sherlock's mind for reading, and his position as observer-reader, it should be noted that the world he lives in is constructed as entirely readable. As Kustritz and Kohnen explain, the original Sherlock stories helped reassure readers that the rapidly expanding, newly industrialized London of the 1800 s was still comprehensible. In the BBC manifestation, his 'intellectual brilliance and mastery of technology' demonstrate that the twenty-first century is still equally comprehensible, a construct 'which ultimately stems from long-standing cultural tropes that structure narratives about securing urban space, and separating criminologists from criminals' (2012, p. 85). Faces, features, marks have one true and logical meaning, available for the detective to read. The world is constructed as fundamentally logical, interpreted and explained by language. Thus, Sherlock can observe a body and visual a chain of events:

Sherlock: Her coat: it's slightly damp. She's been in heavy rain in the last few hours. No rain anywhere in London in that time. Under her coat collar is damp, too. She's turned it up against the wind. She's got an umbrella in her left-hand pocket but it's dry and unused: not just wind, strong wind - too strong to use her umbrella. We know from her suitcase that she was intending to stay overnight, so she must have come a decent distance but she can't have travelled more than two or three hours because her coat still hasn't dried. So, where has there been heavy rain and strong wind within the radius of that travel time? (He gets his phone from his pocket and shows to the other two the webpage he was looking at earlier, displaying today's weather for the southern part of Britain) Cardiff. (ASP, transcribed by Ariane DeVere 2012).

The readability of the logical world is apparently threatened in TAB, where it initially appears that Moriarty has come back from the dead, complete 
with mangled head wound. In the event, however, this is only a dream, and the narrative thread concludes with Sherlock's assertion that though Moriarty's influence remains, he absolutely cannot be alive, given the stark fact 'he blew his own brains out' (TAB 2016). In summary, then, we might say that the discourse of masculinity in Sherlock is constructed through the controlling, ordered, penetrating mind, complicated by the suggestion of vanity or pretension; the hard, defined, singular body whether pale and smooth or scarred; and the position of mastery complicated by imbrication in various social networks. It is placed firmly in London, England, and London is the centre of the world. We might draw the discourse construction thus:

Fig. 4: The discursive construction of masculinity in Sherlock.

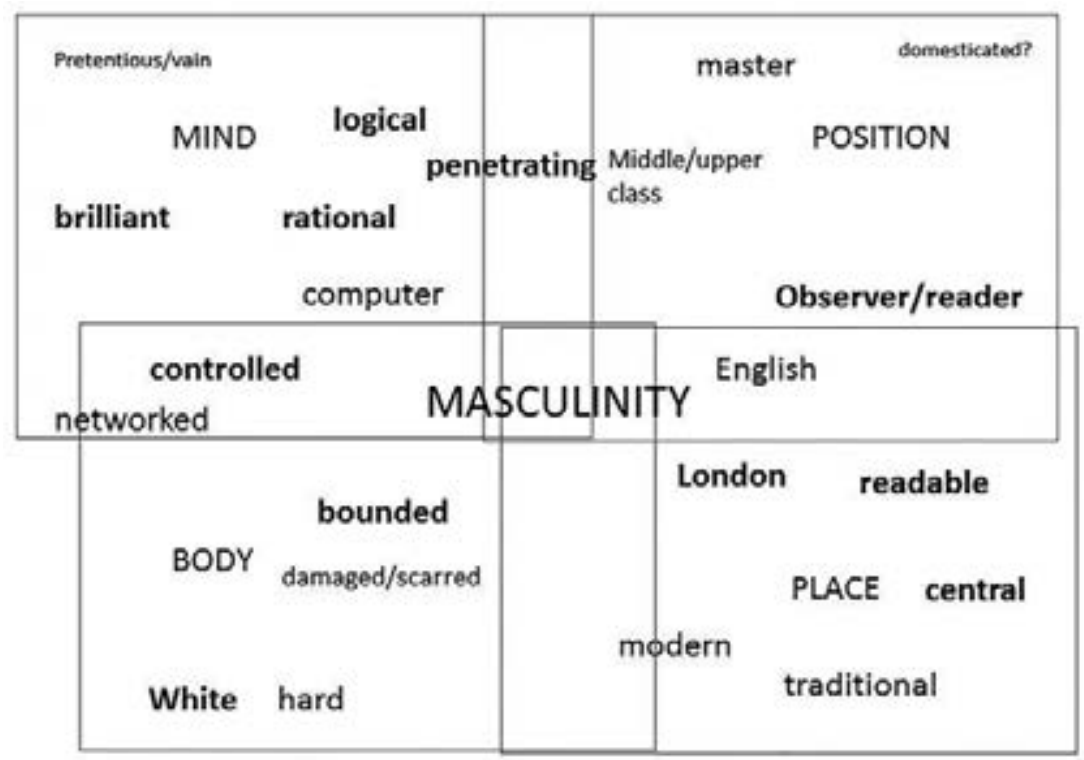

Governing statements are bolded, and a smaller font indicates a less prominent or more contestable statement. There is a little overlap between branches - the penetrating mind enables the position of reader-observer, and the mind and body are both subject to control—but not a great deal. As will be demonstrated, fanfic's reconstruction of the discourse will demonstrate far more explicit links between the branches of the construction, and in doing so, begin to de-naturalize the primacy of the White man's authority even as it depends upon it. 


\section{Fandom's Reconstruction of Masculinity in Sherlock}

By searching at the communities of high fic centralization (Fanfiction.net, LiveJournal, A03), I catalogued the Sherlock fic most important to the (re)construction of masculinity (see methodology, pp. 38-42). At Fanfiction.net, which does not feature tags, I searched for the key terms 'masculinity, male, man and men'. These led me to search the more fan-specific terms 'genderswap' and 'femlock'. In fic utilizing these popular tropes, male characters either are or turn into women. I kept and coded the fics demonstrating an actual change in sex or gender, as these would help illuminate the fan construction of masculinity via difference. Theoretically, so would the fics wherein Sherlock and John have been women all along, or indeed any fic featuring men, but it was necessary to draw the boundaries of the formation studied at some point, and I judged that fics featuring a male-to-female change would demonstrate the construction most clearly. Sherlock fandom on LiveJournal is vast, sprawling and disorganized. Thankfully, there is a centralized community dedicated to searching and finding fic via requests, recommendation and tagging ( $h t t p: / /$ sherlock-search.livejournal.com). I navigated this via the fan-created tags most obviously related to masculinity construction, which were: character study, theme: soldier john (or bamf![bad-ass motherfucker]john); genderswap, theme: have kids; theme: kidfic, mpreg. The trope of turning characters into parents is popular across fandoms, and I was keen to explore the obvious social repositioning this would entail. The relevance of the mpreg tag (a fandom trope wherein a male character gets pregnant via magic, technology or by virtue of the rules of an alternative universe) was obviously crucial to the reconstruction of the male body. Ao3 proved easiest to search: indeed, searchability and organization of fic is part of its mission statement. The relevant tags here were very similar to LJ, if phrased slightly differently: e.g., parentlock (portmanteau of parent + Sherlock), military John, genderswap, mpreg. Notice that the tropes of fandom are already changing the discourse of masculinity, by virtue of their implication in the domestic sphere. Mpreg, genderswap and kid fic predate Sherlock the show by decades. Upon entering the fannish space, Sherlock's character is transformed by these conventions.

Two important tags featuring prominently on $\mathrm{Ao3}$ are 'trans-' (a parent tag covering transgenderism, trans character, etc.), and 'alpha/beta/omega'. The first is self-explanatory, and obviously turned up a list of fic important to the construction of the gendered body, whilst the latter is a specific fan trope that imbues human characters with the properties of wolves or animals, often involving domination and mating. The 'omegaverse', as it is called, is both extremely popular and highly contentious across fandoms, 
some condemning it as revolting and sick, some admiring its deconstruction of bodies and gender roles. As Tumblr user lierdumoa summarizes,

omegaverse is really a fascinating fandom invention. $50 \%$ of it is totally problematic and reinforcing a lot of fucked up patriarchal, rape culture values. The other $5^{0} \%$ is some of the most insightful, subversive social commentary I've ever read on gender identity/gender roles/queer oppression (Fanlore 2014).

Interestingly, there is an absolute abundance of mpreg, omegaverse and parentfic on Ao3: too much, unfortunately, for every example to be coded. For instance, the tags 'Sherlock (TV)' + 'alpha/beta/omega dynamics' turns up 1075 fics as of 04/02/15, many of which are hundreds of thousands of words in length. That genres focusing on the animalistic, the domestic and the bodily are so popular in the fandom demonstrates a strong transformative effect. In order to code a sample of relevant fics from these massive categories without falsifying the data on comments and averages, I coded the most popular ten, the least popular ten, and ten from the precise middle when listed by number of comments. The numeric results were as shown:

Table 1: Table of fic distribution for Sherlock.

\begin{tabular}{|c|c|c|c|c|c|}
\hline Site & Ff.net & LJ & A03 & Other & Total \\
\hline Number of fics & 174 & 49 & 293 & 17 & 402 \\
\hline Highest number of comments on a fic & 558 & 1579 & 8114 & 205 & 9693 \\
\hline Lowest number of comments on a fic & 0 & 0 & 0 & 0 & 0 \\
\hline $\begin{array}{l}\text { Average number of comments on a fic } \\
\text { (mean) }\end{array}$ & 46.7 & 82.6 & 154 & 33.1 & 143.7 \\
\hline $\begin{array}{l}\text { Average number of comments on a fic } \\
\text { (median) }\end{array}$ & 15 & 15 & 12 & 7 & 15 \\
\hline
\end{tabular}

The total number of fics was 402, ranging in length from $<100$ words to hundreds of thousands. The mean number of comments on a single fic, dispersed across the sphere, was 143.7 , whereas the median was 15 . It is important to consider medians as well as means when judging the impact of a fic, as the mean is inflated by the rare highest values in the thousands. Considering only means, a fic receiving 80 comments on A03 may appear to have less impact on the discursive construction than it does in reality, given that it still received more attention than the majority of fanfic. Many fics appeared on multiple sites, hence the total number of fics is smaller than 
the sum of the fics on each site. The total number of comments coded was 57,767 , of which a marginal 66 were unambiguously and entirely negative. LJ user thedeadparrot reflects on the fannish convention for praise over criticism with the metaphor that 'fandom is a giant karaoke bar' (2007): online fanfic is acknowledged as an amateur practice from which we all derive free entertainment, so whilst we might cheer and acknowledge when an amateur is extremely good, we generally do not complain too much when they are bad. This important structuring convention, an internal regulation in Foucault's terms (1981, p. 56) might mean that more experimentation and risk taking is possible here than in professional settings, but it might also mean that problematic consolidations are more likely to go unchallenged. Out of the 66 negative comments total, 12 responded to the same fic, indicating an extraordinary degree of resistance to its statements. This instance will be discussed below.

The remainder of this chapter demonstrates how fanfic reconstructs the discourse of masculinity in Sherlock. Once again, the analysis was conducted by moving outwards from specific statements to general patterns and finally establishing the conditions of their possibility (Foucault 1981, 67 ). I will argue the fandom's reconstruction of the discourse of masculinity can be illustrated like this:

Fig. 5: Fandom's reconstruction of masculinity in Sherlock.

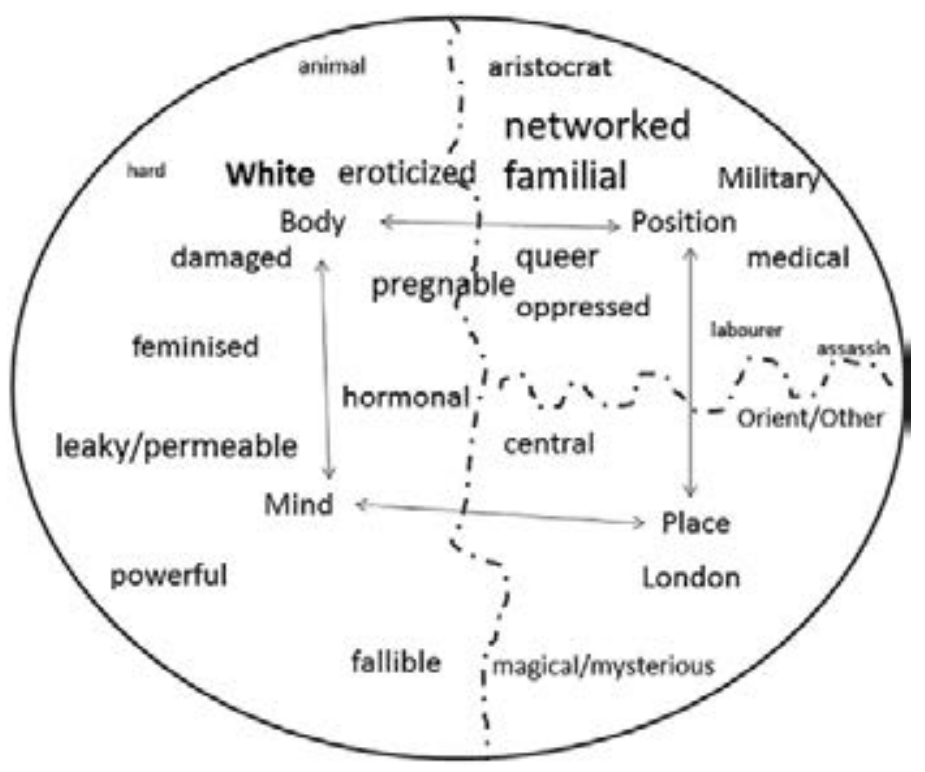


The first point to note here is how much more varied the construction is than canon, which is only to be expected giving the spread, variety, authorship and creative contexts of fanfic. Secondly, we should note that while the construction of mind and body overlap slightly in canon, fandom collapses the distinction. Thus, the reconstruction of body and mind will be addressed first, leading into the construction of sex and sexuality (which is generally absent in canon). Further, observe how the boundaries between all the branches are porous, and each affects all others. I argue that this transformation is important and progressive, demonstrating that the central position and mastery of the White, bounded, male, middle-class, rational genius from London is not natural, but the result of a set of contingent social and political circumstances. As will be discussed, the only governing statement that remains is that of Whiteness (bolded).

With regards to the authorial positioning of the fic, it should be noted that disclaimers of ownership over the characters were not as common here as in the other fandoms. They do appear, typically in a form such as, 'original characters are owned by Arthur Conan Doyle, these versions are owned by Steven Moffat and Mark Gatiss. I just get to play' (Ibegtodreamanddiffer 2012), but did not feature very frequently or prominently. Moreover, consider the statements here. Though 'play' is modified by the minimizing adverb 'just', the use of monosyllabic words to form a short declarative sentence asserts the fan-author's right to transform the characters: thus, whilst fanfic is dependent on reference back to originating author(s), it also claims its own legitimation. Flegel and Roth suggest that "the idea that too much "play" in one's writing makes it less true, and therefore, possibly nonremunerative labor, seems to inform even fan constructions of fan writing,' with 'fun' being set apart from 'legitimacy' (2014, pp. 1098-1099). I would argue the context of an extended creative work, contributing to a transformative archive, renders this 'play' a rather serious business in a cultural if not financial sense of legitimation. The legitimation paradox operates here: reformation of masculinity derives authority from the figure of the White man, and the industrial authorship behind him, yet simultaneously asserts its right to that reformation.

\section{Body-mind}

Fanfiction is notoriously concerned with bodies (Coppa 2006). Sherlock fanfic is no exception, and focus on Sherlock's body is prioritized over mind and deductive processes. Indeed, very little attention is paid to the processes of reasoning and solving crimes that takes up so much 
time in the canon series; imported into the space of fandom, Sherlock is removed from the context of a detective series. In accordance with Fairclough's observation of intertextuality, this has multiple consequences. Statements from fic (re)construct Sherlock's defined White body in literary terms, as 'a pale marble statue. A Michelangelo' (DoctorBilly 2014), as having 'flawless pale skin', (1electricpirate 2012), an 'alabaster torso' (hamishholmess 2014a), as 'the epitome of a self-contained man, a foreign and dangerous planet locked within a six-foot-something frame of whipcord lean muscles and viciously focused intent' (Ergott 2011). Yet, it also stresses androgyny, lingering on 'high cheekbones' or 'full, pink lips' (Ibegtodreamanddiffer 2012). Everything-in-focus-94 makes the point explicitly:

Sherlock is the chiselled creature that is the epitome of what a woman should be, all high cheekbones, that perfectly coifed and styled hair, the clothes that cut the perfect silhouette and eyes that would look out of place on a model on the cover of Vogue. And yet, he's not (2012).

Likewise ZabellaCookie has John observe that 'any model would kill to have his bone structure, male or female' (2010). Moreover, the comparison to a statue is almost always a set-up, a forerunner to descriptions of weaknesses, chinks in armour or 'walls' proved 'paper thin'. The catalyst is typically emotion for John. Moelock's The Man Who Can't Be Moved literalises the trope, for in this story

The statue called Sherlock Holmes was magnificent. He rose six feet tall and was carved from the finest marble in the entire world. Rich curls on his head were chiselled with such care and precision, it looked as if it would flow along with the summer breeze. His expression was pompous, as if he knew of his unparalleled beauty, and his head was tilted upwards, watching the sky with curious, sharp eyes. His body was lean and smooth, a perfect rendition of what Adonis' might have been (2012).

As one might guess, affection for John causes him to come to life via a literal softening of the body. The story does not make a huge impact, gathering 14 reviews on Ff.net, but it neatly illustrates a common trope of Sherlock becoming humanized via softening.

John's body, on the other hand, is typically constructed as scarred and damaged. Where canon shies from the explicit depiction of this (we do not even see John's scar), fandom makes much of it. Hammishholmes's 
Afghanistan or Iraq explores the damaging effects of war on mind and body:

"Please, god, let me live." John was sobbing. A long slice, half the length of his forearm, began to blossom blood from his ribs [...] The tears felt hot and ran through a coat of dirt and filth on his face. He wished he could drown (2014).

Through tears and blood the body loses its definition: the bounded body leaks. Sherlock is typically intrigued, indeed excited, by John's damaged body:

"Lovely," Sherlock finishes, and drops his cards face-up on the table, stretching out a hand toward the web of raised red scar tissue that covers most of John's left shoulder. "Can I touch it?" [...] "I prefer damaged things," Sherlock says, and traces his tongue-tip up the winding scar at John's hip. "Much, much more interesting" (Ibid.).

Damage rather than smoothness is eroticized (cf. the sheet scene) and with it comes a repositioning of the men into a homoerotic relationship. Fandom also explores the consequences of war upon the body in action, something only inferred through flashbacks in canon: Afghanistan or Iraq is a popular fic, receiving 259 positive reviews on Ao3; but fics that transform Sherlock and John's bodies in more direct ways tend to be even more popular.

Consider the well-received Copy That, which gathered 72 comments on Ao3, a total of 87 across the websphere, a recommendation from LiveJournal, and circulating recommendations on Tumblr. The author's summary sums up this story neatly: 'Afghanistan changes a man, some more than others. In which John develops the ability to transform into any animate being he sees' (maybemalapert 2012). In this fic, the bounded masculine body is absolutely unbound: by speaking the magic words, 'copy that', John transforms variously into a fly, a mouse, a caracal, Sherlock, his own reflection, and poignantly, an enemy soldier:

"Copy that," John gasps out. A bullet ricochets off the rock, and John's body spasms [...] He changes, hair darker, eyes and skin, too. Gone is his uniform, and everything else that marks him as a doctor, a soldier, a British citizen.

Someone on his own side of this war. 
Instead he's looking down at the body of an Afghan man (around fifty years of age if he's any judge), who's bleeding horrifically from an arterial wound in his thigh (the pain of it is not immediate; it waits for the dawning horror to settle first; when it comes, though, it hurts as much as such a wound should). There's a groan; someone's saying, "fuck," and John thinks it must be him, but then there's the sound of movement and at the edge of his vision he can see a gun aimed at him, held by Davis's hand (maybemalapert 2012).

The transformation is constructed as a painful process, and by the transportation of his mind out of his body, John is literally forced to experience the perspective of the Afghan, inverting the Orientalist perspective of the source text. So this fic also works to reconstruct masculinity via place and position, explicitly connecting them to the White body. Interestingly, though, the magic term that recalls John to his own body is his name: 'John Watson'. This strong statement indicates an essential, bound self, a correct fusion of body and mind. 'John Watson' can experience the perspective/body of the other but does not dissolve into it: borders can always be redrawn.

Yet more dramatic transformation, and more dramatic integration of body and mind, is evident in mpreg and alpha/beta/omega fic. These tropes borrow intertextually from broader fandom history, and as noted above, prove very popular in Sherlock fic, though not unproblematically. 'Pregnant Sherlock is like a trainwreck you can't look away from,' observes an anonymous commentator (anon. 1), and comments comprising some variation of 'I don't normally read mpreg, but...' were quite common. This pattern suggests a radically transformative urge towards the body-mind synthesis of the male protagonists, yet one tempered by unease and reservation. Indeed, this unease and reservation is often played out in the stories themselves. Vulgar Shudder's Omega Refuge spans both categories, receiving 178 positive comments on $\mathrm{Ao} 3$ and 62 on Ff.net. In this story, John is an omega human and thus capable of pregnancy. Sherlock, meanwhile, is an alpha driven by impulses coded masculine. In this story, as with most of its genre, Sherlock's struggle is to integrate his mind with heightened bodily experience.

"You've really got to keep your hormones under control" [John reprimanded him]. "First you come barging in here like you care, now you're getting all dewy eyed at the thought of me and a baby. You may be on suppressants but your alpha hormones are running rife." 
Sherlock's shoulders tensed. "That's ridiculous. I am not affected by my hormones. I am a logical man who deduces from the evidence presented to him." (Vulgar Shudder 2013).

Of course, Sherlock is lying: he is increasingly affected by a biological urge to protect John and his unborn child. As will be explored in the 'position' section, this altered biology has obvious social consequences. In this story, an unplanned pregnancy has effectively ended John's military career. The explicit linking of bodies and social position is something that fandom's reconstruction of the discourse accomplishes, but canon elides.

The ability to bear children compromises the construction of the bounded body, accompanied as it is by blood, fluid, and intermittent vomiting. Statements that are jarring out of context due to the conjunction of male pronouns with body parts associated with women are absolutely commonplace in these fics, such 'John's water broke on their way down the stairs, staining his pants as well as both his and Greg's shoes' (Sandyleeoo7 2012). The pregnant male body leaks all over the place. A pregnant Sherlock struggles especially with the mental effects to which his body subjects him, exclaiming, 'My body is betraying me, John. You know what I'm like. It's just bloody transport and I've had it so tightly under control and it is mocking me. My body is doing this just—just to spite me!' (emptycel 2014). Sherlock's canonical statement that his body is 'transport' is cited and reconfigured: a popular trope in mpreg fic. The body controls the mind as much as the mind controls the body. To ignore the body has repercussions. Sherlock states in canon that he 'deletes' unwanted information (TGG), and is horrified to realize in He Deserves It by always-black-and-white that 'he had deleted one of the most important things about his 'transport': the ability to carry children' (2014). Similarly, in another fic, he admits in first person that 'Sherlock Holmes gets scared. A lot. Just hides it well. Not now. With all these fresh hormones rampant through my post-birthing body, no, I can't control it' (DannyPhantonOfTheAvatar 2014). Increased ingestion is another trope. Sherlock asserts in canon, 'I don't eat when I'm working. Digestion slows me down' (ASP). The ability to refuse food is a clear demonstration of the mind's control over the body, and an establishment of borders. Mpreg writers tend to invert this for purposes of humour:

"We just need a little extra money for the babies—where did you get chicken?"

Sherlock had popped out of the kitchen while John was talking, a chicken leg hanging from his mouth. 
"I stashed it," Sherlock said, looking mildly ashamed of himself. "It's cravings, John. You wouldn't understand. If you had eaten it, I would have cried. Tears and everything. God, this is horrible" (emptycel 2014).

The male body is constructed as leaky, penetrable, reproductive and with far more malleable borders than canon would allow. And yet the approval and legitimation of this reconstruction depends on the already-established category of maleness. 'I love these AU's where women seem to die off or don't exist and men can have babies,' comments Yaoi-Hellian (2013). Ao3 user perp posted a short fic wherein a female omega John (Joan) gives birth on a case, specifically 'to add more females into the omega!verse world because [she] feel[s] like there aren't enough' (2014) and received no comments. Maher makes a corresponding argument concerning the male-pregnancy movie Junior, starring Arnold Schwarzenegger: that whilst pregnancy is celebrated as transformative, its positive depiction is limited to the male body, 'marginalizing women's reproductive capacity and activity' (2008, p. 279). The legitimation paradox is at work here: the leaky, pregnant, reproductive body is made acceptable almost solely via maleness.

Some fic involving animal transformation plays with the boundaries of genre, and borrows intertextually from literary traditions. For instance, $A$ Rose by Any Other Name recasts John and Sherlock as Beauty and the Beast respectively. Irene Adler is cast as a sorceress who put a spell on Sherlock for his cruelty, but as 'she began to curse him, planning on turning him into a monstrous dragon [...] he pulled out of her grip, leaving him with a few dragon-like characteristics. Although the transformation wasn't complete, he looked monstrous and hideous, like a mutation' (Consulting Writer M 2013). Again, the body is un-bounded, with Sherlock caught in an in-between state. In keeping with the fairytale, he is re-humanized via his relationship with John, who is unafraid of his hideous form and aggressive posturing. 'Act like a gentleman,' Sherlock reminds himself, the statement citing the Disney version of the fairytale: 'Act like a gentleman. Act like a gentle...man.' The dragon-hybrid may be able to act the part, however, but Sherlock can only be man when returned to his canonical form.

Nicodiver's The Bloodline combines mpreg and animal-transformation to cast Sherlock and eventually John as alpha/beta/omega werewolves in a fic intensely concerned with the leakiness and porousness of bodies. Though Sherlock's ability to transform is celebrated, and the fic is full of imagery of blood, tears, ripping, and transformation, the scents of 'blood, werewolf, steel, infection, sweat' (Nicodiver 2012), this fic also constructs the leaky body as potentially dangerous and excessive. Before John is aware Sherlock 
can transform, he believes that a monstrous wolf is on the loose and on capturing it explains to Lestrade:

"I've got the murderous animal."

"What?"

"It has eaten up Sherlock."

The main threat in this fic is of a wolfish savagery consuming the human men, characterized by the evil wolf Moriarty. Moriarty is animal, dangerous and seductive. He appears as a 'gigantic black wolf [...] eyes brimming with darkness and blood-lust [and it] had long and sharp fangs sticking out of its long snout and big muscles.' When John evades his gaze, Moriarty penetrates his mind:

\footnotetext{
“No John. Don't look away." John could hear a deep voice echoing inside his mind. John pretended not to take notice of it. He could hear the wolf's paws moving closer to him and suddenly he could feel warm air fanning his hair.

"Your smell is sooo delicious...! I understand why that Sherlock boy likes you so much..." the wolf said with an over excited voice and put his head on John's lap, staring up at him with amber glowing eyes [...] "Now pet me" (Nicodiver 2012).
}

John, being captured at the time, has little choice but to obey, causing the wolf to 'hum pleasingly'. In canon, Moriarty is a challenge to social order; in this fic, he is the seductive threat to the unity of the body and the family. During the critical fight scene he let[s] his face be torn to threads, in fact - he seemed to like it since his face wore a big, Cheshire cat like grin'. Moriarty is the king of opened bodies, and what is more, in this story, he actually kills Sherlock by ripping the infants from his womb in what must be the ultimate deconstruction of the bounded body, 'gripping the sack with the baby inside with his paws and ripping it out of Sherlock's body. Blood poured out of Sherlock's guts, his body desperately trying to heal everything up.' Granted, Mycroft kills Moriarty immediately afterwards and the family is restored with an epilogue of John telling the tale of their valiant father to their surviving children, but the force of these deconstructive statements remains.

The Bloodline demonstrates an extreme transformation of some governing statements in canon discourse. Compare the hard boundedness of the White male body that governed the canonical construction. This fic's impact 
is significant, with 256 comments across the websphere, but many of the reviews are ambiguous in their appreciation:

Characters are way out, sherlock doesnt like mycroft, he would never help out like that, or cry, or be that timid... but its still a lovely story [sic] (MyCumblrbatch 2013).

sherlock sounds like he is about eight or something (SenpaiNoSasuke 2012).

John's not an animal person :o (3, 2012).

'Animal person' takes on a double meaning here, suggesting both a person who likes animals, and a person who is an animal, or animalistic. Commenters are concerned with the integrity of the canon characters, though they tend to mitigate their criticism with appreciation of the narrative. To transform the governing statements concerning the integrity of the male body is not a simple process, and generates friction. Internal mechanisms of regulation are at work here (Foucault 1981, p. 56) in the resistance to dramatic alteration of canon characters.

Moreover, there are limits to the degree of both leakiness, irrationalism and animalism that can be attributed to the male body without backlash. An anonymous reviewer rejects an mpreg story that is judged to have crossed a line:

I know the mpreg makes a difference, but even so, everyone is really really out of character. It's kind of hard to read. I rather think Sherlock, upon finding himself with child, would blink in surprise, then experiment on himself to find out why [...] All this wailing and whimpering is not at all in character, even with extreme sickness (anon. 2 2013).

Similarly, a reviewer calling themselves 'CriticalAnalysis' comments 'I find that your Sherlock and Mycroft are very out of character' (2013), a statement strengthened by the username that lays claim to a rational and objective perspective. Internal mechanisms in this discourse, then, discipline the attribution of excess to pregnant males (cf. Foucault 1981, p. 56). Maher notes a similar point: that whilst a man may get pregnant in Junior, 'the unruly pregnant body is not allowed to engulf him' (p. 283). Unlike a woman, he does not 'disappear into gestation' (p. 284), and a construction of Sherlock that subordinates his 'character' to the pregnant body is rejected. Moreover, the story that received an exceptional 12 explicitly negative reviews, as well 
as many more ambiguous ones, was criticized on the grounds of rendering the alpha Sherlock and omega John too animalistic and excessive, and placing too much responsibility for what is judged an act of rape on hormones. Responses include:

Ok, i know this is a fantasy and you have every right to write whatever you wish, but you have really lost me with this chapter [sic] (anon. 32014$)$.

To be honest this story was my 'guilty pleasure' before this. Now I'm just... I'm disturbed, disappointed, and slightly disgusted. Really, really disturbed (Belle 2014).

I am so disgusted by how this chapter ended! No I am enraged, pissed off! [...] What happened ruined this fanfic for me! (Kataryna_Krimson 2015).

There are plenty of approving reviews too, but for a single fic to receive this degree of censure and rebuke, indeed expressions of disgust, is unusual and demonstrates that although fandom reconfigures the discourse of mind and body into a more integrated whole, the civilized mind is ultimately called on to prevail. Here is a strong demonstration of the internal regulation of discourse, though influenced by external norms.

Finally, we must address the category of trans* or gender-variant fic. Some fic separates maleness from Sherlock's body, constructing him as having been born in a female body. Here again, the construction of the body as transport and separable from the mind is contested:

Across his right leg, Sherlock carved Girl.

On his left, hand slightly more steady, he wrote Boy. The edge of the Y dripped, trailing into the crook of his thigh muscle.

Neither word fit when he looked in the mirror, and so he slashed the words to ribbons, uncaring of the sting or the pull of the blade. Uncaring really of everything, as he lay on Sebastian's dirty bathroom floor, the fluorescent light keeping him awake and nightmares at bay even as his thoughts tore him apart. His Mind-Palace was far more frayed than his skin could ever be (twistedthicket1 2014).

It is much more typical for Sherlock to be constructed as trans* than John, and this may well be related to the feminine-coded bodily details noted earlier. Consider the author's note to the pointedly-titled, 'Sherlock Holmes is a great man': 
AN: Okay. This is one of my much, MUCH more out there stories. I recently read a story centered around Reid/Morgan from Criminal Minds featuring Reid as a FtM that was incredibly well done, and it got me thinking. Both MGG and B. Cumberbatch are slender, frail, rather ethereal looking, and if Reid could be an FtM then why couldn't Sherlock? (Samuel MacIntyre 2011).

The authority seized to make the transformation is sourced both in visual details of the canonical show, and an 'incredibly well done' work of fanfic. This is another instance of how when a text enters the discursive spaces of fandom, it is impacted by previously existing conventions and tropes. A key line in HLV provided more material for fans to source. As they part, Sherlock confides in John, 'Sherlock is actually a girl's name.' John laughs, and the moment is played off as a joke. Sharadas' Impossibilities, a title that may refer poignantly to the prospect of mainstream media representation of trans* people, reconfigures this:

Sherlock is actually a girl's name, however?

John's reaction to that, more than the plane itself, more than the accepted, painful choice of shooting Magnusson-John's reaction, laughter and disbelief, was his death sentence, and he closed his eyes, forcing himself to become once more that tower of emotionless masculinity, that deductive force that showed emotions only as a play, that man who John knew and seemed, sometimes, to love.

Sherlock had told him, a parting gift, the secret of his birth that by now only his blood family knew.

And John, wonderful John, had, unknowingly, thrown the gift away (Shadaras 2014a).

Commenters express a wistful hope for this to be the canonical explanation, yet at the same time Shadaras acknowledges that it 'didn't happen,' thus the fan 'can only dream and write' (2014b). Similarly, morelindo's There is a Crack in Everything neatly reconfigures canon details including Sherlock's 'bone structure' and drug use (here testosterone rather than nicotine), and the author comments that 'the main reason why this idea wouldn't let me go is just how well it fits with the canon of the show, to the point where trans!Sherlock is nearly headcanon for me.' This fic contributes impactful statements to the discourse, gathering a total of 79 positive comments across the websphere. It has also been recorded as a podfic. Morelindo notes that s/he would 'highly doubt that it'll go that way in canon (as I see the line itself as a bit of a throwaway joke on the writer's part), but I felt it 
was a valid interpretation of the line' (morelindo 2011). Authority is again claimed by the fan and yet legitimated by the source text.

In sum, then, fanfic reconfigures the primacy of mind over body into a more integrated whole. Emotion and mental trauma is felt physically whilst neurochemical changes manifest in the physical form. Fanfic opens the male body, rendering it more receptive, penetrable, productive and porous, but there are limits: statements judged excessive or over the top meet with censure via internal mechanisms of regulation (Foucault 1981, p. 56). The male body in fanfic is more gender-variant; yet, here especially, as with all the reconstructions, we can see the paradox of legitimation at work as fandom legitimates its work with reference to the author-ized source text. As I have observed, bodily reconfiguration has serious consequences in fandom for social position. This will now be explored.

\section{Position}

Fanfic frequently constructs a character's backstory. A large portion of Sherlock fic addresses John's time in the military and its repercussions: as noted, 'BAMF!John' is a popular tag. In dhampir72's Disappear, John takes on a secret revenge mission after Sherlock's death in TRF, reconstructed as a secretive, deadly assassin aided by his connections with the powerful Holmes family:

John took his gun and his wallet, placed them down onto the mahogany desk that separated him from Mycroft Holmes, and said: "Make me disappear." And Mycroft Holmes did (dhampir72 2012).

His healer/doctor side is erased, and he is reconstructed purely as killer, equipped with a range of phallic weaponry and isolated from his former community. He pursues and decimates Moriarty's network, yet in the intertextual echo of the revenge tragedy, this position is an untenable one: John 'felt nothing but emptiness by day and full of broken glass at night,' forgets the colour of Sherlock's eyes, and with his mission complete has nothing left to do except commit suicide. The violent, phallic, deadly and isolated position of the ex-military assassin is quite literally deconstructed. This fic has an above-average impact with a total of 41 comments across the websphere: four of these, however, are negative, and one was the doubleedged statement, 'Not going to forgive you for this one. Wow' (Rhyolight 2015). I initially read this as negative, but as dhampir72 reminded me in personal correspondence, expressions like this in a fandom context can also be read as 
praise for the author's skill in manipulating the reader's emotions. As noted in the introduction, the legitimation paradox is working inversely at this point, for the deconstruction of the lone-assassin position has some backlash when it entails the destruction of John's character. Ascription of qualities that de-legitimate his character meet resistance within the discourse.

Yet, fandom is often a little more reflexive and playful concerning the military or action-man construction than canon. The acronym BAMF, common internet parlance, introduces a playful note due to its invocation of slang and expletives. DancingGrimm's The Acronym plays explicitly with these meanings: in this fic, John is confused about the meaning of 'bamf':

"'Bee Ay Em Eff'. Hm, that's a new one on me. Do you know what it means, Sherlock?" John might not know what it means, but there are many little ways in which he proves the acronym suits him (DancingGrimm 2012).

Some of these are comic ('Big Assed Manipulative Fiend' depicts him tactically manipulating Mycroft via text message) but the final two resolve the fic-and the construction of John — in a medical/military position affirming both fandom and John's hegemonic position regarding masculinity. These are headed 'Ballistic Accuracy Means Fun' and 'Being a Medical Fighter'. Being a Medical Fighter, indeed, is a prominent aspect of fandom's (re)construction of John, retaining both the active body and the middleclass respectability of that position.

Sherlock, meanwhile, is typically constructed as more aristocratic than he is in canon, positioned in grand houses and as the son of landed gentry. In relectricpirate's Multiply, John observes that

Sherlock had been resplendent [in his family home], among all this subdued and understated grandeur. The Holmes family had surrounded themselves with the kind of splendour that spoke to being properly, anciently, filthily rich. They were not flashy, by and large, preferring to use their wealth to buy things of taste rather than opulence. Sherlock, who always seemed too cramped and folded up into awkward shapes in their small, cluttered flat in London, had stretched himself out and strode through these ridiculously beautiful halls with a magnificence that John had not been able to define or quantify (2012).

Sherlock's natural position seems to be that of an aristocrat, whereas John is frequently ill-at ease in such surroundings, fearing the expensive crockery will 'break under his clumsy, Watsonian hands.' Yet again, fandom is more reflexive 
about class construction than canon is: in hamishholmess' Self-Conclusion, these class positions collide. Sherlock is here an upper-class, gentleman-spy posted to the Middle East, and finds himself under John's unwanted care after a 'bout with drugs goes sour.' Distancing himself from John, Sherlock observes the 'sure sign[s] of manual labor and legwork' in John's hands, which 'spoke to Watson doing what he must to earn his keep.' Disgusted with Sherlock's snobbery and ungratefulness, John reprimands him:

"I'm not sure what happened there, Mr. Holmes, or what your life in London is like. But I can assure you, no one here will be impressed with what you call a battle scar. Choose your words carefully, especially among those that risk their lives every day for the things you so obviously take for granted" (hamishholmess 2014b).

Sherlock is taken aback, given that 'normally when he went prima donna, the victims fell silent, or apologized, or retracted their previous statements.' Confronted with the reality of his own privileged position, Sherlock apologises, and John responds, 'Don't apologize for who you are. Just remember not everyone can be like you, and we don't deserve to be punished for that.' The interconnection of class and the body are thus highlighted and deconstructed in ways elided in canon, clearly opening a new interpretative category of the kind Artieri suggests (2012, p. 463). Sherlock's skin is flawless_-bar his self-inflicted wounds-because he has never had to do the 'manual labor and legwork' John has.

Self-conclusion is quite well-received with 58 comments on Ao3, but the most popular fics are those which change Sherlock and John's social position entirely, via fandom tropes of pregnancy, parenthood and/or their relationship with each other. The vast majority of fic coded was Sherlock/ John slash. This could be explicit, involving sex scenes and the development of a relationship, or implicit, where interactions are similar to canon but queerbaiting is removed via tags or notes affirming a homosexual relationship between the characters. Homosociality slides much more easily into homosexuality than it does in canon. As I have argued elsewhere (Fathallah 2014), canon abides by the strictures of Western masculinity explored by Kosofsky Sedgewick (1985). Here, men are compelled and circumscribed by the necessity of the strong male-male bonds upon which patriarchy depends, and so must navigate and exorcize the spectres of homoeroticism. In fanfic, meanwhile, homoeroticism is constructed as the natural extension of homosociality, and frequently repositions the characters in a domestic sphere traditionally coded feminine. 
For instance, the single most impactful fic coded was earlgreytea68's Nature and Nurture, which gathered an astonishing 9693 comments across the discursive sphere, along with an assortment of fanart, translations into Spanish (x2), Italian and German. It is rated and reviewed on Goodreads, a site associated with published books, thus imbuing it with cultural capital and a suggestion of an author-function (cf. Foucault 1991, p. 113). Moreover, the movement of well-received fic to such popular review sites indicate that fandom's discursive transformations are beginning to expand beyond fan sites. In this story, Sherlock and John must raise Sherlock's child-clone after rescuing him from a government laboratory. As the author's note explains,

What happened was that hobbitts on Tumblr wrote the little comic that you can see here (http://earlgreytea68.tumblr.com/post/45650331985/ ohmybenedict-all-misty-eyed-hobbitts-i), and my heart broke into seven million pieces. But I've already written a young Sherlock fic, so I felt I'd gone over that ground. “Too bad," I thought, "that I can't make it Sherlock's son, but I really can't see Sherlock having a kid" (earlgreytea68 2014).

Repositioning Sherlock as a parent, then, produced internal resistance, as inappropriate or un-authorized by canon. The clone was earlgreytea's solution. Sherlock's repositioning is not easy for him, assuming at first it will be easy to raise the child as 'he is me,' but soon running into trouble when the infant proves unready to immediately join him in science experiments. He learns, though, both to love the child as its own person and eventually to love John as a partner. Their repositioning as a couple begins as a matter of practicality:

"Put John's name on the birth certificate," said Sherlock, whirling from the window. "In the space for 'mother'."

"But John is not Oliver's mother."

"Excellently deduced, Mycroft. But I want him on the birth certificate, and there's nowhere else to put him. If something happens to me, I don't want there to be any question as to who should be taking care of Oliver (Ibid.).

The situation develops into the mutual realization that they are, already, in love, and a couple in all but name. They get married with the vows: "I give you this ring as a sign that you are my favorite person on the planet," [said Sherlock] and "I give you this ring as a sign that you, too, at all times and in all ways, are my favorite person on the planet [said John] [...] "And not at all anything like a high-functioning sociopath." (Ibid.). The denial of 
Sherlock as sociopath is a fandom trope, and in this story is explained as a convenient diagnosis sought by his uncaring parents. Sherlock learns to love his clone-son as he was never loved, protecting him from the scientists who wish to reclaim him for their experiment. Feminine-coded emotion and the family network replaces the scientific-rational positioning of the detective.

This is the gist of most parentfics, though it is accomplished with difficulty: fics that demonstrate a learning curve and process to the repositioning of Sherlock and John are much better received than those that simply place him in the domestic sphere. KeelieThompsonı's very popular series of novel-length fics concerning John's niece, Ava Watson, is the most prominent example. In these stories, John is raising five-to-six-year-old Ava due to his sister's alcoholism, and after returning from his apparent death, Sherlock must learn to become a part of their family. Interestingly, the first story is told from Ava's perspective, thus decentring Sherlock from the pivotal role. Initially, Sherlock is confused and irritated by the child, then warms to her but is still incapable of a parental role. When John is injured:

Ava drew in a wobbly breath, suddenly terrified.

"Out," Sherlock enunciated perfectly.

Ava couldn't move.

"I said 'get out'." Sherlock didn't raise his voice but rather clipped his words with even more harshness.

"Where's Daddy?" she asked, her legs glued to the spot.

"Get out, get out, get out, get out," Sherlock started to repeat over and over under his breath as if it were a mantra his life depended on.

"Where's?"

"Dying," Sherlock suddenly roared. "Stupid man. Stupid idiotic man took that damned bullet because he couldn't wait...the bloody minded fool." Everything stopped (KeelieThompson1, 2012).

Sherlock never becomes a conventional father figure, but, by the end of the series, he loves Ava unconditionally and is willing to put her and John before his work, his need for danger and his drug habit.

In these stories, Moriarty represents the threat and temptation for Sherlock to abandon the domestic sphere and return to his old, dangerous exciting life. The climax of that narrative thread is the rewriting of a key canonical scene, wherein Sherlock and Moriarty face off on the roof of the Reichenbach hospital. As I have previously written, Moriarty here confesses his deep disappointment that Sherlock, despite his delight in intelligence 
and power games, has turned out to be on the side of hegemonic authority and conservative constructions of goodness:

Sherlock: I am you - prepared to do anything; prepared to burn; prepared to do what ordinary people won't do. You want me to shake hands with you in hell? I shall not disappoint you.

(Jim shakes his head slowly.)

Jim: Naah. You talk big. Naah. You're ordinary. You're ordinary-you're on the side of the angels.

Sherlock (his voice becoming more ominous): Oh, I may be on the side of the angels, but don't think for one second that I am one of them (TRF, transcribed by Ariane DeVere 2012).

Yet, both the narrative and Sherlock's actions belie his words. His desire at this point is to survive and save his friends. As I discussed in an earlier article, 'if [Sherlock] is not an angel, in this episode's heroic arc, which viewers know through the work of citation will not really lead to his death, he is as close as makes no matter' (Fathallah 2014, p. 497). Now compare KeelieThompsonı's citation and revision in her fic, wherein Moriarty kidnaps Ava and holds her hostage before Sherlock on the same roof:

[Sherlock] wanted his daughter in his arms.

Now.

Moriarty waited, and then started to rock ever so slightly [...]

"You really are so terribly disappointing," Moriarty said eventually, sounding genuinely sad. "I had half suspected that all this" — he waved the gun absently_-was nothing more than you trying to get a half-decent shag out of your pet."

"She's a child," Sherlock started to plead.

“Don't be so DULL!" (KeelieThompson1, 2013).

By 'all this,' Moriarty seems to reference the entire order of reproductive, networked, mutual domesticity to which Sherlock now belongs. As Edelman has demonstrated, 'the child' is a potent cultural symbol for this form of social order (2004). In the end, as one might expect, Ava is saved as John shoots Moriarty and after a great deal of trial and disruption including a prison sentence for John, the family is reunited. Moreover, by the conclusion of the last fic, Sherlock has been solidly repositioned within a network of people on whom he can depend and to whom he is accountable: not only John and Ava, but Mycroft, Mrs. Hudson, and to a lesser extent Lestrade. He is made to 
answer for his poor decisions, such as drug use whilst responsible for a child, in a way he never really is canonically. The title of the last fic in this series, Nest Among the Stars (2013), contributes a strong metaphoric statement to the repositioning of Sherlock and John as productive, nurturing parents whose domestic sphere is surrounded by mutual support, yet distanced from the wider, destructive, dirty, dramatic world Moriarty represents.

Fics in which Sherlock adjusts to parenthood with difficulty are better received, but fics wherein he slots easily and naturally into parenthood are greater in number. John, however, is always constructed as an able mother or father who takes to parenthood naturally. The precedent is canonical, as the most recent episodes depict his delight at impending fatherhood, but this was the case even before Season 3 aired. This is possibly an extraction from the healer/doctor side of his canonical construction, combined with the influence of fandom tropes.

For instance, in Wwwhat's Every Path, Sherlock's reaction to John's unplanned pregnancy announcement is: “I don't want children, John.” (2013). John is not surprised, knowing that 'The work [was] Sherlock's priority, his first love,' but reminds Sherlock that at one time he did not want a relationship either. Sherlock issues an ultimatum:John must give the baby up for adoption or Sherlock will leave him. Commenters find this difficult:

I honestly don't think I can continue to go threw [sic] with this if they go threw with the adoption (Marvaila 2013).

I can't see John wanting to get the baby adopted. I just can't. He'll change his mind, I know he will.

I mean the woman on Corrie wanted to keep the baby she was a surrogate for, and it wasn't biologically hers! Not that a soap can count for anything in real life but still! (Japonicastar 2013).

Notice how the conventions of a soap-opera, a genre coded feminine, are explicitly preferred to reposition the male characters as opposed to a depiction of Sherlock that other reviewers consider 'realistic' (anon. 5 2013). Yet, in the next statement, the commenter denies that a soap can 'count for anything in real life.' 'Real life' thus refers both to non-fictional human life, and to the lives of Sherlock and John in the story, placing them apart from and above soap conventions. However, they do indeed keep the child, apparently at the dictates of biology: John begins 'nesting', for 'even though his brain knows that [he's] not going to be bringing the baby home with you, his hormones are telling him to get ready for it.' Once their daughter is born, John 
is overwhelmed, unable to give her up for adoption as planned. 'John's body seemed entirely overcome by his biological instincts, entirely without control over what was happening to him, but seeming to have handed himself over to it' (Wwwhat 2013). Biology forces him into a new social position, akin to mother. How far this applies to the father is initially dubious, as John admits that though 'Sherlock's [the child's] Daddy, even if he doesn't want to be, and even if he won't be on her birth certificate [...] legally she'll be alphaless baby Watson.' However, Sherlock too is eventually repositioned by his own, alpha biology, becoming a protective if awkward father to their child.

Were this a male-female couple, it would read as a highly conservative story about the biological necessity of the traditional family structure (on conservative structures in mpreg, see Åström 2010). Indeed, there remains the question of how far pregnancy and domesticity is legitimated by its re-writing over the male body. On the other hand, the fact that these are male bodies necessarily imbues the fic with a transformative impulse: reproductive capacity and its attendant social positions are detached from the female body and attached to male ones. Yet consider this response:

In most mpregs that I've read Sherlock is super-happy about the baby. And it's nice, but we all know how often men just don't want anything to do with pregnancy. So, it'll be interesting to see how Sherlock changes his attitude *or maybe he doesn't, and it could be interesting as well* towards the baby/John (Drago 2013).

The wording of this second statement is important, bringing the very category of 'men' into question. For if 'men just don't want anything to do with pregnancy,' what is John, or the 'baby/John' hybrid in this story? We could read it as a re-attachment of the reproductive processes to the female body, rendering John in this story as essentially female. Yet, the canonical John, and all the John Watsons before him, remain inextricable from the new construction, so that female (?) reproductive John is always-already written over-and legitimated by - a prior construction of maleness.

Commenters on Every Path appreciate the difficulties Sherlock has in adjusting to his new position:

This is probably the most realistic portrayal of Sherlock's reaction to an unplanned pregnancy. I've seen some where he is a complete ass about it and wants nothing to do with the child (at least in the start), and I've seen some where he makes a complete 180 almost immediately. Here he is logical about his reasons as to why he doesn't want a child, yet he isn't 
demanding that John aborts it. He asks John what he wants instead and supports him as best as he can (anon. 4 2014).

By contrast, multiple short fics depicting Sherlock and John happily parenting a child without explanation receive zero comments. Abrupt or inexplicable alteration of position is apparently parodied in Benedictsexual's Little Surprise, which opens:

"Oh man!," said John.

"What is it," called Sherlock with passion.

"I think I'm pregnant!," John squealed.

John heard a big crash as Sherlock bound into the room and swept him up in his arms.

"John," Sherlock wispered [sic], "are you fo real?"

"yee, dis b da real deal" john replied in tears (Benedictsexual 2012).

The fic is not tagged parody or crack, and some commenters are unsure how to take it. Little Surprise receives ten negative reviews, which seem to take it seriously, such as 'horrible every word' (anon. 5, 2014) and 'I don't know if I should flame this fic or to laugh at it's [sic] stupidity' (anon. 6 , 2014). The majority, however, construct it as parody, appropriating the mock ghetto-slang discourse to praise 'Brah. That story waz like the bst ting i has evr red like that shit waz off de hook!' (anon. 7, 2013). For some reviewers, the key statement positioning the fic as parody is the characters' decision to name the baby 'Mycrofta', but the sending up of fandom tropes is also fairly obvious, such as the problematic element of Irene Adler:

"i'm leaving you sherlock! $i$ heard you scream irene when we were having da intercourse!"

"No John I would never do not leave me john i love you!," Sherlock began crying. "No one ever gonna love you more than i love you john that is true as science!

"irene said she was sherlocked!" :(

"Damn it john! dat was 3 weeks ago! why you so upset still" (Ibid.)

Compare Sherlock's appreciation of the new baby despite 'it' being 'really covvered in stuff' [sic]. Moreover, the fic concludes with a parenthesis '(Oh yeah...they got married [sic])' that appears to mock abrupt or ill-plotted transitions into domestic life for the protagonists. Fandom's interest, then, is 
more in constructing the process of transformation than simply presenting it, sourcing both its authority and its transformative capacity in canon.

Alpha/beta/omega fics demonstrate a more radical transformation, initially of the body, but strong statements link the body to social position and consequences. A very popular formula sees Sherlock and/or John struggling against the social position his reproductive capacities would place him in, a narrative that is obviously coded as feminine. The most are very long, highly crafted and contain a good amount of world-building, resulting either in a narrative of social revolution centred on the bodies of Sherlock and John, or 'personal adaptation and survival' (BeautifulFiction 2015). The single most impactful A/B/O fic, The Gilded Cage, receives 3151 positive comments on A03, various fanart, and a translation into Chinese. This story is set 'in a world where omegas are the property of the elite alphas, locked away and treasured by those wealthy enough to buy them' (Ibid.). John and Sherlock flat-share as in canon, and John assumes that Sherlock is a fellow alpha due to his work and demeanour. The first hints that Sherlock is hiding something come from his emotional reaction to a botched surgery on a female omega trying to sell her reproductive organs:

Yes, how awful to have no choice in the matter. To be seen as merely a means of producing children and sold into a bond she had no desire to form [...] her only method of acquiring self-sufficiency would be to sell what society views as her primary asset'. He looked back at the surgical slice in her stomach. 'She thought the risk was worth it, not only that of being caught, but that of losing her life as well' (BeautifulFiction 2015).

Empathy is constructed via bodily connection, for Sherlock too is an omega. He is hiding from the abusive alpha he escaped from and has built an independent life outside the dictates of his class and gender. The nobility, to whom Sherlock belongs, are constructed as archaic and dictatorial in their gender politics, whilst most of the world no longer views biology as destiny: 'Times changed but the elite didn't' (Ibid.). Yet, he cannot kill or allow John to kill his bondmate, because an alpha's death triggers a paralysing neurochemical reaction akin to grief in a bonded omega regardless of his or her feelings towards the bondmate. When his bondmate does die, Sherlock must face this:

He had believed those omegas who buckled beneath the strain, pining for people they'd once proclaimed to hate, were weak-willed - the products of a society that sought to keep them in their place. 
For the first time, a glimmer of understanding was within his reach. This was not the bright agony of heartbreak. It was an insidious chill, as if something were digging out his insides and leaving him with a black hole at his core around which he would collapse (Ibid.).

Note the intricate connection of the body to social position. Biology does have dictates, shaping characters' options and social connections. As one would expect, Sherlock and John end up in a healthy bonded relationship: however, Sherlock maintains his identity and his work. Reviewers take the gender politics of the work seriously and reinforce its statements:

This fic has reminded me what good science fiction is supposed to be like; what its purpose is: giving writers the ability to talk about real-world problems by pretending they're fictional (SheKillsCacti 2014).

Here we have an indication of fanfiction's transformative capacity in altering categories of interpretation in the broader social realm (cf. Artieri 2012, p. 463). SheKillsCacti positions herself as a reader, here, rather than specifically a fan, demonstrating fanfic's capacity to impact discursive formations in the same way traditionally published texts can. To a large extent, $\mathrm{A} / \mathrm{B} / \mathrm{O}$ verse explores what would happen if canon characters coded male were placed in a position historically determined as 'female', even while questioning what gender is: presentation? Biology? Reproductive capacity?

Cuddlefish's Organic Chemistry constructs a society where omegas are less valued, less protected and more vulnerable than other genders, and uses Sherlock's omega body as the catalyst for a social revolution. As his gender does not manifest, a phenomenon constructed as equivalent to puberty, until relatively late, Sherlock initially shares a social prejudice against omegas:

While I didn't know any omegas personally at the time, I still found many of their stereotypical attributes objectionable. The thing I hated most about them was their affected infantile behaviour. How on earth could omegas expect to be taken seriously-let alone be granted the same political rights enjoyed by everyone else in Britain - if they acted like toddlers all the time? (cuddlefish 2014a).

When his gender manifests he is gang-raped at university, and advised by an unsympathetic nurse that he brought the attack on himself and there is no 
point tarnishing anyone's name in public by trying to secure a conviction. Even Mycroft, who is sympathetic and assists Sherlock in creating a new life disguised as a beta, admits there is no point taking the attack to court. In this world, omegas hold the legal position of children, and are expected to be virtuous, chaste, nurturing and submissive to their alphas. This is the state of affairs in Britain: in Cuba, from whence Mycroft secretly recruits a doctor to perform an illegal abortion on Sherlock, omegas have full legal personhood with all attendant rights and responsibilities. Cuddlefish explains in a comment:

The reason I went with Cuba and the Eastern European countries as the sole bastions of omega equality in the omegaverse is because of their socialist pasts (or present, in the case of Cuba) in our own world. In other words, I'm equating the omega rights movement with Marxism [...]. In most states, the government, laws and, ideology continued to favour alphas, and they saw the omega rights movement as a huge threat to the status quo, contributing to the outbreak of a Cold War, just like in our universe (2014b).

Gender, then, is explicitly constructed as a social position over and above a biological one. Fascinatingly, in this universe, Moriarty is the head of an omega terrorist network intent on defeating the gender-based social order. Compare his position in KeelieThompsonı's work, as the opposing threat to child-focused social order. In this rewrite of the confrontation scene, Moriarty observes that Sherlock is 'on the side of the alphas' (cuddlefish 2014a, emphasis mine).

"Think about it, doofus! All the laws that you try to uphold? Those were all made by alphas to protect their own interests. Not yours, not mine, not any omega's. The British legal system doesn't even recognize us omegas as persons, and yet you risk your life in its defence" (Ibid.).

This citation and transformation of canon aligns the gender-based, reproductive social order with the normative politics of law and order Moriarty accuses Sherlock of upholding in canon. Gender is a matter of social structure rather than inherent or natural. When Sherlock asks how a criminal network benefits omegas, Moriarty responds that

"It benefits at least one omega: me. And plenty more besides. You see, Sherlock, there are a lot of smart but underappreciated omegas in the world. What they can't achieve in the law-abiding world, I give them 
a chance to attain working for me. I'm probably one of the only equalopportunity multinational firms in Europe."

"A criminal empire run by omegas," I began.

"For omegas." Jim finished. "So, you see, Sherlock. That's why you have to die. You're a traitor to your gender. You use your cleverness to defend a system that oppresses your fellow omegas" (Ibid.).

Thus, not only does Organic Chemistry contribute strong statements that very explicitly connect bodies to social positions, it positions Moriarty less as a purely-destructive psychopath than the potential visionary of a new world order. It is also the single most impactful a/b/o fic in the discursive formation, with 1368 comments on Ao3, none of which are negative. Its statements are consolidated with repeated terms of praise and commendation (Bhabha 1994; Hodges 2011): 'brilliant' (ImUnaware 2014; HarukoWitch 2014; Tosinadekunle 2015); 'amazing' (MyRockInAllThings 2014; EvilConcubine 2014; Marcyo9 2014); and 'wonderful' (Giveusakiss4132 2015; Marlon 2014). Moreover, though Jim is killed and his network destroyed, Sherlock's omega body in combination with Mycroft's increasing position of power in the British government becomes the catalyst by which a series of slow social transformations are enacted. It is always omega bodies that bring change, even if the change must be gradual reformation rather than violent revolution.

This trope is explored most explicitly in Lintilla's Dilaudid (2012a). Here John is the omega undercover, Moriarty is once again an omega terrorist, and Mycroft works misguidedly with an alpha supremacist group at the top levels of government. Sherlock is an alpha with an academic interest in omegas. In this story, betas are the child-bearers, rendering the biological role of the omega uncertain. As the author discusses:

Most a/b/o stories do have mpreg but I decided to exclude it and explore the consequences of a biological absurdity and the social imbalance it would cause. I also wanted to show the arbitrary nature of gender and how it's a societal construct and not the biological fact that people think it is (Lintilla 2012b).

Unlike most a/b/o stories, social discrimination against omegas is grounded in their apparent lack of a reproductive function in a social order organized around reproduction (rather as it operates in our world against women who cannot or will not become pregnant). Once his gender is accidentally revealed, John finds himself the unwilling face of an omega equality movement. The connection between bodies and position is solidified in Mycroft's 
observation of a public kiss: "Congratulations Dr. Watson, your tongue has now officially caused a public riot" (2012a).

Fandom, then, dramatically repositions Sherlock and John primarily via the alteration of the male body and the variety of social positions expected of men. When it consolidates their canonical positioning, especially militarism in John's case, the statements are inflected with both appreciation and reservation. Intertextually influenced by the fandom trope of parenthood, it frequently explores how the lone-hero is disrupted by the presence of children. Finally, it has been heavily influenced by the fannish popularity of mpreg and a/b/o fic, which demonstrate the inextricability of the gendered body from social position, and the difficulties attendant upon that linkage. In some ways, these works are radically transformative; yet, their transformative capacity is still dependent on the author-ized male body, the canonical figures of Holmes and Watson and the Moftiss-authored versions of John and Sherlock. It is the author-ized TV scripts which are adapted and rewritten in crucial scenes, and the White male bodies of the characters which grant cultural legitimacy to feminine-coded stories of pregnancy and gender. We will now discuss the last branch of the discursive formation, which I call 'Place', before summing up the transformative work fanfic has done on the discourse of masculinity in Sherlock.

\section{Place}

Fanfic is generally less invested in place than canon, and certainly less invested in London. Perhaps this reflects its global, dispersed authorship as opposed to the BBC's centralized one; perhaps it is a product of the fact that fans are typically more interested in character. Only one fic took place as its subject matter: this was Incarnations of London, a metaphorical short in the style of a fairytale. In this fic,

[t] here once was a city that called itself London. It was a city so animated and effervescent, a study in contradictions, endless paradoxes of the most esteemed beauty and the harshest crudeness coexisting on historical ground. Tormented by the need to truly live, London devised a plan to make itself a body. However, due to its inborn dichotomy of character and temper, London could not take form as one man. So it became two men, instead (TheBookshelfDweller 2013).

Of course, these men are John and Sherlock. John is 'London's Daytime man', disguising 'hidden treasures that lay below the obvious [...] His scarred skin, 
testimony of a past filled with turmoil and bloodshed, was hidden under present layers - a contemporary polish.' Whereas canon elides the whole history of British colonial violence, this fic constructs a Daytime London that upon the man's return from foreign lands, 'delivered a sun more intense than any that ever shone over the city, a foreign light stolen from Middleeastern planes.' Granted, the adventurer who returns bringing bounty to native England is an Orientalist trope, but the verb choice 'stolen' adds a minor statement of criticism to the construction. Sherlock, meanwhile is 'Night-time London', which may be

captivating like London's countless lights glimmering brilliantly in the witching hour, but he wasn't the lights. Rather, he was the dangers lurking between two lampposts, in the dim contours of street corners, dark back alleys and umbra under overpass arches.

He was utterly uncensored, much like the city in its latest hours, when arms were pricked, punctured to allow anti-gravity matter into the heavy blood, as their owners spread chemically-induced wings to flee far away from park benches [...] In him London amassed its macabre love for all things morbid (Ibid.).

Incarnations goes some way to restoring the side of London canon overlooks then, the poverty and drug abuse and crime against the glossy postmodern structures and grand Victorian heritage, rendering the figure of Sherlock, dirtied and breached by needles, inextricable from that construction. Compare this extract from Multiply, wherein Sherlock appreciated

the whirling dervish that is Westminster at lunch hour [...] the turmoil of people and cars and busses and tourists and cameras and dogs and drunks and shouting and laughter and crying-if this spinning, dazzling, grinding, ghastly mess of a city is somehow able to make the calamitous tumult of his restless mind more bearable (Multiply, 1electricpirate 2012).

As Sherlock's mind is less stable, more penetrable than in canon, so is the place he emblematizes. Yet, as I have argued, a thorough discursive analysis, particularly regarding discourses in flux, must bear in mind the comparative impact and prominence statements within a discursive formation rather than simply nothing that they exist. Incarnations makes only minor impact on the discursive formation, with 5 comments on Ff.net and 10 on LJ. Moreover, it is a rarity. Though not quite rejected, these statements 
are marginalized by internal mechanisms in the form of fanfic conventions cultures, which privilege long, tightly-plotted narrative, character-focused story arcs over what is effectively a prose-poem. Multiply fits all those criteria, and the writing is of professional standard, thus it has much greater impact (590 comments on Ao3, all positive). In that story, however, setting is but one element in a novel-length character drama.

We might argue that the convention for character-focused novels has a reductive effect on the constructions of place. But a different fan convention has productive effect: namely, the interest in backstory. When we meet John in the BBC canon, he has shortly returned from military service in Afghanistan. Fandom's interest in his military career produces a wealth of stories set in the Middle East. Orientalist conventions from canon are solidified - but they are also altered and undercut. Fandom also self-reflexively critiques its own implication in the discursive construction of the Middle East, as in Whiffling1o's Tumblr post, 'A Note on Afghanistan and Iraq in Sherlock fics':

The few fic depictions of Iraq I have read harp on the oppressive heat and barren landscape.* While I understand that characters may perceive Afghanistan and Iraq-at-war as miserable places to be, I would like to remind both authors and readers that Afghanistan and Iraq are countries that a lot of people love and call home. [...]

Listening to white people talk about how wretched these places are when their presence is a huge part of what makes them difficult countries to live in is grating at best, and usually just marches straight into the realm of 'extremely offensive'. [...] There is a way to talk about the difficulties of being a soldier without buying in to the (racist) narrative (which helped justify the wars in the first place) positing Afghanistan and Iraq as wastelands of violence and ugly otherness (Whiffling10 2014).

Whiffling1o urges readers to read Orientalism, and familiarize themselves with the broader discursive construction of the Middle East in which most of us are implicated. As I observed above, fan discourse the connections between gender and social position far more critically and astutely than it does race, and here again we have an indication of both the implication of fandom in broader interpretative categories, including scholastic ones, and its potential to change them.

There is a striking tendency in fanfic to solidify the construction of notBritain as danger, as a danger to British men and the kinds of masculinity they represent. John or Sherlock on revenge missions abroad, typically 
after the other's death, tend to be infected Heart-of-Darkness style with the darkness, dirt and disease of the other place:

Havana was a near miss, but [assassin John] killed two more people and threatened the structural integrity of the government. He skipped Brazil and went straight to Japan, where he played the bumbling tourist by day and at night made deals with the yakuza.

[....]

John went mad in Gibraltar; later he ascribed it to a combination of fever and antimalarials and over two years of service that hadn't been about Queen or country for a long, long time (Mad_Maudlin 2010).

Certainly, these statements alter the construction of the White male mind - as penetrable as the body, here — but as they do so they solidify the construction of England as a harbour at the centre of the dangerous world. Some statements pull against this: when John returns to London in hamishholmess's Afghanistan or Iraq?, he is overcome with alienation, wondering how 'home' could 'feel foreign' and acknowledging his leave as 'a holiday from real'. Afghanistan is constructed as the Real. Yet, in the same fic he judges Kandahar a 'life-sucking city' where 'the dust shifted with every footstep. Everything was covered in it; the filthy powder was inescapable' (2014a). Meanwhile in Self-Conclusion, Sherlock at first considers his new surroundings through disgusted eyes, finding that 'Kandahar was miserable. Dusty, khaki-colored misery,' and resolving that 'as soon as he returned to London, he would take a hot shower for days' (2014b). Interestingly, though, Self-Conclusion demonstrates that the Orientalist gaze is as much a product of Sherlock's class position as his ethnicity:

The hygiene here in Kandahar was shameful; how the soldiers endured it, he had no idea. Although, they were a different class of human altogether-submissive to the orders of those above them. They would never care about having six minutes of lukewarm water and a mutual bar of soap. But Sherlock's skin broke out in gooseflesh at the thought. He missed Baker Street. Desperately.

The 'different class of human' he perceives in working Englishmen blend easily and apparently naturally into the dirty landscape. Moreover, John is part of that landscape:

"You can never see the stars like this in London." John's voice was gentle and lulling. 
"If this is the only good thing about this god-forsaken place, I can't say it's worth it."

John sighed. It was a forgiving sound, as though he disagreed but could maybe, possibly, see why you felt that way. Sherlock sensed that this was Captain Watson's home (2014b).

On one hand, the ability of the Englishman to blend in and naturalize anywhere is a key to his constructed position at the centre of the world; on the other, Sherlock senses here that John would not be at home in England, that he has no family and no particular place to go back to. This throws into question the construction of what nationality is, whether essential as in most of the Sherlock Holmes canon, or whether it is possible to find and recreate a nationality in a new place. Sherlock's class also prompts a Corporal to inform him 'You're in the wrong place' in Fivepips's Combined Operations. In this World War II era story, service in France provides an opportunity for Sherlock and John to develop a relationship:

"People don't care if I'm queer here," [said John]. They only care about killing Jerries. I thought they'd be more outspoken against people like us but its better here than back home. I don't have to hide. When I go home, I will" (Fivepips 2014).

Statements like these connect social position and time to an understanding of place - by repositioning Sherlock and John in relation to each other (as queer lovers), their relationship to London is also changed. They are now peripheral, much more so in a 1940s setting than they would be in the present. Thus, 'home' and 'England' are reconstructed as less imperative, less integral to their characters.

A very popular fic contributes key statements to the construction of Afghanistan: abundantlyqueer's Two Two One Bravo Baker. This fic receives 2549 comments on A03, which again consolidate its statements through much-repeated terms of affirmation like 'fantastic' (Hobocamp 2011; carreracaminos 2012; ellie_hell 2011), 'incredible' (nic 2011; strawberryhiddleslock 2015; jankjay 2015), and 'wonderful' (ErinClaire 2011; thinkpink2o 2011; Infco218 2013), which solidify its position of importance. In Bravo Baker, Marine Commando John Watson is assigned to protect Sherlock Holmes as the detective investigates a series of war crimes in Afghanistan. Together, they uncover a conspiracy implicating Britain and America in arms deals and cover-up causing casualties on both sides. Once the depth 
of the corruption comes to light, the British position in global politics is critiqued:

"What they have done-if it becomes known — will go far beyond stirring up public opposition to the war," Mycroft says. "It would certainly bring down the current administration in the United States - and very probably the British government too - and force a complete change of military leadership."

"The only chance of political survival would be to repudiate the war completely," Sherlock says.

"Quite," Mycroft smiles icily. "And I can't allow that; we must have the war, I'm afraid. The Taliban tolerates poppy-growing because it funds resistance to the occupation. Without an occupying army, they'll be a good deal less permissive. You can't imagine what would happen if heroin became simply unobtainable in this country—or, perhaps you can" (abundantlyqueer 2013).

Ultimately, law and order must prevail in England at any cost; the 'icy' smile and contrast of possessive verb-phrase 'must have' with the connotations of 'war' position Mycroft as a villain here. The primacy of England is not overturned, but it is criticized. Meanwhile, whilst John and Sherlock assert they could 'never live anywhere except London,' it is the stimulus of the Afghan land-and-skyscape that open the possibilities of their relationship. Consider this passage:

The night sky is fractured by a river of light running almost vertically up from the horizon. There are more stars in that river than Sherlock could have ever imagined exist. Hundreds of thousands of them crowd together so closely that the darkness between them is obliterated, turned to glowing rose-violet instead of black. Great clouds of stars fume off from the central flow of the river, billowing outwards into the dark, and tens of thousands of lights sparkle all the way out to the far horizon. [...] The moon has set now. The night sky is broken open above them, and the light of the stars pours out of the fracture (Ibid.).

Certainly, the legitimation paradox is at work in the sense that the White men's presence and the development of their relationship is the viewpoint here. But the imagery is far enough from the dusty khaki, dirt and human misery that informs John's canonical flashbacks and the broader contemporary construction of the Middle East that we can 
safely state transformative potentials being opened here. Notice also that Sherlock does not read the sky. It does not offer up its meanings for his consumption.

Compare Korengal Calling (Ghislainem70 2014), another fic concerning military corruption in the Middle East. The Korengal Valley in north-east Afghanistan was the scene of heavy conflict between American soldiers and the Taliban in 2006-2009, and bears the real-world epithet 'The Valley of Death'. This statement is imported in the story along with the military slogan 'damn the valley'. Yet, the fic's construction of the Valley itself is morally neutral and again interestingly unreadable:

The Korengal Valley is long and narrow, a 6-mile twisting serpent with its head pointed toward the border of Pakistan.

The Korengal Valley has been the safe harbour of smugglers and resistance fighters from time immemorial. Remote, spectacularly rugged, so mountainous that less than ten percent of its inhabitants live on the fertile valley floor. Impossibly tall and ancient pines, formerly the source of now-illicit timber trade, made jagged fingers at the crest of the endless ridgelines (Ghislainem70 2014).

The noun phrase 'smugglers and resistance fighters' is a morally equivocal statement, pairing positive and negative connotations either side of a neutral conjunction, whilst the surface impression of the valley is primarily one of beauty. Moreover, for the first time, Sherlock struggles here with language. His grasp of 'Afghan language was very rudimentary,' and the polyglot composition of the resistance groups baffles his interpretative abilities. Sherlock is not the master-reader of the Middle East the way he is of London, unlike the gentleman-scholar of Orientalist fantasy. This fic is less impactful, with 55 comments, but works in conjunction with Bravo Baker to destabilize the position of the master-Orientalist.

In fact, what fandom reconfigures more dramatically than constructions of the Other/Orient, is the readability of space around Sherlock, rendering his world magical or supernatural. Copy That contributes strong statements. Of his unwanted ability to shape-shift, John observes:

"But it's magic."

If there is a scientific explanation he'll grab it with both hands because otherwise...otherwise his brain might just explode. Or Sherlock's. And no one wants that. 
Sherlock look like he's trying to skin John with his eyes. "Yes, John. Against my better judgment and every law of physics, it's magic." He spits the word out, then buries his face in his hands, and all but groans (maybemalapert 2012).

He is forced to reconfigure his conception of the world around him, and the two seek answers where the problem began, in Afghanistan. Here John 'copies' a local woman to consult a local witch, and while 'the burka is making it harder to read her face [...] the woman (the witch) seems contemptuous - of him.' Having given him his answer she commands: "Now get out; get out and stop fooling around with my sister's body!" In other words, she read him, the intruder in her country. As the author expressed it to me in personal correspondence, she found it important that somebody question John's appropriation of a Muslim female body:

The copying here was at once a form of appropriation (worse because it wasn't 'just' clothes and cultural symbols) and also of violation of the privacy of a person, and the hierarchy of power was adding a lot of weight to the whole thing (maybemalapert 2015).

Admittedly, this is John not Sherlock: I did not find any instances of Sherlock being read by Arabs. But again, these statements de-centre the White man from his reader-role. In these altered worlds, Sherlock and John must be more open to other forms of knowledge, knowledge usually constructed as feminine, be it the witch's traditional learning or Mrs. Hudson's babysitting expertise when, after 'magic came into the world' (Tawabids 2012) with no preamble, John becomes able to bear children. In the a/b/o verse, the world is often less readable than scent-able: in The Gilded Cage 'the stale fragrance of a lie made Sherlock's nose itch' (BeautifulFiction 2015), and people, their genders and positions are recognisable by scent. Moreover, scents can be disguised:John fools Sherlock in Dilaudid and other surprise-reveal fics via the use of a hormone suppressant.

In summary, then, fandom does consolidate to some extent the Orientalist tropes concerning other places, but it is more reflexive and self-critical about that construction than canon is. London is still the centre of the world: apparently that governing statement cannot be undermined-but it is a dirtier, messier and more chaotic London than the London of canon. Moreover, fanfic's convention of intertextuality, importing statements from other like genres the fairytale, supernatural fiction, comedy or the a/b/o verse, render Sherlock and John's world much less rationally readable than 
in canon. Here, magic can confound Sherlock's eyes; scents can deceive his nose. Obviously, this has implications for the construction of mind. In fact, the most striking transformation fandom has enacted is the explicit link and mutual reinforcement between the branches of the discursive formation. Social position and body are mutually dependent. Body and mind are inextricable. Place and social position interconnect, as do place and mind. The fact that canon elides all this naturalizes the central position of the straight White man at the centre of the world. Fandom's statements de-naturalize it, drawing critical attention to its construction.

In conclusion, then, Sherlock fandom's transformative accomplishment has been to radically de-naturalize the position of the White male genius at the centre of the world. Body, mind, position and place are shown to be strongly implicated in each other, via the workings of hormones, illness, reproductive capacity, class, wealth and educational opportunity. On the other hand, we cannot ignore the fact that all this transformative work depends on and is legitimated by citation of a very hegemonic model of masculinity. Whiteness remains a governing statement, indeed the only governing statement to indisputably survive fandom's transformations. I suggest that this is due to both the visual source of the fic and the cultural invisibility of Whiteness as opposed to the raced body (Dyer 1997). Fandom does a much better job de-naturalizing the authority of maleness than it does Whiteness. Finally, we should bear in mind that internal regulation mechanisms seem to guard against excess, particularly with regard to the body and the mind's mastery of it: the characters cannot become too animal, too uncontrolled, too leaky, without significant backlash.

More explicitly, there is also ritual gesture legitimating the fanfic by reference to the authorial source text:

Are you the secret love child of Mark Gatiss and Steven Moffat?

Because you are torturing my feeelsss with this.... (anon. 7 2012).

Disclaimer:The characters in this story belong to Steven Moffat and Mark Gatiss in their current incarnation (Wuerth 2013).

Ugh, your use of spectacular cliffhangers rivals even the Mofftiss's (cassiemgoog 2014).

Though far from ubiquitous, the spread of these paratextual statements across the sites frame the fan's work as legitimate, praiseworthy, but secondary to and dependent upon the canonical text. Compare the reservations 
about Sherlock and John being 'out of character,' suggesting that their 'character' is pre-set by the originating author. The author figure here is firmly 'the Moftiss' - Conan Doyle is scarcely mentioned — but the legitimation paradox revolves more consistently around the idea of fanfic as a genre versus culturally legitimate authorship. A reviewer praises The Gilded Cage:

I second and third my co fan boyz/gurlz in that you elevate the fanfic genre to the realm of great literary fiction. i enjoy several other archive authors who achieve this in their own might-most are found in your bookmarks — and the lot of you comprise a tiny cohort (sanctuary 2014).

The writer is credited with 'authorship' and 'great literary fiction' in her own right here-yet, in doing so appears to have produce something which is not-quite-fanfic, which alters the very nature of fanfic, 'elevat[ing] the genre.' Can fanfic legitimate itself, on its own terms, under its own authority? Or is 'authorship', 'authority' and 'legitimacy' a red-herring here, something that ought to be questioned and deconstructed rather than aspired to? In the next chapter, these questions will be developed further, as we consider the discourse of 'authority' in Game of Thrones and its fic. 


\section{4. 'I AM YOUR KING': Authority in Game of Thrones}

\section{Introduction}

Game of Thrones (hereafter GoT, 2011-), a quasi-mediaeval fantasy series based on George R. R. Martin's A Song of Ice and Fire (ASOAIF, 1996-), has a significant impact on contemporary pop culture. With an average viewership of 18.4 million per episode, at the peak of its popularity, GoT claims the record for the most-watched TV show in the history of the HBO Network (Beaumont-Thomas 2014). The show and cast have received several prestigious awards, including the Peabody Award 2012, three Hugo Awards for Best Dramatic Presentation in short and long forms, and a total of ten Emmys to date. Like Sherlock, its active and productive fandom spans most social media sites, in addition to the major fanfiction archives.

Set in the imagined world of Westeros and Essos, the series charts the feuds and struggles of several powerful families over the Iron Throne, seat of the hereditary monarchy that unifies the seven so-called kingdoms of Westeros. At the outset, the old Targaryen dynasty has been overthrown in a bloody rebellion, and the new Baratheon dynasty is in crisis, plagued by accusations of incest and illegitimacy. Murder, conspiracy and betrayal are the currency of the day amongst the nobility, whilst the hungry, war-torn commons pose an increasing threat to the political structure. It might be argued, then, central problem in GoT is power and authority-who can and should rule Westeros? What gives anyone the right? As Richard Corrigan puts it, "the question of who is the "legitimate authority" in the Seven Kingdoms [...] is of crucial importance' (2012, p. 50). To aid the reader in the following discussion, a chart of the relations between and positions of the key characters is provided below. We are chiefly concerned here with the ruling families of Lannister and Baratheon, the Targaryen dynasty in exile, and the Stark family who govern the north of Westeros. 
Fig. 6: GoT family trees. Copyright Matt Baker.

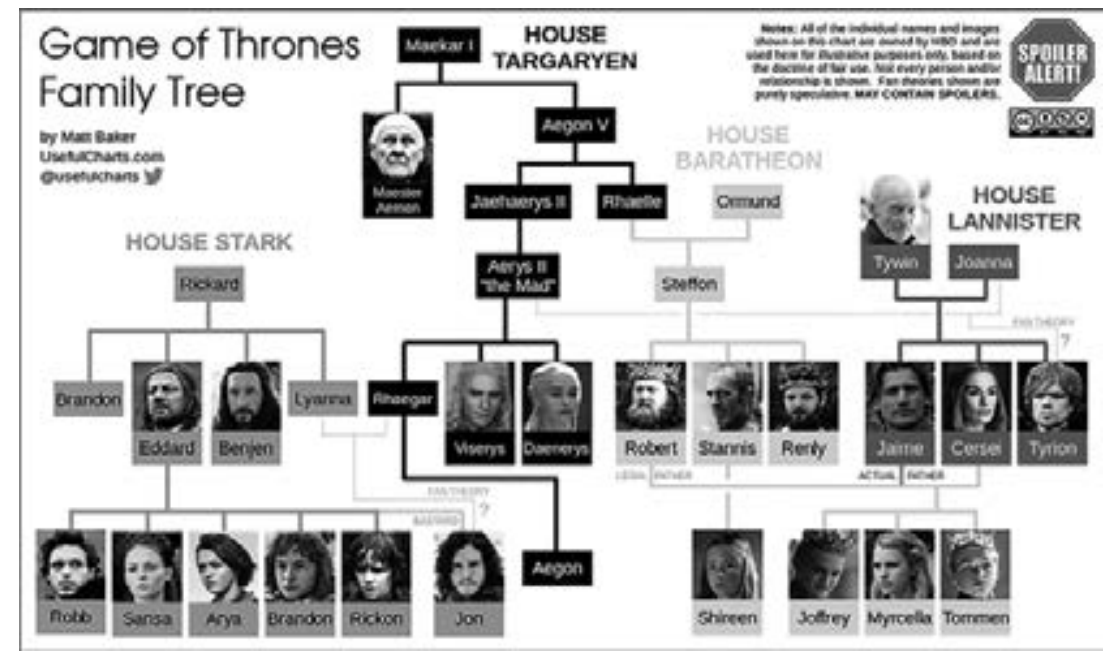

How are these concepts of 'power' and 'authority' constructed then? In Western culture, they are typically defined both in contrast to and in conjunction with each other. Max Weber connected them in his famous typology of 'legitimate rule' ([1922]1958), which is probably the most influential statement in the Western construction of authority. Weber considers the three types to be traditional, rational-legal, and charismatic. Very often the types overlap, and an individual or institution wields a blend of two or all three. Traditional authority is frequently patriarchal: that of kings, lords, fathers and canonical literary masters. It gains legitimacy through appeal to history: this is the way things have always been done, this was good enough for our forefathers and should be good enough for us. Unsurprisingly, GoT constructs traditional authority as the dominant form; but that tradition is in crisis and its legitimacy constantly threatened. Rational-legal authority bases its legitimacy as the name suggests, in law and reason. Heads of state, elected MPs, lawmakers and enforcers, and the heads of companies hold rational-legal authority within their arenas. Charismatic authority is quite different: it has no legal or rational backing, but is based in the perceived divine or otherwise special qualities of individuals. Cult leaders and political revolutionaries are the classic examples. Arguably, GoT constructs charismatic authority as better and more effective than the other types. This is interesting, given that according to Frank Furedi, Western culture has regarded charismatic authority sceptically since the 
fallout of the twentieth-century dictatorships (2013, p. 94), which were founded on the charismatic authority of figures like Hitler, Stalin and Mussolini.

It is after Weber that authority is frequently defined as 'legitimate power', though some critics dispute the construct. Philosopher John Day finds the term insufficient, for 'authority is often contrasted with power, which is regarded, as authority is not, as the exercise of force' (1963, p. 257). He believes that power is reliant on force, but we expect obedience to authority to involve some kind of voluntarism. Day goes on: 'when one person acknowledges another's authority, it cannot be because he is forced to. This is not what authority means' (p. 259). At the same time, Day suggests, we cannot truly disassociate power and authority, because authority seems to entail a certain kind of power. Day suggests this is 'causative' power, rather than 'coercive' power. A directive from a person in authority might cause me to perform an action, but given that I have accepted his or her authority, I have not been coerced into it. Moreover, authority is fallible. As Day writes, 'to say a man is in authority in the legal sense is to say nothing about what he is able to do in fact. It is merely a statement of what the rules permit him to do' (p. 262). As we will explore below, the fallibility and instability of authority is a constant theme in GoT, whose narrative begins, after all, in the aftermath of a rebellion that ended when Aerys 'The Mad King' Targaryen was stabbed in the back by his personal guard.

The English words 'authority' and 'author' share an etymological root in the Latin word 'auctor', which means something like founder or progenitor. As Assis notes,

The relation between author and authority implies the hierarchical authority inherent in the text's addressor. The authority of the writer of the text stems from his perception as the source of the text (2011, p. 1).

As we shall see, George R. R. Martin makes much use of this discourse when he asserts his claims as Author-God of the ASOAIF universe, and mediates and moderates it in discussion of the HBO series. Hannah Arendt observed the connection of authority and authorship as consolidating a form of non-coercive hierarchy. The founder, the progenitor, is constructed as naturally authoritative:

At the heart of Roman politics, from the beginning of the Republic until virtually the end of the imperial era, stands the conviction of the sacredness of foundation, in the sense that once something has been founded 
it remains binding for all future generations. [...] It is in this context that the word and concept of authority originally appeared (Arendt [1954] 2006, pp. 104-105).

Assis observes that 'in such a system, authority (auctoritas) is always a representation of the past, of the founding fathers or gods' (p. 3). It is a distinctly masculine construction. In GoT, Viserys Targaryen, exiled son of the Mad King, bases his claim to authority on the past glories of the Targaryen dynasty, their conquest and establishment of the Seven Kingdoms from the backs of dragons. His frequent references to his ancestors, claim to 'the blood of the dragon', to be 'the last hope of a dynasty [...], the greatest dynasty this world has ever seen' (1xo6, 'A Golden Crown') illustrates Justman's point that 'authority habitually mythologizes itself and its origins' (1979, p. 196) However, his descent into madness and ignominious death construct these claims as futile.

We now turn to the construction of authority in GoT, in contrast and conjunction with the construction of power. This discursive construction is overall piecemeal and fractured. Unsurprisingly, given the influence of Weber on Western thought, I found by working outwards from specific statements to their conditions of possibility that three of its main branches construct that three part schema. Other branches concerned the threat of the commons to authority, authority and women, and, finally, the authority of text in GoT. We will now address these in turn, noting that the establishment of governing statements was much less clear here: the 'domain of concepts' was quite disparate, but certainly still discernible (Foucault 1981, p. 67). The governing statement it is that belief in authority is authority's primary condition. This leads us to a discussion of how the author figures of GoT construct their authority or lack of it, which is complex enough here to warrant its own section. We will then be in a position to observe how fanfic alters the construction of that discursive formation.

\section{Authority in Game of Thrones}

\section{Traditional/Patriarchal}

As mentioned, traditional patriarchal authority is constructed prominently in GoT. Fathers rule their families, lords rule their lands, and the king rules the kingdoms. If the military order of the Night's Watch is made up of 'brothers', as recruit Jon Snow puts it, the Lord Commander is their 'father' 
(4xo6, 'Oathkeeper'). Patriarchy connects private and public authority, as illustrated in the early scene when Lord Eddard Stark brings his young son Bran to witness him execute a traitor. Bran is in training for the duties of a lord, performed 'in the name of' the king, the traditional father of the realm. 'Don't look away,' warns Bran's half-brother: 'Father will know if you do' (1xo1,'Winter is Coming'). Stark's realm of Winterfell is constructed as calm, orderly and prosperous. The camera pans over vast stone walls and wintery landscapes. The palette is black, grey, white, green and brown, visual statements constructing calmness and natural order. Children are seen at play and the people as happy and industrious. Stark is kind to his family and respectful yet commanding to his people. Yet, this model patriarch is executed halfway through the first season, too honest and/or inept to survive the political machinations of the capital. More successful patriarchs, like Lord Frey with his harem of teenage wives, or the wilderness-dwelling Craster who impregnates his daughters and granddaughters while exposing male infants to kill them, are constructed as corrupt and terrible.

Between these extremes is the example of Tywin Lannister, patriarch of that family. The ruthless and effective Tywin is played by Charles Dance, $\mathrm{OBE}$, a casting choice that imbues the character gravitas and accomplishment. Dance has a celebrated history of playing powerful, morally ambiguous characters. His authority is visually constructed in key opening and closing scenes, especially the climax of episode 2xog, 'Blackwater', where he slowly rides a horse up through the aisle of his royal grandson's throne room, having saved the city by succouring its forces in battle. A slow, deep string version of the Lannister theme tune consolidates the visual statements. Similarly, the opening of Season 4 shows Tywin having the fallen Stark's sword, the phallic symbol of his power, melted down and forged into a new sword for his son. There is no dialogue: only the Lannister theme song and the crackle of fire. The leisurely camerawork and slow, deliberate pacing construct a sense of stern inevitability in Lannister triumph. Lannister colours are red and gold, but Tywin generally wears black riding leathers, constructing him as a man of strength and sombre practicality. Tywin takes his role as patriarch seriously, the survival and prosperity of his lineage being his main concern. In a crucial speech to his eldest son, he intones:

Before long I'll be dead. And you and your brother and your sister and all of her children. [...]. It's the family name that lives on. It's all that lives on. Not your personal glory, not your honour, but family. [...]. The future of our family will be determined in these next few months. We could establish a dynasty that will last a thousand years. Or we could collapse 
into nothing, as the Targaryens did. I need you to become the man you were always meant to be (1xo7,'You Win or You Die').

Fig. 7: Tywin (Charles Dance) remonstrates with his son Jaime (Nikolaj CosterWaldau) in 1x07. Copyright and source: HBO.

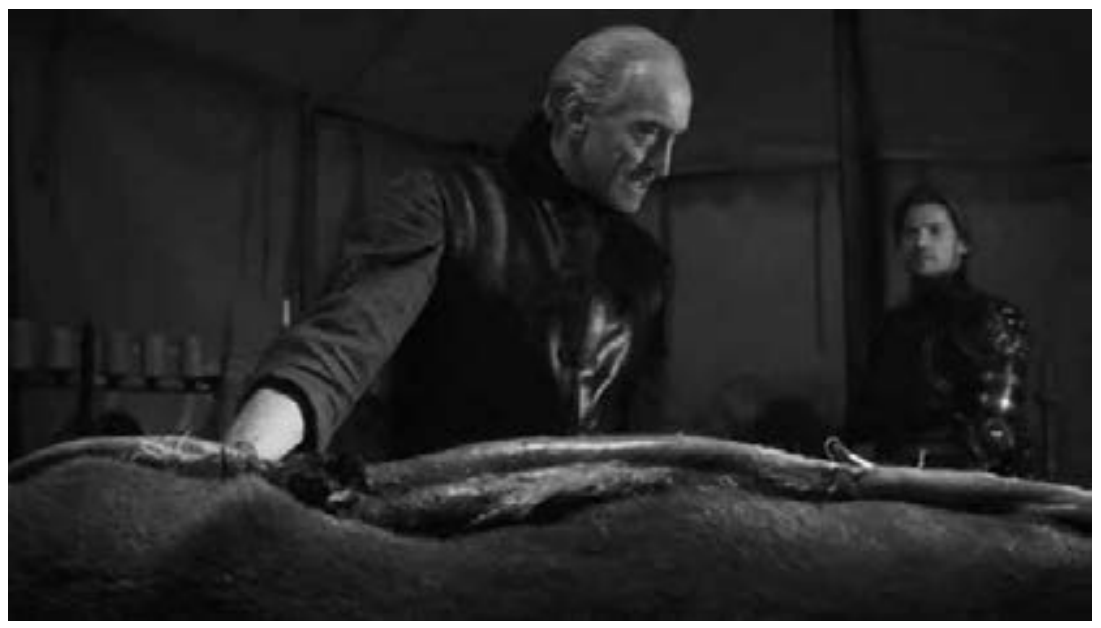

Yet, it could be argued that Tywin actually relies less on patriarchal authority than charismatic authority and illegitimate power. At his introduction above, he is seen butchering a deer, foreshadowing that he is 'not afraid to get his hands dirty,' as the English colloquialism has it. His horse shits on the floor of the throne room, and his deference to the king is perfunctory and scathing. Granted the king is his grandson, but in the patriarchal schema royalty ought to outrank lineage. Tywin does not accept his grandson's authority, and in episode 3x10, 'Mhysa', goes so far as to send him ignominiously to bed. 'I am the King!' protests King Joffrey futilely, to which Tywin calmly retorts, 'Any man who must say "I am the King” is no true king.' This is an important statement. Position and heritage are not enough: Joffrey lacks some inherent quality of kings, i.e. the charisma Tywin possesses. Finally, Tywin's coup de grace in the power struggle is a violation of traditional laws of warfare and sacred guest right: he arranges a massacre at a wedding feast, decimating the Stark family. Tywin's patriarchal authority is ultimately backed by illegitimate, pragmatic force. There is also an element of rational-legal at work here, as the crown is in massive debt to the Lannister family. This mixture of authority and power renders Tywin the de facto ruler of Westeros for many years and across the reign of three kings. 
Yet, his downfall is the ultimate deconstruction of patriarchal authority: murdered on the toilet by the son he scorned and despised.

In a scene that cites the Oedipus myth, Tywin's deformed, youngest son Tyrion corners him with a crossbow, having been himself sentenced to execution. Tywin's final speech is creeping and pathetic. His legs and chest are bare: he appears older and less hale, stripped of his leathers and cloak. He appeals to Tyrion:

You refused to die. I respect that. Even admire it. You fight for what's yours. I'd never let them execute you. Is that what you fear? I'll never let [them] your head. You're a Lannister. You're my son.

Until this point, Tywin's acknowledgment of Tyrion has been pained and grudging, admitting only that he 'cannot prove' the dwarf Tyrion is not his offspring. After Tyrion shoots, the dying Tywin groans, 'You're no son of mine,' to which Tyrion returns with quiet conviction: 'I am your son. I have always been your son' (4x10, 'The Children').

It seems, then, that traditional patriarchal authority in its pure form is constructed as benevolent when wielded by a moral character, though ultimately ineffective. Backed by force, and mixed with the other types, it becomes more brutal, more sinister, and more effective. Ultimately though, patriarchal authority contains its own undoing: it is because Tyrion is Tywin's 'son' that he is able to go through with the murder. These statements gain strength and resonance via their citation of the Oedipus myth, which holds a prominent place in the Western literary canon.

In this patriarchal system, female characters use a variety of techniques to secure power and authority, typically sourcing it through men. Daenerys, who is married off to a foreign clan ruler at the beginning of her story arc, initially depends entirely on him for her authority. As he lies dying, one of the clan remarks that she is only their de facto ruler while her husband lives: 'when he dies, she is nothing' (1xog, 'Baelor'). Daenerys ultimately gains independent charismatic authority (see below), though many of her initial clansmen desert her rather than accept the authority of a woman. Cersei Lannister and Catelyn Stark attempt to influence their first-born sons, heirs of kingdoms, whilst Margaery Tyrell and Melisandre of Asshai employ their sexuality and charisma to gain power over men. In a scene replete with phallic symbolism, the new queen Margaery pretends to be aroused by her young royal husband playing with a crossbow, flattering him: 'You must do whatever you need to do. You are the king' (3x02, 'Dark Wings, Dark Words'), to which he replies breathily, and with heavy dramatic irony 'Yes. I am.' The 
crossbow is soon in Margaery's hands, as he stands behind her adjusting her aim and admiring their image in their mirror. Though Joffrey remains in authority, Margaery has siphoned his phallic power. Meanwhile Melisandre coaxes the would-be king Stannis to impregnate her with the creature that assassinates his brother in her service, and promises him a son, the true patriarchal desire his sickly wife has been unable to fulfil. When he later demands, 'Make me another son,' she replies 'I cannot':

Stannis: Why?

Melisandre: You don't have the strength. It would kill you [...] Your fires burn low, my king (3x03, 'Walk of Punishment').

'King' is delivered with an ironic sneer: Melisandre has literally siphoned Stannis' power via her womb. At another point, she seduces a royal bastard in order to siphon his blood with leeches. Melisandre, a fire-worshipping priestess who appears in sensual red gowns, is a sexual threat to patriarchal authority through her powers over life and death, and the charismatic authority she gains through visions and mysticism. She disavows personal authority, claiming that she is merely a servant of the (male) Red God and a vessel for His power. Nonetheless, this manipulation of a patriarchal system has accrued her significant influence to date; how she will fare after Stannis' death, shown in the last aired episode, remains to be seen.

\section{Rational-legal authority}

Rational-legal authority is constructed by a weaker branch of the discursive formation. Nonetheless, the authority of kings is not based exclusively in tradition and patriarchal heritage. The founders of the Targaryen dynasty had no authority, after all: they conquered and united the lands that became Westeros by pure (fire) power. Littman suggests that the Targaryen dragons are a citation of Thomas Hobbes' seventeenth-century treatise on the authority of kings, titled Leviathan (2012, pp. $5^{-18)}$. According to this work, rational subjects should submit voluntarily to the monarch in exchange for peace, law and order. The king's authority is based on a tacit rational contract. Even a terrible king is preferable to anarchy and civil war. The contract reasonably extends on a smaller scale to the obedience of the commons to the nobility. A lord is responsible for keeping the peace in his holdfast. Thus, although the rebels were unjustified in their war, once Robert Baratheon becomes the new king, authority transfers to him regardless of his bloodline. It does not matter who the king is, so long as 
there is one. This form of rational-legal authority is constructed as weak in GoT, primarily because we have not yet seen a king successful in keeping the commons peaceful and fed. Robert may have come closest, propped up by his small council, yet the vulnerability of the contract is demonstrated when Robert is killed and replaced by his malicious heir, who fails to keep any sort of peace and order in the kingdom.

The rapid turnover of kings in Westeros makes the authority of a Leviathan difficult to maintain. Who will the city guard obey, muses the scheming councillor Lord Baelish, 'when the Queen proclaims one King and the Hand proclaims another[?] [...] Who do they follow?' He draws the point of a dagger on his desk towards himself and pronounces, 'the man who pays them' (1x07, 'You Win or you Die'). When Eddard Stark protests that Baelish's planned coup is treason, Baelish retorts 'only if we lose'. The rational-legal model of submission to a Leviathan depends on a unified and singular authority, and Westeros rarely has one.

Some tentative statements in GoT construct democracy as an alternative form of rational-legal authority. The wildlings, who live beyond the Northern bounds of the kingdoms, elect their own leaders. The Night's Watch is also a proto-democracy, with Lord Commanders elected by vote. These statements jar against the quasi-medieval setting of GoT, which arguably weakens them as lacking diegetic credibility. Democracy, 'rule of the people', would be an utterly alien concept in a feudal system. 'The people' of Westeros have no authority. They do, however, have some power: a point that will be elaborated on below. At the conclusion of the final episode that has aired to date (and the final ASOIAF book Martin has published), Jon Snow is killed by the Night's Watch brothers after his election as Lord Commander. They believe he has betrayed them through associations and negotiations with the wildlings, declaring 'For the Watch!' as they stab him (5x10, 'Mother's Mercy'). There is much speculation based on foreshadowing that Jon will somehow rise from the dead to become the prophesied saviour of Westeros. Should that happen his authority will not be rational-legal, which we can conclude is constructed as weak and ineffective in GoT, but charismatic.

\section{Charismatic authority}

Charismatic authority is constructed as the strongest and most effective form of authority in GoT. When Eddard's heir Robb Stark begins to make himself known as a player in the Game of Thrones, Tywin comments, 'He has a good mind for warfare, his men worship him. And as long as he keeps winning battles, they'll keep believing he is King in the North' 
(2x05, 'The Ghost of Harrenhal'). 'Worship' as a verb choice constructs Rob as a charismatic leader, and the belief of men, rather than inherited or legal position, is what makes him a king. There is a citation here of the councillor Varys' earlier statement that 'power resides where men believes it resides. No more, no less' (2xo3, 'What is Dead May Never Die'). What the statements of the narrative demonstrate, however, is that authority resides where people believe it resides: power is brute force. Granted, authority may be necessary to harness that power, but conversely it may not, hence the murder of Jon Snow. Here, we encounter the governing statement in the discursive construction of authority, it is that authority is created by belief in and acceptance of authority. There is nothing natural or a priori about it.

Tyrion also gains authority through charisma. In a key speech in episode 2xo9, he rallies the failing troops with a speech after the king has fled the field. 'They say I am half a man, but what does that make you?' he demands in an attempt to shame them into fighting:

Don't fight for your king, and don't fight for his kingdoms. Don't fight for honour. Don't fight for glory. Don't fight for riches because you won't get any. This is your city Stannis means to sack, those are your gates he's ramming. If he gets in, it will be your houses he burns. Your gold he steals, your women he will rape (2xog, 'Blackwater').

Consider the employment of tropes from classical rhetoric, notably anaphora, troping on the meaning of 'half', and the rhetorical question (Vickers 1989, pp. 86; 91-95). Tyrion gains authority through his speech and presence, and the taunt of 'half man' that has plagued him his whole life becomes a rallying cry, as the troops' scorn turns to belief.

The strongest construction of charismatic authority operates through the character of Daenerys Targaryen, last confirmed survivor of the old dynasty. Granted, in her journey from abused child-bride to warrior queen, she learns to call on the authority of tradition to present herself by her titles, as 'the blood of old Valyria' and 'the mother of dragons'. Her dragons are the force behind her authority, which she maintains through charismatic displays and hints of divine origin. In the pivotal scene that concludes the first season, she performs the apparent miracle of walking into a fire and emerging unscathed, dragons hatched and perched on her naked body. The camera pans out and the score rises to display Daenerys' new people bowing to her, accepting for the first time her authority rather than her late husband's (1x10, 'Fire and Blood'). She wins the love of foreign peoples 
with speeches, vows of protection, and an address from horseback that visually cites the famed military tactics of Alexander 'The Great' of Macedon, another charismatic authority. She appears in riding leathers or virginal white gowns as the situation requires, and overrides traditional authority in her conquered cities by abolishing slavery, and is lifted on the shoulders of adoring crowds, who hail her as their 'mother'.

Fig. 8: Daenaerys (Emilia Clarke) hailed as mother of the people in 'Mhysa' (3x10). Copyright and source: HBO.

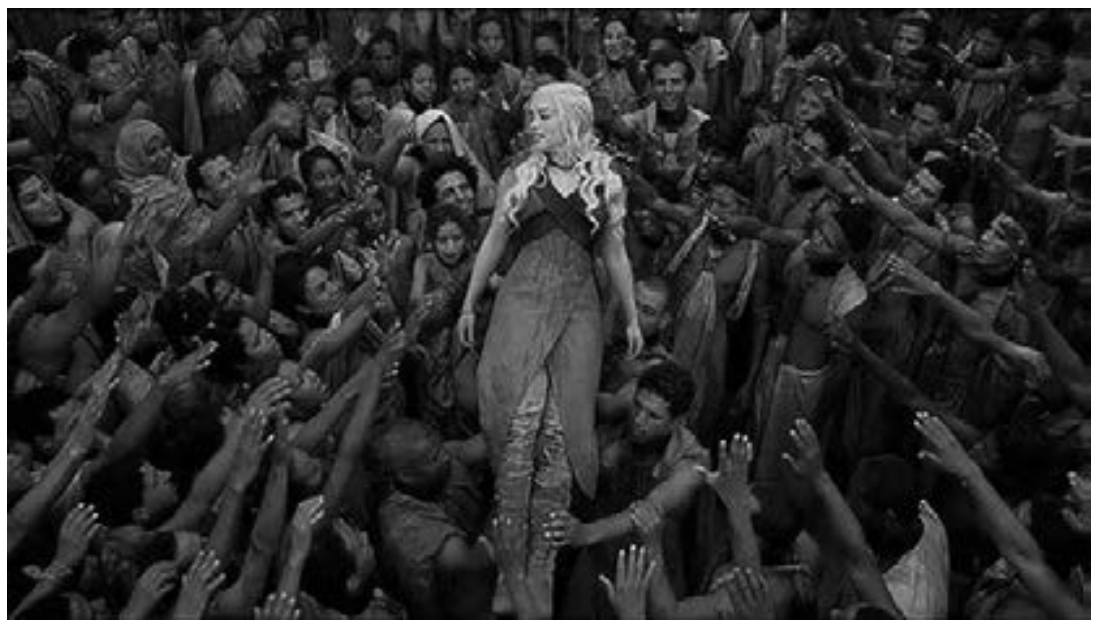

Camera pans picking out Daenerys as 'special', bright and light amid a mass of dark bodies, are a frequent technique constructing her charismatic authority. The problematic racial constructs of such images have been noted by commenters like Aamer Rahman (2013): Dany's narrative constructs her as the White Saviour of benighted dark lands, whose primitive inhabitants love and worship her in return.

Charismatic authority is not infallible, and Danaerys's is ultimately backed up by firepower: she is the only person in the known world in command of living dragons. When other means fail, she is prepared to kill her enemies. Even so, charismatic authority is constructed as the strongest and most successful kind in GoT. We turn now from Weber's schema to consider the construction of 'the people' as a kind of power threatening to authority at every turn, and then finally the construction of power and authority through text. This will lead us to our discussion of extra-diegetic authority over the text, as constructed by its author figures. 


\section{The Commons}

Wiser characters in GoT, who tend to survive to a greater age and make more impactful statements than their younger counterparts, are aware and wary of the commons' power. 'We can't allow rebels behind our lines to harass us with impunity,' notes Tywin Lannister. 'We look like fools and they look like heroes. That's how kings fall' (2xo7, 'A Man Without Honor'). Olenna Redwyne, aged matriarch of the Tyrell family, observes that a flamboyant royal wedding is necessary because 'the people are hungry for more than just food. They crave distractions. And if we don't provide them, they'll create their own. And their distractions are likely to end with us being torn to pieces' (3х05, 'Kissed by Fire'). In a rare moment of self-awareness, the doomed Viserys Targaryen realises the dependence of traditional authority on the people's support, having witnessed his sister's rise: 'I need a large army. I'm the last hope of a dynasty, Mormont. The greatest dynasty this world has ever seen on my shoulders since I was five years old... and no one has ever given me what they gave to [Daenerys] in that tent. Never. Not a piece of it. How can I carry what I need to carry without it? Who can rule without wealth or fear or love?' (1xo6, 'A Golden Crown').

Overlooking the need for 'love' is one of Cersei Lannister's errors. She is prepared to make brutal and unpopular moves in her attempts to consolidate power, such as ordering the deaths of her late husband's illegitimate children. Tyrion, who is typically written as insightful and intelligent, attempts to warn her:

\section{Cersei: I am Queen Regent.}

Tyrion: Listen to me, Queen Regent. You're losing the people. Do you hear me?

Cersei: The people. You think I care?

Tyrion: You might find it difficult to rule over millions who want you dead. Half the city will starve when winter comes. The other half will plot to overthrow you. And your gold-plated thugs just gave them their rallying cry: the Queen slaughters babies' (2x02, 'The Night Lands').

Soon after, Cersei suffers a reversal of fortunes, from Queen Regent to humiliated prisoner, ousted by the younger and more popular Margaery Tyrell, an expert in cultivating the commons' sympathy. But popularity alone is not enough. Renly Baratheon bases his campaign for kingship upon it, claiming that Stannis is unsuitable as a king because 'he inspires no love or loyalty' (1xo7, 'You Win or you Die') and 'no one wants [him] for their King. 
[Stannis] never wanted any friends [and] a man without friends is a man without power' (2x04, 'Garden of Bones'). He is wrong, and killed off early in the narrative at Stannis' instigation: the support and sympathy of 'the people' is constructed as a necessary but insufficient condition of authority.

Finally, two dramatic sequences construct authority in crisis at the literal hands of the commons. The first is a riot in King's Landing. Tension is created as the royal procession follows a narrow street between a hungry crowd, armour and cloaks contrasting with dirty naked skin. The crowd's calls quickly turn from ambiguous to aggressive, a low hum of bass strings building softly in the extra-diegetic score. Then shouts turn to missiles as dirt is thrown and the crowd descends, imperilling the king and tearing the religious leader limb from limb. 'I want these people executed!' shouts the young King Joffrey, to which his personal guard replies 'They want the same for you' (2xo6, 'The Old Gods and the New'). Authority is momentarily levelled. Once safe within the keep, an enraged Tyrion remonstrates with and ultimately slaps Joffrey, disregarding his authority and insulting him:

Joffrey: They attacked me!

Tyrion: They threw a cow pie at you, so you decided to kill them all? They're starving, you fool. All because of a war you started.

Joffrey: (screaming) You're talking to a king!

Tyrion: (slaps him) And now I've struck a king. Did my hand fall from my wrist? (2xo6).

The legal and traditional authority of kings is revealed, momentarily, as a sham. Joffrey is raging, pathetic and ineffective, depending purely on armed force to control the populace. As Day established, this is not authority $(1963$, p. 257). The commons are also constructed as an increasing threat to Daenerys' authority in her conquered cities. Her first error is ignorance. She assumes that outlawing slavery will be universally popular with former slaves, but on the contrary, receives an entreaty that a tutor be allowed to sell himself back to the household where he had security and purpose (4x10). She attempts to abolish gladiatorial fighting pits, an ancient tradition, but popular resistance is so strong she cannot enforce the law. Finally, rebel factions devoted to preserving the traditions of the city against the foreign invader cause a riot in the pits and attempt to kill her; Daenerys only escapes by flight on one of her dragons (5xo9, "The Dance of Dragons'). The dragons themselves, which are both symbols of her authority and the brute force backing it, are becoming increasingly difficult to control and threaten her at several points. 
There is one more identifiable branch to the construction of authority within GoT: that is the authority attributed to the written text. George R. R. Martin's paratextual proclamations uphold the idea of a true, authentic and authorial text; yet, ironically, the text he is so protective of constructs the authority of the written word in a much more unstable way. We will now discuss how the authority of text is construct within the diegesis, then contrast the public statements of Martin and the showrunners with regard to authority over it.

\section{Text}

The story opens in the years following a rebellion and, unsurprisingly, the different families tell different stories about the events of that war. Westeros is a world without an objective history. Either Rhaegar Targaryen was a vicious rapist who abducted Lyanna Stark and helped instigate a bloody civil war, or a gentle minstrel who fought under duress, doomed to die for the love of his life. A representative of the Bank of neighbouring Bravos remarks that

Across the Narrow Sea, your books are filled with words like 'usurper' and 'madman' and 'blood right'. Here, our books are filled with numbers. We prefer the stories they tell. More plain. Less open to interpretation (4xo6, 'Oathkeeper').

Moreover, texts change in transmission. Eddard Stark, knowing Joffrey is illegitimate, silently alters Robert's royal decree when he transcribes it at Robert's deathbed. Cersei has no qualms about ripping up the parchment. When the aged knight Barristan Selmy protests, 'Those were the king's words,' Cersei replies, 'We have a new king now' (1xo7, 'You Win or you Die') and has Stark arrested at sword-point. Power trumps the authority of the text and the authorship of a dead king. She later rips up Robb Stark's missive (2xo2, 'The Night Lands'), and scoffs at the idea that 'a piece of paper' can keep anyone safe (2x03, 'What is Dead May Never Die'). Yet, Cersei has fallen from grace dramatically. It is, after all, a singularly author-ized kind of text that condemns her - the formal confession of her cousin to their affair (5x10, 'Mother's Mercy').

Moreover, it is from an ancient book that Ned Stark learns the secret of Joffrey's parentage. Baratheon children for hundreds of years have been 'black of hair', but Joffrey is the same blond as his biological sibling-parents (1xo6, 'A Golden Crown'). The sympathetic and popular character Tyrion gains wisdom largely from reading: Tyrion compares books to a whetstone to keep the mind sharp, and values them intensely. As Martin's professed 
favourite character (Martin 2014), and the only one for whom he has published a collection of 'wit and wisdom' (2013), Tyrion's opinions and actions gain additional authorization and legitimation within the series. At Joffrey's wedding, Tyrion presents him with a huge book, apparently a work in the tradition of the mirrors (guidebooks) for princes that were popular in the European middle ages. Joffrey initially appears to accept the gift, remarking smarmily, 'Now that the war is won, we should all find time for wisdom,' but with his next gift, a sword from steel of renowned quality, proceeds to hack it to pieces. He then proceeds to cruelly humiliate Tyrion for the rest of the party - which culminates with Joffrey's assassination. Joffrey, in his idiocy and cruelty, treats with disdain the texts Tyrion reveres. He is dead, while Tyrion is exiled but alive, and extra-diegetically protected by fan and authorial favour. It might be argued, then, that in GoT, texts have some unstable authority but little power. Their objectivity cannot be trusted and they are easily destroyed; yet, those who disbelieve and so refuse to grant authority to text, such as Joffrey and Cersei, tend to suffer dramatic falls.

We can conclude, then, that authority in GoT is constructed as multifaceted, fractured, and dispersed, but still a recognisable discourse construction. It is quite different to power, which seems to be a property of the most brutal and violent, though it can be appropriated by cleverness. Authority is dependent on belief. It is found in patriarchs and charismatic leaders but it is always vulnerable: to force, to feminine manipulation, to the violence of the commons. This is an important point, as we will see when we come to discuss Martin's assertions of authority over his text. The fractured, fragmented, vulnerable status of authority is GoT is rather more modern than medieval, yet when Martin asserts his authority over the text, he reverts to some very traditional assumptions about the relations between text and author. We will address these next.

\section{AM YOUR AUTHOR: the word of Martin (and HBO).}

In a now-famous blog post, dated 07/05/10, George R. R. Martin asserted an authorial claim over the world of Westeros that does not 'permit fanfic.' Clearly, he does not have the power to ban fanfic, but discursively lays claim to the patriarchal, traditional authority of the author:

My characters are my children, I have been heard to say. I don't want people making off with them, thank you. Even people who say they love my children. I'm sure that's true, I don't doubt the sincerity of the affection, but still... (2010). 
This is an ancient trope, and the discursive genealogy has been mapped by Rose (2002) and Gunkel (2012). Gunkel argues that 'the idea of a book as the author's child dates back at least to Plato,' quoting him

\begin{abstract}
"And every word," Socrates explains, "when once it is written, is bandied about alike among those who understand and those who have no interest in it, and it knows not to whom to speak or not to speak; when ill-treated or unjustly reviled it always needs its father to help it; for it has no power to protect itself" (Plato in Gunkel, p. 74).
\end{abstract}

During the European Renaissance, 'paternity [...] became the most common figure for expressing the relationship between an author and his works' (Rose, p. 3) and the discourse 'continues to exert conceptual pressure in contemporary copyright law, which, especially through the stipulations provided by the Berne Convention, recognize and seek to protect the "paternal rights" of authors' (Gunkel, p. 74). Martin's statements hinge on and consolidate this discursive formation. Only he, the Author/Father/God, can protect his children from abuse and deformity by the inferior writers who would accost them. Indeed, the word 'plagiarism' comes from a Latin word denoting kidnapping. Martin also claims a legal duty to 'protect [himself] and [his] creations. He asserts that

a copyright MUST BE DEFENDED. If someone infringes on your copyright, and you are aware of the infringement, and you do not defend your copyright, the law assumes that you have abandoned it. Once you have done that, anyone can do whatever the hell they want with your stuff (2010).

This is false-copyright, so far as it goes, is automatic and requires no participation on the owner's behalf, unlike Trademarks, which the law can assume to be lapsed if they are un-enforced (Templeton 2008). What we are concerned with here, however, is the discursive work performed by Martin's statements. Consider Justman's observations that 'authority sets bounds, both formal and informal; a story is a bounded world; a book is bound literally. [...] Framing, an art term itself, can be a strategy of authority' (1979, pp. 197; 200). Martin's statements attempt to draw an authoritative frame that bounds and closes the fictional world.

Martin did admit in the 2010 post, which was primarily about his written works, that he was powerless to prevent people writing fanfic about the HBO TV show. 'If the HBO show is a hit, I am sure it will generate reams 
and reams of fanfiction. Whether $\mathrm{HBO}$ will encourage it, tolerate it, ignore it, or try to shut it down, I cannot say. That's their call' (2010). This may be taken as a milder form of textual provocation: it is baiting, in the sense that Martin is so clearly dismissive of their form, yet provocative of textual production in the sense that he acknowledge he cannot stop it. However, by the time Martin appears on the GoT DVD commentaries, his statements have modified dramatically (2013a,b). He describes his role as 'provid[ing] the underlying material' and is unperturbed by changes to the books, noting that showrunners Benioff and Weiss 'permit' him to write one script per season. He is here subject to their authority and praises the 'wonderful additions' of their lines. He commends the casting choices, claiming that actor Miltos Yerolemou 'is Syrio' and Peter Dinklage 'is Tyrion', despite the fact their physical features diverge from the book descriptions. He claims the character of Osha, dramatically changed from the books, may even influence his own writing and her direction in the book series. He comments that whilst 'book purists' may be upset by some changes, he himself is not: the frame of his work seems to have expanded and become more flexible than the one constructed in 2010.

Benioff and Weiss themselves are actively dismissive of single authorship discourse. Strikingly, they too describe their series as 'fanfiction' (2013a): a highly profitable kind, to be sure, and apparently one Martin entirely approves of. In a radio interview, Benioff describes the ascription of a singular author to film and television as 'just a load of shit' (2013a), and praises the contributions of everyone concerned. In their DVD commentaries, they show none of the deference to Martin that Moffat and Gatiss expressed to Arthur Conan Doyle, and discuss their matching of the cast to their scripts rather than Martin's books (2013b). On the other hand, they do repeat a story in which they proved their fan credentials to Martin by correctly inferring a major plot point to come, in order demonstrate 'that we wanted to make the faithful adaptation. Then he saw the show for the first time and thought "That's my world, those are my characters"' (Lyus 2012). Yet they profess equal concern that 'the fan community seem to understand that we love the books as much as they do' (Cumming 2012, my emphasis).

In sum, then, the highly traditional and patriarchal discourse of sole authority espoused by Martin seems to break down and fragment in the discussion of the books' adaptation to television. Benioff and Weiss do not set themselves up as auteurs, and even defer to the fandom as gatekeepers in cooperation with Martin. Of course this is a rhetorical move- the 'fan community' can hardly be homogenized into holding a single view of what GoT could or should be and, like other fanboy-auteur figures, Benioff and 
Weiss retain their position of industrial and economic power. But their description of the TV series as fanfiction of the books is an important statement and strong example of the legitimation paradox at work: further fanfic of the books is now legitimated via the textual provocation of the TV auteurs, and we will see how fans appropriate this statement, undoing to an extent Martin's claim to the 'principle of thrift in the proliferation of meaning' (Foucault 1991, p. 118). Fanfiction for the TV series is implicitly permitted via the showrunners' positive attitude towards it. Once again, fan activity is legitimated by White men in positions that are already culturally legitimate.

We might draw the discursive construction of authority over and in GoT as such:

Fig. 9: The discursive construction of authority in GoT.

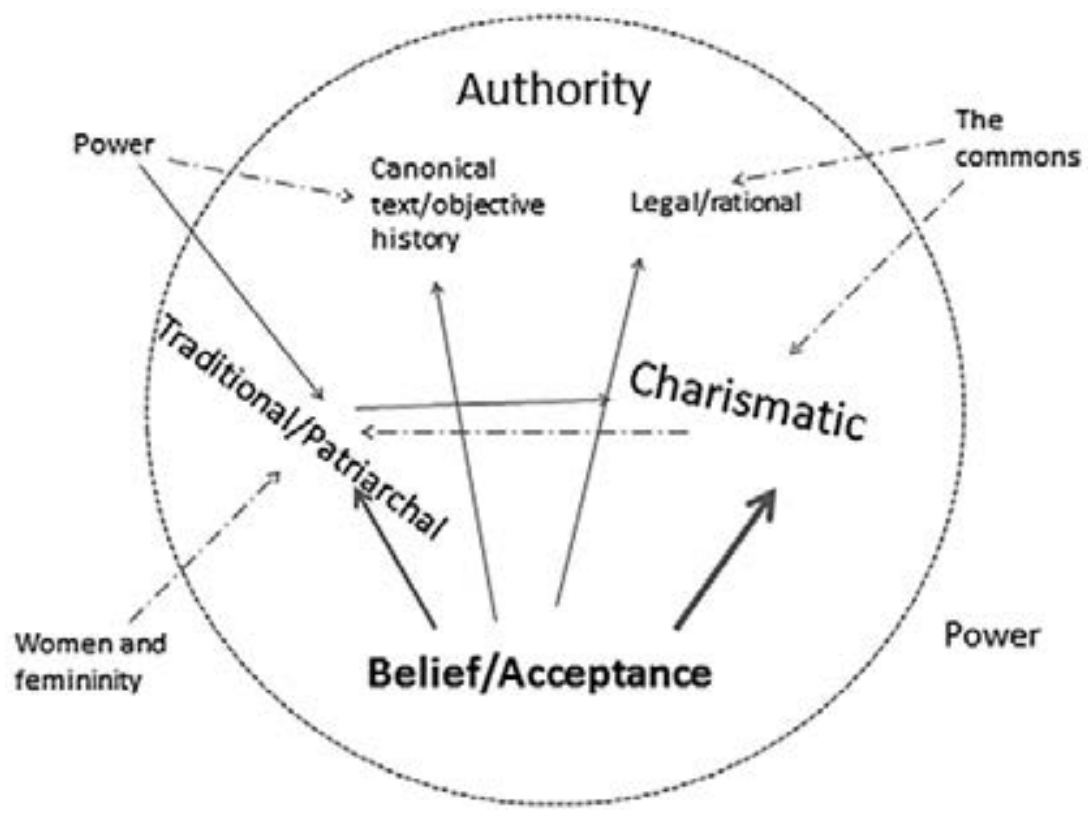

Solid arrows here signify consolidation, broken arrows disruption. The governing statement is that authority depends on belief and acceptance. Rational-legal and the authority of the text are less supported by belief than traditional and charismatic. The white area outside the broken circle is signifies power without authority, in which women, femininity and the commons take part. As we can see, charismatic authority is the strongest construction, though the power of the commons destabilizes it. 
Charismatic authority disrupts patriarchal; yet, traditional/patriarchal can actually reinforce charismatic, as in Daenerys's citation of her mythological history.

We turn now to the transformations and consolidations of the discourse, as reconstructed by fanfic. In doing so, we will necessarily be discussing fandom's negotiation of authorial legitimation more explicitly than previously, due to the fact that all GoT fanfic, by its form, contests an authorial prohibition.

\section{Fandom's Reconstruction of Authority in Game of Thrones}

By searching at the communities of highest centralization (once again Ao3, LJ and ff.net), I located fanfic pertinent to the construction of authority. Because this is not a categorization in typical fannish use (with the exception of the 'abuse of authority' tag on Ao3), I had to utilize the search boxes for key terms 'power' and 'authority' on Ff.net and Ao3, and simply read the description of every entry in the centralized LJ community, as there is no reliable search function on LJ. The first finding of note is that there seems to be much less fanfic overall for GoT than Sherlock or Supernatural. Perhaps Martin's author-function has an effect on this, as an external force of regulation (cf. Foucault 1981, p. 56). Secondly, fans do not always distinguish between the TV and book versions. The LiveJournal community hbo-gotfiction claims to be exclusively for fic based on the television series, in order to respect the wishes of George R. R. Martin, but, in practice, contains fic referring to book-only events or characters. The boundaries of the TV and book text are fluid.

I coded a total of 154 fics with 8722 reviews. The distribution was as follows:

Table 2: Table of fic distribution for GoT.

\begin{tabular}{|c|c|c|c|c|c|}
\hline Site & Ff.net & LJ & A03 & Other & Overall \\
\hline Number of fics & 68 & 79 & 74 & 10 & 154 \\
\hline Highest number of comments on a fic & 293 & 176 & 6461 & 24 & 6461 \\
\hline Lowest number of comments on a fic & 0 & 0 & 0 & 0 & 0 \\
\hline $\begin{array}{l}\text { Average number of comments on a } \\
\text { fic (mean) }\end{array}$ & 30.9 & 15.4 & 121.2 & 8.4 & 80.3 \\
\hline $\begin{array}{l}\text { Average number of comments on a } \\
\text { fic (median) }\end{array}$ & 16 & 9 & 8 & 4 & 13 \\
\hline
\end{tabular}


Values are to the nearest decimal place. Once again, several fics appeared on more than one site (hence the sum of the first four numeric cells in the top row is $>154$ ). There were 66 negative reviews, i.e. $0.8 \%$ of 8722 , but this is still a significant percentage increase from the other fandoms. This suggests slightly differing social norms, with more tolerance for criticism and higher expectations of quality in GoT fandom, which is chronologically the youngest of the three.

Fandom's alteration of the discursive formation can be rendered thus:

Fig. 10: Fandom's reconstruction of authority in GoT.

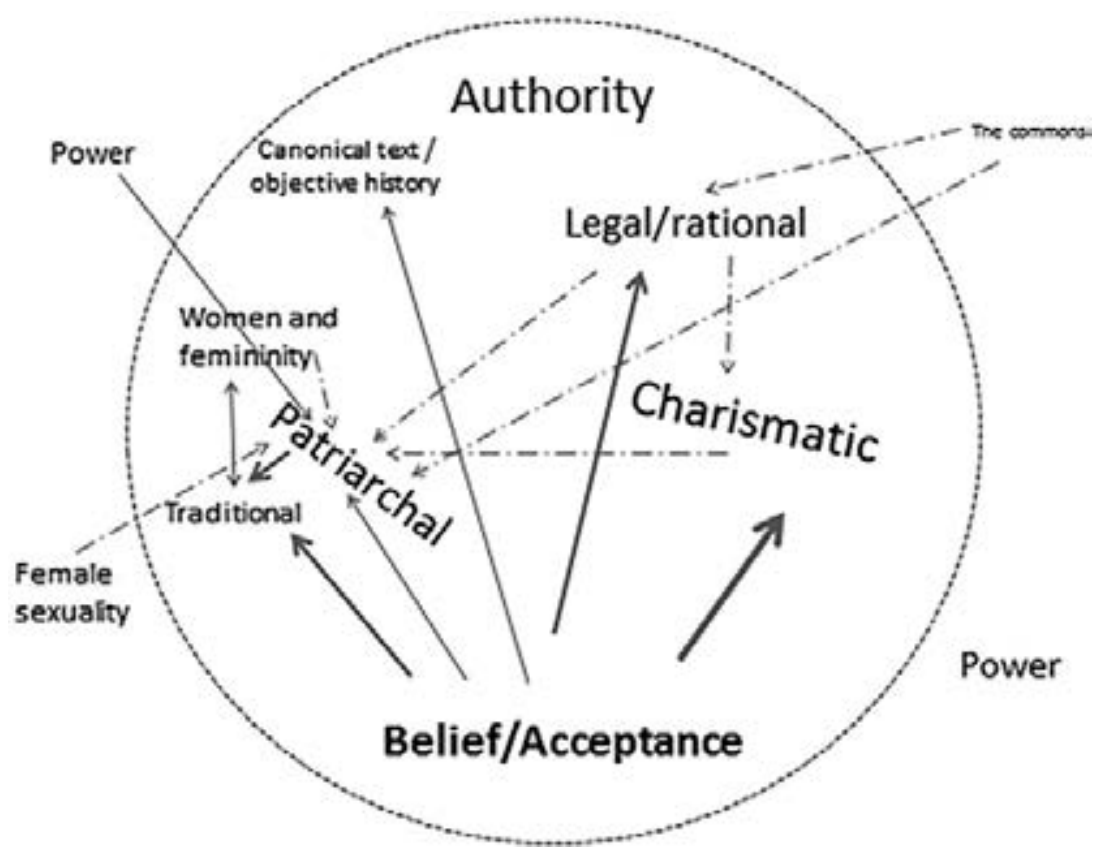

As we can see, while the branches of the discursive formation remained similar to those found in canon, with the governing statement remaining. There is greater attention to and variation in the construction of women and authority. Women and femininity have been accepted into the sphere of authority, though female sexuality remains outside it. I have therefore allocated this branch its own section, in the discussion following patriarchy. Traditional and patriarchal authority have been separated and the prominence of the rational-legal model increased. Charismatic authority remains extremely prominent, and, if anything, the power of the commons to disrupt 
it has decreased, a surprising finding for a supposedly democratic form of writing. One reason for thus, as I will demonstrate, may be that Martin's strong and current author figure has influenced a norm to keep what fic there is relatively close to canon, which focuses primarily on upper class characters. On the other hand, the authority of the canonical text has been pushed to the edge of the formation, as faith in it is decreased (though still evident). We will now consider the branches of this reconstruction.

\section{Patriarchal}

Unsurprisingly given the setting, feudal patriarchy remains an important model of authority in the fanfic. Snafu the Great's Game of Thrones: Vendetta posits an alternative path to destruction for Tywin Lannister as a direct consequence of Tywin's abuse of authority. Vengeance comes at the hands of Lucian Maegyr, a fan-invented father for Robb Stark's wife Talisa. On the TV show, the pregnant Talisa is murdered along with Robb and Catelyn Stark at Lannister's instigation, under the guise of a wedding feast, as noted above. In Snafu's story, Maegyr is constructed as 'the diametric opposite' of Tywin, with

natural charisma about him, in contrast to the forceful personality of Tywin Lannister. Lucian had the gentleness which reminded them of Ned Stark, but underlying that was the ruthlessness of a seasoned warlord (Snafu 2014).

Real patriarchal authority is not force, though force underlies it. As the fan-created House of Maegyr pursues its vendetta, the bad patriarchs of canon are systematically punished. Walder Frey, whose household carries out Tywin's massacre of the Starks, dies 'on his knees, sobbing as he watches his entire line being wiped out.' Joffrey is executed, and Lucian Maegyr kills Tywin in climactic single combat. The end of the story is the restoration of good patriarchy and the Targaryen dynasty, which Joffrey is made to publicly admit as the legitimate hereditary authority, pronouncing: 'I am not the true King [...] The true King of Westeros is Aegon Targaryen, Sixth of That Name, the Lord of the Seven Kingdoms and Protector of the Realm' (Snafu 2014). Repetitive declarative statements construct the end of the Lannister line and restoration of the Targaryen dynasty as critically important: 'So ended the life of Joffrey Baratheon, the deposed King of Westeros . [line break]. So ended the line of Cersei and Jamie Lannister' (Ibid.).

The solemn effect may suggest inevitability, and, indeed, the use of Biblical epitaphs and quotations on the inevitability of vengeance constructs 
the Maegyr victory as a foregone conclusion. Snafu opens chapters with quotations like Ezekiel 25:17, which concludes with the promise of God's vengeance upon the unjust. The selection of Biblical paratexts reinforces the construction of good patriarchal authority as the legitimate and correct order of things; though of course, through the legitimation paradox, the fan author sources and appropriates this authority for himself, to 'correct' the text of GoT in which the just are rarely rewarded. A reviewer explicitly approves of this technique, noting 'you can never go wrong with the holy word of God!' (Runnero43 2014).Vendetta is a popular and well-received fic, gathering 49 reviews on Fanfic.net and a recommendation on Tumblr. There is only explicitly one negative, which is complains of undue credit and attention to the author's original characters.

The restoration of 'good' patriarchy, then, is a significant statement in the fandom construction. However, fics questioning the legitimacy of patriarchy itself are more common. Coolchica87's For Want of a Better King (2015a), an unfinished coming-of-age story for Arya, may sound from the title like a correctly managed patriarchy is the solution, but in fact, Arya has to protect her father, who admits he is 'drowning' in the capital city. This fic receives only ten reviews, but On the Way There (2015b), by the same author, receives 39 , three times the overall median. In this story, Arya is married off to the royal bastard Gendry after the restoration of the Targaryen dynasty, but comes to rule 'as a lord' in Winterfell, negotiating an egalitarian marriage. As she advises her young cousin-by-marriage Shireen, 'The world is changing. And if you don't wish to marry, you don't have to' (2015b). Class and heritage, not gender, are the basis of her authority: she is confident that in Winterfell she will be respected as 'a Northerner' and a 'Stark' above the authority of her husband. Though there is an occasional mild criticism of the author's lexical choices, most reviews are consolidation statements of the 'Good story' (Don 2015) and 'please update ASAP' variety (Anon. 9 2015).

Indeed, there are a whole range of fics that replace the king with a queen, or lords with ladies, separating traditional from patriarchal authority and imbuing women with authority through their class heritage. (Fics imbuing female characters with different kinds of authority will be dealt with in the separate section below). Many address Arya Stark's rise to a position of power:

A slow smile unfurled across the King's face. "[Arya] has mustered an army of wildlings in the Gift. She retook Castle Black and put Bowen Marsh and all of his followers to the sword. This girl sacked the mighty Dreadfort, and fed Ramsay Snow to a pack of wolves." The King gave a shrug then, and leaned back in his seat. "Or so the tales proclaim. In any 
event, she is the last Stark in Westeros who still draws breath, and that's good enough for me" (Valkyrist 2013).

In this story, which gathers 44 reviews on Fanfic.net, 12 on Ao3, and two recommendations on external sites, Arya's traditional authority as a Stark and the charismatic legends attached to deeds compensate for her gender. The legitimation paradox is still at work within the diegesis however: the woman is authorized by the king. Despite many heroic deeds, authority is ultimately granted to her by his proclamation that she is 'good enough.' Clearly, this dynamic is only logical within the diegetic feudal system, but as will be discussed below, it is notable how few GoT fics depart from this canonical structure of authority in any substantial way.

Many stories reconstruct and consolidate the narrative of Daenerys Targaryen's rise to power. There is an explicit tension in these stories between Daenerys-as-authority in her own right, and Daenerys-as-authority via her male relatives. Interestingly, it could be argued that the influence of male relatives is greater in fanfic than canon, where Daenerys' son, brother and husband are dead. Consider PristinelyUngifted's The Song of Rhaego Fireborn (2011), which gathers a significant total of 115 comments across the websphere, and all but three are positive. Here, Daenearys' husband Drogo and her son Rhaego are alive. Though she reflects that '[her brother] Viserys' obsession with the past,' with the mythological foundations of Targaryen authority, 'had earned him an early grave,' and 'it was time to look to the future,' when she descends on Westeros with force, she proclaims authority as dispersed across the patriarchal family structure:

"I am Daenerys Targaryen, and with me rides my husband, Drogo, Khal of the Dothraki, and my son, Rhaego, rightful heir of the Seven Kingdoms. You see that we have swords. You see that dragons fly with us. We are here for my son's birthright, and we will fight for it!" (PristinelyUngifted 2011).

The fronted 'I am' establishes Daenerys as authority via Biblical citation, but Daenerys's conquests are ultimately in the name of her son. One of the rare negative reviews undermines the a patriarchal construction: 'You are my brother Drogo,' Khal Drogo said, 'And I give you my family. Should I fall in battle, they will be yours to care for' (PristinelyUngifted 2011). The response is: 'The "I give you my family" bit ruined the story' (Anon. 10 2014). Yet, on the whole, reviewers appreciate the balancing of the authority construct across the characters and their positions. 
On a similar theme, in lydzi's Queen (2012), Shireen Baratheon becomes the queen of Westeros due to her heritage, a gentle and beneficent ruler who looks to the statue of her dead father for inspiration. Two of the commenters name her 'Stannis's daughter' or 'her father's daughter' (linndechir 2012; sternflammenden 2012). Yet, one significant story deconstructs the legitimacy of patriarchal authority in quite a systemic manner. In Gemmig2's Deviance, which, with 234 comments, is one of the most significant fics in the study from Fanfic.net, the original character of Sarah Baratheon must learn to disobey her father in order to become fulfilled. A strong subtext contributes parallel statements to the discourse, concerning the fan's disobedience of the author. The fact that they are subtextual is an illustration of that principle noted earlier, that at the edges or peripheries of discursive construction, special techniques may be necessary to permit the challenge to what is acceptable in that construction: 'if "tricks" are used, this is an indicator that certain statements cannot be said directly without risking negative sanctions' (Jäger and Maier 2009, p. 47). The trick here is subtext created through the equation of author and father figures. After all, simply in writing fic, one is expressly defying Martin's well-known statements. At the outset of Deviance, Sarah is a dutiful and obedient daughter. Jaime Lannister confronts her:

"Tell me, has your father always dictated your life, or are you just too scared to defy him?"

She took a moment to think before answering. "Both [...] I don't want to disappoint him. What child wants to disappoint their father?"

"Sometimes disappointment is necessary if we are to choose our own path," Jaime told her [...]

"But...it is only right to obey, isn't it?" Sarah checked. "I mean, my father has told me...the King..."

"If I had that thought, do you think your uncle would have been on the throne?" Jaime asked, picking up another piece of bacon. "No, little stag. You make the most of what there is" (Gemmig2 2013).

'Making the most of what there is' serves here as a statement on the construction of fanfic - an act of textual poaching and piecing together. After many trials, Sarah and her father Stannis have a pivotal scene in which she answers his injunction 'You are my daughter. You obey me,' with the correction that she is her 'own person too,' and symbolically takes his sword, emblem of patriarchal authority, from his hands.

Finally, it should be noted that the construction of patriarchal authority and its problems continues in modern AU fic. Given that AUs in many 
fandoms span a huge variation of social systems, from space travel to animal transformation to office environments, we might expect rather more variation than is evident. GoT fic In Lady Jeyne Deadpool's Song of Hormones and Broken Hearts, Tywin the business magnate retains a harsh patriarchal hold over his daughter, limiting her movements and dress choices (2014). In just_a_dram's A City of Fortune and Failure (2015), set in contemporary New York, Robert is the fallen 'king of the military industry'; Lannister Mercantile the massive business conglomerate with de facto power over the city, and Joffrey the irresponsible playboy 'prince' of the city. Tywin's 'family legacy' is still his uppermost concern. Royalty is no longer important:Daenerys does in fact have a royal title, but 'It's meaningless [...] in the States'. She reflects that

Princess Dany of some godforsaken country that ceased to exist more than a century ago and wouldn't care to be ruled by the likes of her irresponsible, hot tempered brother if it did still exist is a title she'd rather be permanently shelved (just_a_dram 2015).

This important fic, set in a modern day would-be democracy that is still demonstrably, visibly structured by patriarchal authority is 'a game of business, politics and love in New York City.' Royalty confers wealth but no power or authority: Daenerys is a naïve, well-meaning socialite who swans about hosting charitable functions for causes she does not understand. Business and money in the hands of men and their male heirs rule New York. City is the second-most influential fic in the websphere. It has 1147 total comments, which consolidate its statements via appreciation of its characterization and faithfulness to a model of authenticity: 'Sansa's voice is so spot-on' (pennylane4 2014); 'Oh, thank you for this!! This is just beautiful and so perfectly Ned and Catelyn' (DKNC 2013). Again, the presence of a strong author figure who defends the integrity of his 'children' in the public realm may be a factor here, though we should not dismiss the possibility that fans simply enjoy reading 'more of' the characters they enjoy (Pugh 2005, p. 19), in addition to adapting and transforming them. Booth argues that 'nostalgia for the text' is an important shaping factor in fanwork as the impulse towards transformation and novelty (2015, p. 18).

The abuse of patriarchal authority in the present is the key theme of Lady Blade_WarAngel's The Seven Deadly Sins of King's Landing Academy (2014). In this high school AU, Jaime and Tyrion gradually uncover that principal Robert Baratheon has been date-raping students and covering up his crimes for decades. The story is concerned with the costs of contemporary patriarchy to women. After a sexual assault, Margaery finds herself almost helpless in 
this modern-day fic as the abused women of Westeros, recognizing her judge as a chauvinist. Patriarchal authority, backed by power, is alive and well in the modern day fics, though they are obviously highly critical of that fact.

This is also the case in the single most impactful fic in the formation. Hellholden's Her Liquor's Top Shelf(2015) receives an extraordinary 6461 comments, all on $\mathrm{A03}_{3}$, mostly simple reinforcement of its statements along the lines of 'Do write soon!!! Your story is so good' (didi45 2013); 'Oh my goodness, I am sooo loving this fic! (littlebirdhound 2013); and 'OMG LOVE THIS! Please post more SOON' (Torie 2013). All but three are positive. The fic has been translated into French, had a playlist compiled for it, and receives much enthusiastic discussion on Tumblr; in sum, it has achieved significant status in fandom, probably due to its great length, fluent and well-plotted writing, and the popularity of its central romantic pairing. Internal mechanisms of regulation favouring these factors have consolidated its impact. Though largely concerned with rational-legal authority and its fallibility (see below), this modern-day AU also contributes to the construction of traditional/patriarchal authority. Sansa Stark is in relationship with the older Sandor Clegane. Her father is upset and attempts to ban her from seeing him, commenting with heavy dramatic irony: 'There are more suitable boys out there for her, boys like Joffrey.' The reader already knows at this point that Joffrey has acted abusively towards Sansa. Sansa disobeys her parents, but his also subject to a certain amount of control from her older boyfriend. When a woman propositions Sansa:

"She's not available," Sandor said curtly. Without any warning, he took Sansa by the chin to lift her head up as he looked down at her. "Are you available, Sansa?" When she couldn't answer him and could only open her mouth to make a few incoherent sounds, Sandor took his hand away from her chin and pointed down at her. "The answer to that is 'no'," he informed her. "You're not available" (Hellholden 2015).

Though the author is always careful to stress in her framing notes that Sandor and Sansa have their problems, and their relationship is not perfect, and the few negative reviews are from readers uncomfortable with this and similar statements, which construct patriarchal authority as part of a romantic male/female relationship:

I don't like how Sansa automatically shuts-up when Sandor is angry. How she becomes afraid to speak her mind. [...] She shouldn't feel scare[d] of him at all, even when he's angry. She should be allowed to get angry back and speak her mind (SanSon23 2013). 
Yet, the fic also features Tyrion's growing awareness of his politician father's corruption and hold over the family. Here he explains his motivations in finally conspiring to have Tywin brought to justice:

\begin{abstract}
"Father," Tyrion began slowly, "asked me to do something very illegal and very traceable. It would have left an electronic fingerprint, a mark that would have led straight to me. I refused [...]I had had it with his lies and his manipulations and his...well, you know our father," Tyrion finished. "He was your father-"

"He was a selfish, arrogant, greedy, and abusive megalomaniac," Tyrion pronounced fervently, and he brought his fist down all of a sudden, banging it against the table (Hellholden 2015).
\end{abstract}

It seems then, that Liquor constructs patriarchal authority as negative, primarily due to its potential for abuse by corrupt or inept men. Yet, some readers perceive it as constructing patriarchal authority within a relationship as natural and, by commenting as such, reinforce the very construct they critique. Overall, the construction of patriarchy in fandom has not changed the canonical one considerably: patriarchal authority is generally dangerous and abusive in practice, though theoretically it may be beneficent in the hands of a good man. However, the context of fanfic is an anti-patriarchal practice, whilst the framing of the legitimate text in Martin's style is an absolutely patriarchal one. Anti-patriarchal statements in canon are thus ironic; whilst those in fandom, where young female characters learn to 'make the best of what there is' in spite of fathers, are rendered sincere by context and opposition to the author-father. There is a sense in which all fanfic is anti-patriarchal, at least that which is freely shared and explicitly acknowledged as a transformative work: its form is oppositional to the single authority of the White male author figure. And yet, as I am arguing, its textual and paratextual appeals to that authority, in various forms, complicate that transformative impulse across fandoms.

\title{
Rational-legal authority
}

Fandom seems more interested in the construction of rational-legal authority than canon, and constructs it with greater detail and variation. Perhaps this is to be expected: rational-legal authority is the kind most people are most familiar with in contemporary culture (Allan 2004, p. 151), given that most of us live in avowedly democratic societies with elected leaders. It is generally constructed positively, particularly through the character of 
Stannis (though now that Stannis has undergone a significant fall from grace in canon, this will probably change in the future). In Linndechirs's Life Lessons, young Stannis observes to his father that he, not his elder brother, would make the more suitable lord of Storm's End. His father explains the necessity of the laws of inheritance to him, relying not on tradition as a justification, but a ration-legal premise:

“Do you know why we have laws, Stannis?” [Steffon asked]. $[\ldots]$

"Because there can be no justice without laws. The law ensures that every many gets what he deserves." It sounded like something Maester Cressen had taught him.

"But the law isn't infallibly just, is it? [...] while the law should of course strive to be as just as possible, its main purpose is to maintain order. A world without laws would sink into chaos [...] That is how the king rules the country, how every lord rules his lands, every knight his castle, every man his family [...] Even a king cannot simply do away with the laws of the land, and if he does, he destabilises the entire continent. For if one man defies the law and gets away with it, others will follow" (Linndechir 2013a).

Linndechir is a well-known fandom author, so her statements come pre-imbued with a certain authority (cf. Hills 2006; Chin 2010, pp. 15-16). Reviewers affirm this via the legitimation paradox in explicit form, commenting on the authentic quality of her writing: 'I felt like I was reading another POV chapter from a GRRM book' (datalenkoass 2013). Fanwork is praised for being almost as good as the author-ed text, for being similar or faithful to it. The 'discussion at the heart of [the] story' is affirmed as a valid argument, reviewers commenting that with a solid legal system, 'life isn't perfect but could be a lot worse' (emynithilien 2013a). This sort of fic, centred on Stannis and the rational justification of authority, is quite common: see also rolfskate's A Father's Sons (2012) and emynithilien's How Long Have I Been in this Storm (2013b). The individual fics do not tend to make huge impact: the last three referenced receive 11, 13 and 9 comments respectively, but their relative frequency and the fact they never provoke objection construct rational-legal authority as uncontroversial and easily accepted.

As mentioned above, Liquor's primary model of authority is rational-legal. Authority is structural not personal. Jaime Lannister's authority comes not from his father, but from his position as a police officer; once stripped of 
his position and arrested, he reflects that 'he was nobody now. There was no power or authority in his voice anymore. [Line break]. He wondered just how his father expected to get him out of this mess.' The 'golden armour' he had been dressed in, metaphorically as opposed to literally in the show, came from his job not his heritage. Likewise, Daenerys poses as a 'mail-order bride' who may or may not be royalty, but is actually a secret agent, and produces her official identification as the means to prove her authority (Hellholden 2015). Though the characters are imperfect, allowing Jaime to abuse his authority behind a 'shiny badge', the system is sound, and it is the impersonality of the system that renders it so. Brienne reminds Jaime that their jobs as police are to 'uphold the law, not to uphold [their] ideas,' and as Brienne is a heroine in the story, the statement is significant. Quite incidentally then, through its sheer popularity, Liquor shores up the construction of rational-legal authority in GoT fanfic as legitimate and sound.

There is also a small subset of fics dealing with systemic change in Westeros. In a LiveJournal fic exchange, prompter janie_tangerine requests a story set

[p] ost-canon, since it's obvious that the absolute monarchy system failed then it's obviously time to find a better one. The Republic of Westeros? Constitutional monarchy? Constitutional monarchy with every realm being separated? Democracy [...]? The wildlings take charge and everything turns into organized anarchy that somehow works? (quoted in redcandle17, 2015).

Redcandle17 responds with Game Change, a story in which Daenerys has come to power and has 'great changes' in store for the governance of Westeros. She intends to institute a representative democracy, convening

"a grand council that will meet every year hereafter. After the tourney, [she] shall convene every lord and landed knight of note, along with representatives from the Citadel, the Faith, the Night's Watch... and the guilds" (redcandle17 2015).

Sansa, who still thinks in terms of traditional authority, 'would not have thought the guilds important enough to warrant a say in matters of the realm,' given that 'they were only commoners,' but Daenerys is determined that though at present she 'cannot have tens of thousands of village elders in the council [...] some day we shall figure out how to give the peasants their say.' 
Given the prompt, the rational-legal authority of elected leaders is obviously constructed as legitimate and correct here. As a_dragonlady comments:

Logically the governance of Westeros had to change or there would only be a repetition of past problems e.g. abuse of power by the monarchy and nobles leading to rebellion and civil war. I think that only Dany of all the contenders for the Iron Throne would be able to conceive of a new system that would eventually curb her powers and those of her successors as absolute monarchs (2015).

Traditional patriarchy descends into brute force regardless of who is in charge: the fault is with the system, which instils too much power in one person. Now the discursive formation begins to change-albeit with the same gradualness described in the story. Game Change has no massive impact, gathering 16 comments across the websphere, though all are positive and intrigued by the premise. There is even some mild objection or at least alertness to the legitimation paradox played out in the text, wherein a hereditary ruler authorizes the people:

And I like that you have Dany herself suggesting this Great Council—how often does an absolute ruler suggest something akin to a parliamentary system? Usually these things come from the bottom up (well, or at least from below the ruler!) and with quite a bit of bloodshed along the way (Zoesong 2015).

ZoeSong is right that these types of changes typically are brought on by the ruled, not the ruler! But perhaps it takes a right minded Queen, eh? (Lilone1776, 2015).

There are two other fics in which Daenerys deliberately delegates and disperses her traditional authority. Selena Dobreva's Freed Bird (2015), which constructs a kind of authority inextricable from femininity and womanhood, will be dealt with in the section on women and authority below. The other is After the Dragons by Ashesintheair, in which Daenerys conquers Westeros but then immediately divides up its rule, leaving Jaime Lannister as regent in the south. In a verbal demonstration of the legitimation paradox, she informs him:

"Dorne has seceded; let them go their own way. The Queen in the North stays where she is [...] Don't war with either of them, find some other way 
to settle your grievances. Last, my nephew has command of the Wall and it protects all of you. All of you will support him. His lands have been given over to wildlings so a tithe will be provided to him [...]. Other than that, the south is yours. We will take a master with us to train ravens to fly across the Narrow Sea. Send me word from time to time. Don't make me wish I had settled for an execution" (Ashesintheair 2015).

Jaime is granted authority at the behest of the queen, an instance of legitimation by appeal to a female character in authority. However, in these fics, the legitimation paradox is at work both diegetically and extra-diegetically. Through traditional authority, and backed by its force, Daenerys divides up the rule of Westeros. Through appropriation of George R. R. Martin's 'child' Daenerys, Ashesintheair re-arranges Westeros to her own desire. In the story Jaime's first act as regent is to melt the Iron Throne, or 'unmake the symbol of [his] authority, which is also George R. R. Martin's. Daenerys, approving of Jaime's actions, has the melted iron 'thrown into the sea,' considering the symbol too powerful to leave in Westeros. It is not merely the 'drunks and monsters' who have recently sat upon the throne that is the problem: the problem is absolute monarchy. Yet, this most careful and explicit deconstruction of traditional authority in favour of a rational-legal system fails to make much impact on the formation. It receives only two comments on A03. Where fandom is changing the discursive construction of authority, it is gradual and slow.

Finally, it should be noted that rational-legal authority is not without its critical dissection. In regertz's unfinished Back to the Throne Room, Westeros has been invaded by technologically advanced aliens known colloquially as Dirters. The Dirters, who bear a striking resemblance to the US administration, have installed the young Aegon Targaryen as a puppet king and Tyrion as a minister. Tyrion is sharp enough to understand the true politics of the occupation; when a Dirter Lieutenant remarks that they once had to 'nuke a planet' whose inhabitants kept killing invaders and were on the brink of a technological breakthrough, Tyrion remarks:

"Of course... [...] That would have been terrible. What a pity those people didn't see the light and realize your people are out for more than just to take resources and put others to work doing it. Even if temporarily there's disruption to our way of life and we seem to receive little benefit at first, in the long run we know we'll be a better place..." Cough, cough... "...For it..." Cough... "You must excuse me, could we put that window up?" (regertz 2015). 
Very obviously, the rational-legal administration of Westeros by the Dirters is designed to do exactly the above. Perhaps Daenerys the charismatic authority who has proved 'brave, a competent ruler [...] but hopelessly out of her depth against Varys and the Dirters he'd chosen to back' would have been preferable in this case. The mentally unstable young king Aegon holds no authority. He fears usurpation, so the Dirter Senator assures him they stand ready to 'support the legitimate government,' quelling the populace by force if necessary to keep their puppet in place. Tyrion muses on the Dirters'

commitment to 'non-interference' or 'equal justice' for natives and their own or the continued 'complete independence' of the societies they encountered, finding the concept 'relative' and 'flexible', particularly in times of crises...The definition of 'crisis' being reserved of course, to them (regertz 2015).

Quite clearly, the rational-legal structure of consent, treaty and legitimate government is as open to abuse here as the traditional patriarchy, though it is constructed as the 'modern' alternative, forcibly ushered in by 'advanced societies'. Back to the Throne Room receives nine comments, rendering it on par with the other the other fics specifically constructing rational-legal authority as the replacement of traditional models. Its statements are arguably strengthened by their allegory of contemporary global politics. Yet, the dominance of Liquor in the overall discursive formations means that the construction of rational-legal authority as natural, sane and sound are the stronger statements, incidental as this may be to its popularity. It is well-received because of factors favoured in fandom: good writing, length, a plot and the employment of a popular pairing, and its statements gain impact due to that popularity. Internal mechanisms of fandom, then consolidate its statements (cf. Foucault 1981, p. 56).

\section{Charismatic authority}

Charismatic authority remains a prominent construction in the formation as altered by fanfic. It is generally presented as strong, effective and largely beneficent, focused around the characters of Jon Snow and Danaerys Targaryen. It is far more prominent, and makes much more impact than the constructions of rational-legal authority explored above, particularly on Fanfiction.net. 
In Mx4's The First Sparks, Jon is constructed as a charismatic authority by virtue of divine heritage. This is non-canonical, though the circumstances of Jon's birth are a mystery, and there is speculation that he is the legitimate hereditary heir of Westeros and perhaps its prophesied saviour. In Sparks, he is a Christ figure, his true father being the Fire God R'hllor. To come into his power, he must 'face three trials. A trial of the mind. A trial of the heart. And a trial of the soul' (Mx4 2015). The three-trial pattern hooks into the discourse of myth, fairytale and religion (notably, the Three Temptations of Christ). First, Jon must battle the image of his stepbrother Robb Stark, the traditional heir of Winterfell. Though the image of Robb is stronger, Jon passes the trial when he realises 'that Robb Stark was as much constrained by his title of Lord of Winterfell as he had been elevated by it. That Robb had been born into a cage that he had no hope of escaping.' He tells his brother, 'I don't need to fight you' for Robb 'may be the Lord of Winterfell, but [he has] no choice [...] I have learned to be a lord. Or a warrior. Or a scholar. No matter what I may become, it will only ever be my choice' (Mx4 2015). Traditional authority may be backed by more force, but Jon's charismatic authority, constructed as is the product of choice and labour, proves the more genuine form.

Jon must then battle his own baser instincts in the form of a wolf/dragon monster (symbols of the houses he is descended from) and empathetically suffer the pains of the vulnerable in society: women, children and the poor. As he feels them, he experiences the sensation of being whipped, a scene intertextually reminiscent of Christ's passion. Further, he experiences a miraculous rebirth through fire, and at last is sent by his divine father on exile from his homeland, in order to fulfil his destiny as Azor Ahai, legendary saviour of Westeros. The story is unfinished, so his authority is not yet consolidated, but the repeated citation of mythological tropes makes it clear that the basis is charismatic. The First Sparks receives a very respectable 168 comments across the websphere, only one of which is negative, and that is simply a flat correction of a spelling mistake.

Jon as charismatic authority through divine or legendary heritage is a common trope. It features in Valkryst's Blood of the Direwolf(2012) and The Bastard Reborn (2013), and also in emynithilien's pointedly titled It's the Man Who Makes the Lord (2012), in which he rises from the dead after his murder by the Night's Watch. Fans often theorize that this will happen in canon: this charismatic authority is constructed as triumphing over the brute force of the people, superior to a democratic (if violent) movement. Interestingly, though, in It's the Man, charismatic authority does not confer the rule of Westeros. That belongs to Stannis, also rumoured to be the 
prophesied saviour of Westeros, and though he does defeats the King of the Others in single combat, his sword

'Lightbringer' no longer glowed, and when other men made comments [Stannis] brusquely said that he had never put much stock in being Azor Ahai anyway, but he not being some mythical hero did not stop him from remaining the rightful king of Westeros (emynithilien 2012).

It's the Man receives 26 comments across the websphere, whilst Blood and The Bastard receive 50 and 56 respectively. Fics where charismatic figures are granted greater power and authority, then, have more impact on the discursive formation. Compare outboxed's OfProphecy and Kingship. Here again, Stannis' traditional, inherited authority is constructed as superior to the charismatic authority Jon Snow has gained as military leader of the Night's Watch. The parallelism in the title explicitly contrasts these types of authority, embodied by the two leading characters. Before meeting Jon, Stannis had been expecting confrontation, prepared for conflict between the military order and the state:

"So it is still my kingdom to you then, Lord Snow?" Stannis asks.

Before all this, Jon might have thought that Stannis was merely testing for insolence but it feels almost a real question now. Jon isn't sure why it should be, though he knows why it is, in truth, has feared all along the expectation that he might rise up and proclaim himself. He will not give credence to such ideas by addressing them though, so he merely says: "you are King Robert's rightful heir."

[...]. "And you do not wish to sue for it?" Stannis asks. "Men would follow you."

"I have no wish to be king and no right even if I did." Jon says (outboxed 2013).

Popular, charismatic power is a potential threat to traditional hereditary authority, but does not have the authority to overthrow it. Jon has power; Stannis has authority. Jon is quite happy with this arrangement. Interestingly, this fic receives only three comments, suggesting that whilst traditional authority is uncontroversial in fanfic, charismatic is constructed as more powerful.

By contrast, in Blood of the Direwolf, Jon and Arya achieve transcendent bonds with their direwolf companions that inspire them to heroic deeds. In The Bastard, Jon is again resurrected from death and must fulfil his 
destiny as 'the prince who was promised.' The story is unfinished, but there is nothing to suggest the projected ending will be overturned. In Blood, Arya too features as a charismatic authority, who has 'trained under the Faceless assassins and the First Swords of Braavos. Her hands had spilt more blood than most knights. And now she had stormed the Dreadfort... and tasted the flesh of men.' She stirs the Northern people to follow her with charismatic speeches:

"These people are Godless!" Arya roared, her heart aflame. "These people have drenched themselves in the blood of your kin, and then demanded you lick their boots clean. These people slew your own lord in cold blood... my father!" Her chest pounding with rage. "And you wish to kneel to them like dogs, and praise their sword arm? Well I'm sick of kneeling. Winter has come, my lords. Now is not the time for dogs. Now is the time for wolves." A choir of cheers erupted from wildling and clansman alike (Valkyrist 2012).

Overall, statements like these, which construct charismatic authority as more admirable and effective than its alternatives, make more impact on the formation. In addition to the higher number of reviews, readers respond with frequent compliments and enthusiasm. There are also four negative reviews of Blood and two of The Bastard, including a critique of charismatic authority:

Why are you demonizing Bowen Marsh [a Nights Watchman, critical of Jon's leadership]?

His actions were rash, but he was right-Jon went against his vows and duty as a Lord Commander once he decided to go to Winterfell.

While this whole wildlings business was more or less acceptable, because it was clearly for the benefit of the Watch, going on a personal revenge/ rescue mission is NOT acceptable for a Lord Commander [...] I just can't accept your portrayal of Marsh as a power-hungry maniac (Blazen 2013).

To keep to one's 'vows and duty' and act in the name of the many, a rationallegal construct, is positioned by these statements as more legitimate than charismatic leadership. Thus, though charismatic authority is generally constructed as powerful and positive, there are some statements acting as a counterweight to that trend.

These observations hold for the construction of Daenerys Targaryen as charismatic authority. Building upon the canonical construct, Daenerys 
as conqueror and ruler of Westeros is a popular fic trope. Sometimes her charismatic authority is constructed imagistically:

Daenerys Targaryen sat on the dais like she was born to sit on thrones. Her crown fit her head like a helm, crafted in the form of three dragons, nestled in her hair and staring out with their ruby eyes. Rather than a long, flowing gown she dressed in a faded leather vest and men's breeches, cinched at the waist with a belt of medallions, and on her feet were strawlike sandals. Her unorthodox attire did nothing to undermine her queenliness; rather, it was the opposite. It said, I am the Mother of Dragons. I dress how I please (elalendi 2014).

Notice the legitimation paradox at work: some elements of patriarchal authority, i.e. battle dress, are appropriated in order to represent the authority of a woman. Compare The Song of Rhaego Fireborn, wherein Daenerys's charismatic authority is legitimated by and through her living son. Rhaego clearly has divine or mystical origin. He grows unnaturally fast and communicates with dragons:

The khalasar viewed all the strange magic surrounding Rhaego as part of his birthright as the Stallion Who Mounts the World [...]. To them he was a legend already, as miraculous as the dragons he had been born with. They accepted all he did and all that he was with wonder and praise (PristinelyUngifted 2011).

Daenerys and her husband go on to reclaim Westeros in the name of their son. As noted, Song receives an impactful 115 comments.

On the other hand, two of the most popular fics in the formation subtly mock the charismatic authority of Daenerys in canon as ineffective and irrational. In Liquor, before her real authority as a secret agent is revealed, Daenerys's 'princess' disguise is a source of humour, as her 'knee-length pearl-colored Armani gown' and petulant fondness for the word 'no' contrast with the capability of practicality of the characters around her:

"She kept demanding that she wanted a crown, so I bought her one," Tyrion said.

"Are you serious?" Jaime asked, unable to stop himself, but he was grinning like a madman. "What's it made out of?" Jaime inquired further.

"Rhinestones and aluminum?" 
Tyrion made a face like he didn't want to answer that question, but he did anyway. "White gold and diamonds," he admitted slowly (Hellholden 2015).

When Daenerys is revealed as a secret agent, the sham is revealed: her authority really stems from a legal position. In A City of Fortune and Failure she is as glamorous and popular as in canon, but utterly ineffective, 'babbl[ing] about social justice [while her advisor] Jorah Mormont had little to share in return but a fair dose of pessimism and a propensity to peer down her dress' (just_a_dram 2015). It is notable that both these examples are set in the modern world. Charismatic authority is glorified-though not without its detractors - when set in the world of Westeros, but its effectiveness and legitimacy in the contemporary world, with its rational-legal models, is more limited. In general, then, fandom has not greatly changed the Weberian scheme of authority in GoT. Charismatic is still the most effective, though rational-legal may be somewhat more prominent, and patriarchy perhaps more criticized through interest in and development of female characters. Moreover, as we will now see, fandom attributes genuine authority to women.

\section{Women, power and authority}

As explained, women in canon are without authority, but gain power through manipulation of powerful men. Fanfic changes this significantly and self-consciously alters this. Some simply establish Daenerys as 'as queen first and as a female ruler' (Selena Dobreva 2015), or in the case of sapphire blue-ruby red roses's $Q$ is for Queens of a Pair (2015), alter the patriarchal structure so that Arya and Daenerys can rule together as 'co-queens'. In Freed Bird, Daenerys' 'pure femininity and power' replaces the appropriation of patriarchal dress and rhetoric. 'She is kind, and strong,' comments Margaery Tyrell, 'not many women are to be so [sic] and be accepted so lovingly' (Selena Dobreva 2015).

Women as embodying a different kind of strength and a different kind of authority is fairly popular trope. In got-exchange, opheliahyde requests 'a story of queens, those that would-be or could-be, those that are and those that were; all of these ladies have a story, I'd love to hear it - if anything else, you could always write an AU where the ladies rule Westeros' (quoted in oparu 2012). Oparu responds with the story Peacekeepers, the canonically dead wife of the last Targaryen prince rules Westeros, and Daenerys, Margaery and Sansa, ruling the various realms, maintain a lasting peace 
through their friendship (oparu 2012). In the same author's Thawing Deep, Sansa as the last Stark becomes the ruler of Winterfell, and establishes an authority based on the empathetic understanding that 'Her people need a lady, not an avenging warrior':

She leaves candles in the sept and lingers in the godswood, listening for the voices of her family [...] Words have no heat in her mouth, and anger slumbers in her chest. She trades jewels for food, then tapestries, what remains of their books, armour, weapons, everything that will not feed or clothe her people is expendable like so many tales of chivalrous princes (oparu 2012b).

She has grown up and put fairytales behind her, but her authority stems from nurturing, the female-coded provision of food and warmth. As illustrated in figure 14, women have entered the sphere of authority via class heritage, destabilizing patriarchy and separating patriarchal authority from traditional. Meanwhile on the throne, Daenerys 'speaks of forgiveness and rebuilding, growing a kingdom from the ashes and mud of too much war' (oparu 2012b). Similarly, in Ghosted's Swallowed by a Wave, Sansa and Asha peaceably rule the North and the Islands as 'sisters of the brothers who should have inherited the world' (Ghosted 2012). Reviewer youremyqueen quotes the line, solidifying its contribution to the discursive formation, and praises:

God, yes, that line. Because Robb and Theon are great, and I love them dearly, but Sansa and Asha are the heroes of their own stories and maybe they won't go down in the histories quite the same, but there they are anyhow (youremyqueen 2012).

Finally, in magisterequitum's When You Kiss Me, I'm Happy Enough, Sansa's 'remaking [of] the history of Winterfell' via her tapestry work is symbolic of her acts to 'sti[ $\mathrm{t}] \mathrm{ch}$ up the north and bind its wounds' (magisterequitum 2011a). Via the feminine activity of weaving, Sansa both establishes her peaceful reign and rewrites herself and her family into history. 'I really think that line there is how she will end up' the author comments on her story, 'She's going to get to a point where she starts shaping reality for herself' (magisterequitum 2011b). When You Kiss Me receives a respectable 41 comments across the sphere, 35 of which are on LJ, but Swallowed by a Wave only 5 and Peacekeepers 18 . All were originally written on $\mathrm{LJ}$, indicating that site as most receptive to the construction of a new feminine form of 
authority. Peacekeepers later appears on Ao3, but none of them appear on FF.net.

There is also a large set of fics consolidating and expanding the canonical construction of sex and motherhood as female paths to power. Fandom, however, tends to explore the psychology of these methods and the necessity of their pursuit. Part of this is probably down to medium: written text provides more space for interior dialogue than television. In makeitfly's The Girl Who Ran So Fast, Myrcella Baratheon, married off to a prince of Dorne, finally comes to understand her mother's power as equal to her father's:

Her mother too was a hunter, Myrcella understood that now. Born a Lannister and raised up to be a Baratheon and a queen, a litter of princesses and princes and kings springing from her loins. She survived King's Landing, even tamed it for a while, the only place in all Seven Kingdoms more infested with snakes than Dorne itself. Perhaps she had been a young girl too, trapped in a different sort of prison, stalking a different sort of prey. Both had destroyed prey, eviscerated their names (makeitfly 2012).

Myrcella becomes a hunter herself as her royal husband impregnates her:

He slid the noose around his own neck at the end. He pulled away too late, spilling inside her for the first time. Afterwards he placed his hand on her stomach, as though to embrace a child who would someday grow in her womb. Their child.

"I love you, Myrcella."

Only a few words. The trap was set, the prey caught. She smiled (ibid).

Sex grants women power, but not authority (see figure 9). In J. M. Parker's Dany's Dream, Daenerys observes that, with the late Drogo and the growing child in her belly, 'Dany had been infinitely empowered [...] Yet, she was still very much reliant on her husband' (Parker 2011). It is a tentative balance. This point is made explicitly in linndechir's The Kingmaker, where Asha and her uncle Victarion arrive at a power-sharing agreement over the iron islands. He has all the authority:

"I don't need a title, nuncle." [Asha] sighed and shook her head. "I don't even need you to acknowledge that you share your rule with a woman, if you're worried about men laughing at you. I simply need to know that you will listen to me."

$[\ldots]$ 
"What makes you think I want that?" [Victarion asked]

"I saw how you looked at me earlier today," Asha said.

Asha is aware that her power here rests on her balancing and manipulation of gender roles:

"You aren't much of a woman, Asha," [Victarion said].

"I'm enough of a man to help you rule, nuncle." [...] "And believe me, I'm enough of a woman to handle you" (linndechir 2013b).

In keeping with the title, Asha states that she will call her uncle a king when she has made him one. These fics draw a distinct line between power and authority: power is attributed to women and authority to men. Thus, female sexuality remains outside the formation of authority in figure 10, in the realms of power, though both that and the forms of female authority which have been accepted into the construction destabilise patriarchy. In these fics, sex is the natural and necessary route to power for women, but other methods, based around nurturance and cooperation, are more successful in the pursuit of authority.

Fandom is moderately invested, then, in consolidating the construction of sex as female power. None of these fics make a massive impact-The Girl Who Ran receives 24 comments, Long Road 11, and The Kingmaker eight, but together they do make up discernible set of statements. By contrast, there is a smaller set of statements that construct female sexual power as insufficient without authority to bolster it. In bkgirl's Running to the Edge of the World, Cersei on trial before an unsympathetic court realises that 'in the end, out of all the lovers she'd taken to bed, all the men that had professed undying affection, she was alone. No one had come to speak in her defense.'

Sex is not enough. Nor is the position of women always so easily manipulated. In tenten_d's What's Buried Underneath, the canonically dead Lyanna Stark attempts to make the best of her position as the consort of the Targryen prince Rhaegar. The summary promises 'five times a woman can do nothing to prevent a tragedy and the one time she can' (2014). The $5+1$ formula is a common template for short fanfics, often used as a challenge prompt. In this Rome-like AU, Lyanna attempts to influence her royal husband but is still beaten and forced to watch her brother brutalized in gladiatorial games. Finally, called away to war, her husband kills her and their child rather than leave her to the barbarians he believes will overrun the city. With 36 reviews across the websphere, Buried has more impact as a single work than those constructing sex as female power, thus providing a vivid and poignant counter-statement. 
Finally, there is a set of statements exploring the reversal of gender roles, either in sexual play or set in an alternative universe. In lainemontgomery's The Flint and the Flame (2012), Joanna Lannister dominates Tywin sexually though without force. In oparu's Beneath the Old Gods, Catelyn and Eddard play at a reverse wedding, in which she would name him 'Lord Tully, her maiden name, and make him 'a trout instead of a wolf,' the sigil of her house (2011a). Commenters appreciate the pleasure and sensuality of these fics. Here, female sexual power grants her authority, but only in play. On the other hand, the same author's The Stranger's Road is self-described as a 'matriarchal AU set during Lyanna Stark's rebellion against Queen Rhaella on Iron Throne.' The full premise follows pre-canonical events of $G o T$, but casts female characters in male roles and vice versa. Men in this world are assigned to

building, farming and music, keeping house and hall warm and snug until the women came home from war. Women gave life and women brought death, men were for the in between, trading and singing; raising children while the women fought and died (oparu 2012c).

Yet, the events of this story, dependent on the abuse of power by monarchs and control of the smallfolk by nobility, are unchanged. As the author comments:

For this story, I think with feudalism and a well-defined class structure it doesn't matter which gender is in charge, the lower classes do most of the work, and some of that would still be split across gender lines but there's nothing stopping the upper classes from doing what they want (2012d).

Matriarchy, then, is constructed as a plausible alternative to patriarchy, but not a necessarily progressive one. Power and authority remain in the hands of the few in this traditional structure, with all the attendant problems. Indeed, most fics addressing women, power and authority tend to leave the class structure of Westeros more or less intact, but fandom also takes up the theme of the commons as a threat to authority. This is addressed in the next section.

\section{The Commons}

As a summary to her fic Our Claws Are Sharp, DaliWritesThings asks:

George Martin has showed us the minds of the noblemen of Westeros, but what of the ordinary people living their lives under the kings' shadows? A poem about the people's bitterness (2013). 
Ostensibly, fanfic.net does not allow poetry, but this instance has apparently been allowed to stand and thus appears as part of the sample. It warns:

We live in fear of cold and winter

The hunger, the ill and the sword

We have no food and we have no water

But our claws are sharp, milord (2013).

The final line cites and alters the canonical song 'The Reynes of Castamere', in which a nobleman warns his rival that his claws 'are long and sharp, my Lord.' Interestingly, this fic only receives one review. Perhaps relative unpopularity of the form influences the lack of impact on the formation.

Statements on class structure worked into longer stories tend to make more impact by virtue of their context. In CoolChica87's popular On the Way There, Arya is confronted by a commoner:

"I'll not be judged by the likes of you." He says.

"A woman, you mean."

"No, a lady. You highborns can judge us all you like, tell us what to do, but you're not here. You weren't here. You've no idea what it's like. You start wars, and it's us who fight in 'em. I'll not apologize for the choices I made [in battle] (2015b).

Arya's position as a noble actually diminishes her authority in a period of upheaval. Compare miss_izzy92's It's Violent Times for Weary Feet (2012a), an AU fic set in Revolutionary Russia. The summary and central question of this short fic is 'Why is your pain worth more than ours?' which the peasant Gendry poses to the noble Arya, last survivor of a decimated house. In this 'world turned upside down,' Gendry awakens to find Arya holding a knife at his throat, accusing:

"You came and took everything! My home, my father, my brother."

"You're... noble?" With her wild hair and wilder eyes, she didn't look noble.

Something flashed across her eyes and he knew he was right.

"You're in pain." Her hand was shaking. He could feel it from where the cold steel vibrated against his throat.

"Yes." She choked out.

"Why is your pain worth more than ours?" Her eyes widened. "I never did anything to your family."

"Your red friends." She spat and he could see her growing angrier. 
"And what have your people been doing to the workers for centuries?" (miss_izzy92, 2012a).

There is no answer to that. The fic opens with an epigraph from Volin, acknowledging that 'it is the people who make [the state] run-whether under compulsion or freely.' The rule of the nobility is maintained through violent exploitation of the ordinary people, and subject to threat from it. Violent Times receives 18 reviews, a respectable reception by LJ standards, but that is about the sum of the statements from the perspective of the commons: The vast majority of GoT fic is concerned with the nobility: here is a circumstance where fandom may have altered categories of interpretation (Artieri 2012, p. 463), but has not. Miss_izzy92 comments on her own fic, 'I have no idea why the ASOIAF ff isn't more varied. It's very limited to slight variations from the plot and modern AUs' (2012b). Perhaps Martin's proprietary statements of authority over his 'children' is one reason; relatedly, the fact that there are simply fewer GoT fics than $S P N$ or Sherlock might mean that meta-discourse around them is less developed, and fewer avenues of variation within the discursive formation are explored. Thus both external and internal factors act as mechanisms of limitation.

There are more fics constructing the nobles' increasing awareness of the commons power. Renly's canonical words to Stannis are quoted in Alikat7's The Wind Itself was their Song:

"The whole of the realm denies it, brother. Old men deny it with their death rattle, and unborn children deny it in their mothers' wombs. They deny it in Dorne and they deny it on the Wall. No one wants you for their king" (2014).

Repetition consolidates the support of the commons as necessary yet insufficient for authority. Meanwhile, in Mistress of the Living Darkness's Don't Blink, Baelish instructs his protégé Sansa in the art of ruling:

"What keeps the lords protected, love?" [he asked].

Sansa cocked her head to the side and glanced at the armory report he was studying so closely, "The soldiers and the gold."

$[\ldots]$

"Those help, but the peasants are the base of any society. To keep everything from tumbling, you must have happy lowborns, and you do that with food and safety. The soldiers protect the land from invaders and bandits. The gold keeps the soldiers happy and fit for battle. It keeps the 
lords in their great castles. It keeps the market going, but it is the food that truly controls everything." He turned and murmured, "The Starks are right. Winter is coming. When that happens, grain will be worth far more than gold. A starving man will do anything for food" (2015).

The term 'base' hooks into a Marxist discourse of power, creating an ironic contrast between Marxist aims and Baelish's vision of a stable feudal society. The commons may be a potential threat to power, but they are easily controlled. Sansa's increasing skill in governance is appreciated by the commenters: 'she should declare herself as the Queen of the North' (Anon. $102014)$.

In combination with the cool reaction to the poem, then, we can observe that fandom grants surprisingly little authority to the idea of the commons. This is striking given that fanfic is sometimes thought of as the democratic answer to the single author theory (cf. Pugh 2005). In the very popular For Want of a Better King (CoolChica87 2015a), the minstrel Tom is disgusted with both sides of the royal feud, declaring 'We seen evil on both sides.' He is 'tired of fightin' for someone else' and would 'rather fight for my own land and my own kin.' Arya cheers along to fit in with the crowd, but is sceptical of this proto-anarchist vision, feeling that the brotherhood 'had a point, but they clearly didn't understand politics.' The popularity of this story and the fact that Arya is the POV character strengthens the impacts of these statements, which construct the feudal hierarchy or a similar system as practically necessary.

Female rulers are constructed as readier to engage with the commons. In fanfic, their authority is typically more dependent on the goodwill of the people, in contrast to the canonical construction of men who rule by a mixture of authority and force. In The Stone Queen by mautadite, Shireen is a much-loved ruler, and while her councillor fears 'something horrible to happen out of her willingness to speak to and interact with her subjects,' she is always ready to do so. Granted, the common folk request her blessings on their children because of her elevated status, but this status is constructed as dependent on the people's acceptance:

Westeros had been quick enough to accept her. Most had only known of Shireen as Stannis' ugly daughter, the girl he took for an heir only because Selyse never gave him a son. But at the worst point in the war, the Others had reached as far south as Goldengrove, and no one could be bothered to argue the legitimacy of one of the women who'd helped to drive them back (mautadite 2014a). 
Reviewer ladybird97 comments: 'I love Shireen as queen. LOVE IT. Love the way she's been embraced by the people-the scene with the mother and baby was just beautiful' (ladybird97 2014). The author observes that Shireen 'knows what it's like to just be thought very little of, and she doesn't look down the smallfolk' (2014b). Meanwhile, in mirime_vy's And Make Them Love $M e$, the legitimacy of Sansa's authority depends on her service of and to the commons. Her councillor Sandor advises her:

"You want them love you but that mustn't be your only reason to try to rule them well. It shouldn't matter to you if they love you or hate you as long as they are taken care of. If you cannot do that, then you will truly fail" (2013).

An interesting tension is constructed here. On the one hand, to rule well is to serve the needs of the people. On the other, the traditional authority knows what is best for the people, despite what the people may think. It could be argued that this is the position Martin takes up when he argues that he cannot permit fanfic, though people might want to write it, for it would lead to the general weakening and demise of ASOIAF. Of course, this is complicated further by the fact that And Make Them Love Me is fanfic itself, and thus defies Martin's declarations. In continuing to write fic, it would seem, the practice claims authority on behalf of the commons, or collective, even as the statements of this story attribute authority to a traditional hereditary ruler who knows what is best for the people.

Finally, consider these statements from snowdarkred's Blood Lion Heart Wolf, which explicitly pits traditional authority against a growing power sourced from the commons:

At least once every seven days, Sansa walks through the streets. Her husband the King is loathed by the people-for being wicked, for being cruel, for being eager to levy taxes and shed blood for the privilege. Joffrey is hated and feared, but Sansa is loved.

She does not have the court on her side, so she must claim the people instead.

She wins the people's loyalty, so that when the time comes to put down her monster husband, she'll have an army at her back. A pack (2012).

This story is not particularly impactful, with a total of six comments-Make Them Love Me receives 8, Stone Queen 27. The power of the commons is almost always mediated through a figure of traditional authority-and 
where it is not, as in the poem we began this section with, the statements constructing it fail to make much impact. The legitimation paradox is being worked out diegetically in the fanfic as the power of the commons will potentially overthrow the traditional structure, but through a traditional authority figure, and extra-diegetically as writers disobey Martin's injunctions but focus their fic on noble characters, thus sticking relatively close to the author-ized characterizations of the canon. We will now conclude this discussion by turning to analyse how the legitimation paradox operates around the text, by analysing the construction of text and authorship.

\section{AM YOUR AUTHOR, revisited}

Fanfiction is always already reflexive on its own status as text, and the status of the text it adapts. This is the case even when it lacks disclaimers and author's notes, due to its contexts of production. As Pappas has argued, the 'typical attitude towards authority' in reading outside the academy is that

the right way to read is the way which leads us - by plan or not — to the author. We may call this the pull of the author's person. It's not so much that we believe the author knows best what the work is about, as that what matters most about the work is what the author thinks it means. What we want most to know is what the author said. [However] A subversive reading will release the reader from the power of the author as seen symbolically in such legal structures as copyright laws, but experienced more intimately as limitations upon the creation of meanings (1989, p. 325).

Fanfic, then, particularly in the GoT/ASOIAF fandom, can be understood as a form of subversive writing. Pappas goes not to argue that it is perfectly possible for

authority [to be] un-seated by some means which the authority made possible in the first place. If the authority behind a text is its author, then unseating the authority will mean carrying on some activity the author has instigated, to a point at which it no longer is relevant to ask about the author's own desire (p. 328).

Pappas does not find this paradoxical, but rather asserts than argues this point. I believe the legitimation paradox remains intact until fanfic starts 
to destruct and question the construction of singular authorship, which we will see most explicitly in the next chapter. Here, the author's authority may begin to be usurped through the practice of subversive writing, though for the most part remains paradoxically dependent upon it.

In the first instance, as I have argued throughout, subversive writing itself enacts the legitimation paradox. Secondly, fans insert their judgements upon dubious or yet-to-be revealed points of Martin's canon, frequently its backstory. The popular fan theory that Lyanna Stark and Rhaegar Targaryen are Jon Snow's parents is evoked in siraloPPolaris's A Realm in Rebellion, and constructed as the 'true' account of history.

"We must hide him, you must." The boy stirred is his sleep, clutching at his mother in her ruined cloth. "Ned, please. Sweet Ned." Her brother shook his head in disbelief, his shaggy hair falling about his unshaven, weary face. "Call him your bastard, keep him safe, please" (2013).

The judgement is that Lyanna was not abducted, but went with Rhaegar willingly. Thirdly, author's notes and disclaimers assert the fan's appropriation and adaption of the text:

Sorry I don't know the exact geography of westiros so im just gonna wing it. X) [sic] (echoxknox 2013).

The casual style and inclusion of a smiling emoticon juxtaposes Martin's formal postures of authorship. Compare:

A/N: This story will not follow the books, as I have not read them (Selena Dobreva 2015).

Reviewer Vwchick responds: 'This is such a Great Story! You said you haven't read the books, all I can say is please don't, lol. I mean the 1 and maybe the 2 [sic] are great but then the characters start acting very strange' (Vwchick 2014). The fan's authority is here sourced from the conviction that Martin has produced an 'incorrect' text that betrays the characters it has established. The fan-text is the corrective (cf. Jenkins 20o6b; Goodman 2015). The capitalization of 'Great Story' whilst 'books' remains in lower case underlines this statement typographically.

Fans also resolve the complex story in preferred arrangements, sometimes through the authority of a character who has become king or queen. In this passage from Freed Bird, the new Queen Daenerys (and through her, 
the fan) places popular characters in positions of authority, and dismisses disliked ones:

"Lord Commander of the Kingsguard, Lord Tyrion Lannister, is to be The Hand of the Queen." Her eyes glimmered with amusement at the stunned faces circling the table. "Lord Petyr Baelish, and Grand Maester Pycelle, your services will no longer are required at the small council. You may leave [...] Ser Barristan Selmy will regain his position as. "Lord Varys, you will remain on my council. During my time here at King's Landing, you proved to be a valued asset" (Selena Dobreva 2015).

Favoured dead characters are saved, and villains killed. The reception of this kind of statement tends to be double-edged:

I just wish that was the way it was in season 1...sigh (tinawinna 2013).

I'm wishing this is how the story would've gone. I would've been saved from all the tears. This is very well written, I like it very very much (ErinacchiLove 2012).

Consider the verb choices: wish, wishing would've. Though fix-it fic is appreciated, it is not author-ized at the level of canon. The fix-it genre is selfconscious, the discourse having crossed the threshold of meta-discourse to discuss its own construction with reference to Martin's prohibitions:

:) well, if [Martin] kills his toys, he shouldn't mind me making them happy again (oparu 2011b).

UGH, I KNOW, RIGHT. WE ARE SO MUCH KINDER TO YOUR 'CHILDREN' THAN YOU (kindness_says 2011).

\section{SERIOUSLY. IF YOU TAKE BETTER CARE OF YOUR TOYS, OTHERS WON'T NEED TO RESCUE THEM (oparu 2011b).}

Fans also, paradoxically, source their authority to write dark or disturbing content in the fact that their stories are 'set in George RR Martin's world, which is fucked up. So really, a fluffy story was never gonna happen' (CoolChica8 7 2015b). Reviewers hold fan-authors to account for 'inauthentic' fic, complaining when stories are judged as too 'convenient for the good guys' when 'what makes GOT and ASOIAF so fun, is the unpredictability, 
the logical nature of actions, and the fact that the story is never twisted to make the good guys win'(SSJRyo10oo 2014). The fan-author is taken to task for 'violating that theme with this story' (Ibid.). The metaphor of violation here consolidates the discourse of fanfic-as-kidnapping Martin instigated. Subversive writing may be conservatively read.

Fanfic is also constructed as a corrective to Martin's style:

This was such a joy to read [...] because you take what's good about Martin's world; the loose political set up and court intrigue, the cutthroat characters and wrap it up in your own clean, crisp prose that is so far superior to his, it's unbelievable (corleones 2011).

Your prose is amazing and cleans up Martin's sometimes overly indulgent way with words (hariboo 2011).

This is beyond words. it makes me ardently wish that GRRM was a better writer, because this fic makes me want more of this world, and of these characters, but auuuugh his prose is so shitty! why! why can't you just write all of the books for him so i can immerse myself in this world and not have to abide terrible writing in order to do so! (shecrows 2011).

The author responds:

Thank you so much [...] And I agree so hard re: GRRM! I really do love the world he created with these books, but omg, his prose leaves SO MUCH to be desired. Like, bro, no one wants to read about teats or how she was red and terrible and red or whatever other garbage there is LOL (falseeyelashes 2011a).

The construction of Martin as a much better storyteller and world-builder than he is a prose stylist is fairly common, and fanfic takes that criticism of authority a step further by correcting it. On the other hand, pulling against, we find in the same comment section the more typical fandom compliment of fan-authors as almost as good as author-ity, the compliment through comparison:

I truly believe George Martin could have written this (FANFAVMOMA 2014).

I've asked myself a couple of times if you are George R. R. Martin, even though I know how impossible that is (Phantom white lady of 221b 2013). 
These are clear instances of the legitimation paradox at work: the fan's work is author-ized by similarity to canon. And notably, a long review attempts to accommodate fanfic within the schema of authority Martin sets out:

Often in fanfiction, it seems as if some Authors use FF as a conduit to abuse the characters they hate, or attempt to 'out-dark' Martin, which makes me sympathetic to why Martin hates fanfiction, because only Martin knows the end-game, and why he puts his characters, or his 'children' through what he does.

BUT, every now and again there is an aspiring Author who uses this forum as an opportunity to truly hone their skills, perhaps 'spring-boarding' into their own works and ideas later on.

And this Author I think is one of those who truly re[s]pects the Authors work, keeps it Canon as much as what any of us can speculate, and treats another Authors 'children' with dignity. If Martin saw works like this, as well as a few others he might well be more comfortable with FF (shadow2001, 2013, capitalizations in original).

Here, the legitimation paradox operates to negotiate the author's own prohibition, even as a highly traditional author-function is upheld. Fanfic is constructed as a stage on the way to 'real' authorship, author-ized by 'keep[ing] it Canon' and respecting the Author's progeny.

A variation on this is the legitimation of fanfic through reference to the TV show:

If Benioff \& Weiss can do it... well, I hope I'm not doing it to the extent they do (elinorofealdor 2014).

Since Beinoff and Weiss insist on writing fanfiction during season 4, they might as well have done it right. So, Arya and the Hound meet Brienne and Pod in the Moon Mountains. Let's assume the Hound and Brienne don't draw swords. (Nhaz 2014)

I've read all the books but I usually write the show because I have less guilt that way. GRRM hates fanfic, but... HBO is like paid fanfic so I can rip them off? (oparu 2011b).

This is somewhat different to legitimation in the author's name, because Benioff and Weiss are not quite constructed as proper authors. Recall that they refer to their own text as fanfic, albeit from a position of industrial 
and economic power, in that practice of fanboy-auterism regonized by Scott (2011). The fan takes her licence to 'rip them off' from the impression that Benioff and Weiss are doing something illegitimate in the first place.

Some fics explicitly address the canon construction text as an unstable source of authority. Usually they consolidate it. ladyrostova's Remember Me in Blood opens 'This is a story about a lie' (2012). The lie could be interpreted as a) the love story of Rhaegar and Lyanna; b) the legitimacy of the Targaryen dynasty; c) Jon Snow's heritage; d) the legitimacy of the revolution; and e) all of the above. In any case it was 'a lie that caused a thousand deaths. Sent women wailing to their graves. Bowed men's heads with agony. Tore the world apart. Never died.' The key theme of the story is the problem of history. The narrator reports that Rhaegar 'had lived a selfish life and he had died a selfish death, but they did not say this in the songs' and claims to be a tale 'told truthfully only by those who know the truth,' but given that 'lies are interwoven so tightly in the thread of time that it is impossible to tell where they began and where they end,' the narrator can hardly be trusted. The authority of text itself, or the concept of an authentic and true text, is beginning to be picked apart here. As we will see more explicitly in the next chapter, this is one method by which the legitimation paradox - the legitimation of 'derivative' text by appeal to an authentic model — may begin to be deconstructed.

Remember Me is well received, with 40 reviews including a notable 23 on $\mathrm{LJ}$, though one dissenter complains that the author 'betrayed the character of Rhaegar and at the end made him a monster' (Anon. 10), arguing for a fixed text in which canon is stable and interpretable. Articioc's BRIEF HISTORYOF THE VVARR of the FIVE KINGS in VVESTRROS (sic) is a treatise supposedly written by the unreliable and sneaky Grand Maester Pycelle. It is written in an approximation of late Middle or Elizabethan English, and recounts canonical events in a light that casts Pycelle's benefactors as heroes and their enemies as villains, except for the following passage:

My sweet Lord Joffrey, first of his name, that he Resolved to make Justice and ordered Lord Eddard to be put to death; and had the Executioner missed and cut good his head instead, yea good Joffreys head, he would have deserved one thousand times such an end, or even a worse one.(1) (1)=Pycelle is old and sometimes lets a bit of truth filter. Maybe he's dead before finish this work [sic] and so he had not revised it (Articioc 2014).

The fanfic author, then, takes on the role of a reliable editor in the place of unreliable history. Strikingly, this story is blanked, receiving o reviews on Ff.net, the only place it is posted. Perhaps such explicit statements on 
the unreliability of history are pushing the boundaries of the discourse formation, or perhaps the style of humour is simply not appreciated, and the statements' rejection follows incidentally.

By contrast, falseeyelashes's The Joinery constructs the texts of history as fixed and inevitable, at least in their outcomes. It opens with a quotation from the source text:

When Ned Stark entered the hall, Jaime had called to him. "Ah, so it is to be King Robert Baratheon then?"

(GEORGE R. R. MARTIN)

But continues:

This story opens with a different start though you shall find it ends the same - the same song, a different singer.

(The start of a story is easy to change. It is easy to alter it, warp it, bend the first to your will. It is the end you cannot change. The ends we meet are decided by the gods. Our ends are their ends, and while the path may vary, the end shall not (falseeyelashes 2011b).

So the story plays out with some variations that result in pre-set endings. The Joinery receives 111 comments, all of which are positive. Thus fandom still has some investment in constructing the authority of the set text, and with it, the outcomes of history.

Yet, there was also a set of fics criticizing the authority of the canonical text through parody and humour. Parody is inherently double faced, both mockery and homage, consolidation and deconstruction of the author-ized text (cf. Booth 2015, p. 20). Drawing on Dan Harries' study of parody in cinema, Booth argues that parody functions by means of a 'double referent', pointing to both itself as emulation and the original text, which it simultaneously consolidates and ridicules (78). 10ooth Ghost's Game of Thrones Predictions juxtaposes the high fantasy setting with contemporary slang and casual diction to create humour and lower the tone:

Daenerys decides that 1 . Dragons do not make good house pets because they do things like scorch innocent people and 2. Keeping them cooped up will make them weak and unable to fight. So, she attacks King's Landing RIGHT NOW!

Then she arrives at King's Landing and is all, "WHAT UP, SUCKERS, I'VE GOT DRAGONS,” and scorches everyone. 
So then she is queen of...everything, I guess.

"Herp de derp, you can fly," says the three-eyed raven old guy.

"Cool beans," says Bran, so he flies alongside the dragon (2014).

Reducing Martin's canonical sage to a 'three-eyed raven old guy' and the workings of magic to a nonsense rhyme debase the authority of the text. Generally, parody does not make a huge impact on the formation: Predictions receives five reviews. Whenyoudonthavealife's Love with a Side of Pasta (2014) and Harmonic Friction's Because the King Dies as He Pleases (2014), which use the same technique of juxtaposing high and low tone, receive 12 and 11 respectively.

But we should note here that whilst parody mocks the authority of the source, it also turns a humorous mirror on the authority of fandom to rewrite any text. Kal-El Fornia's comment 'let's hope George R. R. doesn't come across this to steal your idea' (2015) has the effect of humorous irony when applied to a deliberately absurd premise. Parody is inherently self-mocking as well as mocking of its source. Awesomepigman's Fandom Conquerors asks:

Who rule the world? Tumblrlerlers [sic]. That's right when the world is overrun by a maleficent sorceress two heroes step up to rule all the realms (fandoms) for the sorceress. Conquering realms such as the realm of Supernatural, Game of thrones, Middle Earth, and many more (2014).

In this story, two fangirls are sucked into a mystical realm via

a compilation of adorable pigs in cat suit photos [that] showed up on their [Tumblr] dashboards. The sorceress knew that pigs in cat suit photos were the easiest way to both of their hearts. As they each hit 'reblog' they were pulled through their computers into the sorceress' castle (Ibid.).

The sorceress has enlisted the fangirls to rule over various 'realms', including GoT. Once the fans realize she means a 'fandom', the sorceress confirms: 'yes, fandumb. I prefer to not use such peasant terms,' self-mocking the spaces of fan activity via the comic homophony between (fan)-'dom'(ains) and 'dumb'. The author also disavows: 'I do not own any of the fandoms, that's just too much power' (Awesomepigman 2014).

Rena_Sally_Giles's Crushing the Patriarchy is sharper, its satire less affectionate and more concisely directed at fandom, or at least its more political dimensions. The summary reads: 
My OC decides to liberate the ASOIAF/GoT universe from operassion, which is cussed bi their patrickarial feudall system. Can she do it or will da patricky stop her? Reed and revoirw plz!!111 No flamming, you misogymnast, rassist, ablelist, elitits, homophonic, transphonic, overprivilegged cis-cum!!!!111 Cheque your privilog!111!!11 (2014).

The humour relies largely on puns through misspelling and malapropisms, as the author/narrator greets us 'Hullo peephole of the internetz!' A 'peephole' has connotations of something small and sordid, in contrast to the self-conception of socially motivated online activity. This story's original character explicitly sets out to change the power structure of Westeros, and end

da operasession of da kangs, for kings were nothin but strait, white, cis, mail, ableist, whalethy, thin bustards ho exploided the smallfork fur his own selfist game. Thy lived like fat cats while everyone else had nothing, it wuss a socialpathic, capitolits sociey designated bi the partiacky to operass da peepole of color, womyn, da handicrapped, da LGBT, da otterkin, da punsexal, da asexul, da zoophilics, da poor, da ugly and fate peephole (Ibid.).

Fandom's intervention in the text and world of Westeros, then, is constructed as absurd and self-important, rather than effectual in any real sense-including, by inference, this fic itself. Reception of this parody is a 50/50 split: out of 10 comments on A03, five consolidate the mockery: 'excellent satirical chronicle of Tumblr S[ocial]J[ustice]W[arriors]' (Raskolnikova 2014); and five undermine it: 'So is this supposed to be your oh-so-clever attempt to make fun of feminists, or at least your warped, misguided idea about what being a feminist means?' (Shiera 2014). We could argue, then, that whilst the context and production of fanfic contributes to the instability of the text and deconstruction of the author figure, it's re-presentation of these discursive formations is much more ambiguous. The fic that constructs text as stable and inevitable, at least in its endings, is received much better than those which deconstruct it totally. Parody of the original text rarely makes much impact, yet parody of fandom's interventions meets a suspect reception. Martin's author-function is used both to legitimate fanfic and correct its perceived inadequacies; whilst Benioff and Weiss's liberties with their original text are used to justify fans doing the same, even as they are lightly denigrated for it. For these reasons, it seems too hasty to remove the construct of a canonical text from the 
sphere of authority, though it has been pushed to the edge and the strength of belief and acceptance reduced.

So, whilst fandom has changed this discursive formation, the changes are perhaps less dramatic than we might expect given a source text set in a feudal system and presided over by a traditionalist author figure. Women are shown to have entered the sphere of authority based on traditional class legitimacy, and their style of rule has changed it, separating patriarchy and traditional authority to a degree not found in the source. Yet, the power of the commons is if anything diminished, in favour of a strong form of charismatic authority. The authority of the text, and the traditional author, is obviously deconstructed via fanfic as a form, but we have found the content of the statements to be highly ambiguous, wary of the TV show for deviating from the 'authentic' text and not particularly receptive to parody. There is little variation in the sense of AU. By keeping focus on the nobility, and concern to keep characters 'canon', GoT fic has not gone as far as Sherlock in the generation of new interpretative characters, or transformation of the original discourse that shows up its assumptions and absences. In Booth's (2015) terms, the balance seems tipped more towards nostalgia for the original text than an impulse to novelty. Several factors may account for this: again, GoT fandom is simply smaller, and a smaller sample will naturally produce less variation. Moreover, GoT's fragmented construction of authority may be less politically objectionable to fandom than Sherlock's naturalization of the dominance of White upper-middle class men. External forces, in the shape of socio-political awareness, may exert a more transformative pressure on Sherlock fic, particularly with regard to gender and the male body. It is worth noting that gender is the area in which GoT fic is most transformative. Martin's strong and current author function may also be a factor in the relatively 'faithful' or canonical usages of $G o T$, as opposed to the permissive, fanboy-auteur stances of Moffatt and Gattis. Now, in our final research chapter, we turn to address the construction of authorship explicitly in the meta-textual Supernatural, a text which contains its own author figure and constructs its own fans. We will then be in a position to overview our findings, and compare the results. 



\section{5. 'I'm a God': The Author and the Writing Fan in Supernatural}

\section{Introduction}

As we have observed, cult television makes frequent use of symbolic author figures. Though TV shows are, in reality, a product of many people's labour and dependent on a multi-level network of financial and industrial support, individuals in the horror/drama/sci-fi genre are often constructed as the primary creative force behind a program (Mittell 2012). Inherited from twentieth-century film theory, and the singular model of Romantic authorship before that, these figures help imbue the text with an aura of value (Gray 2010, pp. 99-102) and a symbolic 'guarantee of value' (Newman and Levine 2012, p. 1020). This is itself a rather paradoxical strategy of legitimation, depending on an appeal to already-legitimate cultural texts, rather than arguing for the legitimation of television as a distinct form (cf. Newman and Levine, p. 198). Whilst the previous texts discussed are adaptations, with the author-function split more obviously between writers and showrunners (c.f Newman and Levine, p. 187), the CW's Supernatural (2005-) has a singular author figure in the form of Eric Kripke, who conceived of the text, plotted the initial five-season myth arc, and served as chief writer and showrunner until the end of that fifth season.

Supernatural is a fantasy/horror/drama with comic elements. The early seasons were built on a fairly simple formula, in which the brothers Sam and Dean Winchester followed more-or-less reluctantly in their father's footsteps, hunting ghosts, monsters, demons and other supernatural beings. From the fourth season onwards the show became increasingly complex and meta-textual, involving angels, demons, heaven, hell and questioning the existence of God or an ordered universe. It was here that Kripke's textual proxy was introduced, in the form of is the Prophet Chuck, alias Carver Edlund, a hack writer who receives divine visions of the other characters and writes them into a series of pulp novels also called Supernatural. Chuck's books develop a cult following, including slash-writing fangirl Becky Rosen (Emily Perkins). Her first appearance in 5x01, 'Sympathy for the Devil', is a remarkable instance of a televisual writer writing fanfiction about his show into the show itself. Fans responded with a range of approval and approbation to this destruction of the fourth wall (Felschow 2010, 6.3; Schmidt 2010, 2.8-9), and Chuck, Becky and other canonical fan-representations have 
been re-appropriated into fanfic. Further, Supernatural fandom now exists in a post-Author-God era: at the end of his projected five Seasons, Kripke stepped down. In a gendered distinction, his successor Sera Gamble was never imbued with an author-function, received by fans as chief fangirl at best and a talentless fumbler at worst (cf. Zubernis and Larsen 2012, p. 216). Newman and Levine argue that 'in order to be considered a televisual auteur, it is usually necessary for the showrunner to also be the show's original creator' (2012, p. 983). This is certainly the case with Supernatural, and when we consider the relatively prominent influence of George Martin over GoT fandom, it is clear that the construction of authorship at stake depends on the concept of an originator or founder, even when that personality may no longer exert significant influence over the text.

Kripke consistently presents and is presented as a fanboy-auteur. As Scott argues,

We could frame the fanboy auteur as an 'undead author,' or an author who understands that metaphorically 'killing himself' is an ideal way to engender fannish solidarity, and [to] 'fashion himself as "just one of the fans", when he is decidedly privileged in the relationship' (Scott 2011, p. 168, quoting Gray 2010, pp. 113; 112).

These sorts of statements are typical from Kripke and other SPN writers, and I want to clarify here that this chapter addresses discursively constructed presentations of authorship, rather than falling into Said's trap of shifting to address real-world practices or claiming insight into the actual attitudes of the showrunners. So, paratextually, Kripke discursively presents his love for and loyalty to fandom (Ausiello 2007), and claims to 'love' and 'welcome' fan production (Zubernis and Larsen 2012, p. 214). He was written in as a character to a meta-textual Season 6 episode, wherein his sole plot function was to die, a comic slow-motion sequence set to a mock-Western soundtrack. Kripke declared himself delighted with the scene, thanking director Charles Beeson 'for letting [him] die in such a manly way! With none of the urinating or begging or crying' (Bekakos 2011). The definite article self-effacingly delineates the verbs 'urinating', 'begging' and 'crying' as actions that Kripke would expect to take place at his own death. For the construction of 'Eric Kripke' is split and maintained between his paratextual self-presentation and his proxies in the text. The death is performed by an actor, not by himself, thus simultaneously maintaining an extra-textual presence as the real author and performing abnegation for his fans. The practice of fanboy-auterism is thus refined to an art. 
Zubernis and Larsen (2012) have made an extended study of boundarycrossing in relation to Supernatural and its fandom. But their interviewdependent work has a different orientation to mine: they are concerned with the attitudes and responses of fans and producers, not the establishment of discursive formations and their alteration by writing. Their project is more a socio-psychological study of fan cultures, and thus, where they do attend to fanfic (pp. 83-115), it is from the perspective of trauma and healing that Bacon-Smith inaugurated (1992). Nonetheless, they present much useful data on Kripke's paratextual presentation of himself as showrunner, some of which will be utilized in this chapter.

Here, I seek the statements constructing the discursive formation 'The Author and the Writing Fan'. Originally, I had intended to study 'The Author' alone, but it quickly became clear that the canonical dyad was inextricable, the two constructed in terms of each other. 'Real' authorship is largely defined by its negative. Chuck and Becky are introduced in parallel circumstances, their writing compared and contrasted (Cherry 2011, p. 212), and though the canonical author remains in control and privileged, the characters become romantically involved for some time. As Zubernis and Larsen read it, "that Kripke/Chuck is literally in bed with his fans can be seen as indicative of the fact that we - the creator, the actors and the fans- are all in this together' (p. 170). This rather overlooks the inequality of the power relationship: both between the characters, and between Kripke and fandom. Moreover, the dyad is problematically broken during Season 7 , where Becky has been dumped by Chuck and crosses new lines of pathological behaviour. However, fanfic also intercedes with statements that separate the discourse formation 'fan' from 'author', reconstructing them in ways that shift the balance of power.

At the conclusion of Season 5, the series suggests that Chuck may indeed be God, a literal manifestation of the originating deity Barthes recognized as standing behind the authority of the Author (cf. Busse 2010; Scott 2011, pp. 296-97). If Chuck is not God, then God is definitively absent or non-existent in Supernatural's apocalyptic storyline. Garcia argued that the Author-God/fan relationship was further complicated by Chuck's direct address to the audience and discussion of writing the series before he vanishes (5x22, 'Swan Song'), leaving the series and the fans to carry on without, if not his presence, at least his leadership (2011, pp. 158-159). However, Kripke remains an executive producer (Ausiello 2010), and notably, wrote the critical Season 6 finale himself, rather than leaving it to Sera Gamble. Gamble's proxy in the text is fannish publisher Sera Siege, who in a problematically gendered distinction is ultimately a gatekeeper rather than 
a 'real' author - the characters must prove their fan credentials to her before she directs them to him (Scott 2011, p. 304). Then, as we will explore, Chuck makes one final appearance at the coda of 10x05, 'Fan Fiction', which enacts the legitimation of fan activity by the Author-God in almost literal terms.

\section{The Construction of Authorship and Fandom in Supernatural}

In the text of Supernatural, I found that statements constructed the author as a fanboy-auteur quite specifically: as a geek and a fanboy on one hand, and a visionary or God on the other. The fan who writes, meanwhile, was constructed variously as excessive, excitable and feminine: characteristics that date back to some of Jenson's (1992) descriptors of fan pathologization. On the other hand, fan activity is permitted, even valorized to an extent by the Author-God, and in a sense they are shown as parallels. Chuck and Becky both speak their first lines sitting at their computers, writing about Sam and Dean and reading their work aloud. But the governing statements of the dyad define a consistent power relation:

Fig. 11: The construction of authorship (by its negative) in Supernatural.

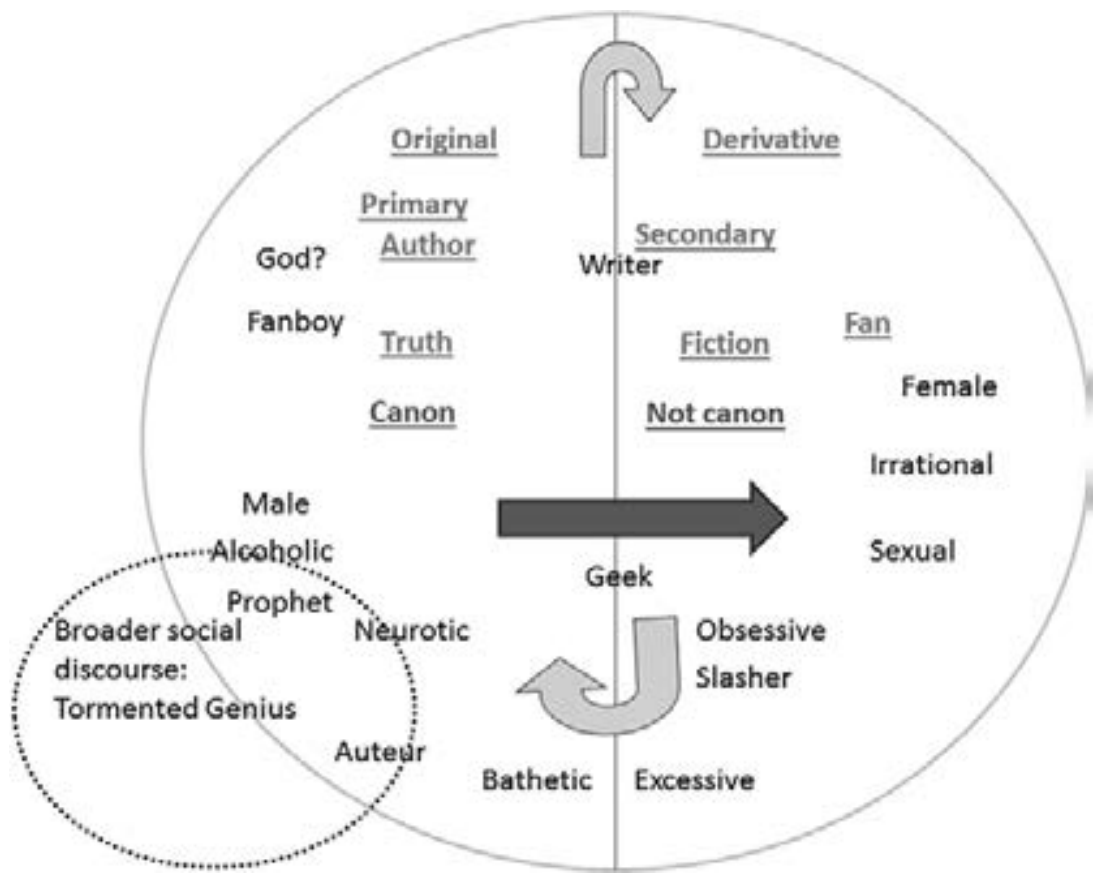


1) That the Author-God's text is canonical truth, and

2) The fan's text, though permissible, is secondary, derivative, false.

This canonical discursive formation 'Author and Fan' is more coherently and solidly iterated in the text than either masculinity or authority, so it is not particularly helpful to divide it into branches for discussion. It can be delineated thus:

Governing statements are underlined. The straight arrow (one-way) represents legitimation, which flows only from the author to the fan. The curved arrows represent love and need, which are constructed as reciprocal, though the flow from the fan to the author is greater.

Our introduction to Chuck Shurley comes in the midst of a vision. At the opening of episode $4 \times 18$, 'The Monster at the End of this Book', he sleeps restlessly in his bathrobe and boxer shorts, despite clear sounds of daytime outside. His house is in disarray. Zubernis and Larsen write that 'the tongue in cheek portrayal of Chuck here is one of the things that saves the episode from slipping into a mean-spirited parody of fans' (p. 16o). I agree, though it must be acknowledged that statements which construct the author as nervous, distracted, disorganized and at least semi-alcoholic hook into a broader discourse of the author as tormented genius. Though Chuck's publisher describing him as 'very private...like Salinger' (4X18, 'The Monster at the End of this Book') is obviously played for laughs, humour does not negate this hook. Where Chuck is constructed as bathetic, fans were initially constructed as excessive. Becky is primarily constructed through excess: excess love, excess commitment, and excess deviant sexuality. These statements hook into of the oldest and most conservative constructions of pathological fandom (Jenson 1992; Jenkins 1992). Johnson names this practices 'fan-tagonism': a form of discipline by discursive containment, in which the text displays the fan to herself in controlling forms (2007). Fan-tagonism supposedly de-legitimates certain kinds of fandom - notably the excessive and feminine - by exposing, exaggerating and shaming (pp. 295-299), but the construction of Becky particularly is complex, somewhere between celebration and censure, and moreover, probably renders the production of Supernatural fic absolutely legal until further notice (McCardle 2003, pp. 449-250). Episode 10xo5, 'Fan Fiction', consolidated this statement. Here, in Supernatural's $2^{\text {th }}$ episode, a girls' school is putting on a musical based on the canon. Whilst writer/director Marie shares some properties with Becky: she is also a slightly obsessive fan, much invested in the homoerotic 'subtext', as she puts it, she is also a capable creator and showrunner who turns out to be a valuable hunting ally. Though we will go on to discuss 
this episode, at the time of this research, fandom had not yet had time to re-appropriate Marie into its discourse. What it does with her will make a fascinating topic for future research into the legitimation paradox, but each discursive study must address a time period, after all, and fandom has made highly transformative use of Becky that deserves focus here. Indeed, it might be argued that the reconstruction of Becky, in addition to other fan responses to her, influenced the more progressive portrayal of fandom in the $200^{\text {th }}$ episode. This would be an example of discursive transformation at the level of statement altering the broader media archive.

Re-appropriations of Becky in fic alter the construction with new statements. Discourse incites as well as represses, and thus, as noted, I prefer the term textual provocation. The construction of Becky in Supernatural is quite clearly double edged, provocative in the sense of baiting, and provocative of the production of more text, which then alters the formation. The danger of fans is first established in the text when Sam and Dean confront Chuck: taking them for role-players, he claims to appreciate their enthusiasm, but advises, 'for your own good, I strongly suggest you get a life' (4x18). 'Get a life' is of course the original insult to fandom, provocation in the first sense, made famous by William Shatner's Saturday Night Live sketch (Jenkins 1995, p. 1). When his protagonists forcefully enter his house, Chuck wails, 'Is this some kind of Misery thing? Ah, it is, isn't it? It's a Misery thing!', referencing the novel many King fans took as an insult (Palko 2009, pp. 119, 4n).

In 5 x01, 'Sympathy for the Devil', Chuck Shurley contacts Becky Rosen via Skype, requesting that she 'get a message to Sam and Dean.' The author is thus constructed as needing the fan (cf. Zubernis and Larsen p. 164). Becky responds with initial scepticism giving way to hyperventilating excitement, before finding Sam and Dean and sexually harassing Sam. She later organizes the Supernatural convention (5xog, 'The Real Ghostbusters'), where she and Chuck fall in love with each other, visually sealing the dyad as they stand together at the end. However, this positive if unbalanced fan/author binary was separated by new statements in $7 \times 08$, 'Season Seven, Time for a Wedding!', still provocative in the first sense. Here, Becky admits that Chuck dumped her, probably because he was 'intimidated by [her] vibrant sexuality.' Fan excess can overstep boundaries and harm relationships. Indeed, that is rather the theme of the episode, wherein Becky briefly kidnaps Sam with the aid of a love potion before realizing the error of her ways and assisting the Winchesters in a hunt. Most serious objections to the construction of Becky concern the kidnapping, with fans finding her funny and charming up to a point but considering that episode to cross a line of pathologization. 'Becky was awesome and now she's just ruined,' 
objects rossettaslair (2011), whilst blogger Lady Geek Girl also states that it 'ruined' the character for her (2012). Hells_half_acre argues that 'Becky worked as an inside-joke about the fans before, because she was confident, crazy, but, most importantly, completely unashamed,' but this episode 'undermine[d] the character' (2012). Separated from Chuck, and in the meta-textual absence of Eric Kripke, Becky devolves. Booth would call her a 'hyperfan': a construction of fandom that, drawing on Baudrillard's conception of hyperreality, makes no real reference to objectively-existing fans but serves to discipline contemporary fandom into [economically] usable fan audiences (2015, p. 82JH).

Fig. 12: Becky (Emily Perkins) and Chuck (Rob Benedict). Copyright and source: CW.

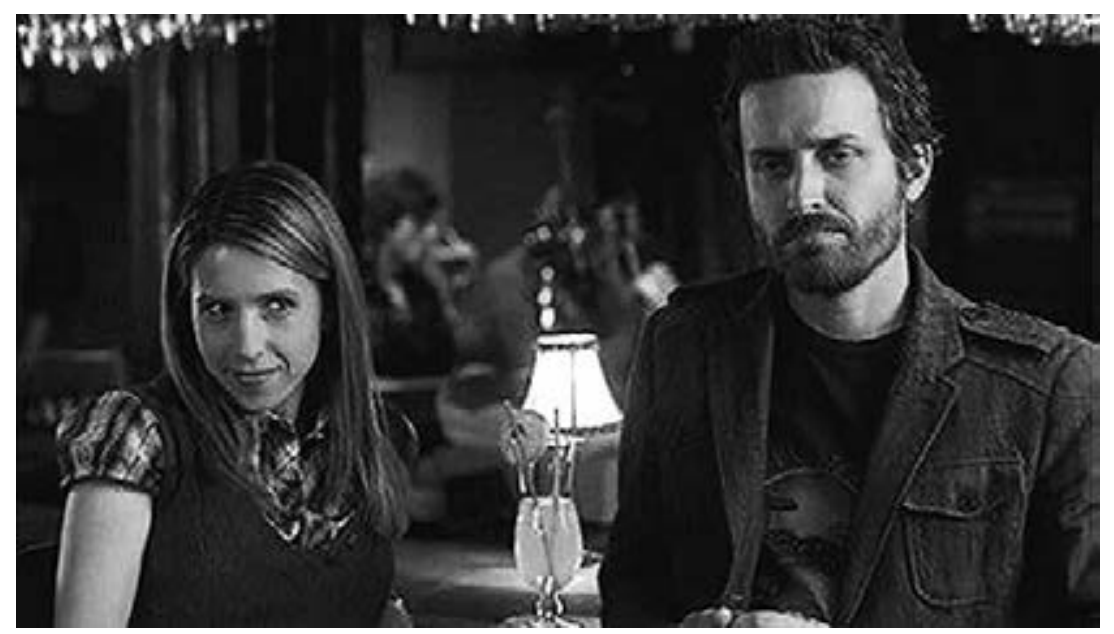

Once convinced that the narrative of his books is real, Chuck concludes, 'Well, there's only one explanation. Obviously I'm a god' (4x18). Again this is played for humour: Chuck is still in his bathrobe, and has just been thoroughly petrified by his imposing protagonists. Sam returns, 'You're not a god,' but Chuck insists: 'How else do you explain it? I write things and then they come to life. Yeah, no, I'm definitely a god. A cruel, cruel, capricious god.'

Later, it is established that Chuck is a prophet, tasked with writing 'The Winchester Gospels'. Even granted Chuck's less-than-impressive character, this could be perceived as an audacious meta-textual positioning on Kripke's part, as a 'conduit of the inspired word' (Castiel, 4x18). Yet, criticism of this is pre-empted. Chuck admits that though he had a vision revealing this role, 
he did not write this into the books because it was too preposterous. Not to mention arrogant. I mean, writing yourself into the story is one thing, but as a prophet? That's like M. Night-level douchiness.' The Chuck/Kripke division is thin here, the implication being that though Kripke is loath to be as arrogant as director M. Night Shyalaman, with his penchant for 'auteurist cameo' (Hills 2010b, p. 110), the trope must in this case be excused, for he is, despite himself, a visionary. He is not constructed here as an originating author, but 'a passive subject who brings to the role whatever the Creator dictates' (Garcia 2011, p. 156). These statements do not necessarily reduce the cultural capital associated with the role: canonical authors from Homer to Milton depicted themselves as the conduit of a muse (hence 'prophet' overlaps with the broader discourse in figure 11). It does, however, inflect the meaning of a diner logo displayed earlier in the episode, which reads, 'Kripke's Hollow'. Cleverly upholding his textual proxy in his place, the author performatively kills himself, empties himself out, whilst gesturing to his text as truth.

Gestures such as this, culminating in his staged 'death' in Season 6, construct Kripke as creatively open-handed. Paratextually, he performs a great deal of fannish allegiance and affection. He claims to love our fans to death', 'love how passionate they are' (Ausiello 2007); 'like Supernatural. tv' and 'pop around the various LiveJournal stuff' (Zubernis and Larsen, p. 178). He 'love(s)' and 'welcome(s)' fanfiction, including slash (p, 214). He stresses his receptivity to fan opinion, and willingness to moderate the text in anything 'apart from the main storyline' (p. 180). There is then, a limit - he retains ultimate control over the story, but claims subplots are 'completely negotiable' (p. 180). Perhaps Kripke's performance of allembracing permissiveness is enabled through the use of his other, textual half to delegitimize - though not ban - unruly practice. Not only does Chuck fear that his fans are insane, but in a deleted scene to 5 xog, available as a DVD extra, Chuck answers implied questions from his fandom. Shaking his head, he states, 'Uhhh no...I can't read your LiveJournal short story. No, I get it. Sam and Dean really love each other. I just don't need to see that.' Hills calls this kind of paratext 'fanagement'. Directed not at the casual viewer but the active fan, 'expectations and dissatisfactions are problematically engaged with, and disciplined and contained, at the level of niche paratexts rather than in the TV show' (2012b, p. 409). Again, I prefer the term textual provocation. The paratext is provocative in the sense of deliberately aggravating, because it suggests there is something wrong with a popular fan practice. On the other hand, by acknowledgement and tacit affirmation that Chuck/Kripke has no intention of attempting to ban incest fic, it provokes further fan production. 
This leads us to the first governing statement: that the (real) author's text is canonical truth. Chuck is not a good writer. His first extended scene shows him reading aloud as he types at his computer, and the text is over-written and melodramatic. Tautology is used for comic effect. But as he types, 'with determination, Dean pushed the doorbell with forceful...determination' (4X18), before throwing his manuscript down in disgust, the camera cuts to the character Dean doing just that. According to Garcia, this creates 'a disturbing impression of a work in progress as it reveals its structures and mechanisms' (p. 156). I disagree. The objective camera angle is utilized for the Chuck/Winchesters/Chuck sequence, which as Dancyger notes, 'provide(s) information about what is going on without choosing a distinct point of view' (2006, p. 90). Chuck may be a bad writer, but what he writes, during his time in the diegesis, is constructed as objectively true.

More statements consolidate the construction in 5x22, 'Swan Song'. As conceived by Kripke, this would have been the final episode of the show, and framed Supernatural as a classical five-act tragedy ending in the death and/or devastation of its protagonists. This kind of conclusion hooks into the cultural capital of tragic drama rather as Lopes recognized comic books 'emulat[ing] the conventions of literary works' in a bid for cultural capital (2007, p. 132; see also McCabe and Akass 2009, pp. 89-90). Some fans consider this the real, author-ized end of the series, with everything that happens afterwards a kind of 'visual fanfic' (kongjingying 2012). 'Swan Song' is narrated by Chuck. At the opening, he provides the following voice-over:

On April 21, 1967, the 100 millionth GM vehicle rolled off the line at the plant in Janesville - a blue two-door Caprice.

There was a big ceremony, speeches. The lieutenant governor even showed up. Three days later, another car rolled off that same line. No one gave two craps about her. But they should have, because this 1967 Chevrolet Impala would turn out to be the most important car-no, the most important object-in pretty much the whole universe.

He goes on to describe the first owner of the car, which has been iconic throughout the series, until it comes to the Winchester family, adding 'I guess that's where this story begins. And here's where it ends' (5x22).

The camera cuts between Chuck, typing at his computer, and images of 196os-quality film affirming the veracity of his statements. They are again objective shots, and the flashbacks are muted, Chuck's voice and the clicking of his keyboard carrying over them in a split-edit that constructs his writing as an accurate record of history. Chuck displays emotional 
knowledge and insight into the characters that was lacking in his earlier comic characterization, describing details of Sam and Dean's daily existence that the viewer is privy to for the first time. His narration also concludes the episode, as he ruminates over a series of emotionally-charged flashbacks that whilst it's 'hard to say' what 'it all adds up to,' he believes his protagonists 'did alright':

Up against good, evil, angels, devils, destiny, and God himself, they made their own choice. They chose family. And, well... isn't that kinda the whole point? (5×22).

The characters are intermittently muted, and the extra-diegetic music accords with the tone of Chuck's statements, constructing the Winchesters and friends for the first time as characters in his narrative rather than independent individuals whose lives we witness through suspension of disbelief. An authorized interpretation is thus placed, within the text, on the narrative, and the boundary between Chuck and Kripke is thin, especially as he laments the difficulty of endings and impossibility of pleasing all the fans. It would be just as logical to conclude that the moral is, in the Greek tradition, that we should struggle to do the right thing simply because it is right, though we will suffer and be punished anyway. Chuck types 'the end' under his manuscript, and admits, 'No doubt - endings are hard. But then again... nothing ever really ends, does it?' and, with a wink to the camera, disappears. On one level, this could be read as the Author-God writing himself out of the text, to continue without him; but it also imbues what Chuck/Kripke has written with the aura of magic and omnipotence, a statement which is never contradicted in Supernatural itself. Chuck's actor Rob Benedict has stated para-textually that cast and crew referred to his character as 'God', but the tone was joking and ambiguous (Benedict 2011). It seems that Chuck's exact status is deliberately and provocatively left open, though deification is a strong possibility.

Meanwhile, the fan's text, though permissible, is constructed as secondary and derivative. As Cherry notes, our introduction to Becky parallels our earlier introduction to Chuck (2011, p. 212): she is alone at her computer, writing about Sam and Dean, reading aloud and correcting herself as she goes. She, however, is writing bad slash: 'And then Sam touched-no-caressed Dean's clavicle. 'This is wrong,' said Dean. 'Then I don't want to be right,' replied Sam, in a husky voice' (5x01). Becky's fic employs the conventions of small-r romance, which SPN and its fans 
often denigrate and Other with implicit or explicit reference to Twilight (cf. Bode 2010; Pinkowitz 2011). Though this is Authorized in the sense that Kripke literally wrote it, there is no visual parallel to confirm the truth of her words. Indeed, Sam and Dean have already discovered their slash fans (4x18), and declared their texts 'sick' (on grounds of incest, not homosexuality).

Further fan production is constructed in 10x05. When Sam and Dean investigate a disappearance at a girls' school, Dean is duly horrified to find rehearsals for the musical Supernatural well underway. 'There's no singing in Supernatural,' he informs the director, to which her stage manager friend replies, 'Well, this is Marie's interpretation...' of which Dean is scornful. By the end of the episode, however, he has changed his tune. When he informs Marie of the canonical events that have taken place since the departure of Eric Kripke and disappearance of Chuck:

Dean: Alright, Shakespeare! You know that I can actually tell you what really happened with the-the Sam and Dean? A friend of mine hooked me up with the, uh, unpublished unpublished books. So, Sam came back from Hell. But without a soul. Then, Cas' brought in a bunch of leviathans from Purgatory. They lost Bobby. And then, Cas' and Dean got stuck in Purgatory, Sam hit a dog. They met a prophet named Kevin, they lost him too. Then Sam endured a series of trials, in an attempt to close the gates of Hell. Which nearly cost him his life. Then Dean? Dean became a demon. Knight of Hell, actually (10x05).

She bursts out laughing, and responds:

Marie : That is some of the worst fan fiction that I've ever heard! I mean, seriously, I don't know where your friend found this garbage! I am not saying that ours is masterpiece, or anything, but geez! (10x05).

Marie's 'version' apparently includes robots, tentacles, and Dean/Castiel slash, tropes that commonly appear in fic and evidence of the showrunners' continued attention to the nuances of fandom. Contrary to Booth's argument (2015, pp. 75-76), then, it cannot be said that Marie represents a good, rational model of fandom that serves to emphasize the opposing bad fandom of Becky, but rather that they exist on a continuum, and the construction of the writing fangirl has moderated since the fifth season. Bear in mind, though, that the events of $10 x 05$ took place on screen unsanctioned by the authority of the ultimate author. The last text Marie has access to is 
'Swan Song'. These statements go some way towards levelling the different 'versions' of what happens after Kripke, as Dean ultimately concedes: 'I have my version, and you have yours,' and tells her to keep writing, with as much homosexual/incestuous subtext as she pleases. Indeed, it is her belief in her interpretation, regardless of what Dean thinks, that summons the monster of the week so it can be killed. Marie's interpretation is ratified for now, in the post-author era, but does not impact the authority and status of the initial five season arc. Then finally, in a surprise twist and literal fulfilment of the legitimation paradox, Chuck is revealed in the episode coda. As Marie and her friend observe the emptying theatre after closing night, they notice a mysterious figure sat alone at the back.

Maeve: The ticket you left for the publisher? Someone claimed it! [...] Go, fangirl!

(Marie runs up the steps)

Marie: [breathless with excitement, to a figure off camera] Hum... Hi! Thank you... so much for coming! Uh... I know the second act is a little bit wanky, and the first act has some issues, but.... What did you think? (The camera reveals Chuck.) Chuck: [smiling kindly] Not bad.

(Fade out)

Marie is 'fangirl', once more: overwhelmed, eager and needing the approval of the Author God. The camera lingers on Chuck's face as the episode closes, his beneficent smile granting affection and permission to the creative productions of the his fangirls.

I will argue that fandom reconstructs the discursive formations of fandom and authorship separately, as follows:

Notice that the canonical dyad of author and fan is gone, and with it, the primary/secondary binary. The author's relationship with truth is brought into question, for he is constructed as a participant and collaborator rather than originating God. On the other hand, many of the statements constructing the fan pathologically in canon have not been removed, but simply been placed onto the other side of a binary: that of the good fan/bad fan (cf. Stanfill 2013; Booth 2015, pp. 79-100). Arguably, rather than redeeming the figure of the fangirl, this divide has now simply been canonized in the division between Becky and Marie. This divide, however, which in itself is fragmented and uneven, each half mixing into the other rather than statements that specifically compromise other statements. 
Fig. 13: Fandom's reconstruction of authorship.

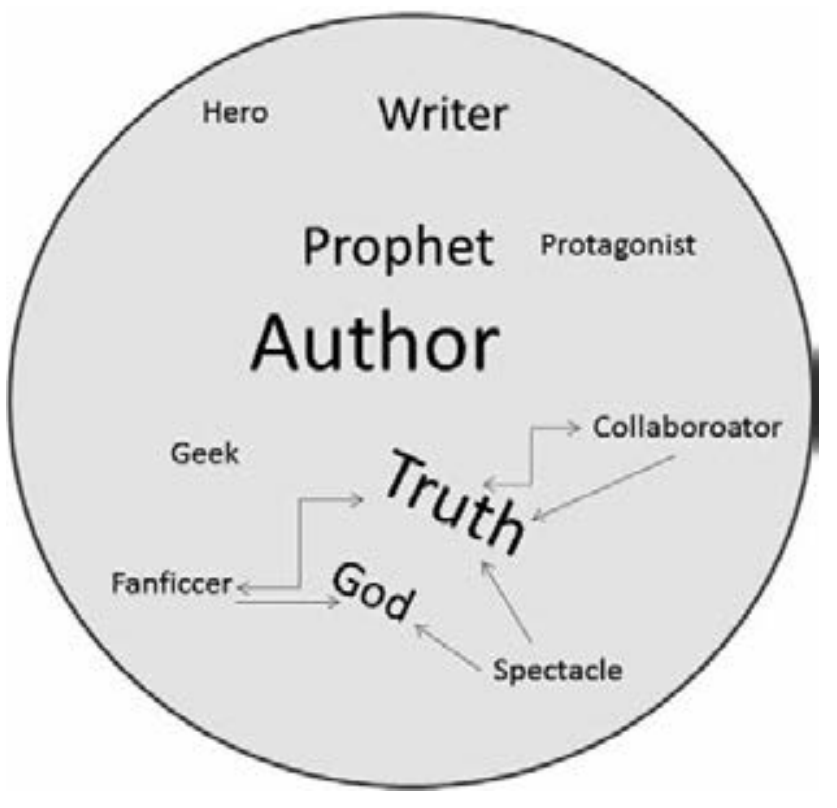

Fig. 14: Fandom's reconstruction of the writing fan.

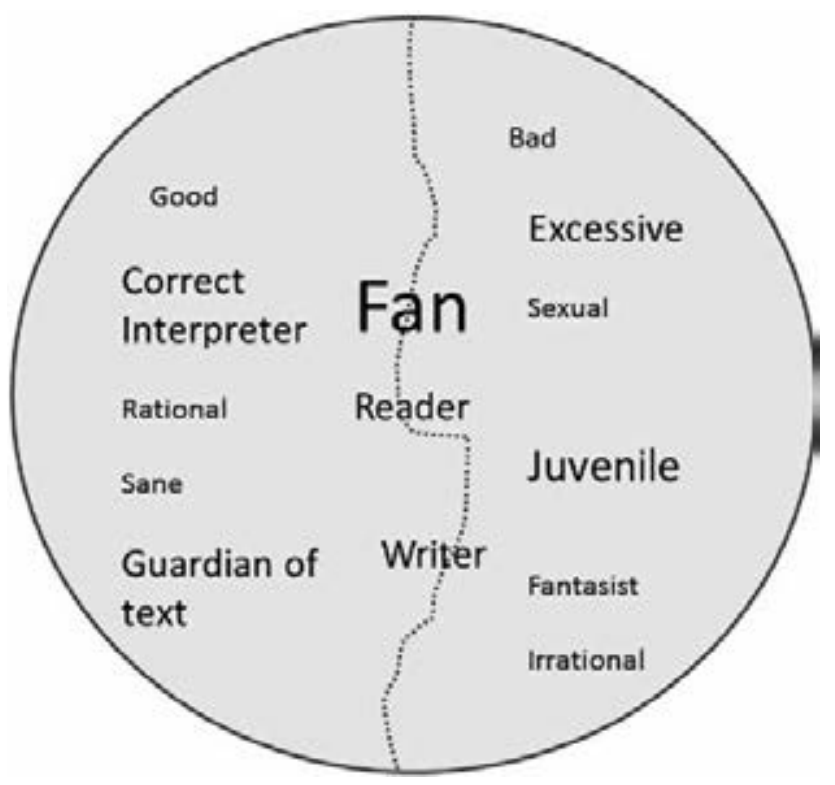




\section{Fandom's Reconstruction of Authorship and Fandom}

Pursuing the flow chart given in the methodology (p. 41), I found 704 works and 32,025 reviews to code. At the time of writing, fandom has not made any significant re-uptake and transformation of Marie, so our focus with regard to the ongoing interchange between fandom and canon is the transformation of Becky and Chuck. Once again, I moved outwards from particular statements to find patterns and regularities, then finally the conditions of their possibility (Foucault 1981, p. 67). As 87 of these fics were on Dreamwidth (DW), it receives its own column in the table. LiveJournal was the most popular hosting site here, probably due to the fact that $S P N$ is the oldest fandom studied and the height of its popularity coincided with that of LJ.

Table 3: Table of fic distribution for SPN.

\begin{tabular}{|c|c|c|c|c|c|c|}
\hline Site: & Ff.net & LJ & DW & A03 & Other & Overall \\
\hline Number of fics: & 217 & 337 & 87 & 492 & 33 & 704 \\
\hline $\begin{array}{l}\text { Highest number of } \\
\text { comments on a fic }\end{array}$ & 458 & 2741 & 822 & 130 & 163 & 2791 \\
\hline $\begin{array}{l}\text { Lowest number of } \\
\text { comments on a fic }\end{array}$ & 0 & 0 & 0 & 0 & 0 & 0 \\
\hline $\begin{array}{l}\text { Average number of } \\
\text { comments on a fic (mean) }\end{array}$ & 22.4 & 63.9 & 32.8 & 5.1 & 12.2 & 45.4 \\
\hline $\begin{array}{l}\text { Average number of com- } \\
\text { ments on a fic (median) }\end{array}$ & 5 & 19 & 6 & 2 & 2.5 & 8 \\
\hline
\end{tabular}

Again, many fics appeared in more than one place, hence the sum of the top row is 1166. A miniscule percentage of the reviews were entirely negative (nine in total, or $0.03 \%$ ). This suggests a strongly supportive websphere where harsh criticism is unwelcome.

Following the methodological flowchart meant that I had to code my own fic. In doing so, I discovered that I have largely contributed to consolidating the discourse established by the text itself. Thus, one outcome of constructing a rigorous methodology was forcing me to engage in what Bourdieu and Wacquant called 'reflexive' practice: removing myself from the 'know-how', or learned practice (1992, p. 228) of writing fanfic, in order that this research is able to investigate a social world that my writing is the product of and contributes to. It is not some special insight or capacity that enables me to map these discursive formations, but the construction of a systematic method enabled by my academic position. If social behaviour is, as Giddens has it, an 
essentially reflexive practice (1984, especially pp. 1-9), this explains how the same 'me', whilst caught up in and reflexive of the culture of writing within this discourse, produced statements that, through the tool of my methodological framework, I later fitted into the specific discursive categories established. The step of 'locat[ing] [one] self in the picture' (Fook 1999, p. 11) that research produces is missing from Zubernis and Larsen's investigation. The lack of a methodology that would reflect on their own actions and positions as well as demonstrate how the evidence for their chapters is selected means that their account sometimes slips into the anecdotal. It is not enough to state that one is both a fan and an academic: the implications for what is then presented must be explored. As a fan, I contributed statements that shored up a discursive formation through learned practice; later, my position as an academic and the method I constructed from academic sources then allowed me to recognize it. Placing my own text in the discursive formation is an act of 'assembl[ment] using hindsight'(Ellis et al. 2011, p. 2), enabled by my position in an academic network, a 'culture of research production' (May and Perry 2011, p. 176) as opposed to a fannish culture of fic production.

In an illustration of the fact that discursive formations can solidify by internal mechanisms unconnected to the specific construct under discussion, most of the fics of high impact were so for reasons unrelated to Chuck and Becky. Typically, they were: long; of high literary capital; written by big name fans; set in the Endverse ${ }^{3}$ and featured the pairing Dean/Castiel. Thus, statements constructing the author and the fan set in this context gain the most weight. The discursive formation 'The Author and the Fan' was quite definitively transformed by fic statements, though the primacy of the 'real' text was still respected in the majority of cases (cf. Stanfill forthcoming). This suggests that though fans may alter the construction within the spaces and boundaries of fandom, they may retain a sense of fandom's limited ability to alter hegemonic discourse in the wider media archive. Former PR worker David Gardner writes that media producers often let fans (and some popular academics) believe they have more of a voice than they do' (2012, p. 51), and yet, the airing of $10 x 05$ suggests in retrospect that fannish impact may actually have been underestimated here, demonstrating the explicit transformative capacity of fanfic on the broader cultural sphere.

3 A dystopian future world revealed canonically to Dean by the angel Zachariah, in an attempt to manipulate him into following the angels' plan. The name derives from the episode title, 'The End' (5xo4, 'The End'). In this world, Sam is unavailable as a partner for Dean, having given himself to Lucifer as a vessel, and Castiel is no longer an angel, but a drug-addled faux-spiritual guru outcast from heaven. 
Due to fandom's tendency to treat Chuck and Becky more separately than canon does, the remainder of this chapter is divided into two halves. The first concerns the author and his text; the second, the fan and hers. There is more fic constructing the author without the fan than vice versa. This is partly due to the fact that Chuck was introduced before Becky in canon, so fanfic about Chuck was produced for a time before the dyad was obvious, but it nonetheless helps consolidate the primary/secondary binary.

\section{The Author and His Text}

In some fanfic, the author Chuck is literally God. Supernatural does not explicitly state this, so these statements definitely consolidate the construction of the Author-God. They are most popular on Ff.net, rendering this part of the websphere less critical and more reverential towards the text. The writer will often assume God's point of view with an apology like, 'this fangirl owns nothing and would like to humbly apologize to the Big Man upstairs for this blasphemy' (PwnedByPineapple, 2012). Paradoxically, the fic-writer is assuming the right to speak from God's perspective. As PwnedByPineapple continues, 'what's the point of believing if you can't have some fun with religion, eh?' Chuck — the male Author-God-is the tool needed for the fic writer to assume this voice. Sometimes this is played 'straight', and God directs the narrative in traditional manner:

[The angel Castiel] looked up in surprise as he felt another hand on his head and was even more startled to find Chuck smiling down at him. "Chuck?" Cas asked in wonder. "Cas you are on your way to redeeming yourself... Now go save your family" (iamtryN 2011).

This fic received 12 reviews on Fanfiction.net. Though below average where average is taken as mean, the mean here was raised by a few fics with hundreds of reviews. The median number of Ff.net reviews is five, so these statements constructing the author as literal God are not insignificant. On the other hand, another fic depicts God-Chuck as rewriting the story to remove all misery with the following revelation:

Dean, I am God. I am not Chuck the prophet as you know me. I can change the course of time. Alter realities and change history. I have made it so that your mother never dies in a fire. You never become a hunter. Your daddy dies in his bed, an old man next to your mommy. Mommy dies an old lady surrounded by her grandchildren and great-grandchildren. 
Sammy marries Jess and has babies. [...]As for all the evil in the world...I can make it so that it doesn't exist. I am God. I created all the beings on this Earth, be they good or bad (harakal1, 2011).

This fic is blanked, receiving no reviews on Fanfic.net or anywhere else. The statements fail to impact the formation, but this possibly has more to do with the un/acceptable construction of God, and/or the removal of the premises on which Supernatural is based, than the attribution of divinity to the author.

Other times, Chuck is constructed as God in a comic mode, and the fan uses him to correct the unpopular ending of Season 6. Here, the angel character Castiel suffers a psychotic break, releases the many-headed monster Leviathan from purgatory to take into himself, and declares himself the new God. Many fans were unimpressed, considering the twist unjustified, out of character, and a cheap trick on behalf of the un-Authorized post-Kripke writers. As msormanti6696 put it,

This is the moment that completely ruined Supernatural for me. And then just when I thought Cas going dark side was the worst mistake the writers ever made, they kill off Bobby, Dean has become a cynical, hopeless drunk, and Sam is mental. Sera Gamble what are you doing to our show, do you care for these characters at all? (2012).

Chuck, as Kripke's proxy, is utilized by fan writers to correct matters. In Krissy749o's fittingly titled, How Season 6 Should Have Ended, or How Season 7 Better Start, Chuck descends in a 'bright flash of light' at the critical moment to command:

"Alright. This is how it's gonna work. We're going back a year. Castiel, when you were thinking about talking to Dean while he was raking the leaves, you're gonna talk to him. I'll bring back Sam, soul way more intact than anyone else could. And, Bobby. Well, you just keep being kick ass, alright?" And that's what happened. Because this writer made it so (2011).

The tone is flippant and comic, and as with the GoT fandom, reviewers acknowledge that this fic is not the 'real' text, much as they might wish it:

WHY DIDN'T THIS HAPPEN! (Sheridan Holmes 2011).

Oh...if only (Frannie-pants 2011). 


\section{AM BOICOTING THE LAST EPISODE AND MAKING THIS STORY}

CANNON IN MY OWN BRAIN.:D (LastBishop 2011).

Canon in one's 'own brain', accompanied by a manic smiley face, is not quite legitimate canon. Such statements consolidate the paradox established with Becky's canonical licence to borrow Chuck's characters: that the fan, a 'writer', has power, but that power is legitimated and sourced from the Author-God, and rejects his female successor. The coda of 10xo5 would consolidate this, and in fanfic, the fan's authorial position is necessarily ironized by the context in which she writes in.

Herzog has demonstrated how authors' notes on fanfic register a tension between the individual fan's authority over the text and the communal authorship model demonstrated in fan practice. She shows that 'varying fannish interpretations provide a more nuanced perspective' than simple fruition of Barthes predictions $(2012$, ch. 2.5$)$. She goes on to argue that 'attempt[ing] to actively direct the story's audience into a certain, premeditated reader position[, some fans may] curtail the very sort of interpretive and agentive practice they themselves are engaged in while writing fanfiction' (ch. 2.7). I found that conversely, where paratextual author's notes existed in this formation, they tended to be brief thanks to other fans whose input helped shaped the fics. This would indicate a communal concept of authorship; but strong authorial positioning could be found in the fics themselves. This strong positioning, I argue, is enabled through the legitimation paradox which allows fanfic to present itself as authentic text. The legitimation paradox is simultaneously deconstructive of the Author-God's role and consolidating of it. This accords with Stein and Busse's observation that though fanfic is a recombination art, in practice it often displays adherence to older models of cultural author/ ity (2009, p. 205). The comedic Chuck-as-God fics, where he descends to repair Season 6 and 'the random stuff we've been getting from Gamble' (angel_gospel 2011), gesture toward the hypothetical 'true text', informed by the author-function, which this fic is approaching: the true text would be faithful to the ordered, coherent vision of the originator, not the haphazard attempts of his stand-in. Romirola's review articulates, 'love this, and I totally agree. Castiel would never, ever do that. It was stupid. I feel used, as if the show only exists to keep up ratings. RIP original supernatural' (2011).

Chuck-as-God is less common off Ff.net. Ao3 contains a vast number of AUs, most of which depict him as a geek and struggling writer, consolidating the other side of the geek/God formation. On LiveJournal, canon tends to be 
more popular than $\mathrm{AU}$, and Chuck is typically depicted as a man, prophet and mouthpiece 'in all his lovable, neurotic glory' (thevinegarworks 2009). The fanboy-auteur strategy succeeds here, as the textual guidance to love and pity Chuck, to take him as our friend, is wholeheartedly followed. The phrase 'poor Chuck' occurred 93 times in reviews, rendering the construction very solid. I have written it myself, because those were the feelings the fic called up in me, and because I had unconsciously learned that the response was appropriate. Later, I understood these statements as part of the pattern consolidating the fanboy construction of the author. It is this depiction of Chuck that tends to turn up in the most popular fics, and thus these statements make the most impact. In tracy_loo_who's legendary Endverse epic, And I Will Walk on Water (2009), which has 2741 LJ comments and 2791 total, Chuck turns up at the end to greet the conquering heroes with 'a huge banner hanging from the low ceiling that read, in large, colorful lettering, Happy End of the End of the World!' to which he has 'added some sparkles.' He still drinks, has visions, and is guarded/trapped by the angels, though permitted a 'pet hedgehog' named Frodo. But other LiveJournal texts construct him, if rarely as a serious God, certainly with more weight and cultural capital.

'Death of the Author' (Barthes 1977) may have been an earnest attempt to deconstruct the cultural capital attached to the figure, but if the author is constructed in the process of dying, as writing enacts 'the destruction of every voice, of every point of origin' (p. 142), this capital is rather restored. Proxydialogue's The Winchester Revision (2011a) is quite significant, with a total of 105 comments between LiveJournal and A03, a circulating recommendation on Tumblr, four recommendations on LiveJournal; one on Dreamwidth and one on an external site. This fic is the story of a desperate re-write, in which 'a recently de-deified Chuck, dying in Italy, decides to revise the story of Sam and Dean and Cas to give it the fairytale ending it deserves.' The fan utilizes the voice of the author to legitimate her desires, composing a story in which the characters

fuck the system and live happily ever fucking after and die of natural causes like weak immune systems and old age and too much happiness. In Chuck's version of the story, Dean and Cas and Sam live the lives a fangirl would have written for them.

Fuckin-A right they do.

He centers the cursor and types:

The Winchester Revision

It's a God-damned fairytale (proxydialogue 2011a). 
Chuck opens his story with the ironic and bitter declaration, 'here 'bigynneth' the total and utter fucking tragedy of an older brother.' In a further example of the legitimation paradox, proxydialogue uses Chuck to rewrite the authorized interpretation placed on 'Swan Song' by Chuck in canon. Canon is restructured not as a trial by fire that makes heroes of the protagonists, but the cosmically unfair and undeserved ruination of a small set of characters defined by their family bonds. On the other hand, though utilizing the author-character and the discourse of authorship goes a long way to legitimate the plot as authentic, Chuck here is no longer a prophet. This is only a 'version' of the story. For God had been using him as a vessel, and has now departed. Chuck finds that 'the side effects of divine possession are a bitch' what with 'his body falling apart from the inside,' and the 'sudden onset of acute existential uncertainty.' In between sparsely-written episodes of physical deterioration, Chuck continues to write the story 'how it would have been done if God wasn't such a mean motherfucker,' and the reader has access to his text. He finds himself unable to create the fairytale he intended, learning as he goes that 'The moral is not: They lived happily ever after; but just: They lived,' which is more justice than the conclusion of 'Swan Song' at least.

Defiant in the face of impending death, determined to write in spite of God, there is definite cultural capital attached to this construction of the author, held in tension with the story's ambiguity about if, when and where Chuck's rewrite has any effect on 'reality'/canon. The value of fiction as a form of writing is in question. Chuck's voice legitimates the fanfic, but constructing his writing as 'a fangirl would have written it' may delegitimate the text-inside-the-text, which he produces. Absent from Ff.net, polished and elegantly phrased, these statements give the impression of a writer speaking to writers, playing upon our self-perception and vacillation between faith in fiction's power and despair of its futility. Though half of the story is devoted to the text Chuck writes, the alternate universe for his protagonists/friends, the dying author is very much the hero of the story. Proxydialogue comments, 'I guess of all the characters in the canon I find Chuck the easiest to write and the easiest to extrapolate with. And I always felt that, if he were himself, human, and used as a tool, he would be rebellious against his role' (2011b). Here then is another way in which the author Chuck legitimates the fan as writer: by providing a model of self-conception. It also adds potential statements like 'hero' or 'protagonist' to the discursive formation 'author', existing independently of the fan.

However, these are not governing statements, as a limit case demonstrates. I'll Take My Chances Here and Now by HappyFunBallXD explicitly 
undercuts the elevation of the author. It is a fairytale AU, wherein the Supernatural protagonists find themselves in a mysterious land. Chuck, in a role approximating the Wizard of $\mathrm{Oz}$, is a psychic who lives in a castle, and is rumoured to be able to help Sam and Dean get home. Chuck first appears as a dragon, accompanied by smoke and light. But when Dean loses his temper with the dragon and hits it, his fist goes

straight through, until he was shoulder- deep in Chuck's side [...] Instead of blood and guts that should be pouring out of a wound that size, there was nothing. [...] The younger hunter stepped in closer, pushing back a scale to see the hole more clearly. It was hollow. Mostly. There were a few gears inside, turning the head and joints, but for the most part, it was just scales over a frame. It wasn't real (HappyFunBallXD, 2012).

These statements inflect the meaning of the 'Kripke's Hollow' pun in the source text. The construction of the author is lights and smoke and all that [...] more chemistry than magic.' In other words, it is showmanship, fakery, a para/textual spectacle without substance. What is needed to break the illusion is an act of violence - here physical, but a para/textual parallel might be the Tumblr blog titled, 'Fuck the canon, old man' (http://crowleyshouseparty. tumblr.com/), which collects subversive fic recs and commentary.

That said, Chuck - whose true form is as usual, a small scruffy man in a bathrobe - does have prophetical insight, and utilizes the dragon illusion in the hope of making people listen to him. He is enabled by Becky, who lives at the castle with him: an interesting reversal of the source text's dyad. He needs her legitimation, whilst she just 'thought he was cute, trying to be all authoritative.' Before meeting Chuck, Sam dreams about him, and since he has no mental reference point, Chuck is 'represented by a floppy rag doll, which Becky held up on a silver platter.' This fic reverses the construction of the fan as dependent on the author for authority-here, the illusion 'author' is dependent on the fan for construction, just as Foucault describes an author-function as dependent on the institutions that maintain the fiction of the author, and Mittell considers reception the vital constituent of a televisual author-function (2012, p. 36).

Despite its 90,000-word length and high literary capital, this story is less well received, with 36 total comments. The statements that maintain the author as legitimately special, then, whether as author (primarily LiveJournal/Ao3) or God (primarily Ff.net) can be contradicted, but still have more impact in the discursive formation. Chuck's authority legitimates the voice of the fan, just as Kripke's para/textual statements legitimate 
fanfic. However, the possibility of writer as constructed by audience, with a critical slant, is opened by fanfic in a way excluded by the source text. Moreover, when the writer is explicitly constructed as writing like a 'fangirl', the relationship of his writing to truth is ambivalent. In these ways, though the legitimation paradox dominates, it can be subverted to an extent, constructing the author-function as dependent on audience critiques the primacy and originality of authorship.

It is fair to say that the governing statement that the author's text is canonical and true is largely consolidated in fanfic, though this is complicated by the fact that the fan writer assumes control of the in-text author, and thus her version of what Chuck writes becomes 'truth'. Some comedic fics explore this as a meta-textual realization, with the writer realising that the pen is mightier than the sword. In DarkLady's Making a Prophet (2009), Chuck happens upon the Bible verse Matt. 26:56, 'But all this was done, that the scriptures of the prophets might be fulfilled.' He takes this to mean that prophets are not merely witnesses and recorders, but that their writing influences events. As lex_rhetoricae comments on an Endverse fic, this is actually closer to the Biblical meaning of prophecy than the passive visionary construction:

So, Martin Buber has this essay in On the Bible about the difference between the 'prophetic' and the 'apocalyptic' modes of Judeo-Christian apocalyptic literature. And in the prophetic, the prophet has an actual chance of saving people though his message, while in the apocalyptic, it's a 'put your head between your knees and kiss your ass goodbye' kinda prophecy (lex_rhetoricae 2010).

In the comedic pieces, this tends to be taken literally. In Making a Prophet, Chuck saves the day by grabbing a computer and hastily typing:

Chuck 32:6 - **So verily it came to pass that Lucifer slipped on a banana peal [sic] and slid arse-first down to the depth of the fiery pit, and took Zachariah and all his snot-nosed angels with him. And there was peace upon the land, and rejoicing, and also fresh apple pie. And the Righteous Man and his brother and the good folk who hung with them ate of the pie and also mostly got laid (DarkLady 2009).

At other times, the appropriation of Chuck as prophet allows the fan to affirm her and other fans' desires. Quite often, the fan writes Chuck writing fanfiction, which comes true whether he intends it to or not. Again, Chuck 
is the device by which the fan's writing is legitimated, but she controls what he writes. Maskedfangirl's very popular Chuck Verse - which sparked the creation of Making a Prophet - contains three main stories: The Apocrypha of Chuck (2009); The Code of Chuck (2010a); and The Tribulations of Chuck (2010b). The overarching plot is that Chuck travels, lives, and eventually undertakes the adventure to stop Lucifer with the heroes, despite knowing that were this the Council of Elrond, he would be 'background Elf \#3. Or maybe the pack mule' (2009). He is a thorough and unrepentant geek, thinking in terms of Joss Whedon programmes and admitting he would 'rather write slash fiction than deal with real life.' When life gets hard, he retreats into his 'Happy Verse', an extended fanfic he is writing about his friends, wherein Sam and Dean hug, Dean and Cas get together and the apocalypse is averted. Again, he is constructed as writing like a stereotypical fangirl. However, over time, reality and the Happy Verse begin to overlap, until the main points of Chuck's fantasy become reality.

Maskedfangirl uses a Chuck avatar as her icon, and in the many celebratory comments (670 total for the trilogy), a now-deleted comment asked, 'Like, holy shit, Ben Edlund, is that you!??!?!' Ben Edlund is the Supernatural writer most known for comedy and meta-textual cleverness. Maskedfangirl is delighted with the attribution, claiming that made her week. Although Chuck's writing, in the hands of the fan, becomes the tool by which the fan can alter the 'truth' of the text, the highest legitimation still comes by association with the male professional writers (cf. again 10x05). On the other hand, falcytan_dream compliments, 'I like to think that you had the true prophetic gift for the show, and the telly series we all know is just an elaborate fanfic off of this' (2011). This statement structures the fanfic as truth. Yet, notice the caveat, 'I like to think,' which recalls the kind of approving review claiming fics are 'personal canon' (oximore 2011); 'my official post season 5 canon' (ataratah 2010) or 'cannon in my own brain' (LastBishop 2011). 'Personal canon' is something of a contradiction in terms, suggesting that the transformative power of fic on discourse is real, but limited to individual psychical pleasure rather than influence on the text itself.

Two popular fics construct the author's word as truth and the entertainment industry as a threat to that. This accords with the author-function popularly attributed to cult TV showrunners in contrast to the mechanisms of industry. In Thursday's Child (strangenessandcharm 2009) and Amen to That! (Mardy Lass 2010), Chuck's novels are to be adapted by Hollywood and a television network respectively. Amen to That! is primarily a comedy, concerned with the exploits of Sam, Dean, Chuck, Cas and Becky as they 
run around a television set attempting to prevent or dictate the production. Whilst Dean is worried about the further exploitation of his life, Castiel is concerned for the damage a TV show will do to the authenticity of the prophet's word. This fic makes above-average impact, with a total of 64 reviews. Conversely, Chuck's work is not a major plot point of Thursday's Child, but this is one of the most famous fics in the formation, one of those Dean/Castiel Endverse epics with several hundreds of reviews. It would easily have broken the thousand-mark, perhaps even overtaken And I Will Walk On Water, but it has been deleted from its original home on Livejournal and resides only on Dreamwidth, with an exceptional 822 reviews there. There is even a fan-created trailer for the fic, available on YouTube (Sapphiamur 2013), which itself has over 52,000 views. Set post-apocalypse, the Winchester Gospels have been recognized as religious texts, and the government invests in their conversion into blockbusters as a public morale booster. The distortion of truth by Hollywood provides a great deal of the comic subplot, including the casting of Lindsay Lohan as Castiel before she is fired for unreliability.

In the end, it is up to Chuck to insist on the truth of his text against industry economics, which here entails legitimating the pairing Dean/ Castiel when Castiel is played by a male actor. Dean reports that 'Chuck went to the studio and told them about our big gay love and demanded they put it in the next movie. They told him no, but apparently he threw a fit. Dean explains that 'a gay relationship [...] won't play well for some audiences' of what are essentially religious texts in the fic, and Castiel insists, 'it's not anything to do with it 'playing well'. It's just how it is.' This is why Chuck 'played hardball' and 'told them they could find another prophet unless they made the films true to life.' The true text then, the author's text, would legitimate Dean/Cas: it is only the present climate of homophobia that censors it. Where Chuck is mentioned in the entirely positive comments, it is to affection for his character or approval for his guardianship of the true and authorial text which endorses the popular pairing: 'I adore Chuck for putting his foot down about the Big Gay Love ${ }^{\mathrm{m} w}$ between Dean \& Cas' (sycophantastic 2009). The fact that these statements become some of the most influential and impactful in the discourse via context rather than content is illustrated by a contrast. Amorremanet's snippet fic, 'It's Not That Kind of Show' (2012), is focused entirely on this theme. In this fic, Dean is really a girl named Deanna, and Becky is her girlfriend. They go to the cinema to see the adaptation of Chuck's word, and Deanna endures a 'painfully inaccurate' account of her life portrayed by 'some weird white dude.' They resolve to 'post subversive fanfiction on Tumblr' and go home. Becky 
explains that Chuck had to sell all the rights to his manuscript because he had no money for rent. The fic receives no comments. Seven people have pressed the 'kudos' button, so it is not completely unacknowledged, but the impact is hardly comparable to statements of Chuck's true word triumphing over industrial imperatives made in the popular fics. If it were better received, it might post a significant challenge to the legitimation paradox, eschewing the figure of the straight White male, and substituting a lesbian couple as the figures of revaluation.

On the other hand, there is a significant set of fics that deliberately undermine the construction of the author's text as the only legitimate truth, as compared with the comparatively small impact of I'll Take My Chances Here and Now, which debunked him as a figure. As noted above, The Winchester Revision constructs the truth-status of Chuck's writing ambivalently. The Chuck Writes Story: An Unauthorized Fandom Biography (lettered 2011) deals specifically with this theme. Chuck Writes is a series divided into six fics on LiveJournal/Dreamwidth/Ao3, which receives a total of 140 comments. Most fics dealing with the matter of text and truth are on these platforms, reflecting a longstanding division within many fandoms that view Ff.net as more juvenile and of lower quality than others archives mostly 'written by children and teenagers' (Lawrence 2007, 8.1; cf. Hadas 2009). The few that do appear on Ff.net tend to be in the light-hearted mode, including Making a Prophet and Amen to That. The Chuck Writes Story is both light-hearted and serious, its subject matter being the location of the 'real' Supernatural. Chuck writes a fanfic under a fake identity, posts it on LiveJournal, and receives just a single review. Thrown into an existentialist crisis, he begins to explore the world of fic, making increasingly desperate attempts to be noticed within his own fandom, including posting an unpublished Supernatural manuscript. Failing to realize the indispensability of the name to the author-function, as the descriptor that allows certain texts to be set apart and differentiated from others (Foucault 1991, pp. 105-107), he is driven to increasing distraction by this evidence fans could love the text and not the author:

if they liked Carver Edlund so much, why wouldn't they like his sock [pseudonym]? Because if they didn't ... was it really the writing they loved, or was it the marketing, (the covers with their shirts ripped off, the models, the hair)—or was there actually some other Supernatural? Was there some amorphous, non-text, non-content driven Supernatural, a zeitgeist!Supernatural, some über Supernatural, a Supernatural that was his Supernatural and yet his no longer-now part of the collective mind, now part of the cultural maelström, or other words with umlauts, some 
Supernatural that belonged to the world and to the fans and no longer to the mind of the creator? A meta!SPN? Was it that Supernatural that they really loved-or was it Carver Edlund? (lettered 2011).

The series subtitle, 'an unauthorized fandom biography', implies that this is the work of fandom in action, the communal creation of a text without an Author-God, rather than one with an Author-God as a source of legitimation.

When it becomes known that the LJ user 'chuck_writes' is in fact Carver Edlund, the fictional fans engage in just such a debate. There is really no way to describe these statements other than to quote at length:

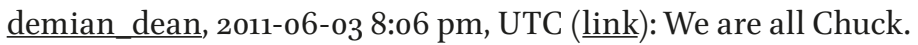

$[\ldots]$

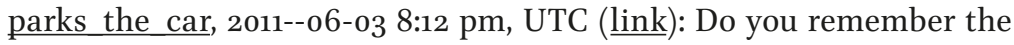
uber Supernatural? The one with umlauts.

spnfangirl, 2011-06-03 8:15 pm, UTC (link): I remember the über!Supernatural. The meta!SPN. It was another Supernatural.

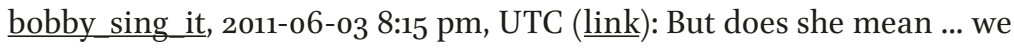
were all writing the same thing.

glass family, 2011-06-03 8:28 pm, UTC (link): How do we know what's canon now?

long seige, 2011-06-03 8:28 pm, UTC (link): How do we know what's real?

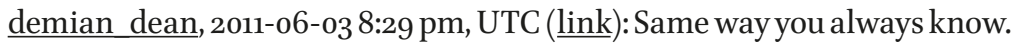
twop barnes, 2011-o6-03 8:29 pm, UTC (link): Create.

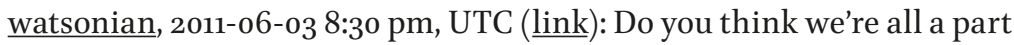
of something? (lettered 2011).

Notice the coding, which imitates how actual conversations appear on LJ, blurring the distinction between Chuck's Supernatural, which these fictional fans discuss, and Kripke's Supernatural, which is discussed in the same format on LiveJournal. Some of the fictional fans remain convinced that 'books are canon. Fanfic isn't. Supernatural is concrete, finite. The SPN in our heads isn't,' which raises the question of whether 'chuck_writes' or only Carver Edlund can produce canonical text. The debate recalls Foucault's argument that the unity of the author-function could not merely be replaced with the unity of a 'work', for the concept 'work' has no pre-extant unity (1991, pp. 103-104). Writing on Skins fan production, Hunn asks,

What is the original and what is the copy? Is there really an authentic and authoritative Skins text, a Skins essence? Or, is it all really just skin 
deep-a series of competing textual performances made more ontologically unstable by the overlap between official and fan productions that an embrace of participatory and collaborative practices inevitably engenders? (2012, p. 94).

These are exactly the questions enacted by the Chuck Writes saga, yet in the format of fanfic, and conducted through the social and technological codes of fandom rather than academia.

Thus Chuck Writes, with its sophisticated intertextually and irreverent humour, enacts a mode of 'good', rational fandom on behalf of its own author, inclusive of the enlightened reader and exclusive of 'bad' crazy fans, like Becky.

Becky appears in Chuck Writes to support the authority of the author with her canonical pseudonym, 'samlicker81':

Sorry all you haters...but $\mathrm{CW}$ is canon...the writer is canon...C.E. is canon... in the time of our writer...the Creator is God. I know it might be hard for some of you to recognize...some of you wish you were him...but you're not ...we're all in his hands (lettered 2011).

Once again the author is legitimated by the fangirl—but the definition of 'fan' is here reconstructed to include the whole range of responses. Not all fans are Becky, and not all fans accept the authority of the author. The most famous fic in the fictional fandom is a rewrite of Chuck's series, intensifying the emotion between the brothers and hinting at the possibility of a sexual relationship between them. This writer of this epic is known as 'lord_kripke', an epithet of Kripke's in real-world fandom. Possibly then, though it contributes statements which greatly destabilize the primary/ secondary, author/fan binary and indeed the legitimation paradox, Chuck Writes re-instates the Author-God in the end through manipulation of the Chuck/Kripke divide. The real author may well be 'Lord Kripke', hiding in plain sight, he who has written the series as we know it. For Chuck's work in the fic is not our Supernatural, but a series of badly-written pulp novels. Our Supernatural - the real Supernatural? - is (Lord) Kripke's.

This statement is complicated by an iconographic coincidence. The abbreviation of 'chuck_writes' is CW. CW is the name of the network that Supernatural airs on, including now, in the post-Kripke era. This means that statements like 'CW is canon' or 'CW isn't canon. Just another fanfic' cut two ways: they could either refer to the text written by the author or to the productions of an industry in the post-author era, whose concerns are 
economic. The text is held in negotiation between CW-with the referents of Chuck's fanfic, and the network; and the revered 'lord_kripke' — with the referents of a slash-inclined fan and Eric Kripke. Lettered claims not to have noticed this until she began typing up the fic, which illustrates again the profound impact happenstance has on discursive formations.

So statements upholding Chuck and/or Kripke as author, and his text as original and true, retain a strong influence in fandom's construct. But the appropriation of Chuck empowers fans to utilize some of that authority, even reversing the terms of the legitimation paradox by demonstrating that fans enable the author-function as much as the other way around. Moreover, fanfic contributes statements that question connections between the author and the 'real' text, notably Chuck Writes, whose graphical-lexical density and instability of referents complicates the attribution of truth to an author. Though not the strongest statements, constructions of Chuck as fanficcer and contributor to the 'meta-SPN' destabilize his relationship with truth, as well as his construction as God. His 'truth' also modifies the statements 'fanficcer' and 'collaborator', raising those attributions by legitimation. The author-function remains strong.

\section{The Writing Fan}

The (re)appropriation of Becky into fanfic is theoretically significant, recalling Fuery's recognition of a 'post-panopticism of new media in which we are so aware of being watched that part of our strategy of transgression is to incorporate the very acts of surveillance' (2009, p. 141): responding, in other words, to textual provocation. But the figure of the fan is still problematic, even reclaimed and re-constructed by the fans themselves, placing a question mark over Fuery's 'transgression'. I prefer to substitute 'negotiation'; for some fics make statements that construct the fan even more pathologically than 7xo8, 'Time for a Wedding'. Hills (2002, pp. 61-64) theorized a good fan/bad fan imagined dichotomy in the self-construction of most fan cultures, and Stanfill found a similar discursive structure at work in her interviews with Xena fans (2013). Though her interviewees 'accepted negative portrayals of fans as valid,' they 'refused to take on that meaning for themselves, instead bracketing themselves out of it and shifting it off onto others' (2013, p. 117). As Stanfill comments,

This simultaneous acceptance and refusal of stereotypes suggests that being a fan is a subject position fraught with baggage from historical 
and contemporary media representations, which troubles triumphalist renderings of a new media order centered on the fan (2013, p. 117).

Stanfill points out that research into other non-normative groups, including lesbians and Black women, has shown that members

will subdivide their group into (a) themselves and others like them, whom they classify as normal, and (b) a deviant subgroup they declare actually deserves the stigma or pathologization to which the entire group is subjected (Ault 1996; Collins 2000; Fanon 1994; Ferguson 2003), a process that Ault (1996, p. 314) terms 'split subjectivity' (2013, p. 121).

In other words, we fans are normal, because we are not like 'those' fans, the crazy ones that give us all a bad name; that behave, in the worst case scenario, like the Twihards. Zubernis and Larsen also document the tendency for fans to construct dualisms between good and bad fan practice (2012, pp. 30-31, 37-38, 145; cf. Hills 2002, esp. pp. 61-64, 101-103).

The discursive formation of fandom, as re-conceived by fans, clearly includes attributes deserving of stigmatization, to an even greater degree than the source text would posit. Adrenalineshots' Bean Stalker is well received, with 245 reviews, and constructs the non-canonical fan Alexa as entirely insane. Based on Misery, this is a story of a girl who, dissatisfied with Chuck's ending to the series, means to kidnap him and discovers by happenstance that his characters are real. Thus, she instead kidnaps Dean, her love object, and tortures him for her psychosexual gratification, drawing clear parallels with torture and the hurt/comfort genre of fanfic. Indeed, Supernatural itself offers plenty of opportunity for voyeuristic pleasure in the tortured male body. Adrenalineshots has Dean observe of the fan:

Her eyes were glittering like beetles in the back drop light, lustful of pain and misery. Was his torture that much of an entertainment for her? Was this why people liked Chuck's books, because they enjoyed reading about all the suffering that he and Sam had endured their whole lives? (adrenalineshots 2009a)

Reviewers are privy to the game. They use Alexa as a model of bad fanship to construct their personas against: 
The difference between some crazy thoughts and some sane ones is the way we act upon them ${ }^{*} \mathrm{~g}{ }^{*}$ (adrenalineshots 2009b).

Marlowe78 rationalizes the investment in seeing our heroes hurt in terms of restoration:

for me, reading the fanfiction that bloodies our heroes is about fighting the odds, surviving even though that seems impossible, staying alive even though the world wants you to die-and stick together for better or worst [...] I don't get off reading about bloodied noses (or shoulders) but it is a fine line, I admit (2009).

'Crazy' is retained as a property of fannishness, but not our kind. Statements like this displace it onto a hypothetical bad other, an other who will not be legitimated but, on the contrary, further pathologized through the capital of the White male.

In related statements, Becky is redeemed in fic by being 'educated out' of some Bad (excessive) aspects of fandom and displaying some Good (rational) ones (cf. Hills 2002, p. 61). For instance, in sothereyougo's We Are All Made as an Afterthought (2009a), she apologizes to Sam for groping him and explains that she needs time to process that Chuck's books are real, rather than an extended use of Campbell's journey-metaphor for the development of the individual, and justifies her slash habit with the rationale that 'commercial porn is almost all crap.' Sothereyougo describes the fic as an attempt to 'show a little more of Becky that gave her back a bit of her dignity' (2009b), and the commenters appreciate it as such. Similarly, in M.D. Jensen's Little Wet Tears on Your Baby's Shoulder (2011), Becky learns from experience that having Sam cry in front of her is not pleasurable as she finds it in fic, and she wants him to feel better, not 'prolong it'. In Gatergirl79's At His Side (2012), she attempts to get over Sam and 'close[s] down her website, her forum groups, clear[s] her Twitter account and Facebook.' For learning to curb her excess, she is rewarded, and actually ends up in an adult relationship with him. So Becky is constructed as inhabiting a juvenile stage we must outgrow.

Sometimes Becky's lesson is harsh: in kasey8473's Killing the Fandom (2012), Becky meets Sam's pregnant wife and is at first horrified, but comes to understand that she is behaving badly and ought to apologize:

He'd looked happy before she'd interrupted them. Becky recalled that touch to the woman's—Gwen's — back. It had been gentle, caressing, and 
loving. He seriously cared for the woman, like in a 'love for Jess' way, and Becky had pretty much spit on that.

Embarrassment for her own behavior welled up. Here she'd been trying to be mature and adult and she'd acted like an idiot teenager. Apparently, she hadn't managed to leave those days behind.

Later, she is briefly turned into a vampire, unable to control herself, and faces the prospect of execution by her heroes before she realises their lives are not so glamorous after all. The title refers to an exclamation by Becky - that Sam and Dean getting married and having children is killing the fandom'-but the statement also constructs Becky's experience as killing some of the fandom in her, the Bad part we must resist. Still, her gleeful excess is not quashed: she transfers her joy to the imminent arrival of the baby. Exuberance is not extinguished, but it does have to be contained, and the characters will not permit her to host her planned 'baby shower'.

Becky is also celebrated in fic, often in flippant style that flouts the good fan/bad fan construction. In girl_wonder's How Becky Totally Saved the World Without Becoming a Mary Sue or: PLEASE R\&R OR I'LL NEVER WRITE ANOTHER CHAPTER (2009), the title is a playful employment of bad practice. 'Mary Sue' is a disparaging fan term for original characters that are or read like idealized self-insertion. The 'Mary Sue' character is an annoyingly perfect female inserted into the fictional universe. Through some contrived series of events, she typically manages to save the day and have the heroes fall in love with her. 'R\&R' means 'read and review'. Threatening to withhold a continuation unless people review is a classic example of bad fandom, and an open invitation to mockery if done in earnest. Here it is compounded by Capslock, considered a breach of netiquette. Context inflects the statement parodically: the demand to ' $R \& R$ ' is associated with Ff.net; but this piece appears on LiveJournal/Ao3, where 'we' older fans know how to read it (cf. Hadas 2009 on inter-fandom divisions between age/ experience and youth/naivety). In between writing fanfiction and editing Chuck's new draft, Becky and her fan friend stop Lucifer by trapping him in a ring of holy fire. Becky considers that he 'is actually taller than Chuck had written him, and looks like all he wants is a hug.' She 'couldn't resist giving him some of the chocolate she was saving for the after-party' (2009). Hugs, chocolate, flippancy and humour are the properties structuring the fan here, and all are slanted positively. Chuck loves her, as he does in many fics, but that is not presented as a condition of her legitimation. How Becky Totally Saved the World is also high impact, with 227 comments. There are shorter examples with less impact on Ff.net, such as Lucifer Meets Crazy 
Becky (DeanFan 2010). In this series, Becky encounters characters she did not meet in canon, including Castiel and Lucifer. She so annoys Lucifer that he returns to hell willingly to get away from her, resulting in reviews like, 'YAY! Becky saves the day!' (DjinnAtwood 2012). The construction is not likewise self-reflexive, but Becky is certainly more sympathetic here, so these statements open the possibility that 'we' have a little of the bad fan in us too, and are not ashamed of it.

Usually, though, Becky's redemption in fic is legitimated by Chuck. She is constructed as an apostle of the Winchester Gospels, whose task is to spread the message. In both trinityofone's Writing (And Other Things that Are Hard) (2009) and twoskeletons's Restore From Saved Draft (2010a), Castiel informs Becky of her role as an apostle. Twoskeletons admits that Becky-as-apostle is one of her favourite fan innovations, and the comments express much love for the character. Both these fics are high status, particularly considering they are short, not cross-posted, and mostly concern minor characters, gathering 97 and 231 comments respectively. In twoskeletons Peanuts, the metaphor is extended as Chuck reflects on Becky's evangelical role:

I think our side can really use someone like Becky [...] We can use someone who believes so hard and is so joyous in her faith, even if her equivalent of singing hymns is writing gay incest porn [...] There have been hundreds of religions that have died out for want of believers, but Becky? She mods nine Livejournal communities and five exchanges, and has a novel-length Wincest pirate AU WIP that she's writing the eleventh chapter of. $[\ldots]$

It's like that guy Matt said one time in some testament somewhere: "You are Becky, and on Livejournal I will build my Church, and flame wars will not prevail against it" (twoskeletons 2010b).

This fic is also high status with 82 comments, and the description of Becky has been copied and pasted in comments, solidifying the construction their repeatable materiality. Moreover, Chuck does not set himself up here as the origin and source of legitimation, but admires Becky because 'she has a sense of purpose and a lot of drive, and these things are hardwired into her instead of copy-pasted in by God's divine ineffability.' There is a God, but it isn't Chuck. It might, however, be Kripke, another example of how the Chuck-avatar allows Kripke to retain control over the text whilst avoiding 'M. Night-level douchiness' (4x18).

The fan is sometimes constructed as guardian and/or interpreter of the Author-God's truth, as opposed to the rampant fantasist of Bean Stalker or 
Killing the Fandom. For instance, in scaramouche's AJudicious Application of Free Will (2011), Chuck has vanished, and Becky owns his last manuscript. Though multiple gods vie for the text, this manuscript is divinely protected, and only its rightful owner can read it. Becky is kidnapped and the gods demand she read it in their presence, censuring her for inserting 'personal comments'. In a variation of the legitimation paradox, this maintains the primary/secondary statement hierarchy, though it empowers the fan by her access to and definition of the 'right reading'. As the deity Baldur grudgingly admits, Chuck's text is meant for her, not them. Similarly, in earis's Draw Back the Curtain, Chuck disappears post-apocalypse, leaving a note:

Bex - Sorry about us. Take care of these, make sure they find a home. I'm going away for a while, it's your turn now. L, Chuck P.S. Take my house. I don't need it anymore (earis 2010).

But though Becky moves into Chuck's space, she does not become the new prophet. Her turn is not to write gospel but become the 'guardian' of Chuck's stories, as Sera Siege was in the canon. Unable to find a publisher, 'she launches www.winchestergospel.com', where 'every single book is available as a downloadable pdf' and 'there is an apocrypha link to fanfiction communities and archives'. Apocrypha are by definition non-canonical. Moreover:

She looks at all the stories that she has becomes the guardian of, that she has protected. They're pretty grim. She can't make anything better for real, but she can still come up with a potentially better scenario. They boys gave everything to the world, so that it might live. The least she can do is write them one crappy, fake, fan-fiction happy ending. After all, didn't Chuck tell her, 'It's your turn'? (earis 2010).

Her turn is not to write the new Book but protect and preserve it, empowering her through that secondary status.

This brings us to the second part of the governing statement recognized in the canon formation: that the fan's writing, though permissible, is secondary and derivative. Though there are statements that uphold this, there are also significant statements that challenge and deconstruct the binary, as already broached in The Chuck Writes Story. If a discursive formation is defined by what is thinkable and sayable, rather than united by agreement, it must be concluded that statements from fic have altered the formation of The Author and the Writing Fan significantly. 
Becky's writing is utilized in fic in a number of ways. Sometimes, her voice is appropriated for comic purposes, as in LolaAnn's In the Arms of an Angel-by SamLicker81. The fic is a mashup of clichéd self-insertion on the 'Mary Sue' model and is prefaced by parodic author's notes referring to an implied flame war: ${ }^{4}$

Pre-emptive Warning to DeanSam4Evr69: If I get any flames from you for this fic, I will be banning you from the site (permanently this time) [...] I am NOT 'selling out to the hetero-normative majority' by writing Sam as having a soulmate that happens to be a woman. It does NOT cheapen what he has with Dean. So, save it and stop being such a narrow minded hater. If you don't like het, then don't read my story. Personally, I think you're suffering from some severe internalized misogyny and I pity you (LolaAnn 2012).

It is difficult to explain how funny this is to fan outsiders, but essentially it condenses several long-worn fannish arguments over self-insertion, misogyny and homophobia into one high-minded paragraph. The 'author's notes' continue: if Samlicker81 does not receive at least ten reviews, she

will NOT be continuing [her] Brothers: Forbidden Love and Burning Desires series. Which means you'll never get to find out if Sam is able to save Dean from his most recent bout with pneumonia/hypothermia by the power of his love and body heat alone.

The rest of the fic skewers fanfic clichés with equal wit and precision. The main character is Becky, who after a hard day's work counselling suicidal orphans, learns that her true identity is that of a 'half-angel'. For some reason, she is 'the only one' who can save Sam from another 'dark haired Jezebel' placed in his path by Lucifer, defeating her with the power of her goodness and purity before assuring Sam and Dean that even though she and Sam are in love, she is perfectly happy for the brothers to continue to have sex with each other. After all it is 'completely normal' for them to be 'only gay for each other', due to their mutual attractiveness and the great adversity they have endured together. Again, this refers to a debate around slash regarding the improbability and latent homophobia of the only-gay-for-x trope that appears in some slash fanfic. 
This fic sets up a parallel to the good fan/bad fan dichotomy: good fic (which 'we' write) and bad fic, (which 'they' write in earnest and 'we' parody: cf. Carruthers 2004). LolaAnn appropriates the form of author's notes to disguise her own authorial position, passing off bad writing to that other kind of fan. The portmanteau 'badfic' already has currency, and can refer either to fic that is actually bad, or fic like this that parodies it. The reviews continue this: Defincupark found this hilarious but 'can't wait to read [LolaAnn's] real post' for the challenge this fic is submitted to (2012, my emphasis). My own review, submitted after I had finished hyperventilating with laughter, salutes the author, 'well played' (reading_is_in 2013a).We understand LolaAnn as a good writer appropriating a bad mode. JohannaMK states appreciation for the fic but warns her not to stray too far into the bad fan side, reviewing 'thank you. (Please don't do it again! (;)' (2012). Thus, the parodic author's notes on one hand mock the concept of an originary genius, and the privilege of a writer to direct the reading of the text. On the other hand, they subtly reserve it to the real writer, who constructs a model of bood versus bad fanfic and fanfic writers.

In other fic, Becky takes over from Chuck to write in a secondary mode, paralleling the departure of Kripke and installation of Gamble as showrunner. This is another manifestation of the legitimation paradox, in which the newer female showrunner is authorized by the fanboy- auteur. As gabehorn puts it, 'Kripke could have made any one of the bigger male names on the show the runner, but he chose Sera' (2012). His choice authorizes her. Arguments circulate in fandom over Gamble's authority, hinging on the consensus that her tenure as showrunner did see a decrease in writing quality, combined with an awareness of the gender issues inherent in the legitimation paradox. Crowleyshouseplant argues that without excusing some of Gamble's writing decisions, we should bear in mind that focusing criticism purely on her as showrunner perpetuates the misogynist context of the entertainment industry (2012a); whilst quarterclever 'can't help but think that if Sera Gamble were a man the fandom wouldn't have half the complaints about her they do [.] Because we can complain about the show being misogynistic all we want but so often that's a matter of pots and kettles' (2012a).

My own fic fits into the formation by contributing statements of this sort, in which the secondary female writer is authorized by the author. It is an AU, set in a world where the characters are pitted between a totalitarian state and a terrorist resistance movement, rather than Heaven and Hell. The Resistance's chief weapon is bioengineering, of which Chuck is a failed product, leaving him with erratic visions and alcohol problems. Whilst Chuck is alive, Becky persistently believes that her heroes will overthrow the State 
and save the world, considering it her job to 'spread hope' to the people. After he is killed, Becky takes over his role, salvaging his journal from the wreckage:

"I'm going to carry it on," Becky said. "I mean, I may not have visions, but I can still write down what's happening. I could be like a chronicler of the revolution."

Sam put his hand on hers. "I'm sure Chuck would be proud."
"No he wouldn't." She smiled, a little wobbly. "He'd tell me I was wasting my time, that there wasn't going to be a revolution, and try not to make it obvious he was looking at my boobs." She sighed. "I miss him," (read- ing_is_in 2013b).

These statements demonstrate my internalization of learned practice. I did not plan to contribute statements that constructed Becky in this way and solidified the legitimation paradox, but according to my 'know how' (Bourdieu and Wacquant 1992, p. 228) it seemed appropriate at that point in the story. Moreover, this fic is a sequel I produced by request, gratified that people liked the first novella in the series and eager to continue my performance and validation as a good fan and good writer. I perform to my strengths and respond to what my audience approves, hence I could not resist using a passage of 'Becky's' chronicle to open the epilogue in comic mode:
And that is the story of how Dean killed Lilith. (Although really, in the opinion of the writer, it was mostly thanks to Sam. I mean Dean fired the actual bullet, and he did turn out to be pretty awesome when he wasn't being a dick. But it was totally Sam who heroically used himself to entice and trap her despite knowing it was him she wanted to kill). And so, like the great teachers of old-
Becky frowned, crossed out old, and wrote antiquity. Then she crossed out antiquity and wrote, historic times. She huffed, and dropped the journal (reading_is_in 2013b).

Thus, I contributed to the formation of Becky's writing as secondary, derivative, and improper, being unable to omit her bias for Sam from a supposedly objective history.

That story was modestly successful and received complimentary reviews, but a major contribution to this aspect of the discourse, which makes explicit the Gamble/Becky parallel, is tenoko1's The Path We Choose (2012). 
After the disappearance of Chuck, Becky is enraged by the 'new books', which represent Season 6:

Have you read the new books? You know: the ones after Sam saved the world- no thanks to you, I might add? [...] They're terrible! The stupid stuff the two of you pull? The obvious plot holes? The bad writing? It's defamation of character is what it is. There's no way Chuck wrote these, even at your worst, he still tried to protect your images in the eyes of the fans, and he certainly never would have made you look silly! It's all bad filler written by someone who doesn't care! (tenoko1 2012).

Statements such as these, common in fandom, have been readopted by canon as expressed by Marie in 10xo5 (see p.167), a clear example of fandom's discursive transformations making industrial impact, and impacting the broader cultural sphere. The author-function operates to de-legitimate Season 6 and the 'new books' by spanning the Chuck/Kripke binary: the author would never have produced it or them. The 'new books' are 'false prophecies', produced by ghost writers under contract to the publisher. Horrified at the travesty the series has become, the characters help Becky get a job as the new writer, and though she admits that she cannot 'compete with the end of the world' they judge that she has done a good job with the new books, keeping everyone 'in character'. She is not the prophet of the Apocalypse, but she does know how Sam, Dean and Castiel ought to be portrayed: the fan writer is secondary and faithful to the author, thus ranked above industrial production. The reviews shift this construction onto Tenoko1, judging her fic 'much better then [sic] current canon' (kojonoyuri 2012). The objections are to Season 6 directions that fans believe ring false: the 'truth' of matters was established by Chuck/Kripke, and fan writing is legitimated by portraying it as more authentic than post-authorial a production that 'only exists to keep up ratings' (romirola 2011).

Occasionally, however, statements that construct the writings and persons of the Author and the Fan are juxtaposed to undermine the primary/ secondary, original/derivative binary, and the paradox it creates. Consider crowleyshouseplant's B. Rosen and C. Shurley Are Dead (2012b). This fic is based of course on Stoppard's Rosencrantz and Guildenstern are Dead, which is, in turn, based on Shakespeare's Hamlet, itself based on Saxo Grammaticus' version of the Amleth legend, which is based on an earlier chronicle, whose sources are lost to history. These statements open an 'anti-theological' (Barthes 1977, p. 147) perspective: there is no primary text, only an endless series of repetition with difference (Kristeva 1980). In 
this story, Chuck and Becky are summoned by the angels to investigate the mysterious changes in Castiel. Becky is placed in the role of Rosencrantz, and in Stoppard's text, Guildenstern becomes angry that Rozencrantz is always copying him. Rozencrantz, by his own admission, 'can't think of anything original” and is 'only good in support' (Stoppard 1968, p. 78). But in B.Rosen, when Chuck asks,

"Don't you ever wish, Becky [...] that you had written anything original. Instead of just silly fan-fiction?"

She coughs, huffs, seethes. "I have written original things. Besides, just because it's fanfiction doesn't mean it's not original" (crowleyshouseplant 2012b).

Everything may be fanfiction, but every citation is also an original statement. Compare her admonishment to Chuck in Writing (And Other Things That are Hard):

Everything anybody writes has a chance of making you see the characters, the people, in a whole new way. It can transform them and their relationships and the world and you into something new and amazing (trinityofone2009).

The original/derivative binary is challenged, and the case for fandom's transformative impact on the cultural sphere is articulated. Fans, after all, live and work in the world, and fanfic's transformations changes perceptions. Becky's writing does not need to be legitimated by Chuck, nor ours by Kripke. In B. Rosen, Chuck attempts to tell her that the things she has written, notably resurrecting dead female characters, 'never happened' and are 'not canon', but 'fanfiction.' Becky replies, 'I reject your canon and substitute my own' (crowleyshouseplant 2012b). Her work is not constructed as better than Chuck's, or truer, but equal because 'all the words are important.' She suggests that the angels, who think Chuck can rewrite Castiel's floundering story, do it themselves: 'Write your own stories. Instead of doing what someone says. Instead of having someone else do it for you. If you don't like what's going on, just write your own.' Though the angels and Chuck continue to insult her fic as not real, it is ultimately she who frees herself and Chuck from the nooses of their execution, and begins to narrate to him as they walk off and end the story: "It's a wonderful universe [...] Full of adventure and bravery." Her voice is lost as they continue to travel east, towards the ribbon of blue sky and a rising sun.' 
Again, it seems that statements like this have been canon-ized, to some extent, by 10x05, as 'Marie's version' of Supernatural is celebrated onscreen, and the transformative work of fandom is explicitly celebrated. Yet, the paradox is at its most acute here: legitimation through the canonization and broadcast of fanfiction, finally approved, in 10x05, by Chuck's blessing. Meanwhile, B. Rosen receives no comments, and just seven kudos on Ao3, so has not had a great deal of impact in fandom. The Path We Choose gets 212 comments total. So the stronger statements with most impact tend to uphold the secondary position of Becky's writing.

On the other hand, xenoamorist's Tons offeels (2012) receives a respectable 48 comments, and this fic is a clear illustration of how mixing statements from two or more discourses results in a new kind of text. 'Feels' is fan slang for feelings: to have tons of feels is to be overwhelmed with emotions. It is tagged as a crossover with Danielewski's House of Leaves (2000), and mimics the novel's mixed-media layout, excessive footnotes, notes from unknown editor(s), and pastiche of texts from supposedly different sources. House of Leaves is a difficult book to make sense of: the first words, on an otherwise blank page, are 'this is not for you.' In it, several narrators contribute versions of events, mostly linked by the first narrator's obsession with a dead man's account of a documentary film. Chanen suggests its subject is 'the creation of and search for meaning in a remediated narrative' (2007, p. 163). It is a text about a text about a text; about obsession with text; and as Woodcock (2009) suggests, a satire on academia. Each 'contributor' has a different font. Tons of Feels is also a text about a text that deals with the location and creation of meaning; it is also about obsession with text, and a satire on academia. It takes the form of an essay written by Becky for a university English class and sent to Chuck, which has been prefaced and appendixed by him, and variously annotated by unknown 'eds'. Again, the contributors each have their own font, and the opening statement, 'this is not for you', appears to be written by Chuck to himself, an attempt to separate the writings of the fan from his own. The discourses that clash here are academic, fannish, authorial and literary-academic.

The fannish and authorial discourses are in conflict with each other Becky and the editors appear to be Wincest and Dean/Cas fans respectively, and xenoamorist's authorial statements are rather different to Chuck's, positioning her outside the text as an orchestrator. Her author's notes advise us that 'neither Becky's feels nor Chuck's feels reflect my own' and metatextual jokes of which none of the characters can be aware construct the fan-author's overarching presence. For instance, the word 'minotaur', wherever it appears in House of Leaves, is crossed out: one of the editors 
remarks that a previous contributor has 'attempted to systematically eradicate the "Minotaur" theme' (Danielewski 2000, p. 336). In Tons of Feels, every instance of 'Cas' or 'Castiel' is similarly struck through, referencing a longstanding fan division between those who wished for the series to remain with the relatively simple formula of the early seasons, before Castiel was introduced, and those who appreciated the introduction of angels, heaven and the apocalypses. Xenoamorist, the fan author, is thus subtly constructed as master of ceremonies, and the good fan-reader as the enlightened audience. In that sense, the good fan/bad fan divide is maintained between us and Becky: she is a character in the text, helping to produce the mingled discourse, whilst we overlook it from a privileged position.

In Tons of Feels, Chuck's statements form a discourse of Romantic authorship, heightening and satirizing the 'prophet' and 'God' constructions of the original. He reads Becky's essay, and is horrified at the violation of his 'creation', the 'artistry' of his 'vision'. Desperate to believe he is a 'God-chosen genius', fanfic is forcing him to confront this as an 'illusion'. Chuck wanted to keep his vision pure and unsullied, textual analysis being 'almost the same as this fanfic abomination'. He resorts to quoting Barthes in academic style, but then footnotes that footnote: 'Look ma, I know how to cite bullshit that people spew and publish for more people to regurgitate. Only article that ever stuck with me after three semesters of English classes.' The imagined purity of academia is brought into conflict and conjunction with both fannish discourse and outdated discourses of authorship, so that each shows up the cracks in the other. The author is alive enough to reject his own death, but in doing so, shows himself out of touch with the workings of text. He can claim the right and desire to control meaning, but cannot carry out his will. Meanwhile, Becky's essay, which begins conventionally enough, breaks down with an apology:

i'm sorry prof daniels but i just cannot with my feels (xenoamorist 2012).

'Feels' is in blue font. The absences and limitations of academic discourse are revealed in its clash with statements from fandom: with its prescribed style and format, it fails to account for the emotional, passionate, anti-rational aspects of our relations with text, the 'emotional rush' explored by Zubernis and Larsen (2012, p. 1). Indeed, Louisa Stein has argued that, whilst fan communities often posit standards for correct English and a traditional model of high quality writing, they can also be understood as 'cultures of feels', where 'emotions remain intimate but are no longer necessarily 
private, with the emotional impulse to collective authorship operating as a binding force of community (2015, pp. 156-159). The good fan/bad fan divide is also flouted, as the rational mode, which as Chuck Writes demonstrates can come very close to academic writing, may not account sufficiently for our 'feels' either (cf. Hills 2002, pp. 16-21). The next page is a series of twitter hashtags, strings of letters approximating the random smashing of keys, and a text-boxed excerpt from Becky's canonical fic. Even the fanfic eventually breaks down into the bare letters, spaced out across several pages on individual lines, which spell out 'goddamit wincest'. Ultimately, this fic enacts the collision and mutual undermining of statements from varied discourses, in a style only possible in this space, culminating in the final statement, gar nichts muss sein (nothing must be), answering the opening, and the opening of House of Leaves, 'muss es sein?' (must it be?).

This undermining of the author's writing/fan writing binary, and the fan writer/academic writer binary in addition, is of moderate impact. The comments also enact the collision of fannish and academic, or good fan/ bad fan registers: I commented myself that 'I was srsly having lit-crit squees' (reading_is_in 2012). The fan/author dyad has been replaced, and many of the statements constructing the fan in canon have simply been placed onto the bad fan side of the dyad. However, self-identification sometimes straddles the divide, which in itself is broken and uneven, each half blending into the other rather than statements specifically destabilizing other statements (fig. 20). Fics like Tons of Feels suggest that good fan discourse does not properly account for the sexual/emotional aspects of fandom, in short, the feels.

Thus, in this sense, fanfic has transformed the governing statements of the source, the author/fan primary/secondary binary; but the most popular and influential statements in the formation are still those which uphold it. Chuck's writing is usually upheld in fic as canonical and true, even whilst the figure of the fanboy-auteur is mocked. Paradoxically, the fan writer can utilize the figure of Chuck to author-ize her own writing, though when he is constructed explicitly as writing 'like a fan,' then the non-canonical construction of fan writing consolidated from the source text may actually work backwards to de-legitimate writing attributed to Chuck. Moreover, though Becky and her writing are redeemed and revalued in fic, it is frequently in relation to Chuck and legitimated by him, in the same way the fan and her fic is canonically legitimated, within boundaries, by Eric Kripke. Further, though specific fannish interventions in the discourse open a space for the positive constructions of some kinds of fandom, we seem unable to eschew the shadow of the other, bad fan, constructed largely 
as broader culture would have it (cf. Hills 2002; Stanfill 2013; Zubernis and Larsen 2012). Sometimes we acknowledge the artificiality of the good fan/ bad fan divide, or construct our own personas as overlapping it, but the divide itself, and the 'split subjectivity' of fandom created by it, is apparently indispensable. Nonetheless, in fics which negate the divide, the legitimation paradox begins to be tentatively deconstructed. We are beginning to see fics that specifically address the questions of originality, authorship, and the value of fanfic as transformative work that opens categories of interpretation in broader society. Finally, in a striking example of how fanfic changes popular cultural texts in a concrete industrial sense, we then saw the legitimation paradox taken up and played out on screen, canonized by Supernatural and validated by the blessing of Chuck in 10x05. The case of Supernatural thus goes furthest in demonstrating the transformative impacts of fandom in a concrete sense, and whilst the same potentials exist in Sherlock and GoT fic, it may well be the case that the showrunners' explicitly permissive stances with regard to fan production have enabled these discursive transformations. This case has also demonstrated the most radical discursive transformation, and unlike the others, begins to undermine the very concepts on which the governing statements depend. Nonetheless, whilst Supernatural is an extreme case, the increasing industrial trend of acknowledging and incorporating fandom, even for economic reasons, means that fanfic's is becoming an increasingly visible means of transforming discursive social categories. Now, in conclusion, we will assess the results and potentials this study has made visible, and discuss future work that could use different methodologies to further and build on these insights. 


\section{Conclusion}

This study has established that statements from fanfic do alter the discursive formations of canonical media in fundamental ways, altering governing statements. However, fanfic's legitimation of othered properties frequently depends on the capital of the already-empowered White man, especially the author. We established this is in the first chapter, where fanfic legitimated the construction of femininity, emotion, the global East and the body via the figures of Sherlock and John, the archetypal Englishmen. This may be implicated by the problem some postcolonial critics recognize, of counternarratives as ultimately reaffirming the primacy of the canonical author's voice through citation and reference (Jacziminski 2009; Singh 2012); but equally, they may be taken in a more postmodern spirit as undermining that primacy by showing up the gaps and absences of the 'original' (cf. e.g. Kraus 1985; Hutcheon 1988; Bhabha 1994; Anyinefa 2000; Bannet 2011), thus questioning its status. Moreover, fanfiction demonstrates that the intricate connections between the male body and its social position, in a way that canon elides. In accordance with Dyer's arguments, Canon's silence on the matter renders the supremacy of the White man natural and unquestioned; fanfic de-naturalizes it.

We saw less illustration of this in the authority chapter, where the word of the traditional White male author seems to exert quite significant power. Constructions of authority in fanfic are not drastically different from those of the series. Certainly, forms of feminine authority that are absent from canon are constructed and patriarchal structures illustrated as both fragile and brutal, yet on the whole the discursive formation is not as dramatically changed from canon as one might expect, particularly in its relative disinterest in authority of the commons. The strong authorial posture Martin strikes, hooking into the popular cultural discourse of authority, does seem to have some effect, particularly as parody tends to meet with a lukewarm response. Here fanfic is primarily 'colour[ing] inside the lines' (Booth 2015, p. 2) rather than transforming a picture, replicating and consolidating ideological statements from canon. Martin's authorship is generally respected, but the authorship of Benioff and Weiss is not constructed in the same way; in a sense, the licence they have taken with the 'real' text seems to permit fans to take even more licence, in an illustration of what I have named textual provocation. That said, Martin's author figure is not above rebuke: the authority of his text is gently mocked on the grounds of alleged poor style and the excessive killing-off of characters. This aligns 
with theories of fan-text as corrective to canon (Jenkins 2006b, pp. 54-57; cf. Goodman 2015).

Fandom's reconstruction of the Author and the Fan is both the clearest expression of the legitimation paradox, and also goes furthest to undermine it. Fics like The Chuck Writes Story; I'll Take my Chances and Tons of Feels suggest, the primacy of the author and his text is an illusion to be deconstructed. However, the quantitative aspect of my methodology demonstrates that fics which uphold the author's text as primary and the fan's as secondary tend to be of highest impact in the formation. Nonetheless, fanfic is tentatively starting to de-construct the legitimation paradox, and in this way, the statements which fandom has contributed in all formations may begin to compromise the legitimation paradox, and the authorial position of the fanboy-auteur begins to be undermined. 10x05's uptake of these statements demonstrates the paradox at its most acute: a simultaneous canonical approval of fanfic's transformative capacity, approved and legitimated by the beneficent Author-God. This is also a concrete example of transformations enacted by fanfic taken up and broadcast in the public sphere. 'Fan fiction' explicitly addresses the question of authority over text, author-ized versions and fan versions, and validation — to an extent - of the fantext may well 'generate different interpretative categories' as Artieri described the transformative work of fic (2012, p. 463). Moreover, as the explicit discussions of gender and Oriental othering in regard to fanfic demonstrate, fanfic overlaps with and involves current social discourses with transformative effect. As fanfic becomes increasingly visible and easy to access, appearing even as noted on sites like Goodreads, there is no longer any reason we should treat its social potentials less seriously than any form of fiction.

By addressing the question of how fanfic transforms and upholds the discursive formations of a cult text, I have established a persepctive that undermines both overly-celebratory readings of fandom (Jenkins 1992, 1995, 2006a; Bacon-Smith 1992; Costello 1999) and understandings of fandom as co-opted by industry (Andrejevic 2008; Russo 2009). By adding its own statements to discursive formations, undermining, contradicting and consolidating canonical constructions, fandom can and does work to legitimate what is culturally othered, including and especially itself. Through the collision of statements from varying discourses, fanfic begins to create new knowledge in fictional spaces, utilizing the gaps and possibilities of canon and reality to reveal basic assumptions and the possibilities they exclude. But, by the very fact that those transformations depend on a canonical source, the legitimation becomes paradoxical. The characters 
that fic appropriates are White men, or women living in a world ruled by them. Fan writing is legitimated through the word of the author. However, in some cases, we are beginning to question and deconstruct that process of legitimation in terms of what is already legitimate, thus revaluing Othered properties like irrational fan-attachment on their own terms.

The implications of this paradox and its development are applicable to all text that is self-consciously transformative, derivative, or secondary. Scholars could analyse how those texts are positioned in relation to their temporal predecessors, and whether their modes of citation are such that shore up the primacy of the original, or question the construction of that primacy and the concepts of authorship and originality inherent in it. How this paradox operates in different genres and contexts will be various, and require the study of scholars familiar with their histories and conventions. In the case of fanfiction, addressing absences and elisions in the 'original', or, from a more explicitly theoretical perspective, mix discourses that draw attention to the constructs and constraints of both authorial and fan production. Shoring up the concept of primacy might take the form of legitimating an Othered property via a White male character; or explicit deference to the originating author. We must be careful, though, not to fall into a false binary of 'text that subverts original authority' versus 'text that confirms original authority': all derivative or transformative text is, by its very form, both legitimating and critical of the primacy of its sources. This is why I have suggested we can 'begin to deconstruct' or 'compromise' the paradox, rather than employ liberatory rhetoric like 'break free' or 'overcome'.

Different genres and contexts of production will produce their own possibilities. In a sense, the paradox is applicable to all text, being citation with difference, but has particularly relevance in contexts like fandom, women's writing, and postcolonial studies, being forms of text that have been Othered until relatively recently. The paradox and the issues it raises can be immediately applied to other fandoms and their fic for, as noted, cult television in general still privileges White male author figures and characters. Scholars could attempt to ascertain if there are factors in particular source texts and/or fan spaces which influence fanfic's tendency to shore up or deconstruct the paradox, and how statements play out different settings and arenas. Does the written text, for instance, retain a greater aura of authority than the screen? Do the statements of other strong author figures restrain the productions of their fandoms? As we have seen, authorial statements may well be a limiting or restrictive factor in media characters' afterlives, as Foucault's author function theorized (1991). Does the kind of fanwork influence transformative statements_-are cosplay and modelling, which 
often serve a 'mimetic' function based on recreation of an original text at the denotative level (Hills 2014), typically more faithful to the discursive and ideological statements of their canon than written text or vidding? Scholars might attend particularly to the kinds of statements I have called textual provocation: acknowledgements of active audienceship that, though implicitly or explicitly derivative, provoke the production of more text.

Discourse analysis helped inform a method that has been attentive to the literary, televisual, fannish, academic and broader cultural discourses that inform fanfiction, an explicit practice of mingled citation with difference. This enabled me to note where the impact of statements from one discourse impacts the meanings of others, such as impact of fannish tropes on the characters of Sherlock and Watson, or the critique of rational academia from fannish statements of 'feels'. Foucauldian theory has helped me to identify the conditions of existence of discursive formations, formulate their rules of possibility, and perceive the governing statements that make further statements possible. This has been very useful in demonstrating where and how a practice as varied as fanfic alters canon's constructions and where and how it solidifies them.

Fan subjectivities and psyches are not addressed by the orientation of this study. Indeed, a psychoanalytic method is explicitly at odds with discursive analysis, which operates as Foucault argued according to a 'principle of exteriority' (1981, p. 67). That is to say, it attends to surfaces and exteriorities in order to make demonstrable, empirical arguments concerning processes of change in action. If the founding principles of Critical Discourse Analysis - that language is taken active and effective, and that a statement is material event, an 'incision into a discursive field' (Young, p. 402; cf. Foucault 1989, p. 28), then intentions and motivations behind said statements are irrelevant. What matters is effect, and the range of possibilities that is enabled or closed down. Discursive formations deserve study in their own right, for as Fairclough and Fairclough have written, discourse is 'on the one hand an effect of social life, and on the other, ha[s] effects on social life, both helping to keep existing forms in existence and helping to change them' (2012, p. 79). Fanfiction studies lacks large-scale empirical studies with transparent methodologies, and I hope future scholars can take precedent from this work in accounting for their selection and reading of fan-texts. Yet, scholars more comfortable and accomplished in psychoanalytic theory could explore fans' interpretations and awareness of the legitimation paradox in ways I have not done so. Whilst it may be harder to make arguments regarding cultural impact and change from this perspective, an exploration of fans' private reception of statements, and how they uphold or subvert textual 
authority and constructions, could add another qualitative dimension to the analysis of statement-impact that goes beyond a strictly textual study.

As has been noted, Foucauldian methodology up until now has lacked analysis of reception. This project goes some way to address that lack, via documenting and analysing reviews, but despite the fact that internal mechanisms of regulation were in evidence it is likely that the fannish norms of praise over criticism prevent some resistance from taking textual form. Again, a psychoanalytic methodology using interviews or focus groups could supplement this picture. Moving beyond fic, the legitimation paradox could be used to explore how fans affirm and accept othered aspects of their identities, activities and desires through relation to and appropriation of their canons and author figures. The concept might be usefully applied to a whole range of fan activities sourced from favoured texts, from role-playing to crafting to game modification. Quite likely, methodological tools that attend more closely to visual semantic content will be needed in those contexts, though the principles of discursive analysis, at the level of the statement, transformation and consolidation of discourses need not necessarily be applied to the written word only. Researchers wishing to read the fanart, vids, and music mixes that exist within these same networks will need to bring their own academic background to reconceive my reading of 'statements'. One potential weakness of this book is that it is very much the work of a literary scholar. Whilst in my situated experience, fanfic is strongly invested in literary capital and conventions, it is still part of a multimedia network involving other kinds of text. This limitation could only be overcome by a team of scholars trained in reading various arts; lacking that, the present researcher can only be explicit concerning her biases, and hope that the example provided in this work can stimulate further study.

By utilizing tools from internet studies and network analysis, the methodology of this study demonstrated a quantitative and qualitative way to read texts in a networked, new media context, enabling the researcher to make empirically-based statements concerning impact and alteration. I have not attended only to fanfic, but the contexts in which it appears, the number and type of responses, and the ripples of impact it makes in other sites. Demonstrating the range and average number of comments/ reviews, I have been able to evidence what is meant by terms like 'high impact' or 'insignificant'. I have attended also to the qualitative aspect of responses, as mockery and derision can reduce the status of fic as much as praise can raise it. There was a slight margin of error here, due to a) some fic being locked, and b) the fact that, as described in the methodology, common author-names and titles had to be searched in only one pair of 
quotation marks. A researcher with better computer literacy than I may be able to improve upon this. In addition, the precision of impact measurement would be improved if software became available to count links and recommendations for fic from Tumblr, a platform that was increasing in popularity at my time of writing. The overall method should be transferrable to other fandoms, as fic is typically archived and networked in similar ways, according to social and technological structures that existed before these fandoms and will exist after their cultural moment is over. Though I have made my processes as transparent as possible, there is necessarily a danger that the frames drawn by any given researcher may artificially separate one formation from another, or connect them in ways biased by personal and intuitional context.

The transposition of fan texts into an academic context can be ethically conducted where a) permission is sought and drafts shared and b) the researcher accounts for her position in an academic network as well as a fannish one, especially the power imbalance that may be entailed therein, and draws attention to fact that research and presentation of discursive formations to an academic audience itself plays a role in their consolidation. As the analysis of my own fic demonstrates, I have not exempted my own writing as an object of analysis, but in following the methodology, addressed it and the discourse it is implicated in as I would any other fic. Relatedly, I hope that I have demonstrated that it is possible to conduct a full scale research project into fanfic with full knowledge, awareness and consent of the fans quoted, and that this consideration is appreciated by fans. There were certainly cases in which the writer could not be reached, but in every case I made a good-faith effort, as described in the Ethics section. I respected all requests for anonymity and the omission or inclusion of links; and conversely, honoured some fans' requests to be quoted by their real names. Academics who choose to quote texts intended for limited circulation, without permission, must work harder to justify that choice, and with it, the fannish identity they afford themselves.

As world's fastest-growing form of writing (Mirmohamadi 2014, p. 5) the increasing visibility and influence of fanfic on popular culture demands innovative tools of study. The uptake and to an extent promotion of fanfic by big media producers, as we have seen explicitly in Supernatural especially, means it can no longer be considered a hidden subculture, but a contemporary mode of writing with demonstrable impact on media culture. As I hope this work has demonstrating, this rapidly expanding, rapidly changing phenomenon demands serious study, both as a means of transformation and resistance, and as a means of consolidation of contemporary cultural discourse. 


\section{Bibliography}

\section{Written Texts}

$1000^{\text {th }}$ Ghost. 2014. Game of Thrones: Predictions. Fanfiction.net. Available at: <https://www.fanfiction.net/s/10705252/1/Game-of-Thrones-Predictions > [accessed 17/08/15].

3. 2012. Review of The Bloodline. Fanfiction.net. Available at: <https://www.fanfiction. net/r/8070911/o/2/> [accessed 17/08/15].

1electricpirate. 2012. Multiply (The Sum of our Parts). LiveJournal. Available at: $<$ http://1electricpirate.livejournal.com/7499.html\#cutid1> [accessed 05/02/15].

Abundantlyqueer. 2013. Two Two One Bravo Baker. Ao3. Available at: <http://archiveofourown. org/works/180121?view_full_work=true> [accessed 05/02/15].

Adkins, Lisa. 2002. 'Reflexivity and the Politics of Qualitative Research'. In: May, Tim, (ed.), Qualitative Research in Action. London and Thousand Oaks, California: Sage, pp. 332-348.

a_dragonlady. 2015. Comment on Game Change. LiveJournal. Available at: <http://got-exchange. livejournal.com/148748.html> [accessed 14/08/15].

adrenalineshots. 2009a. Bean Stalker. LiveJournal/Ao3. Available at: <http://adrenalineshots. livejournal.com/32434.html> [accessed 22/02/13].

- 20ogb. Comment on Bean Stalker. LiveJournal. Available at: <http://adrenalineshots.livejournal.com/20980.html> [accessed 22/02/13].

AliKat7. 2014. The Wind Itself Was Their Song. Fanfiction.net/LiveJournal/Ao3. Available at: <http://archiveofourown.org/works/683297/chapters/1253839> [accessed 17/08/15].

Allan, K. 2005. Explorations in Classical Sociological Theory. London and Thousand Oaks, California: Sage.

— Seeing the Social Worldalways-black-and-white. 2014. He Deserves It. Fanfiction.net. Available at: <https://www.fanfiction.net/s/1001189o/1/He-Deserves-It > [accessed 05/02/15].

amorremanet. 2012. 'It's Not That Kind of Show'. Ao3. Available at: < http://archiveofourown.org/ works/428131> [accessed 22/02/13].

Andersen, Niels Å. 2003. Discursive Analytical Strategies: Understanding Foucault, Koselleck, Laclau, Luhmann. Bristol: Policy Press.

Andrejevic, Mark. 2008. 'Watching Television without Pity: The Productivity of Online Fans'. Television \& New Media 9 (1), pp. 24-46.

angel_gospel. 2011. Comment on I'm Still Waiting on the Right Words. LiveJournal. Available at: <http://dontbitethesun.livejournal.com/206o.html> [accessed 26/02/13].

Anyinefa, Koffi. 200o. Postcolonial Postmodernity in Henry Lopé’s Le Pleurer-Rire'. In: Glover, Daniel, et al. (eds), The Postcolonial Condition of African Literature. Trenton, New Jersey: Africa World Press.

Anon. 1. 2012. Review of Waking Up to Us. Fanfiction.net Available at: <https://www.fanfiction. net/r/6920912/> [accessed 02/02/15].

Anon. 2. 2013. Review of The Birds and Bees. Fanfiction.net. Available at: <https://www.fanfiction. net $/ \mathrm{r} / 9374659 />$ [accessed 05/02/15].

Anon. 3. 2014. Review of The Baker Street Dozen. Available at:<https://www.fanfiction. net/r/9733099/> [accessed 05/02/15].

Anon.4. 2013. Review of Every Path. Ao3. Available at: <http://archiveofourown.org/ works/929417?view_full_work=true> [accessed 05/02/15].

Anon. 5. 2014. Review of Little Surprise. Fanfiction.net. Available at: <https://www.fanfiction. net $/ r / 7763811 />$ [accessed 05/02/15]. 
Anon. 6. 2013. Review of Little Surprise. Fanfiction.net. Available at: <https://www.fanfiction. net $/ \mathrm{r} / 7763811 />$ [accessed 05/02/15].

Anon. 7. 2013. Review of Little Surprise. Fanfiction.net. Available at: <https://www.fanfiction. net $/ \mathrm{r} / 7763811 />$ [accessed 05/02/15].

Anon. 8. 2012. Review of Little Things. Ao3. Available at: <http://archiveofourown.org/ chapters/887881?show_comments=true $>$ [accessed 09/02/15].

Anon. 9. 2014. Review of On the Way There. Fanfiction.net. Available at: https://www.fanfiction. net/r/10951220/o/3/ [accessed 14/03/15].

Anon. 10. The Song of Rhaego Fireborn. Fanfiction.net. Available at: <https://www.fanfiction. net $/ \mathrm{r} / 7432238 />$ [accessed 14/08/15].

Anon. 11. Review of Don't Blink. Fanfiction.net. Available at: <https://www.fanfiction. net/s/11095491/2/Don-t-Blink> [accessed 17/08/15].

Anon. 12. Review of Remember Me in Blood. Fanfiction.net. Available at: <https://www.fanfiction. net/r/7889998/> [accessed 14/08/15].

Archimedes, Sondra. M. 2005. Gendered Pathologies: The Female Body and Biomedical Discourse in the Nineteenth-Century English Novel. London and New York: Routledge.

Arendt, Hannah. [1954] 2006. Between Past and Future: Eight Exercises in Political Thought. London: Penguin.

Artieri, Giovanni Boccia. 2012. 'Productive Publics and Transmedia Participation'. Participations 9 (2), pp. 448-468.

Articioc 2014. A Brief History of the Warr of the Five Kings. Fanfiction.net. Available at: <https://www.fanfiction.net/s/9790796/2/A-Brief-History-of-the-Warr-of-the-Five-Kings > [accessed 17/08/15].

Ashesintheair. 2015. After the Dragons. Ao3. Available at: <http://archiveofourown.org/ works/3294917/chapters/7192457> [accessed 14/08/15].

Assis, Amit. 2011. Author-ity. Mafte'akh: Lexical Review of Political Thought, $2^{\text {nd }}$ edition, pp. $1-28$.

Åström, Berit. 2010. 'Let's Get Those Winchesters Pregnant': Male Pregnancy in Supernatural Fan Fiction'. Transformative Works and Cultures 4. Available at: $<$ http://journal.transformativeworks.org/index.php/twc/article/view/135/141 [accessed o9/02/15].

ataratah. 2010. Comment on Your Apple Pie Suburban Hell Happily Ever After. Available at: $<$ http://archiveofourown.org/works/86875?show_comments=true\#comments $>$ [accessed 22/02/13].

Ault, Amber. 1996. 'The Dilemma of Identity: Bi Women's Negotiations'. In: Seidman, Steven (ed.), Queer Theory/Sociology. Cambridge: Wiley-Blackwell, pp. 311-330.

Ausiello, M. 2007. Supernatural Exec: 'We won't be One Tree Hill with monsters!' TV Guide. 21 July 2007. Available at <http://www.tvguide.com/news/Supernatural-Exec-We-8522.aspx> [accessed 20/01/12].

- 2010. 'Supernatural' Exclusive: Eric Kripke Stepping Down as Showrunner'. Entertainment Weekly. 16 February 2010. Available at: <http://insidetv.ew.com/2010/02/16/supernatural-erickripke-steps-down-showrunner/> [accessed 30/12/11].

Awesomepigman. 2014. Fandom Conquerors. Fanfiction.net/Ao3. Available at: $<$ http://archiveofourown.org/works/1325767/chapters/2759875> [accessed 17/08/15].

Aycock, Alan and Norman Buchignani. 1995. 'The Email Murders: Reflections on 'Dead' Letters'. In: Jones, Steven (ed.), Cybersociety: Computer-Mediated Communication and Community. London and California Sage, pp. 184-231.

Bacon-Smith, Camille. 1992. Enterprising Women: Television Fandom and the Creation of Popular Myth. Philadelphia University of Pennsylvania Press. 
Bailey, Steven. 2005. Media Audiences and Identity: Self-construction in the Fan Experience. Basingstoke: Palgrave Macmillan.

Baker-Whitelaw, Gavia. 2014. 'Why the Latest Episode of Sherlock was a Gift Meant for Fans'. The Daily Dot. 7 January 2014. Available at: <http://www.dailydot.com/fandom/sherlocksign-three-fandom-fanservice/> [accessed 02/02/15].

Bannet, Eve T. 2011. Transatlantic Stories and the History of Reading, 1720-1810 Cambridge: Cambridge University Press.

Barthes, Roland. 1977. 'Death of the Author'. In: Image, Music, Text. Heath, Stephen, trans. London: HarperCollins, pp. 142-148.

Basu, Balaka. 2012. 'Sherlock and the [re]invention of modernity'. In: Stein, Louisa E. and Kristina Busse (eds), Sherlock and Transmedia Fandom: Essays on the BBC Series. Jefferson: McFarland, pp. 196-209.

Baym, Nancy K. 1995. 'The Emergence of Community in Computer-Mediated Communication'. In: Jones, Steven, ed, Cybersociety. London and Californi: Sage, pp. 138-163.

— 1998. 'The Emergence of On-Line Community'. In: Jones, Steven (ed.), Cybersociety 2.o: Revisting Computer-Mediated Communication and Community. London and Thousand Oaks, California: Sage, pp. 35-68.

- 2000. Tune In, Log on: Soaps, Fandom, and Online Community. California: Sage.

- 2010. Personal Connections in the Digital Age. Cambridge: Polity.

BBC Media Centre. 2012. Media Pack: Sherlock. Interview with Stephen Moffat. Available at: <http://www.bbc.co.uk/mediacentre/mediapacks/sherlock/moffat.html > [accessed 02/02/15].

Beaulieu, Anne. 2005. 'Sociable Hyperlinks: An Ethnographic Approach to Connectivity'. In: Hine, Christine (ed.), Virtual Methods: Issues in Social Research on the Internet. Oxford and New York: Berg, pp. 183-198.

Beamont-Thomas, Ben. 2014. 'Game of Thrones Becomes Most Popular HBO Show Ever'. The Guardian online. 6 June 2014. Available at: <http://www.theguardian.com/tv-and-radio/2014/ jun/o6/game-of-thrones-most-popular-hbo-show-sopranos> [accessed 29/07/15].

BeautifulFiction. 2015. The Gilded Cage. A03. Available at: <http://archiveofourown.org/ works/1103555?view_full_work=true> [accessed o9/02/15].

Bekakos, Liana. 2011. 'Supernatural Holds Panel at the Paley Festival'. Empire Magazine. Available at: <http://shma.diary.ru/p152625707.htm?oam/> [accessed 20/02/15].

Belle. 2014. Comment on The Bakers Street Dozen. Available at: <http://archiveofourown.org/ works/991717/chapters/2449596> [accessed 02/02/15].

Benedictsexual. 2012. Little Surprise. Fanfiction.net. Available at: <https://www.fanfiction. net/s/7763811/1/Little-Surprise $>$ [accessed o9/02/15].

Benwell, Bethan. 2002. 'Is There Anything New About These Lads?' In: Litosseliti, Lia and Jane Sunderland (eds), Gender Identity and Discourse Analysis. Philadelphia and Amsterdam: John Benjamins, pp. 149-174.

Bhabha, Homi. K. 1994. The Location of Culture. London and New York: Routledge.

Black, Rebecca. 2008 Adolescents and Online Fanfiction. New York: Peter Lang.

Blazen. 2013. Review of Blood of the Direwolf. Fanfiction.net Available at: <https://www.fanfiction.net/r/7519156/4/1/> [accessed 14/08/15].

Berglund, Gun. 2008. 'Pathologizing and Medicalising Lifelong Learning: A Deconstruction'. In: Fejes, Andreas and Katherine Nicoll (eds), Foucault and Lifelong Learning: Governing the Subject. London and New York: Routledge, pp. 138-150.

Blank, Grant. 2008. 'Online Research Methods and Social Theory'. In: Fielding, Nigel G., Raymond M. Lee, and Grant Blank (eds), The Sage Handbook of Online Research Methods. London and California: Sage, pp. 537-549. 
Bode, Lisa. 2010. 'Transitional Tastes: Teen Girls and Genre in the Critical Reception of Twilight'. Continuum 24 (5), pp. 707-719.

Booth, P. 2015. Playing Fans: Negotiating Fandom and Media in the Digital Age. Iowa City: University of Iowa Press: Kindle edition.

Bourdieu, Pierre. 1977 [1979] 1986. Distinction: A Social Critique of the Judgment of Taste. Nice, Richard, trans. London and New York: Routledge and Kegan Paul.

— 1993. The Field of Cultural Production. Johnson, Randal (ed.), Columbia: Columbia University Press.

- [1992] 1996. The Rules of Art: Genesis and Structure of the Literary Field. Emanuel, Susan, trans. Cambridge: Polity.

Bourdieu, Pierre and Loïc J. D. Wacquant. 1992. An Invitation to Reflexive Sociology. Cambridge: Polity.

Brandt, Deborah. 1998. 'Sponsors of Literacy'. College Composition and Communication 49 (2), pp. $165^{-185}$.

- 2001. Literacy in American Lives. Cambridge: Cambridge University Press.

Bury, Rhiannon. 2005. Cyberspaces of Their Own: Female Fandoms Online. New York: Peter Lang. Busse, Kristina. 2006. 'Podcasts and the Fan Experience of Disseminated Media Commentary. Austin, Texas. Flow Conference, 26-29 October 2006. Available at: $<$ http://www.kristinabusse. $\mathrm{com} / \mathrm{cv} /$ research/flowo6.html> [accessed 22/04/11].

— 2010. 'Author as God? or, Kripke, We Don't Need You to Explain Supernatural to Us'. Antenna: Responses to Media and Culture. Available at: <http://blog.commarts.wisc.edu/2010/05/17/ author-as-god-or-kripke-we-don $\% \mathrm{E} 2 \% 80 \% 99$ t-need-you-to-explain-supernatural-to-us/> [accessed 20/01/12].

Busse, Kristina and Shannon Farley. 2013. 'Remixing the Remix: Fannish Appropriation and the Limits of Unauthorised Use'. $M / C_{1} 6$ (4). Available at: <http://journal.media-culture.org.au/ index.php/mcjournal/article/viewArticle/659> [accessed 30/08/13].

Busse, Kristina and Alexis Lothian. 2009. 'Bending Gender: Feminist and (Trans)Gender Discourses in the Changing Bodies of Slash Fan Fiction'. In: Hotz-Davies, Ingrid, Anton Kirchofer and Sirpa Leppänen (eds), Internet Fictions. Newcastle upon Tyne: Cambridge Scholars, pp. 103-126.

Busse, Kristina and Louise E. Stein. 2012. 'Conclusion: Transmedia Sherlock and Beyond'. In: Sherlock and Transmedia Fandom, pp. 224-231.

Butler, Judith. 1993. Bodies That Matter: On the Discursive Limits of "Sex." London: Routledge.

Callewaert, Staf. 2006. 'Bourdieu, Critic of Foucault: The Case of Empirical Social Science against Double-Game-Philosophy'. Theory, Culture \& Society 23(6), pp. 73-98.

Campbell, John. E. 2011. Aca-Fandom and Beyond: John Edward Campbell, Lee Harrington, and Catherine Tosenberger. Part One. Available at: <http://henryjenkins.org/2011/07/acafandom_and_beyond_harringt.html> [accessed 14/02/12].

Carabine, Jean. 2001. 'Unmarried Motherhood 1830-1990: A Genealogical Analysis'. In: Wetherell Margaret, Stephanie Taylor, and Simeon J. Yates (eds), Discourse as Data: A Guide for Analysis. London and California: Sage, pp. 267-307.

carreracaminos. 2013. Comment on Two Two One Bravo Baker. Aoz. Available at: $<$ http://archiveofourown.org/works/180121?view_full_work=true> [accessed 24/05/15].

cassiem9009. 2014. Review of The Gilded Cage. Ao3. Available at: <http://archiveofourown.org/ works $/ 1103555$ ?page=32\&show_comments=true $>\&$ view_adult=true $>\&$ view_full_work=true $>$ [accessed 02/02/15].

Chanen, Brian W. 2007. 'Surfing the Text: The Digital Environment in Mark Z. Danielewski's House of Leaves'. European Journal of English Studies11 (2), pp. 163-176. 
Chin, Bertha. 2010. 'From Textual Poachers to Textual Gifters: Exploring Fan Community and Celebrity in the Field of Fan Cultural Production'. PhD dissertation, Cardiff University.

— 2013. 'The Fan-Media Producer Collaboration. How Fan Relationships are Managed in a Post-Series X-Files Fandom'. Science Fiction Film \& Television 6 (1), pp. 87-99.

Cherry, Brigid. 2011. 'Sympathy for the Fangirl: Becky Rosen, Fan Identity and Interactivity in Supernatural'. In: Abbott, Stacey and David Lavery, (eds), TV Goes to Hell: An Unofficial Roadmap of Supernatural. Toronto,Canada: ECW Press, pp. 203-218.

chiiyo86. 2009. Comment on Bean Stalker. Available at: <http://adrenalineshots.livejournal. com/20980.html $>$ [accessed 22/02/13].

Cicioni, Mirna. 1998. 'Male Pair-Bonds and Female Desire in Fan Slash Writing'. In: Harris, Cheryl and Allison Alexander, (eds), Theorizing Fandom: Fans, Subculture and Identity. New York:: Hampton, pp. 153-177.

Collin Smith, Anne. 2009. 'Playing [with] Multiple Roles: Readers, Authors, and Characters in "Who is Blaise Zabini?”'. Transformative Works and Cultures 3. Available at: <http://journal. transformativeworks.org/index.php/twc/article/view/186> [accessed 12/06/10].

Collins, Patricia H. 200o. Black Feminist Thought: Knowledge, Consciousness, and the Politics of Empowerment. 2nd edition. New York: Routledge.

Conan Doyle, A. 1887. A Study in Scarlett. Available at: <http://www.gutenberg.org/ebooks/244> [accessed 05/09/15].

- 1891. 'A Scandal in Bohemia'. In: The Adventures of Sherlock Holmes. Available at: <http:// www.gutenberg.org/files/1661/1661-h/1661-h.htm> [accessed 05/o9/15].

Connell, Rae Wyn. 2005. Masculinities. 2nd edition. Cambridge: Polity.

Consulting Writer M. 2013. A Rose by Any Other Name Fanfiction.net. Available at: <https://www. fanfiction.net/s/9298106/21/A-Rose-by-Another-Name> [accessed 05/02/15].

CoolChica87. 2015a. For Want of a Better King. Fanfiction.net/Ao3. Available at: <https://www. fanfiction.net/s/10951236/1/For-Want-of-a-Better-King > [accessed 14/08/15].

- 2015b. On the Way There. Fanfiction.net/Ao3. Available at: <https://www.fanfiction. net/s/10951220/1/On-The-Way-There> [accessed 14/08/15].

Coppa, Francesca. 2006. 'Writing Bodies in Space: Media Fanfiction as Theatrical Performance'. In: Hellekson, Karen and Kristina Busse (eds), Fan Fiction and Fan Communities in the Age of the Internet: New Essays. Jefferson, North Carolina: McFarland pp. 225-244.

corleones. 2011. Comment on The Joinery. LiveJournal. Available at: <http://falseeeyelashes. livejournal.com/320840.html > [accessed 17/08/15].

Corrigan, Richard. 2012. 'The War in Westeros and Just War Theory'. In: Jacoby, Henry (ed.), Game of Thrones and Philosophy: Logic Cuts Deeper Than Swords. Blackwell: Kindle edition, pp. 49-6o.

Costello, V.J. 1999. 'Interactivity and the 'CYBER-FAN': An Exploration of Audience Involvement within the Electronic Fan Culture of the Internet'. PhD dissertation, University of Tennessee.

CriticalAnalysis. 2013. Review of The Birds and The Bees. Fanfiction.net. Available at: <https://www.fanfiction.net/r/9374659/> [accessed 22/02/13].

crowleyshouseplant. 2012a. Tumblr post. Available at: <http://crowleyshouseparty.tumblr.com/ post/19616739638/i-think-that-when-we-criticize-sera-gamble-as-a> [accessed 22/02/13].

- 2012b. B. Rosen and C. Shurley Are Dead. Ao3. Available at: <http://archiveofourown.org/ works/344152> [accessed 22/02/13].

Cummings, Ed. 2012. 'Game of Thrones interview: DB Weiss and David Benioff'. The Telegraph. 10 April 2012. Available at: <http://www.telegraph.co.uk/culture/tvandradio/game-ofthrones/9195683/Game-of-Thrones-interview-DB-Weiss-and-David-Benioff.html> [accessed 13/08/15]. 
Cuddlefısh. 2014a. Organic Chemistry A03. Available at: <http://archiveofourown.org/ works/1647056/chapters/3491432> [accessed 05/02/15].

— 2014b. Comment on Organic Chemistry. Ao3. Available at: <http://archiveofourown.org/ works/1647056/chapters/3491432> [accessed 05/02/15].

DaliWritesThings. 2013. Our Claws are Sharp. Fanfiction.net. Available at: <https://www.fanfiction.net/s/9868462/1/Our-Claws-are-Sharp> [accessed 17/08/15].

DancingGrimm. 2012. The Acronym. Fanfiction.net. Available at: $<$ https://www.fanfiction. net/s/8656915/10/The-Acronym $>$ [accessed 05/02/15].

Dancyger, Ken. 2006. The Director's Idea: The Path to Great Directing. Oxford: Elsevier.

Danielewski, Mark Z. House of Leaves. London: Random House.

DannyPhantomoftheAvatar. 2014. Not Your Average Mpreg. Fanfiction.net. Available at: $<$ https://www.fanfiction.net/s/9529351/1/Not-Your-Average-Mpreg> [accessed 05/02/15].

DarkLady. Making a Prophet. LiveJournal/Fanfiction.net. Available at: $<$ http://www.fanfiction. net/s/5518391/1/Making-a-Prophet> [accessed 22/02/13].

datalenkoass. 2013. Comment on Life Lessons. LiveJournal. Available at: <http://got-exchange. livejournal.com/9279o.html > [accessed 14/08/15].

Data Protection Act. 1998. Available at:<http://www.legislation.gov.uk/ukpga/1998/29/contents> [accessed 31/05/11].

Day, John. 1963.'Authority'. Political Studies 11 (3), pp. 257-271.

DeanFan. 2010. Lucifer Meets Crazy Becky. Fanfiction.net. Available at: $<$ http://www.fanfiction. net/s/6491928/1/Lucifer-Meets-Crazy-Becky $>$ [accessed 15/08/13].

Deacon, David. 2007. 'Yesterday's Papers and Today's Technology: Digital Newspaper Archives and 'Push Button' Content Analysis'. European Journal of Communication 22 (1), pp. $5^{-25}$.

Defincupark. 2012. Review of In the Arms of an Angel_by Samlicker81. Fanfiction.net. Available at: <http://www.fanfiction.net/r/7709292/> [accessed 22/02/13].

Dennis, J. P. 2010. 'The Boy who Would be Queen: Hints and Closets on Children's Television'. Journal of Homosexuality 56 (6), pp. $73^{8-756}$.

Derecho, Abigial. 2006. 'Archontic Literature: A Definition, a History, and Several Theories of Fanfiction'. In: Fan Fiction and Fan Communities in the Age of the Internet, pp. 61-78.

DeVere, Ariane. 2010-16. Transcriptions of Sherlock and commentaries. LiveJournal. Available at: $<$ http://arianedevere.livejournal.com/36505.html $>$ [accessed 02/02/15].

Dhampir72. 2012. Disappear. A03. Available at: $<$ http://archiveofourown.org/works/575868> [accessed 05/02/15].

didi45. 2013. Comment on Her Liquor's Top Shelf. Ao3. Available at: <http://archiveofourown. org/works/812921?view_full_work=true> [accessed 24/05/15].

DjinnAtwood. 2012. Review of Lucifer Meets Crazy Becky. Available at: <http://www.fanfiction. net $/ \mathrm{r} / 6491928 />$ [accessed 22/02/13]

DKNC. 2013. Comment on A City of Fortune and Failure. A03. Available at: $<$ http://archiveofourown. org/works/800809?page=3\&show_comments=true\&view_adult=true\&\&view_full_work=true > [accessed 25/03/15].

DoctorBilly. 2014. The Other One. A03. Available at: $<$ http://archiveofourown.org/works/2205123 [accessed 05/02/15].

Don. 2015. Review of On the Way There. Fanfiction.net. Available at: <https://www.fanfiction. net $/ \mathrm{r} / 10951220 / 0 / 3>/$ [accessed 24/05/15].

Doty, Alexander. 1993. Making Things Perfectly Queer:Interpreting Mass Culture. Minneapolis, Minnesota: University of Minnesota Press.

- 2000. Flaming Classics: Queering the Film Canon. New York: Routledge. 
Drago. 2013. Comment on Every Path. Ao3. Available at: <http://archiveofourown.org/ works/929417?view_full_work=true $>$ [accessed 05/02/15].

Driscoll, Catherine. 2006. One True Pairing: The Romance of Pornography, and the Pornography of Romance'. In: Fan Fiction and Fan Communities in the Age of the Internet, pp. 79-96.

Dyer, Richard. 1977. 'Victim: Hermeneutic Project'. Film Form 1 (2), pp. 3-22.

- 1997. White. London and New York: Routledge.

earis. 2010. Draw Back the Curtain. Ao3. Available at: <http://archiveofourown.org/ works/94260?view_adult=true> [accessed 22/02/13].

earlgreytea68. 2014. Nature and Nurture. Ao3. Available at: <http://archiveofourown.org/ works/729134/chapters/1354275> [accessed 09/02/15].

Echoxknox. 2013. Note to Out of the Shadows, House Mortem. Fanfiction.net. Available at: $<$ https://www.fanfiction.net/s/9450596/32/out-of-the-shadows-house-mortem> [accessed $17 / 08 / 15]$.

Edelman, Lee. 2004. No Future: Queer Theory and the Death Drive. Durham, North Carolina: Duke University Press.

Edwards, Tim. 2006. Cultures of Masculinity. London and New York: Routledge.

elalendi. 2014. Lucky Like Us. LiveJournal. Available at: <http://got-exchange.livejournal. com/123253.html> [accessed 14/08/15].

Elinorofealdor. 2014. Note to Iced. Available at: $<$ https://www.fanfiction.net/s/10183027/6/Iced > [accessed 17/08/15].

ellie_hell. 2011. Comment on Two Two One Bravo Baker. Ao3. Available at: <http://archiveofourown.org/works/180121?view_full_work=true> [accessed 24/05/15].

Ellis, Carolyn, Tony E. Adams and Arthur P. Bochner. 2011. 'Autoethnography: An Overview'. Forum: Qualitative Social Research 12 (10). Available at: < http://www.qualitative-research. net/index.php/fqs/article/view/1589/3095> [accessed o6/11/13].

emptycel. 2014. The Five Steps of Nesting. Fanfiction.net. Available at: $<$ https://www.fanfiction. net/s/10527277/1/The-Five-Steps-of-Nesting $>$ [accessed 05/02/15].

Emynithilien. 2012. It's the Man Who Makes the Lord. LiveJournal/Ao3. Available at: $<$ https://archiveofourown.org/works/44721> [accessed 14/08/15].

— 2013a. Comment on Life Lessons. Available at: <http://got-exchange.livejournal.com/9279o. html $>$ [accessed 14/08/15].

— 2013b. How Long Have I Been in This Storm? LiveJournal/Ao3. Available at: <http://archiveofourown.org/works/765312> [accessed 14/08/15].

ErinClaire. 2011. Comment on Two Two One Bravo Baker. Ao3. Available at: <http://archiveofourown.org/works/180121?view_full_work=true $>$ [accessed 24/05/15].

Ergott, M. W. Clever Man. Fanfiction.net. Available at: <https://www.fanfiction.net/s/732346o/1/ Clever-Man> [accessed 05/02/15].

ErinacchiLove. 2012. Review of IfThings Were Different. Fanfiction.net. Available at: <https://m. fanfiction.net $/ \mathrm{r} / 7284591 / 0 / 4 />$ [accessed $17 / 08 / 15]$.

Ess, Charles, and the Association of Internet Researchers ethics working committee. 2002. Ethical decision-making and Internet research. Approved by AoIR, November 27, 2002. Available at: $<$ www.aoir.org/reports/ethics.pdf $>$ [accessed 05/31/11].

Evans, Adrienne and Mafalda Stasi. 2014. 'Desperately Seeking Methodology: New Directions in Fan Studies Research'. Participations:Journal of Audience \& Reception Studies 11 (2), pp. 4-23.

EvilConcubine. 2014. Comment on Organic Chemistry. Ao3. Available at: $<\mathrm{http}: / /$ archiveofourown.org/works/1647056?view_full_work=true> [accessed 24/05/15].

Fairclough, Isabela and Norman Fairclough. 2012. Political Discourse Analysis: A Method for Advanced Students. London and New York: Routledge. 
Fairclough, Norman. 1993. Discourse and Social Change. London: Polity.

- 2003. Analysing Discourse: Textual Analysis for Social Research. London and New York: Routledge.

falcytan_dream. 2011. Comment on The Tribulations of Chuck. LiveJournal. Available at: $<$ http://maskedfangirl.livejournal.com/44785.html?page=2\#comments $>$ [accessed 22/02/13].

Falseeyelashes. 2011a. Comment on The Joinery. LiveJournal. Available at: $<$ http://falseeeyelashes. livejournal.com/320840.html?page $=2$ [accessed 17/08/15].

— 2011b. The Joinery. LiveJournal/A03. Available at: <http://falseeeyelashes.livejournal. com/320721.html> [accessed 17/08/15].

Falzone, P.J. 2005. 'The Final Frontier is Queer: Aberrancy, Archetype and Audience-Generated Folklore in K/S Slashfiction'. Western Folklore 64 (3-4), pp. 243-261.

Fanlore. 2014. Alpha/Beta/Omega. Available at: <http://fanlore.org/wiki/Alpha/Beta/Omega > [accessed 02/02/15].

— 2015. Meta essays. Available at: <http://fanlore.org/wiki/Category:Meta_Essays $>$ [accessed $02 / 03 / 15]$.

Fanon, Frantz. 1994. Black Skin, White Masks. New York: Grove Press.

FANFAVMOMA. 2014. Review of A Realm in Rebellion. Available at: <https://www.fanfiction. net $/ \mathrm{r} / 8288324 />$ [accessed 17/08/15].

Fathallah, Judith M. 2014. 'Moriarty's Ghost: Or the Queer Disruption of the BBC's Sherlock'. Television \& New Media 16 (5), pp. 490-500.

Fejes, Andreas. 2008. 'Historicising the Lifelong Learner: Governmentality and Neoliberal Rule'. In: Foucault and Lifelong Learning: Governing the Subject, pp. 87-99.

Felschow, Laura E. 2010. 'Hey, Check it Out, There's Actually Fans': (Dis)Empowerment and (Mis)Representation of Cult Fandom in Supernatural'. Transformative Works and Cultures 4. Available at: <http://dx.doi.org/10.3983/twc.2010.0134> [accessed 05/13/2011].

Ferguson, Roderick A. 2003. Aberrations in Black: Toward a Queer of Color Critique. Minneapolis, Minnesota: University of Minnesota Press.

Fetterman, David M. 1998. Ethnography: Step by Step. $2^{\text {nd }}$ edition. London and Thousand Oaks, California: Sage.

Filmberg, Hilda [nicodiver]. 2012. The Bloodline. Ao3. Available at: <http://archiveofourown. org/works/417933> [accessed 04/02/15].

Fiske, John. 1990a. Reading the Popular. London and New York: Routledge.

— 199ob. Understanding Popular Culture. London and New York: Routledge.

Fivepips. 2014. Combined Operations. Ao3. Available at: <http://archiveofourown.org/ works/1296208?view_full_work=true $>$ [accessed 05/02/15].

Flegel, Monica and Jenny Roth. 2010. 'Annihilating Love and Heterosexuality without Women: Romance, Generic Difference, and Queer Politics in Supernatural Fan Fiction'. Transformative Works and Cultures, 4. Available at: <http://dx.doi.org/10.3983/twc.2010.0133> [accessed 02/02/14].

- 2014. 'Legitimacy, Validity, and Writing for Free: Fan Fiction, Gender, and the Limits of [Unpaid] Creative Labor'. The Journal of Popular Culture. 4 (6), pp. $1098-1108$.

fleshflutter. 2009. The Incestuous Courtship of the Antichrist's Bride. LiveJournal. Available at: <http://fleshflutter.livejournal.com/102268.html> [accessed 06/12/10].

Flyvbjerg, Bent. 2006. 'Five Misunderstandings about Case-Study Research'. Qualitative Inquiry 12 (2), pp. 219-245.

Fogde, Marinette. 2008. 'Self-Governance in the Job Search: Regulative Guidelines in Job Seeking'. In: Foucault and Lifelong Learning: Governing the Subject, pp. 103-113. 
Foss, Erica. 2011. 'Villainy and Physiognomy: Identifying the Dangerous Foreigner In: Sherlock Holmes'. Third Global Heroes and Villains Conference. Mansfield College Oxford. September 2011.

Fook, Jan. 1999. 'Reflexivity as Method'. Health Sociology Review 9 (1), pp. 11-20.

Foucault, Michel. [1970] 1971. 'The Discourse on Language'. (Swyer, Rupert., trans), Social Science Information 10 (2), pp. 7-30.

— [1976] 1980. 'Two Lectures'. In: Gordon, Colin (ed.), Power/Knowledge: Selected Interviews and Other Writings 1972-1977. New York: Pantheon Books and Toronto: Random House, pp.78-108.

— 1981. 'The Order of Discourse'. In: Young, Robert (ed.), Untying the Text: A Poststructuralist Reader. London: Routledge, pp. 51-76.

— [1977] 1980. 'The Eye of Power. A Conversation with Jean-Pierre Barou and Michelle Perot'. In: Gordon, Colin (ed.), Power/Knowledge: Selected Interviews and Other Writings 1972-1977. New York: Pantheon Books and Toronto: Random House, pp. 146-165.

- [1969] 1989. The Archaeology of Knowledge. (Smith, Sheridan A. M., trans), London: Routledge.

- [1969] 1991. 'What is an Author?' In: Rabinow, Paul (ed.), The Foucault Reader. New York: Pantheon, pp. 101-120.

- [1966] 2002. The Order of Things. London: Routledge.

Frannie-pants. 2011. Review How Season 6 Should Have Ended or How Season 7 Better Start. Fanfiction.net. Available at: <http://www.fanfiction.net/r/7013539/> [accessed 21/02/13].

Freund, Katharina and Diana Fielding. 2013. 'Research Ethics in Fan Studies'. Participations 10 (1), pp. 329-334.

Fuentes Peres, Teresa. 2003. Visions of Filth: Deviancy and Social Control in the Novels of Galdós. Liverpool: Liverpool University Press.

Fuery, Kelli. 2009. New Media: Culture and Image. Basingstoke and New York: Palgrave Macmillan.

Furedi, Frank. 2013. Authority: A Sociological History. Cambridge: Cambridge University Press. gabehorn. 2012. Tumblr post. Available at: <http://gabehorn.tumblr.com/post/20521918088/ ontheside-oftheangels-the-most-feminist $>$ [accessed 08/03/13].

Garcia, Alberto N. 2011. 'Breaking the Mirror: Metafictional Strategies in Supernatural'. In: TV Goes to Hell, pp. 146-16o.

Gardner, David. 2012. 'Abracadabra: Key Agents of Mediation that Define, Create, and Maintain TV Fandom'. PhD dissertation, Georgia State University.

Gatergirl79. 2012. At His Side. Fanfiction.net. Available at: <http://www.fanfiction. net/s/7725823/1/At-His-Side> [accessed 22/02/12].

Geertz, Clifford. 1973. 'Notes on the Balinese cockfight'. In: Geertz, Clifford, The Interpretation of Cultures. New York: Basic Books, pp. 412-453.

Gemmig2. 2013. Deviance. Fanfiction.net. Available at: <https://www.fanfiction. net/s/9608454/53/Deviance> [accessed 14/08/15].

Ghislainem70. 2014. Korengal Calling. Ao3. Available at: <http://archiveofourown.org/ works/229302?view_full_work=true $>$ [accessed 05/02/15].

Ghosted. 2011. Swallowed By a Wave. LiveJournal. Available at: <http://got-exchange.livejournal. com/45520.html $>$ [accessed 17/08/15].

Giddens, Anthony. 1984. The Constitution of Society: Outline of the Theory of Structuration. Berkeley: University of California Press.

girl_wonder. 2009. How Becky Totally Saved the World Without Becoming a Mary Sue or: PLEASE R\&R OR I'LL NEVER WRITE ANOTHER CHAPTER. LiveJournal/Ao3. Available at: $<$ http://archiveofourown.org/works/205042> [accessed 22/02/13]. 
Giveusakiss4132. 2015. Comment on Organic Chemistry. Ao3. Available at: <http://archiveofourown.org/works/1647056?view_full_work=true> [accessed 24/05/15].

Goodman, L. 2015. 'Disappointing Fans: Fandom, Fictional Theory, and the Death of the Author'. The Journal of Popular Culture 48 (4), pp. 662-676.

Grandi, R. 2009. 'Web Side Stories: Janeites, Fanfictions, and Never Ending Romances'. In: Hotz-Davies, Ingrid, Anton Kirchofer and Sirpa Leppänen (eds), Internet Fictions. Newcastle upon Tyne: Cambridge Scholars, pp. 23-42.

Gray, Jonathan. 2010. Show Sold Separately: Promos, Spoilers, and Other Media Paratexts. London and New York: New York University Press.

Gray, Jonathan, Cornell Sandvoss and C. Lee Harrington. 2007. 'Introduction: Why Study Fans?' In: Gray, Jonathan, Cornell Sandvoss and C. Lee Harrington (eds), Fandom:Identities and Communities in a Mediated World. London and New York: New York University Press, pp.1-16.

Green, Shoshanna, Cynthia Jenkins and Henry Jenkins. 1998. "Normal Female Interest in Men Bonking': Selections from The Terra Nostra Underground and Strange Bedfellows'. In: Theorizing Fandom: Fans, Subculture and Identity, pp. 9-38.

Gunkel, David. J. 2012. 'What Does it Matter who is Speaking? Authorship, Authority, and the Mashup'. Popular Music and Society 35 (1), pp. 71-91.

Hadas, Leora. 20o9. 'The Web Planet: How the Changing Internet Divided 'Doctor Who' Fan Fiction Writers'. Transformative Works and Cultures 3. Available at: $<$ http://journal.transformativeworks.org/index.php/twc/article/view/129> [accessed o6/11/13].

Halperin, David. M. 2002. How to do the History of Homosexuality. London and Chicago: University of Chicago Press.

hamishholmess. 2014a. Afghanistan or Iraq. Ao3. Available at: <http://archiveofourown.org/ works/2020182> [accessed 05/02/15].

— 2014b. Self-Conclusion. A03. Available at: <http://archiveofourown.org/works/2278554/ chapters/5007174> [accessed 05/02/15].

HappyFunBallXD. 2012. I'll Take My Chances Here and Now. LiveJournal/Dreamwidth/Ao3. Available at: $<$ http://archiveofourown.org/works/589620 > [accessed 21/o2/13].

harakal1. 2011. It's All a Nightmare. Fanfiction.net. Available at: <http://www.fanfiction. net/s/6911782/1/It-s-All-a-Nightmare> [accessed 21/02/13].

HarukoWitch. 2014. Comment on Organic Chemistry. A03. Available at: <http://archiveofourown. org/works/1647056?view_full_work=true > [accessed 24/05/15].

Hariboo. 2011. Comment on The Joinery. LiveJournal. Available at: <http://falseeeyelashes. livejournal.com/320840.html> [accessed 17/08/15].

Harmonic Friction. 2014. Because the King Dies as He Pleases. Fanfiction.net. Available at: $<$ https://www.fanfiction.net/s/10274572/1/Because-the-King-Dies-as-He-Pleases $>$ [accessed $17 / 08 / 15]$.

Haraway, Donna. 1988. 'Situated Knowledges: The Science Question in Feminism and the Privilege of Partial Perspective'. Feminist Studies 14 (3), pp. 575-599.

Harrison, Andrew. 2013. Stephen Moffat: 'I was the Original Angry Dr. Who Fan'. The Guardian. 18 November 2013. Available at: <http://www.theguardian.com/tv-and-radio/2013/nov/18/ steven-moffat-doctor-who-interview $>$ [accessed 06/02/15].

Harwood, Valerie. 2006. Diagnosing 'Disorderly' Children: A Critique of Behaviour Disorder Discourses. Oxford and New York: Routledge.

Hayes, Sharon and Matthew J. Ball. 2010. 'Queering Cyberspace: Fan Fiction Communities as Spaces for Expressing and Exploring Sexuality'. In: Scherer, Burkhard (ed.), Queering Paradigms. Bern, Switzerland: Peter Lang, pp. 219-239. 
Hellholden. 2015. Her Liquor's Top Shelf. Ao3. Available at: <http://archiveofourown.org/ works/812921> [accessed 14/08/15].

hells_half_acre. 2012. Rewatch $\mathrm{S}_{7}$ : Season 7 , Time for a Wedding (7xo8). Available at: <http://hellshalf-acre.dreamwidth.org/367033.html> [accessed 21/01/13].

Herring, Susan. 2004. 'Online Communication: Through the Lens of Discourse'. In: Consalvo, Mia, et al., (eds), Internet Research Annual: Selected Papers From the Association of Internet Researchers Conferences 200o-2002. Vol 1. New York: Peter Lang, pp. 63-76.

Herzog, Alexandra. 2012. 'But This is My Story and This is How I Wanted to Write it': Author's Notes as a Fannish Claim to Power in Fan Fiction Writing'. Transformative Works and Cultures 11. Available at: <http://journal.transformativeworks.org/index.php/twc/article/ view/406/337 > [accessed 20/o9/13].

Hetcher, Steven. 2009. 'Using Social Norms to Regulate Fan Fiction and Remix Culture'. University of Pennsylvania Law Review 157, pp. 1869-1935.

Hills, Matt. 2002. Fan Cultures. London and New York: Routledge.

- 2005. The Pleasures of Horror. London and New York: Continuum.

— 2006. 'Not Just Another "Powerless Elite"? When Media Fans Become Subcultural Celebrities'. In: Holmes, Su and Sea Redmond (eds), Framing Celebrity: New Directions in Celebrity Culture. London: Routledge, pp. 101-118.

- 2010a. Triumph of a Time Lord:Regenerating Doctor Who in the Twenty-First Century. London: IB Tauris.

— 2010b. 'Making Sense of M. Night Shyamalan: Signs of a Popular Auteur in the 'Field of Horror". In: Weinstock, Jeffrey A., (ed.), Critical Approaches to the Films of M. Night Shyamalan. Basingstoke and New York: Palgrave MacMillan.

- 2012a. 'Sherlock's Epistemological Economy and the Value of 'Fan' Knowledge: How ProducerFans Play the 'Great Game' of Fandom'. In: Sherlock and Transmedia Fandom, pp. 27-40.

— 2012b. 'Torchwoods' Trans-Transmedia: Media 'Tie-Ins and Brand 'Fanagement”. Participations 9 (2), pp. 409-428.

2013. Fiske's 'Textual Productivity' and Digital Fandom: Web 2.o Democratization Versus Fan Distinction?' Participations 10 (1), pp. 130-153.

- 2014. 'From Dalek Half Balls to Daft Punk Helmets: Mimetic Fandom and the Crafting of Replicas'. Transformative Works and Cultures 14. Available at: <http://journal.transformativeworks.org/index.php/twc/article/view/531/448> [accessed 29/o3/16].

Hine, Christine. 200o. Virtual Ethnography. London and Thousand Oaks, California: Sage.

- 2005. Virtual Methods: Issues in Social Research on the Internet. Oxford and New York: Berg.

- 2008. 'Virtual Ethnography: Modes, Varieties and Affordances'. In: The Sage Handbook of Online Research Methods, pp. 257-270.

Hobocamp. 2011. Comment on Two Two One Bravo Baker. Ao3. Available at: <http://archiveofourown.org/works/180121?view_full_work=true> [accessed 24/05/15].

Hodges, Adam. 2011. The 'War on Terror' Narrative: Discourse and Intertextuality in the Construction and Contestation of Sociopolitical Reality. Oxford and New York: Oxford University Press.

Hodkinson, Paul. 2005. "Insider Research' in the Study of Youth Cultures'. Journal of Youth Studies 8 (2), pp. 131-149.

Hogan, Bernie. 2008. 'Analysing Social Networks Via the Internet'. In: The Sage Handbook of Online Research Methods, pp. 141-160.

Hunn, Deborah F. 2012. “The Dark Side of Naomily': Skins, Fan Texts and Contested Genres'. Continuum:Journal of Media \& Cultural Studies 26 (1), pp. 89-100.

Hutcheon, Linda. 1988. A Poetics of Postmodernism: History, Theory, Fiction. London and New York: Routledge. 
iamtryN. 2011. Your Answer. FanFiction.net. Available at: <http://www.fanfiction.net/s/6987708/1/ Your-Answer $>$ [accessed 21/02/13].

Ibegtodreamanddiffer. 2012. Sherlock:Nothing and Everything. Fanfiction.net. Available at: $<$ https:// www.fanfiction.net/s/7733715/1/Sherlock-Nothing-and-Everything $>$ [accessed 06/02/15].

ImUnaware. 2014. Comment on Organic Chemistry. Ao3. Available at: $<$ http://archiveofourown. org/works/1647056?view_full_work=true $>$ [accessed 24/05/15].

Jaczminski, Daniel. 2009. 'Liberating the Strange Fish: Visual Representations of Caliban and their Successive Emancipation from Shakespeare's Original Text'. In: Meyer, Michael (ed.), Cross/Cultures 116: Word \& Image in Colonial and Postcolonial Literatures and Cultures. ASNEL papers 14. New York: Rodopi, pp. 1-20.

Jaffe, Audrey. 2000. Scenes of Sympathy: Identity and Representation in Victorian Fiction New York: Cornell University Press.

Jäger, Siegfried and Florentine Maier. 2009. 'Foucauldian Critical Discourse Analysis and Dispositive Analysis'. In: Wodak, Ruth and Michael Meyer (eds), Methods of Critical Discourse Analysis. $2^{\text {nd }}$ edition. London and Thousand Oaks, California: Sage, pp. 34-61.

jankjay. 2014. Comment on Two Two One Bravo Baker. Ao3. Available at: <http://archiveofourown. org/works/180121?view_full_work=true> [accessed 24/05/15].

Japonicastar. 2013. Review of Every Path. Ao3. Available at: <http://archiveofourown.org/ works/929417?view_full_work=true> [accessed og/o2/15].

Jeffries, Stuart. 2012. "There is a Clue Everybody's Missed': Sherlock writer Steven Moffat Interviewed'. The Guardian. 20 January 2012. Available at: <http://www.theguardian.com/ tv-and-radio/2012/jan/20/steven-moffat-sherlock-doctor-who $>$ [accessed 03/02/15].

Jenkins, Henry. 1992. Textual Poachers: Television Fans and Participatory Culture. London and New York: Routledge.

— 1995. 'Infinite Diversity in Infinite Combinations': Genre and Authorship in Star Trek'. In: Tulloch, John and Henry Jenkins. Science Fiction Audiences: Watching Doctor Who and Star Trek. New York and London: Routledge, pp. 175-195.

- 2006a. Convergence Culture: Where Old and New Media Collide. London and New York: New York University Press.

— 2006b. Fans, Bloggers and Gamers: Exploring Particpatory Culture. London and New York: New York University Press.

Jensen, M.D. 2011. Little Wet Tears on Your Baby's Shoulder. FanFiction.net. Available at <http://www. fanfiction.net/s/7555462/1/Little-Wet-Tears-on-Your-Baby-s-Shoulder> [accessed 22/02/13].

Jenson, Joli. 1992. 'Fandom as Pathology: The Consequences of Characterization'. In: Lewis, Lisa (ed.), The Adoring Audience: Fan Culture and Popular Media. London and New York: Routledge, pp. 9-29.

JohannaMK. 2012. Review of In the Arms of an Angel_by Samlicker81. Twisting the Hellmouth. Available at: <http://www.tthfanfic.org/Reviews-26766/> [accessed 22/02/13].

Johnson, Derek. 2007. 'Fan-tagonism: Factions, Institutions and Constitutive Hegemonies of Fandom'. In: Fandom: Identities and Communities in a Mediated World, pp. 285-300.

Jones, Gabriella [everything-in:-focus94]. 2012. Beauty and the Beholder. Fanfiction.net. Available at: $<$ https://www.fanfiction.net/s/7816869/1/Beauty-and-the-Beholder [accessed 05/02/15].

Jones, Paul. Mark Gatiss on Sherlock series 4: 'You can expect tragedy as well as adventure'. Radio Times. 20 November 2014. Available at: <http://www.radiotimes.com/news/2014-11-20/markgatiss-on-sherlock-series-4-you-can-expect-tragedy-as-well-as-adventure [accessed 16/02/15]. Jones, Sara. G. 2002. 'The Sex Lives of Cult Television Characters'. Screen 43 (1), pp. 79-9o. just_a_dram. 2015. A City of Fortune and Failure. Fanfiction.net/Ao3. Available at: $<$ http://archiveofourown.org/works/800809/chapters/1508860> [accessed 14/08/15]. 
Justman, Stewart. 1979. 'Authority and Authorship'. Higher Education Quarterly 33 (2), pp. 196-203. Kal-El Fornia. 2015. Review of The Chronicles of King Joffrey. Fanfiction.net. Available at: $<$ https://m.fanfiction.net/r/10732827/0/2/> [accessed 17/08/15].

Kaplan, Deborah. 2006. 'Construction of Fan Fiction Character through Narrative'. In: Fan Fiction and Fan Communities in the Age of the Internet, pp. 134-152.

kasey8473. 2012. Killing the Fandom. FanFiction.net. Available at: <http://www.fanfiction. net/s/7686843/1/Killing-The-Fandom $>$ [accessed 22/02/13].

Kataryna_Krimson. 2015. Comment on The Bakers Street Dozen. Available at: $<$ http://archiveofourown.org/works/991717/chapters/2449596?view_adult=true> [accessed 22/02/13].

KeelieThompson1. 2012. Paved With Love. Ao3. Available at: <http://archiveofourown.org/ works/367309/chapters/597128> [accessed 06/02/15].

- 2013. Nest Among the Stars. A03. Available at: <http://archiveofourown.org/works/419503/ chapters/698898 [accessed 06/02/15].

Kendall, Gavin and Gary Wickham. 1999. Using Foucault's Methods. London and Thousand Oaks, California: Sage.

Kennedy, Eileen and Laura Hills. 2009. Sport, Media and Society. Oxford and New York: Berg.

Kestner, Joseph A. 1997. Sherlock's Men:Masculinity, Conan Doyle, and Cultural History Aldershot and Brookfield, VT: Ashgate.

kindness_says 2011. Comment on Beneaththe OldGods. Dreamwidth. Available at: $<$ http://oxoniensis. dreamwidth.org/40106.html?thread=6533290\#cmt6533290> [accessed 17/08/15].

Kirchengast, Tyrone. 2010. The Criminal Trial in Law and Discourse. Basingstoke: Palgrave Macmillan.

kojonoyuri. 2012. Comment on The Path We Choose. LiveJournal. 6Available at: <http://tenoko1. livejournal.com/155902.html> [accessed 22/02/13].

Kompare, Derek. 2011. 'More 'Moments of Television': Online Cult Television Authorship'. In: Kackman, Michael, et al., (eds), Flow TV: Television in the Age of Media Convergence. Oxford and New York: Routledge, pp. 95-113.

kongjingying. 2012. Comment on Time For a Wedding Remix. A03. Available at: <http:// archiveofourown.org/chapters/1014413?add_comment_reply_id=1733627\&show_ comments=true\#comment_1733627> [accessed 21/02/13].

Kozinets, Robert. V. 1997. “I Want to Believe': A Netnography of the X-Philes' Subculture of Consumption'. Advances in Consumer Research 24, pp. 470-475.

Kristeva, Julia. 1980. Desire in Language: A Semiotic Approach to Literature and Art. Roudiez, Leon S., (ed.), New York: Columbia University Press.

Kraus, Rosalind E. 1985. The Originality of the Avant-Garde and Other Modernist Myths. Cambridge, Massachusetts: MIT Press.

Krissy7490. 2011. How Season 6 Should Have Ended or How Season 7 Better Start. Fanfiction.net. Available at: <http://www.fanfiction.net/s/7013539/1/How-Season-6-Should-Have-Endedor-How-Season-7-Bet> [accessed 21/02/13].

Kustritz, Anne. 2003. 'Slashing the Romance Narrative'. Journal of American Culture 26 (3), pp. 371-384.

Kustritz, Anne and Melanie E. S. Kohnen. 2012. 'Decoding the Industrial and Digital City: Visions of Security in Holmes' and Sherlock's London'. In: Sherlock and Transmedia Fandom, pp. 85-100.

Lackner, Eden, Barbara L. Lucas and Robin E. Reid. 2006. 'Cunning Linguists: The Erotics of Words/Silence/Flesh'. In: Fan Fiction and Fan Communities in the Age of the Internet, pp. 189-206.

Ladybird97. Comment on The Stone Queen. Available at: <http://got-exchange.livejournal. com/136715.html > [accessed 17/08/15]. 
Lady Geek Girl. 2012. 'The Road So Far: What's Up Tiger Mommy Review' [sic]. Blog post. Available at: <http://ladygeekgirl.wordpress.com/2012/10/11/the-road-so-far-whats-up-tiger-mommyreview/> [accessed 21/02/13].

Lady Jeyne Deadpool. 2014. A Song of Hormones and Broken Hearts. Available at: <https://www.fanfiction.net/s/10073710/1/A-Song-of-Hormones-and-Broken-Hearts> [accessed 14/08/15].

Lady_Blade_WarAngel. 2014. The Seven Deadly Sins of King's Landing Academy. Ao3. Available at: <http://archiveofourown.org/works/1107268/chapters/2755204> [accessed 14/08/15].

lainemontgomery. 2012. The Flint and the Flame. LiveJournal. Available at: <http://gotexchangemod.livejournal.com/1067.html?thread=194603> [accessed 17/08/15].

Lamb, P. F. and D. L. Veith. 1986. 'Romantic Myth, Transcendence, and Star Trek Zines'. In: Palumbo, D. (ed.), Erotic Universe: Sexuality and Fantastic literature. Westport, Conneticut: Greenwood, pp. 235-255.

LastBishop. 2011. Review How Season 6 Should Have Ended or How Season 7 Better Start. Fanfiction.net. Available at: <http://www.fanfiction.net/r/7013539/> [accessed 21/02/13].

Lavën, Eleni. 2013. 'Detection, Desire and Contamination: The Strange Case of Sherlock Holmes'. MA dissertation, University of Waikato.

Lawrence, K. Faith. 2007. 'The Web of Community Trust-Amateur Fiction Online: A Case Study in Community Focused Design for the Semantic Web. Supplemental material: appendix B.2. Basic survey results'. PhD dissertation, University of Southampton. Available at: <http://eprints.ecs.soton.ac.uk/14704/6/B2-BasicResults.html> [accessed 22/06/11].

Lawson, Mark. 2014. 'Sherlock and Doctor Who: Beware of Fans Influencing the TV they Love'. The Guardian. 3 January 2014 Available at: <http://www.theguardian.com/tv-and-radio/ tvandradioblog/2014/jan/o3/sherlock-doctor-who-fans-influencing-tv> [accessed 03/02/15].

Leppänen, Sirpa. 2009. 'Playing with and Policing Language Use and Textuality in Fan Fiction'. In: Internet Fictions, pp. 62-83.

lettered. 2011. The Chuck Writes Story: An Unauthorized Fandom Biography. LiveJournal/Dreamwidth/Ao3. Available at: <http://archiveofourown.org/series/14975> [accessed 22/02/13].

Lexigent. 2011a. There is a Crack In Everything. LiveJournal. Available at: inis-mor.livejournal. com/14474.html [accessed 04/02/15].

- 2011b. Comment on There is a Crack In Everything. Available at: inis-mor.livejournal. com/14474.html [accessed 04/02/15].

lex_rhetoricae. 2010. Comment on Last One Out Hits the Lights. LiveJournal. Available at: <http://libraryofsol.livejournal.com/132903.html\#comments> [accessed 22/01/13].

Lilone1776. 2015. Comment on Game Change. Ao3. Available at: <http://archiveofourown.org/ works/4030777> [accessed 14/08/15].

Lindgren Leavenworth, Maria and Malin Isaksson. 2013. Fanged Fan Fiction: Variations on Twilight, True Blood and The Vampire Diaries. London and Jefferson, North Carolina: Macfarland.

Linndechir. 2012. Comment on Queen. LiveJournal. Available at: <http://gotexchange-mod. livejournal.com/1067.html>?thread=196395\#t196395> [accessed 14/08/15].

— 2013a. Life Lessons. LiveJournal/Ao3. Available at: <http://archiveofourown.org/works/812921/ chapters/1769680> [accessed 14/08/15].

— 2013b. The Kingmaker. LiveJournal/A03. Available at: <http://archiveofourown.org/ works/651621?view_adult=true $>$ [accessed 17/08/15].

Lintilla. 2012a. Dilaudid. A03. Available at: <http://archiveofourown.org/works/380265?view_ full_work=true> [accessed 06/02/15].

— 2012b. Comment on Dilaudid. Available at: <http://archiveofourown.org/works/380265?view_ full_work=true $>$ [accessed 06/02/15]. 
littlebirdhound. 2013. Comment on Her Liquor's Top Shelf. Ao3. Available at: <http://archiveofourown.org/works/812921?view_full_work=true> [accessed 24/05/15].

Littman, Greg. 2012. 'Maester Hobbes goes to King's Landing'. In: Game of Thrones and Philosophy. Blackwell: Kindle edition, pp. $5^{-18}$.

Infco218. 2013. Comment on Two Two One Bravo Baker. Ao3. Available at: <http://archiveofourown. org/works/180121?view_full_work=true > [accessed 24/05/15].

Lopes, Paul. 2007. 'Strategies of Rebellion in the Heroic Age of the American Comic Book'. The International Journal of the Arts in Society 2 (2), pp. 127-134.

LolaAnn. 2012. In the Arms of an Angel-by Samlicker81. Fanfiction.net/LiveJournal/Dreamwidth/Ao3 Available at: <http://lola-ann.dreamwidth.org/2909.html> [accessed 22/02/13].

Lothian, Alexis. 2007. 'Yearning Void and Infinite Potential': Online Slash Fandom as Queer Female Space'. English Language Notes 45 (2), pp. 103-111.

- 2009. 'Living in a Den of Thieves: Fan Video and Digital Challenges to Ownership'. Cinema Journal 48 (4), pp. 130-136.

- 2011. 'Aca-fandom and Beyond: Roberta Pearson and Alexis Lothian. Part One'. Available at: http://henryjenkins.org/2011/o8/aca-fandom_and_beyond_roberta.html [accessed 13/08/15].

Lydzi. 2012. Queen. LiveJournal. Available at: <http://gotexchange-mod.livejournal.com/1067. html $>$ ?thread=196395\#t196395> [accessed 14/08/15].

Lyus, Jon. 2012. Game of Thrones interview - writers David Benioff and D. B. Weiss. HeyUGuys. Available at: <http://www.heyuguys.com/game-of-thrones-interview-writers-david-benioffand-d-b-weiss/> [accessed 13/08/15].

Mackinnon, Richard C. 1997. 'Punishing the Persona: Correctional Strategies for the Virtual Offender'. In:Jones, Steven, (ed.), Virtual Culture:Identity and Communication in Cybersociety. London and Thousand Oaks, California: Sage, pp. 206-235.

MacIntyre, Samuel. 2011. Sherlock Holmes is a Great Man. Fanfiction.net. Available at: < https:// www.fanfiction.net/s/6997888/1/Sherlock-Holmes-is-a-Great-Man > [accessed 05/02/15].

MadMaudlin. 2010. Apotheosis. A03. Available at: <http://archiveofourown.org/works/136440 [accessed 06/02/15].

magisterequitum. 2011a. When You Kiss Me, I'm Happy Enough. LiveJournal/Ao3. Available at: <http://magisterequitum.livejournal.com/496097.html> [accessed 17/08/15].

— 2011b. Comment on. When You Kiss Me I'm Happy Enough. Available at: <http://magisterequitum.livejournal.com/496097.html $>$ [accessed 17/08/15]. Ladyrostova.

- 2012. Remember Me in Blood. Fanfiction.net. Available at: <https://www.fanfiction. net/s/7889998/1/Remember-Me-in-Blood > [accessed 17/08/15].

Maher, JaneMaree. 2008. 'A Pregnant Man in the Movies: The Visual Politics of Reproduction'. Continuum:Journal of Media \& Cultural Studies. 22 (2), pp. 279-288.

Makeitfly. 2012. The Girl Who Ran So Fast. LiveJournal. Available at: <http://got-exchange. livejournal.com/60823.html> [accessed 17/08/15].

Marcyo9. 2014. Comment on Organic Chemistry. A03. Available at: <http://archiveofourown. org/works/1647056?view_full_work=true> [accessed 24/05/15].

Mardy Lass. 2010. Amen to That! FanFiction.net/Supernaturalville. Available at: <http://www.fanfiction.net/s/5724791/1/Amen-To-That > [accessed 22/02/13].marlowe78.

Marlowe78. 2009. Comment on Bean Stalker. LiveJournal. Available at: <http://adrenalineshots. livejournal.com/32246.html $>$ [accessed 22/02/13].

Marlon. 2014. Comment on Organic Chemistry. Ao3. Available at: < http://archiveofourown.org/ works/1647056?view_full_work=true> [accessed 24/05/15].

Martin, George R. R. 1996. A Song of Ice and Fire. 7 vols. London: Voyager. 
- 2010. Someone is angry on the internet. Livejournal. Available at: <http://grrm.livejournal. com/151914.html> [accessed 17/08/15].

— 2013. The Wit and Wisdom of Tyrion Lannister. London: Voyager.

- 2014. A few words from Switzerland. Livejournal. Available at: <http://grrm.livejournal. com/381419.html > [accessed 25/08/15].

Marvaila. 2013. Review of Every Path. Ao3. Available at: <http://archiveofourown.org/ works/929417?view_full_work=true $>$ [accessed 09/02/15].

maskedfangirl. 2009. The Apocrypha of Chuck. LiveJournal/Ao3. Available at: $<$ http://archiveofourown.org/works/268704?view_full_work=true> [accessed 22/02/13].

— 2010a. The Code of Chuck. LiveJournal/Ao3. Available at: <http://archiveofourown.org/ works/520251?view_full_work=true> [accessed 22/02/13].

— 2010b. The Tribulations of Chuck. LiveJournal/A03. Available at: $<$ http://archiveofourown. org/works/520347/chapters/919675> [accessed 22/02/13].

mautadite. 2014a. The Stone Queen. LiveJournal/Ao3. Available at: <http://archiveofourown.org/ works/2733539> [accessed 17/08/15].

— 2014b. Comment on The Stone Queen. LiveJournal/A03. Available at: $<$ http://archiveofourown. org/works/2733539> [accessed 17/08/15].

maybemalapert. 2012. Copy That. A03. Available at: <archiveofourown.org/works/594032/> [accessed 09/02/15].

- 2015. Personal correspondence.

May, Tim and Beth Perry. 2011. Social Research and Reflexivity. London and Thousand Oaks, California: Sage.

Mazher, Waseem. 2012. 'A Foucaultian Critique of Learning Disability Discourses: Personal Narratives and Science'. International Journal of Qualitative Studies in Education 25 (6), pp. $767-800$.

McCabe, Janet and Kim Akass. 2009. 'It's not TV, it's HBO's Original Programming: Producing Quality TV'. In: Leverette, Marc, Brian L. Ott and Carla L. Buckley (eds), It's Not TV: Watching $\mathrm{HBO}$ in the Post-Television Era. New York and London: Taylor and Francis E-library, pp. 93-94.

McCardle, Meredith. 2003. 'Fan Fiction, Fandom, and Fanfare: What's all the Fuss?' Boston University Journal of Science \& Technology Law 9, pp. 433-470.

McCaw, Neil. 2013. 'Sherlock Holmes and a Politics of Adaptation'. In: Vanacker, Sabine, and Catherine Wynne (eds), Sherlock Holmes and Conan Doyle:Multi-Media Afterlives. New York: Palgrave and MacMillan, pp. 36-48.

Miles, Robert. 2002. Gothic writing 1750-1820: A Genealogy. $2^{\text {nd }}$ edition. Manchester and New York: Manchester University Press

Milner, R.M. 2011. 'Discourses on Text Integrity: Information and Interpretation in the Contested Fallout Knowledge Community'. Convergence: The International Journal of Research into New Media Technologies 17 (2), pp. 159-175.

Mirime_vy. 2013. And Make Them Love Me. LiveJournal. Available at: $<$ http://archiveofourown. org/works/64025> [accessed 17/08/15].

Mirmohamadi, Kylie. 2014. The Digital Afterlives of Jane Austen:Janeites at the Keyboard. Basingstoke: Palgrave Macmillan.

miss_izzy92. 2012a. It's Violent Times for Weary Feet. LiveJournal. Available at: <http://missizzy92.livejournal.com/11621.html> [accessed 17/08/15].

— 2012b. Comment on It's Violent Times for Weary Feet. LiveJournal. Available at: <http://missizzy92.livejournal.com/11621.html> [accessed 17/08/15]. 
Mistress of the LivingDarkness. 2015. Don't Blink. Fanfiction.net. Available at: <https://www.fanfiction.net/s/11095491/2/Don-t-Blink> [accessed 17/08/15].

Mittell, Jason. 2012. 'Authorship'. In: Mittel, Jason. Complex TV: The Poetics of Contemporary Television Storytelling. Media Commons Press. Available at: $<$ http://mediacommons.futureofthebook.org/mcpress/complextelevision/authorship/> [accessed 12/01/15].

moelock. 2012. The Man Who Can't Be Moved. Fanfiction.net. <https://www.fanfiction. net/s/7749286/1/The-Man-Who-Can-t-Be-Moved $>$ [accessed 04/02/15].

Moncrieff, Joanna and Sami Timimi. 2013. 'The Social and Cultural Construction of Psychiatric Knowledge: An Analysis of NICE Guidelines on Depression and ADHD'. In: Anthropology \& Medicine 20 (1), pp. 59-71.

morelindo. 2011. Comment on There is a Crack In:Everything LiveJournal. Available at: inis-mor. livejournal.com/14474.html [accessed 04/02/15].

Mx4. 2015. The First Sparks. Fanfiction.net/A03. Available at <http://archiveofourown.org/ works/2330453/chapters/5135225> [accessed 14/08/15].

My Cumblerbatch. 2013. Comment on The Bloodline. Ao3 Available at: <http://archiveofourown. org/works/417933> [accessed 04/02/15].

MyRockInAllThings. 2014. Comment on Organic Chemistry. Ao3. Available at: <http://archiveofourown.org/works/1647056?view_full_work=true> [accessed 24/05/15].

Neal, Andrew W. 2006. 'Foucault in Guantánamo: Towards an Archaeology of the Exception'. Security Dialogue 37 (1), pp. 31-46.

Newman, Michael Z. and Elana Levine. 2012. Legitimating Television: Media Convergence and Cultural Status. Routledge: Kindle edition.

Ng, Philiana. 2014. 'Sherlock Boss on 'Moving' Holmes/Watson Reunion and “Funnier” Season 3 [Q\&A]'. Hollywood Reporter 1 January 2014. < http://www.hollywoodreporter.com/live-feed/ sherlock-season-3-preview-steven-667990 [accessed 03/02/15].

nic. 2011. Comment on Two Two One Bravo Baker. Ao3. Available at: <http://archiveofourown. org/works/180121?view_full_work=true> [accessed 24/05/15].

Nicol, Bran. 'Adapting Doyle in the Twenty-First Century'. In: Sherlock Holmes and Conan Doyle. pp. 124-139.

Nhaz. 2014. Note to Wolf, Hound, Sapphires and Coins. Available at: <https://www.fanfiction. net/s/10462037/1/Wolf-Hound-Sapphires-and-Coins $>$ [accessed 17/08/15].

O'Brien, Harvey. 'The Curious Case of the Kingdom of Shadows: The Transmogrification of Sherlock Holmes in the Cinematic Imagination'. In: Sherlock Holmes and Conan Doyle, pp. 64-79.

oparu. 2011a. Beneath the Old Gods. LiveJournal. Available at: <http://oxoniensis.dreamwidth. org/40106.html $>$ ?thread=653329o\#cmt653329o [accessed 17/08/15].

- 2011b. Comment on Beneath the Old Gods. LiveJournal. Available at: <http://oxoniensis. dreamwidth.org/40106.html>?thread=6533290\#cmt6533290 [accessed 17/08/15].

— 2012a. Peacekeepers. LiveJournal. Available at: <http://got-exchange.livejournal.com/15172. html $>$ [accessed 14/08/15].

— 2012b. Thawing Deep. LiveJournal/Ao3. Available at: <http://archiveofourown.org/ works/442592 [accessed 14/08/15].

— 2012c. The Stranger's Road. LiveJournal. Available at: <http://oparu.livejournal.com/330216. html $>$ [accessed 17/08/15].

— 2012d. Comment on The Stranger's Road. Available at:<http://oparu.livejournal.com/330216. html> [accessed 17/08/15].

outboxed. 2013. Of Prophecy and Kingship. LiveJournal. Available at: <http://got-exchange. livejournal.com/77372.html> [accessed 14/08/15]. 
oximore. 2011. Comment on Now That the War is Through With Me. LiveJournal. Available at: <http://gypsydancergirl.livejournal.com/16468.html> [accessed 22/02/13].

Palko, Amy J. 2009. 'Charting Habitus: Stephen King, the Author-Protagonist and the Field of Literary Production'. PhD dissertation, University of Stirling.

Pappas, N. 1989. 'Authorship and Authority'. The Journal of Aesthetics and Art Criticism 47 (4), pp.325-332.

Parker, J.M. [Doppelicious]. 2011. Dany's Dream. Fanfiction.net. Available at: $<$ https://www.fanfiction.net/s/7255500/1/Dany-s-Dream > [accessed 17/08/15].

Patton, Paul. 1979. 'Of Power and Prisons'. In: Morris, Meaghan and Paul Patton (eds), Michel Foucault: Power, Truth, Strategy. Sydney: Feral Publications, pp. 109-47.

Park, Han Woo and Mike Thelwall. 2003. 'Hyperlink Analyses of the World Wide Web: A Review'. Journal of Computer-Mediated Communication 8 (4). Available at: <http://onlinelibrary.wiley. com/doi/10.1111/j.1083-6101.2003.tboo223.x/abstract> [accessed 17/08/15].

Penley, Constance. 1997. Nasa/Trek: Popular Science and Sex in America. London: Verso.

perp. 2014. Unexpected Ao3. Available at: <http://archiveofourown.org/works/1143298> [accessed 05/02/15].

Pennylane4. 2014. Comment on A City of Fortune and Failure. Ao3. Available at: $<$ http://archiveofourown.org/works/800809? page=3\&show_comments=true\&view_ adult=true\&view_full_work=true $>$ [accessed 25/03/15].

Phantom white lady of $221 \mathrm{~b} 2013$. Review of A Realm in Rebellion. Available at: $<$ https://www.fanfiction.net/r/8288324/0/2/> [accessed 17/08/15].

Pia [Sandylee007]. 2013. Baby Steps. Fanfiction.net. Available at: <https://www.fanfiction. net/s/9065062/1/Baby-Steps $>$ [accessed 05/02/15].

Pimenova, Daria. 2009. 'Fan Fiction: Between Text, Conversation and Game'. In:Internet fictions, pp. 44-61.

Pinkowitz, Jacqueline M. 2011. 'The Rabid Fans that Take [Twilight] Much Too Seriously': The Construction and Rejection of Excess in Twilight Antifandom'. Journal of Transformative Works and Cultures 7. Available at: <http://journal.transformativeworks.org/index.php/twc/ article/view/247/253> [accessed 09/10/13].

PristinelyUngifted. 2011. The Song of Rhaego Fireborn. Fanfiction.net/Ao3/LJ. Available at: $<$ https://www.fanfiction.net/s/7432238/1/The-Song-of-Rhaego-Fireborn > [accessed 14/08/15].

Porter, Lynette. 2012. 'Welcome to London: The Role of the Cinematic Tourist'. In: Porter, Lynette (ed.), Sherlock Holmes for the 21st Century: Essays on New Adaptations. Jefferson, North Carolina: McFarland, Kindle edition, pp. 163-79.

proxydialogue. 2011a. The Winchester Revision. LiveJournal/Ao3. Available at: $<$ http://archiveofourown.org/works/269972> [accessed 22/02/13].

— 2011b. Comment on The Winchester Revision. Ao3. Available at: <http://archiveofourown.org/ works/269972?show_comments=true\&view_adult=true\#comments $>$ [accessed 06/og/13].

Pugh, Sheenagh. 2005. The Democratic Genre: Fan Fiction in a Literary Context. Bridgend, Wales: Seren Books.

PwnedByPineapple. 2012. God is the Biggest Meta. FanFiction.net. Available at: <http://www.fanfiction.net/s/8011775/1/God-Is-The-Biggest-Meta> [accessed 21/02/13].

Rahman, Aamer. 2013. Daenerys' whole storyline on Game of Thrones is messed up. iog. Available at:http://iog.com/daenerys-whole-storyline-on-game-of-thrones-is-messed-513189766 [accessed 13/08/15].

Raskolnikova. 2014. Comment on Crushing the Patriarchy. Ao3. Available at: $<$ http://archiveofourown.org/works/2609504/chapters/5815208> [accessed 24/05/15]. 
reading_is_in. 2012. Comment on Tons of Feels. A03. Available at: <http://archiveofourown.org/ works/384916?show_comments=true\#comments $>$ [accessed 22/02/13].

- 2013a. Comment on In the Arms of an Angel-by Samlicker81. Ao3. Available at $<$ http://archiveofourown.org/works/312840?show_comments=true\#comments $>$ [accessed 22/02/13].

- 2013b. Western Rising. LiveJournal/Ao3. Available at <http://archiveofourown.org/ works/468541> [accessed 22/02/13].

Rebaza, Claudia. 2008. 'Online Gestures: Icon Use by Fan Communities on LiveJournal'. Proceedings of the 4ist Hawaii International Conference on System Sciences. Big Island, HI, 7-10 January 2008. Available at: <http://csdl2.computer.org/comp/proceedings/ hicss/2008/3075/00/30750150.pdf> [accessed 04/22/11].

- 2010. 'The Modern Coterie: Fan Fiction Writers as a Community of Practice'. PhD dissertation, University of Illinois.

redcandle17. 2015. Game Change. LiveJournal/Ao3. Available at: <http://got-exchange.livejournal. com/148748.html> [accessed 14/08/15].

Redmond, Christoper. 2009. Sherlock Holmes Handbook. $2^{\text {nd }}$ edition. New York and Ontario, Canada: Dundurn.

Regertz. 2015. Game of Thrones Tales: Back to the Throne Room. Fanfiction.net. Available at: $<$ https://www.fanfiction.net/s/10981476/1/Game-of-Thrones-Tales-Back-to-the-ThroneRoom> [accessed 14/08/15].

Rheingold, Howard. 1993. Virtual Community: Homesteading on the Electronic Frontier. Boston, Massachussets: Addison Wesley.

Rhyolight. 2015. Review of Disappear. A03. Available at: <http://archiveofourown.org/ works/575868 [accessed 05/02/15].

Rina_Sally_Giles. 2014.Crushing the Patriarchy. Ao3. Available at: $<$ http://archiveofourown.org/ works/2609504/chapters/5815208> [accessed 14/08/15].

roflskate. 2012. A Father's Sons. LiveJournal. Available at: <http://got-exchange.livejournal. com/1879o.html> [accessed 14/08/15].

romirola. 2011. Review of How Season 6 Should Have Ended or How Season 7 Better Start. Fanfiction.net. Available at: <http://www.fanfiction.net/r/7013539/> [accessed 21/02/13].

Rose, Mark. 2002. Copyright and its metaphors. UCLA Law Review 5 (1), pp.1-15.

rosettaslair. 2011. Tumblr post. Available at: <http://rosettaslair.tumblr.com/post/12685447643/ season-seven-time-for-a-wedding $>$ [accessed 21/02/13].

Runnero43. 2014. Review of Game of Thrones: Vendetta. Fanfiction.net. Available at: $<$ https://www.fanfiction.net/r/10157649/o/2/> [accessed 14/o8/15].

Russ, Joanna. 1985a. 'Pornography by Women, for Women, with Love'. In: Magic Mommas, Trembling Sisters, Puritans and Perverts. New York: The Crossing Press, pp. 79-99.

— 1985b. 'Another Addict Raves about K/S'. Nome 8, pp. 28-37.

Russo, Julie L. 2002. NEW VOY “Cyborg sex" J/7 [NC-17] $1 / 1$ : New Methodologies New Fantasies. Available at: <http://j-l-r.org/asmic/fanfic/print/jlr-cyborgsex.pdf $>$ [accessed10/11/10].

— 2009. 'User-Penetrated Content: Fan Video in the Age of Convergence'. Cinema Journal 48 (4), pp. $125^{-130 .}$

Said, Edward. [1978] 2003. Orientalism. London and New York: Penguin.

Samutina, N. 2016. 'Emotional Landscapes of Reading: Fan Fiction in the Context of Contemporary Reading Practices'. International Journal of Cultural Studies. Published ahead of print at <http://ics.sagepub.com/content/early/2016/01/27/1367877916628238.abstract $>$ [accessed 29/03/16]. 
Sanctuary. 2014. Review of The Gilded Cage. Ao3. Available at: <http://archiveofourown.org/ works $/ 1103555$ ?page=31\&show_comments $=$ true $>\&$ view_adult $=$ true $>\&$ view_full_work=true $>$ [accessed 05/02/15].

SanSon23 2013. Comment on Her Liquor's Top Shelf. Available at: <http://archiveofourown.org/ works/812921/chapters/1769680> [accessed 17/08/15].

sapphire blue-ruby red roses. 2015. Q is for Queens of a Pair. Fanfiction.net. Available at: <https://www.fanfiction.net/s/11073571/1/Q-is-for-Queens-of-a-Pair> [accessed 14/08/15].

Sapphiamur. 2013. Thursday's Child [Fanfic Trailer]. YouTube. Available at: $<$ https://www.youtube. com/watch?v=mfDNdoqMHoI $>$ [accessed 20/02/13].

scaramouche. 2011. A Judicious Application of Free Will. Dreamwidth/Ao3. Available at: <http://scaramouche.dreamwidth.org/267773.html> [accessed 22/02/13].

Scodari, Christine. 2003. 'Resistance Re-Examined: Gender, Fan Practices, and Science Fiction Television'. Popular Communication 1, pp. 111-130.

Scott, Suzanne. 2011. 'Revenge of the Fanboy: Convergence Culture and the Politics of Incorporation'. PhD dissertation, University of Southern California.

Scott-Zechlin, Ariana. 2012. 'But it's the Solar System! Reconciling Science and Faith through Astronomy'. In: Sherlock and Transmedia Fandom, pp. 56-69.

Schäfer, Mirko T. 2011. Bastard Culture! How User Participation Transforms Cultural Production. Amsterdam: Amsterdam University Press.

Schmidt, Lisa. 2010. 'Monstrous Melodrama: Expanding the Scope of Melodramatic Identification to Interpret Negative Fan Responses to Supernatural. Transformative Works and Cultures 4'. Available at: <http://journal.transformativeworks.org/index.php/twc/article/ view/152/155> [accessed 05/01/11].

Schneider, Steven M. Kirsten A. Foot. 2005. 'Web Sphere Analysis: An Approach to Studying Online Action'. In: Virtual Methods, pp. 157-170.

Sedgwick, Eve Kosofsky. 1985. Between Men:English Literature and Male Homosocial Desire. New York: Columbia University Press.

Selena Dobreva. 2015. Freed Bird. Fanfiction.net. Available at: <https://www.fanfiction. net/s/9955918/1/Freed-Bird $>$ [accessed 14/08/15].

SenpaiNoSasuke 2012. Comment on The Bloodline. Fanfiction.net. Available at: <https://www.fanfiction.net/r/8070911/o/2/> [accessed 05/02/15].

Sheridan Holmes. 2011. Review of How Season 6 Should Have Ended or How Season 7 Better Start. Available at: <http://www.fanfiction.net/r/7013539/> [accessed 21/02/13].

Shadaras. 2014a. Impossibilities. Ao3. Available at: <http://archiveofourown.org/works/1145017> [accessed 05/02/15].

— 2014b. Comment on Impossibilities. A03. Available at: <http://archiveofourown.org/ works/1145017> [accessed 05/02/15].

shadow2001. 2013. Review of A Realm in Rebellion. Available at: <https://www.fanfiction. net $/ \mathrm{r} / 8288324 / 18 / 1 />$ [accessed 17/08/15].

shecrows 2011. Comment on The Joinery. Available at: <http://falseeeyelashes.livejournal. com/320840.html?page $=2>$ [accessed 17/08/15].

SheKillsCacti 2014. Comment on The Gilded Cage. Ao3. Available at: <http://archiveofourown. org/works/1103555/chapters/2219986 [accessed 05/02/15].

Shiera. 2014. Comment on Crushing the Patriarchy. A03. Available at: <http://archiveofourown. org/works/2609504/chapters/5815208> [accessed 24/05/15].

Shultz, Staci L. 2011. 'Exploring Literacy Sponsorship in the Digital Extracurriculum: How Students' Participation in Fan Fiction Sites can Inform Composition Pedagogy'. PhD dissertation, University of Michigan. 
siraloPPolaris. 2013. A Realm in Rebellion. Fanfiction.net. Available at: <https://www.fanfiction. net/s/8288324/1/A-Realm-in-Rebellion > [accessed 17/08/15].

Singh, K. D. 2012. 'Reading the Short Stories of Temsula Ao: Looking Towards an AlternateNarrative'. E-pao. Available at: <http://epao.net/epSubPageExtractor.asp?src=education. Scientific_Papers.Reading_the_short_stories_of_Temsula_Ao_looking_towards_an_alternate_narrative_part_1> [accessed 30/07/12].

Skålén, Per, Martin Fougère and Marcus Fellesson. 2008. Marketing Discourse: A CriticalPerspective. London and New York: Routlege.

Snafu the Great. 2014. Game of Thrones: Vendetta. Fanfiction.net. Available at: <https://www. fanfiction.net/s/10157649/1/Game-of-Thrones-Vendetta> [accessed 14/08/15].

Snowdarkred. 2012. Blood Lion Heart Wolf. LiveJournal/Ao3. Available at: <http://archiveofourown.org/works/369663> [accessed 17/08/15].

Solomon, Nicky. 2008. Academic work and adult education: a site of multiple subjects. In: Foucault and Lifelong Learning: Governing the Subject, pp. 178-9o.

sothereyougo. 2009a. We Are All Made as an Afterthought. LiveJournal. Available at <http://sothereyougo.livejournal.com/10247.html> [accessed 22/02/13].

- 20ogb. Comment on We Are All Made as an Afterthought. LiveJournal. Available at <http://sothereyougo.livejournal.com/10247.html> [accessed 22/02/13].

SSJRyo10oo. 2014. Review of Game of Thrones: Consequences. Available at: <https://m.fanfiction. net/r/10854875/0/3/> [accessed 17/08/15].

Stagg, Guy. 2012. 'Casting Lucy Liu as Dr Joan Watson Will Ruin One of the Great Bromances of All Time. The Telegraph. 29 February 2012. Available at: http://blogs.telegraph.co.uk/ culture/guystagg/100061063/casting-lucy-liu-as-dr-joan-watson-will-ruin-one-of-the-greatbromances-of-all-time/ [accessed 05/02/15].

Stanfill, Mel. 2013. “They're Losers, But I Know Better”: Intra-Fandom Stereotyping and the Normalization of the Fan Subject'. Critical Studies in Media Communication 30 (2), pp.117-134.

- (forthcoming). 'The Resurrection of the Author: Fans, Textual Authority, and 'The Creator'. Author's MS copy.

Stein, Lousia E. 2006. “This Dratted Thing': Fannish Storytelling through New Media'. In: Fan fiction and Fan Communities In the Age of the Internet, pp. $245^{-260 .}$

- 2008. 'Pushing at the Margins: Teenage Angst in Teen TV and Audience Response'. In: Ross, Sharon M. and Louisa E. Stein (eds), Teen Television: Essays on Programming and Fandom. Jefferson, North Carolina: McFarland, pp. 224-244.

- 2015. Millenial Fandom: Television Audiences in the Transmedia Age. Iowa City: University of Iowa Press.

Stein, Louisa E. and Kristina Busse. 2009. 'Limit Play: Fan Authorship between Source Text, Intertext, and Context'. Popular Communication 7 (4), pp. 192-207.

Sternflammenden. 2012. Comment on Queen. LiveJournal. Available at: <http://gotexchangemod.livejournal.com/1067.html $>$ ?thread=196395\#t196395> [accessed 14/o8/15].

Stoppard, Tom. 1968. Rosencrantz and Guildenstern are Dead. London: Faber and Faber.

strangenessandcharm. 2009. Thursday's Child. Dreamwidth. Available at <http://strangenessandcharm.dreamwidth.org/104788.html> [accessed 22/02/13].

strawberryhiddleslock. 2015. Comment on Two Two One Bravo Baker. Ao3. Available at: <http://archiveofourown.org/works/180121?view_full_work=true> [accessed 24/05/15].

Supernaturalwiki 2011a. Crack. Available at: <http://www.supernaturalwiki.com/index. php?title=Crack $>$ [accessed 07/02/12]. 
Sultana, Farhana. 2007. 'Reflexivity, Positionality and Participatory Ethics: Negotiating Fieldwork Dilemmas in International Research'. ACME: An International E-Journal for Critical Geographies 6 (3), pp. 374-385.

sycophantastic. 2009. Review of Thursday's Child. Dreamwidth. Available at: $<$ http://strangenessandcharm.dreamwidth.org/106978.html> [accessed 24/02/13].

Talbot, Mary. 1997. "Randy Fish Boss Branded a Stinker': Coherence and the Construction of Masculinities in a British Tabloid Newspaper'. In:Johnson, Sally and Ulrike Hanna Meinhof (eds), Language and Masculinity. London: Blackwell, pp. 173-187.

Tawabids. 2012. Doctor. Detective and Sons. Ao3. Available at: <http://archiveofourown.org/ works/525166?view_full_work=true> [accessed 05/02/15].

Templeton, Brad. 2008. 10 Big Myths about Copyright Explained. Available at: $<$ http://www.templetons.com/brad/copymyths.html > [accessed 17/08/15].

tenoko1. 2012. The Path We Choose. LiveJournal/ Ao3. Available at: <http://tenoko1.livejournal. com/153541.html> [accessed 22/02/13].

Tenten_d. 2014. What's Buried Underneath. Fanfiction.net/Ao3. Available at: $<$ http://archiveofourown.org/works/1380577/chapters/2889901> [accessed 17/08/15].

TheBookshelfDweller. 2013. Incarnations of London. Fanfiction.net. Available at: $<$ https://www.fanfiction.net/s/9678391/1/Incarnations-of-London> [accessed 09/02/15].

thedeadparrot. 2007. I Thought I Didn't Have More to Say on This Issue. But Apparently. I was Wrong. LiveJournal. Available at: <http://thedeadparrot.livejournal.com/38615o.html [accessed 21/02/13].

thinkpink20. 2011. Comment on Two Two One Bravo Baker. Available at: <http://archiveofourown. org/works/180121?view_full_work=true > [accessed 24/05/15].

Thompson, Edward P. 1971. 'The Moral Economy of the English Crowd in the 18th Century'. Past and Present 50, pp. $76-136$.

Thompson, Jon. 1993. Fiction. Crime. and Empire: Clues to Modernity and Postmodernism. Champaign, Illinois: University of Illinois Press.

Thomas, Bronwen. 2011. “'Update Soon!" Harry Potter Fanfiction and Narrative as a Participatory Process'. In: Thomas, Bronwen and Ruth Page (eds), New Narratives: Stories and Storytelling in the Digital Age. London and Lincoln, Nebraska: University of Nebraska Press

Thomas, Lynn. 2002. Fans, Feminisms and 'Quality' Media. London and New York: Routledge. Thornton, Sarah. 1995. Club Cultures:Music, Media, and Subcultural Capital.Cambridge: Polity Press. thevinegarworks. 2009. Comment on The Drinking Bone's Connected to... that Angel Thing. LiveJournal. Available at: <http://chica-charlie.livejournal.com/30846.html\#comments > [accessed 22/02/13].

tinawinna 2013. Review of If Things Were Different. Available at: <https://www.fanfiction. net $/ \mathrm{r} / 7284591 / 7 / 1 />$ [accessed 17/08/15].

Toadvine, April. 2012. 'The Watson Effect: Civilizing the Sociopath'. In: Sherlock Holmes for the 21st Century, Kindle edition.

Torie. 2013. Comment on Her Liquor's Top Shelf. Ao3. Available at: <http://archiveofourown.org/ works/812921?view_full_work=true> [accessed 24/05/15].

Tosenberger, Catherine. 2008. “The Epic Love Story of Sam and Dean”: Supernatural, Queer Readings, and the Romance of Incestuous Fan Fiction'. Transformative Works and Cultures 1. Available at: $<$ http:// http://journal.transformativeworks.org/index.php/twc/article/view/30> [accessed 06/12/10].

Tosinadekunle. 2015. Comment on Organic Chemistry. Available at: $<$ http://archiveofourown. org/works/1647056?view_full_work=true > [accessed 24/05/15]. 
tracy_loo_who. 2009. And I Will Walk on Water. LiveJournal/Ao3. Available at: <http://archiveofourown.org/works/68707?view_adult=true\&view_full_work=true $>$ [accessed 22/02/13].

trinityofone. 2009. Writing (And Other Things That Are Hard). LiveJournal. Available at: $<$ trinityofone.livejournal.com/183112.html $>$ [accessed 22/02/13].

twistedthicket1. 2014. The Odd-Edged Puzzle. Ao3. Available at: <http://archiveofourown.org/ works/1153158> [accessed 05/02/15].

twoskeletons. 2010a. Restore from Saved Draft. LiveJournal. [link omitted at author's request].

— 2010b. Peanuts. LiveJournal/Ao3. Available at: <http://archiveofourown.org/works/78987 > [accessed 09/07/12].

Valkyrist. 2012. Blood of the Direwolf. Fanfiction.net/A03. Available at: <https://www.fanfiction. net/s/7519156/1/Blood-of-the-Direwolf $>$ [accessed 14/o8/15].

- 2013. The Bastard Reborn. Fanfiction.net/Ao3. Available at: <https://www.fanfiction. net/s/8231529/3/The-Bastard-Reborn $>$ [accessed 14/08/15].

Vanacker, Sabine and Catherine Wynne (eds). 2013. Sherlock Holmes and Conan Doyle: MultiMedia Afterlives. New York: Palgrave and MacMillan.

Van Dijck, José. 2009. 'Users Like You? Theorizing Agency in User-Generated Content'. Media Culture \& Society, 31 (1), pp. 41-58.

Vickers, Brian. 1989. Classical Rhetoric in English Poetry: With a New Preface and Annotated Bibliography. Carbondale and Edwardsville: Southern Illinois University Press.

Vulgar Shudder. 2013. Omega Refuge. Fanfiction.net. Available at: <https://www.fanfiction. net/s/8977022/1/Omega-Refuge $>$ [accessed 09/02/15].

Vwchick. 2014. Review of Freed Bird. Available at: <https://www.fanfiction.net/r/9955918/11/1/> [accessed 17/08/15]

Walker, Hilary. 2002. A Genealogy of Equality: The Curriculum for Social Work Education and Training. London and Portland, Oregon: Woburn.

Walther, Joseph. B. 1992. 'Interpersonal Effects in Computer-Mediated Interaction: A Relational Perspective'. Communication Research 19 (1), pp. 52-9o.

Watson, N. 1997. 'Why We Argue about Virtual Community: A Case Study of the Phish.net Fan Community'. In: Virtual Culture, pp. 102-132.

Weber, Max. [1922]1958. 'Three Types of Legitimate Rule'. (Gerth, H., trans). Berkeley Publications in Society and Institutions, 4(1), pp. 1-11.

Wetherell Margaret, Stephanie Taylor and Simeon J. Yates (eds). 2001. Discourse as Data: A Guide for Analysis. London and CA: Sage.

Whenyoudonthavealife. 2014. Love With a Side of Pasta. Fanfiction.net. Available at: <https:// www.fanfiction.net/s/10800977/1/Love-With-a-Side-of-Pasta $>$ [accessed 17/08/15].

Wexelblat, Alan. 2002. 'An Auteur in the Age of the Internet: JMS, Babylon 5, and the Net'. In: Jenkins, Henry, Tara McPherson and Jane Shattuc (eds), Hop on Pop: The Pleasures and Politics of Popular Culture. Durham, NC: Duke University Press, pp. 209-26.

Whiffling10.2014. A note on Afghanistan and Iraq In: Sherlock fics. Tumblr. Available at: <http:// whiffling10.tumblr.com/post/49973702157/a-note-on-afghanistan-and-iraq-In:-sherlockfics $>$ [accessed 05/02/15].

Whitehead, Stephen M. 2002. Men and Masculinties. Cambridge: Polity

Williams, Rebecca. 2010. 'Good Neighbours? Fan/Producer Relationships and the Broadcasting Field'. Continuum:Journal of Media \& Cultural Studies 24 (2), pp. 281-291.

Willig, Carla. 2001. Introducing Qualitative Research in Psychology: Adventures in Theory and Method. Berkshire and New York: Oxford University Press.

Woledge, Elizabeth. 2006. 'Intimatopia: Genre Intersections between Slash and the Mainstream'. In: Fan Fiction and Fan Communities in the Age of the Internet, pp. 97-114. 
Woodcock, Lynne. 2009. 'The Comic Gothic'. The Luminaryı. Available at: <http://www.lancaster. ac.uk/luminary/issue1/article3.htm> [accessed 07/11/13].

Wright, Susan A. 2009. 'The Discourse of Fan Fiction. PhD dissertation, University of Louisville.

Wuerth, Jessica M. [allonsysherlocklove]. 2013. The Female Detective. Fanfiction.net. Available at: <https://www.fanfiction.net/s/9681360/1/The-Female-Detective $>$ [accessed 05/02/15].

Wwwhat. 2013. Every Path. Ao3. Available at: < http://archiveofourown.org/works/929417?view_ full_work=true $>$ [accessed 05/02/15].

xenoamorist. 2012. Tons of Feels. Dreamwidth/Ao3. Available at:

$<$ http://archiveofourown.org/works/384916?view_adult=true> [accessed 22/02/13].

YaoiHellian. 2013. Comment on Spoils of War. Fanfiction.net. Available at: $<$ https://www.fanfiction.net/r/9116285/> [accessed 05/02/15].

Young, Robert J.C. 2001. Postcolonialism: an Historical Introduction. Oxford and Malden, Massachussets:: Blackwell.

youremyqueen 2012. Comment on Swallowed By a Wave. Available at: <http://got-exchange. livejournal.com/45520.html> [accessed 17/08/15].

ZabellaCookie. 2010. Weep Little Lion Man. Fanfiction.net. Available at: <https://www.fanfiction. net/s/625636o/1/Weep-Little-Lion-Man> [accessed 05/02/15].

Zoesong. 2015. Comment on Game Change. Ao3. Available at: <http://archiveofourown.org/ works/4030777> [accessed 14/08/15].

Zubernis, Lynn and Kathy Larsen. 2012. Fandom at the Crossroads: Celebration, Shame and Fan/ Producer Relationships. Newcastle Upon Tyne: Cambridge Scholars.

\section{Film, Television and Other Media}

'A Golden Crown'. 2011. Game of Thrones 1xo6. Minahan, Daniel, dir. Benioff, David, Weiss, D.B., and Espenson, Jane, writers. First broadcast: 22/05/11. US: HBO.

'A Man Without Honor'. 2012. Game of Thrones 2x07. Nutter, David, dir. Benioff, David, and Weiss, D.B., writers. First broadcast: 13/05/12. US: HBO.

'A Scandal in Belgravia'. 2012. Sherlock 2xo1. McGuigan, Paul, dir. Gatiss, Mark, and Moffat, Stephen, writers. First broadcast: o1/o1/12. UK: BBC.

'A Study in Pink'. 2010. Sherlock 1xo1. McGuigan, dir. Gatiss and Moffat, writers. First broadcast: 25/07/10. UK: BBC.

Benedict, Rob. 2011. Jus in Bello Convention Panel. Hilton Rome Airport Hotel. Rome. Available at: <https://www.youtube.com/watch?v=Ni7uidj9Rx8 > [accessed 20/08/15].

Benioff, David, and Weiss, D. B. 2013a. Podcast. Grantland Podcasts. ESPN. Available at: $<$ http://espn.go.com/espnradio/grantland/player?id=9101761> [accessed 13/o8/15].

— 2013b. Commentary on. [DVD]. Game of Thrones: The Complete First and Second Season. HBO and Warner Home Video.

'Baelor'. 2011. Game of Thrones 1xog. Taylor, Alan, dir. Benioff and Weiss, writers. First broadcast: 12/06/11. US: HBO.

'Blackwater'. Game of Thrones 2xog. Marshall, Neil, dir. Martin, George R. R, writer. First broadcast: 27/05/12. US: HBO.

'Dark Wings, Dark Words'. 2013. Game of Thrones 3x02. Minahan, Daniel, dir. Taylor, Vanessa, writer. First broadcast: 07/04/2013. US: HBO.

Elementary. Doherty, Robert, creator. First broadcast: 27/og/12. US: PBS. 
'Fan Fiction'. 2014. Supernatural. 10x05. Sgriccia, Phil, dir. Thompson, Robbie, writer. First broadcast: 11/11/14.

'Fire and Blood'. 2011. Game of Thrones 1x10. Taylor, Alan, dir. Benioff and Weiss, writers. First broadcast: 19/06/11. US: HBO.

'Garden of Bones'. 2012. Game of Thrones 2x04. Petrarca, David, dir. Taylor, Vanessa, writer. First broadcast: 22/04/12. US: HBO.

'His Last Vow'. 2014. Sherlock 3x03. Hurran, Mark, dir. Moffatt, writer. First broadcast: 12/01/14. $\mathrm{UK}$ : BBC.

'Kissed by Fire'. 2012. Game of Thrones 3x05. Graves, Alex, dir. Cogman, Bryan, writer. First broadcast: 13/05/12. US: HBO.

'Many Happy Returns'. 2013. Sherlock 3xoo. Gatiss and Moffat, writers. First broadcast: 24/12/13. UK: BBC.

Martin. G. R. R. 2013a. Commentary on 'Blackwater' [DVD]. Game of Thrones: The Complete First and Second Season. HBO and Warner Home Video.

— 2013b. Commentary on 'The Pointy End' [DVD]. Game of Thrones: The Complete First and Second Season. HBO and Warner Home Video.

'Mhysa'. 2013. Game of Thrones 3x10. Nutter, dir. Benioff and Weiss, writers. First broadcast: 09/06/13. US: HBO.

'Mother's Mercy'. 2015. Game of Thrones 5x10. Nutter, David, dir. Benioff and Weiss, writers. First broadcast: 14/06/15. US: HBO.

'Oathkeeper'. 2014. Game of Thrones 4xo6. MacClaren, Michelle, dir. Cogman Brian, writer. First broadcast: 27/04/2014. US: HBO.

'Point of no return'. 2010. Supernatural 5x18. Sgriccia, Phil, dir. Carver, Jeremy, writer. First broadcast: 15/04/10 [DVD]. Warner Home Video.

'Season Seven, Time for a Wedding!'. 2011. Supernatural 7xo8. Andrew, Tim, dir. Dabb, Andrew, and Loflin, Daniel, writers. First broadcast: 11/11/11 [DVD]. Warner Home Video.

Sherlock: Series 3 Special Edition 2014. Gatiss, Moffat and Thompson, Steve, writers. Lovering, Jeremy, et. al, dir [DVD]. 2entertain.

Star Trek II: The Wrath of Khan. 1982 [film]. Meyer, Nicholas, dir. Sowards, Jack B., writer. Nichol United States: Paramount.

Star Trek VI: The Undiscovered Country. 1991 [film]. Meyer, dir. Meyer and Flinn, Denny Martin, writers. United States: Paramount.

'Swan Song'. 2010. Supernatural 5x22. Boyum, Steve, dir. Kripke, Eric. and Gerwitz, Eric, writers. First broadcast: 13/06/10 [DVD]. Warner Home Video.

'Sympathy for the devil'. 2010. Supernatural 5x01. Singer, Robert, dir. Kripke, writer. First broadcast: 10/o9/o9 [DVD]. Warner Home Video.

'The Abominable Bride'. 2016. Sherlock 4xo. Mackinnon, D., dir. Gatiss, M., and Moffat, S., writers. First broadcast: 01/01/16. UK: BBC.

The Adventures of Sherlock Holmes. 1984-94 [TV], Cox, Michael, creator. Produced by Granada. First broadcast: 24/04/84. UK: ITV.

'The Blind Banker'. 2010. Sherlock 1x02. Lyn, Euros, dir. Thompson, writer. First broadcast: 01/08/10. UK: BBC.

'The Children'. 2014. Game of Thrones 4x10. Graves, dir. Benioff and Weiss, writers. First broadcast: 15/06/14. US: HBO.

'The Dance of Dragons'. 2015. Game of Thrones 5xo9. Nutter, dir. Benioff and Weiss, writers. First broadcast: 07/06/15. US: HBO.

'The Empty Hearse'. 2014. Sherlock3xo1. Lovering, dir.Gatiss, writer. First broadcast: 01/01/14. UK: BBC. 
'The End'. 2010. Supernatural 5x04. Boyum, Steve, dir. Edlund, Ben, writer. First broadcast: 01/10/og. [DVD]. Warner Home Video.

'The Great Game'. 2012. Sherlock 1x03. McGuigan, dir. Gatiss, writer. First broadcast: 08/o1/12. $\mathrm{UK}: \mathrm{BBC}$.

The Great Mouse Detective 1986 [film]. Clements, Ron, et al., dir. Young, Pete, e. al, writers. United States: Buena Vista.

'The Ghost of Harrenhal'. 2012. Game of Thrones 2x05. Petrarca, dir. Benioff and Weiss, writers. First broadcast: 29/04/12. US: HBO.

'The Hounds of Baskerville'. 2012. Sherlock 2x02. McGuigan, dir. Gatiss and Moffatt, writers. First broadcast: 08/01/12. UK: BBC.

'The Laws of Gods and Men'. 2014. Game of Thrones 4xo6. Sakharov, Alik, dir. Cogman, writer. First broadcast: 11/05/14. US: HBO.

'The Lion and the Rose'. 2014. Game of Thrones 4x02. Graves, dir. Martin, writer. First broadcast: 13/04/14. US: HBO.

'The Monster at the End of this Book'. 2009. Supernatural 4x18. Rohl, Mike, dir. Siege, Julie, and Weiner, Nancy, writers. First broadcast: 04/04/o9 [DVD]. Warner Home Video.

'The Night Lands'. Game of Thrones 2x02, Taylor, Alan, dir. Benioff and Weiss, writers. First broadcast: 08/04/12. US: HBO.

'The Old Gods and the New'. 2012. Game of Thrones 2xo6. Nutter, dir. Taylor, Vanessa, writer. First broadcast: 22/04/12. US: HBO.

The Private Life of Sherlock Holmes [film]. Wilder, Billy, dir. Diamond, I.A.L and Wilder, Billy, writers. United States: United Artists, 1970.

'The real Ghostbusters'. 2010. Supernatural 5xo9. Conway, James L., dir. Kripke, and Weiner, Nancy, writers. First broadcast: 12/11/o9 [DVD]. Warner Home Video.

'The Rains of Castamere'. 2013. Game of Thrones 3xo9. Nutter, dir. Benioff and Weiss, writers. First broadcast: 02/06/13. US: HBO.

'The Reichenbach Fall'. 2012. Sherlock 2xo3. Haynes, Toby, dir. Thompson, writer. First broadcast: 15/01/12. UK: BBC.

The Seven Percent Solution.1976 [film]. Ross, Herbert, dir. Conan Doyle, Arthur, and Meyer, Nicholas, writers. UK: Universal Studios.

'The Sign of Three'. 2014. Sherlock 3xo2. McCarthy, Colm, dir. Thompson, Moffatt and Gattis, writers. First broadcast: 05/01/14. UK: BBC.

VeggieTales: Sheerluck Holmes and the Golden Ruler. 2006. Nawrocki, Mike, dir. Lee, Robert G., writer. [DVD] US: Big Idea Productions.

'Walk of Punishment'. 2013. Game of Thrones 3x03. Benioff, dir. Benioff and Weiss, writers. First broadcast: 14/04/13. US: HBO.

'Winter is Coming'. 2011. Game of Thrones 01x01. Van Patten, Tim, dir. Benioff and Weiss, writers. First broadcast: 17/04/11. US: HBO.

'What is Dead May Never Die'. 2012. Game of Thrones 2xo3. Cogman, writer. Sakharov, dir. First broadcast: 15/04/12. US: HBO.

Young Sherlock Holmes. 1985 [film]. Levinson, Barry, dir. Columbus, Chris, writer. United States: Paramount.

'You Win or you Die'. Game of Thrones 1xo7. Minahan, dir. Benioff and Weiss, writers. First broadcast: 29/05/11. US: HBO. 


\section{Index}

alpha/beta/omegaverse 65-66, 71-76, 85, 87-91, 98 Afghanistan, construction of $55,62,70-71,93-98$ archaeology, Foucauldian 37-38, 42 archive, Foucauldian 19, 23, 68, 162, 171 Archive Of Our Own (Ao3) 39, 44-45, 47, 65-66, $70,71,73,80,87,90,93,95,119,123,126,131$, $139,154,170,174-75,177,181,187,195$ auteur

fanboy $9,13,21,50-51,53,5^{8}, 117-18,15^{0-51}$, $155,158,160,175,191,197$

TV 9-10, 50-53, 117-18, 120-21, 157-59, 163-66, 177,179

author

as father $20,115-16,124,127$

Death of the $175,207,214$

figure (White male) 12, 53, 127, 199, 201

Function 10, 12-13, 20-21, 52, 81, 119, 150-51, 154-55, 157-58, 174, 177-79, 181-82, 184, $193,198,201$

God 13, 51, 103, 116, 122, 157-69 passim, $172-75,177,182-84,188,196,200$

authorship 9-10, 12, 20-21, 38, 68, 91, 100, 103, 114, $117,132,168,146-47,150,155,157-201$ passim authority

fallibility of 103, 111, 126, 128

fragmentation of 12, 115, 117, 155

of the author see author and authorship patriarchal 28, 66, 80, 102, 104-08, 115, 117, 119-27 passim, 130, 132, 136-38, 140, 141, 155,199

rational-legal 102, 106, 118, 120, 126-32, 137

traditional 12, 102, 104-07, 111-13, 115, 117-120, 122-23, 126, 129-134, 138, 141, 145-46, 150, 155,199 , see also patriarchal

Baratheon, Robert (character) 102, 108-09, 114, $125,134,15^{2}$

Renly (character) 102, 112, 143

Shireen (character) 102, 122, 124, 144-45

Stannis (character) 102, 108, 110, 112-13 124, $128,133-34,143,144$

Bacon-Smith, Camille 17, 21-23, 17, 28, 30, 159, 200 Barthes, Roland 20, 159, 174-75, 193, 196 body 12, 27, 48-49, 53-54, 56-61, 64-65, 68-8o, 85, $87-88,90-91,94,98-99,110,155,185,199$ /mind dualism 12, 48-49, 53-54, 56, 64 /mind integration 68-78, 94, 99

Bourdieu, Pierre 17, 26, 32, 170

Brienne of Tarth (character) 129, 150

Busse, Kristina 24, 30, 44, 61, 92, 159, 174

capital, cultural 10-11, 17, 20, 25-26, 32, 47, 81, 174-76

Castiel (character) 163, 167, 171-74, 180, 188, 193-94, 196 class, social 17, 25-27, 6o-61, 68, 70, 79-8o, 87, $94-95,99,121-22,138,141-42,155$ citation $14,34,49-50,54,57-58,63,83,89,99$, 107-08, 110, 119, 123, 133, 194, 199, 201-02

copyright $44,116,146$

discourse analysis 10, 15, 24, 33-36, 202 Dreamwidth.org 39, 170, 175, 180-81

ethics, research $33,42-45,204$

fan, the $14,21,26,162,204$, see also auteur, fanboy good/bad divide $168,184-85,187,191-92,196-98$ writer 10, 12-14, 23-27, 43-44, 99-100, 124, 128, 146-51, 153, 159-61, 166-69, 171-98 passim, 200-02

'fanagement' 164

fandom

as convergence $22-23$

as democracy $9,121,144$

as female culture 21,30

as labour 44,68

as resistance 12, 21-31, 204

as pathology $21-22,159-62,168,184-86$

as poaching $21-24,28,124$

fanfiction

as corrective 22, 122, 147, 149, 173-74, 193, 200

as labour 44,68

as education 23,26

as literature $13,21,23-26,36$

as kidnapping 116,149

as poaching $21-24,28,124$

as subversive writing $28-31,66,146-49,177,180$

hierarchy in 9, 11, 25-26, 32-33, 40, 81, 128, $171,177,189,203$

slash 14, 21, 27-32 passim, 37, 80, 157, 164, 166-68, 171, 179-80, 184, 186, 190, 195, see also alpha/beta/omegaverse (a/b/o)

fanfiction.net (ff.net) 30, 37-39, 42, 47, 65, 66, 69, $71,92,119,132,139,151,170,172,174,176-77,181$ fangirl 13-14, 153, 157-58, 168, 172, 175-76, 178-79, $182-83$

fan-shaming $14,51,58,161$

fan studies (academic) 10-11, 20-32 passim

'fan-tagonism' 14, 161

femininity $9,14,27,29,58,80,82,84,87,91,98$, $115,118,120,130,137-41,160-61,199$

fiction $10,19,23,26,29,32,34,36,40,38,5^{2}, 88$, $98,100,167,176-79,200$

force 103, 106-07, 110, 113, 115, 119, 121, 123, 130-33, 141,144

Foucault, Michel 9-12, 15, 17-22, 24, 29, 31-38, 41-42, 45, 50, 52-54, 59, 67, 75 78, 81, 104, 118-19, 132, 170, 177, 181-82, 201-03 
Game of Thrones 9-12, 14, 20, 38, 42, 100, 101-55 passim, $158,173,198$

Gamble, Sera 158-59, 173-74, 191-92

Gatiss, Mark 50-52, 58, 68, 99, 117

genealogy, Foucauldian 34, 36-38, 116

Gender 9, 10, 12, 21-22, 27, 30, 57, 65-66, 76, 78, $878-91,93,98,122-23,140-41,155,158-59$, 191, 200

Gendry (character) 122, 142

HBO 9, 11, 101, 103, 106, 111, 115-117, 150

Hills, Matt 9, 17, 20-21, 38, 51, 61, 128, 164, 184-86, 197-98, 202

Holmes, Sherlock (character) 47-100 passim, 57, 155, 199, 202

House of Leaves (novel) 195, 197

internet studies 33, 35-39, 203

Jenkins, Henry 10, 17, 20-24, 28-29, 31, 147, 161-62, 200

Kripke, Eric 9, 11, 13, 20, 28, 157-58, 161, 163-68, $173,177,182-84,188,191,193-94,197$

Language 17-18, 26-27, 31, 33-34, 42, 49, 56, 63, 97, 202

Lannister, Cersei (character) 102, 107, 112, 114-15, 121,140

Jaime (character) 102, 106, 124-25, 152, $128-31,136,15^{2}$

Tyrion (character) 102, 107, 110, 112-15, 117, $125,127,131-32,136-37,148$

Twyin (character) 102, 105-107, 106, 109, 112, $121,125,127,141$

Larsen, Kathy 13, 42, 158-59, 161-62, 164, 171, 185, 196,198

legitimacy, cultural 10-14, 20, 24, 26, 68, 73, 78-79, 85, 91, 96, 99-100, 118-19, 128, 137, $146-47,150-51,157,160-203$ passim

legitimation paradox, the 9-10, 12-14, 24, 51, 53, $68,73,78-79,91,96,100,118,122-23,128,130-31$, $136,146-48,15^{0-51,157,162,168,172,174,176,}$ $178,181,183-84,189,191-93,195,197-98,200-03$

LiveJournal (LJ) 22, 37-39, 42-43, 45, 47, 65-67, $66,70,92,119,129,138,143,151,164,170$, $174-75,177,180-82,187-88$

London, construction of 49-50, 54, 58-59, 61-64, 91-98

Martin, George R. R. 11-12, 20, 103, 109, 114-19, 121, $124,127,131,141,143,145-50,152-55,158,199$

masculinity 10, 12-100 passim

British 47-53, 6o, 93-94

Victorian 12, 47-50, 57

White 10, 12-13, 21, 56-59, 64, 68-75, 91, 94, $96,98-99,118,127,155,181,186,199,201$

Melisandre (character) 107-08 mind 49, 53-56, 63, 64, 92-94, 99, 133, 181-82 /body dualism see body/mind dualism /body integration see body/mind integration

Moffat, Stephen 50-52, 68, 91, 99-100, 117, 155

Moriarty (character) 58, 63-64, 74, 78, 82-84, 89-9o

Mpreg 65-66, 71-75, 85, 90-91

network analysis 9-12, 40-43, 45, 203

Orientalism 33-34, 59, 62, 71, 92-98, 200

Other, the $10,34,47-48,56,62,97-98,167,201$

place (geographical) 53, 59, 61-64, 71, 91-99 position (social) 17, 53, 59-64, 68, 71-72, 78-10o passim, 106, 122, 128-29, 137, 140, 142, 170-71, 199 postcolonialism 14, 34, 199, 201, see also Orientalism

postmodernism 13-14, 23, 30, 92, 199 power 10, 20-21, 26, 29, 33-35, 43, 98, 101-46 and authorship 9-10, 21, 115-118, 146-55, 159-6o, 174, 184

and language 9-15, 17, 26, 33-35, 179 and Whiteness $33-34,47-49,56,98$ and women $137-46$ vs authority $12,101-15,118-19$

queerbaiting 60,80 queer space $30-31$

reception $31,33-40,45,47,49,43,148,177,202-03$ Redwyne, Olenna (character) 112

research, insider 42-45 reflexive 43-44, 170-71

Rosen, Becky (character) 14, 157-98 passim, 163 Rosencrantz and Guildenstern are Dead (play) 193-94

Scott, Suzanne 9, 20-21, 50, 151, 158-6o

Sherlock (BBC show) 9-12, 14, 31, 34, 38, 42, 45, 47-10o passim, 101, 119, 143, 155, 198

Shurley, Chuck (character) 157, 159-200 passim, 163

Snow, Jon (character) 102, 104, 109-10, 132-35, 147,151

Supernatural 9-14, 19, 22, 28, 31, 37n, 38, 42-43, 119, 153, 155, 157-198 passim, 204

Stark, Arya (character) 102, 122, 134-35, 137, 142, 144,150

Bran (character) 102, 105, 153

Catelyn (character) 102, 107, 121, 125, 141

Eddard (character) 102, 105, 109, 114, 141, 151

Robb, (character) 102, 109, 114, 121, 133, 138

Sansa (character) 102, 126, 129, 137-38, 143, 145

Statement (as a unit of discourse) 17-19, 34, $38-40,42,50,54,56,59-61,64-65,68,71-73$, 75, 78, 84-86, 92, 97-99, 102-104, 106, 110, 118, $120,122,124,129,140,147-48,161-62,165-66$, $178-79,183,187,189,194-95,197,202-03$

Stanfill, Mel 168, 171, 184-85, 198 
Targaryen, Daenerys (character) 107, 110-13, 123, $125,129-30,135-39,147,152$

Text 10, 11-14, 17, 21-24, 26, 30, 31-33, 35-36, 40, 43-44, 45, 48-54, 6o, 71, 77-79, 99, 103-04, 111, 114-15, 118-19, 121-22, 125, 127-28, 130, 139, 146-47, 150-184 passim, 188-91, 193-97, 200-03 'authenticity' of 20, 6o, 103, 114, 125, 128, 155, 158-6o, 161-76, 184, 188-91, 200 authority of 12-13, 20-21, 52-53, 78, 99, 103-04, 111, 114-15, 127-28, 152, 158-76, 180, $184,188-91,200$

fallibility of 17-18, 51-53, 121-22, 146-47, $150-55,176-84,193-201$

Television (TV) 10, 28, 39, 48, 19, 28, 99, 101, 11619, 121, 137, 139, 157, 179-80, see also auteur, TV cult 11, 21, 31, 200-01

textual provocation $14,53,117-18,162,164,184$, 199, 202
Tumblr.com 45, 47, 51, 66, 70, 81, 93, 122, 153-54 $175,177,180,204$

Tyrell, Margaery (character) 107-08, 112, 125-26, 137-38

Watson, John (character) 47-10o passim, 199, 202

Winchester, Dean (character) 157, 160, 162, 164-68 171-73, 175, 177, 179-80, 185, 187, 190, 192-93, 195 Sam (character) $157,160,162-64,166-67,171 \mathrm{n}$, $173,175,177,179,185-87,190,192-93$

women, authority and 13, 25, 104, 118, 120, 122, 130, 137-46, 155 and power see power and women

Zubernis, Lynn 13, 42-43, 158-59, 161-62, 164, 171, $185,196,198$ 
